$$
D O E / S F / 15303 \ldots 52
$$

\title{
Promising Freeze Protection Alternatives in Solar Domestic Hot Water Systems
}

by

David E. Bradley
RECEIVED

FFR 171998

OSTI

A thesis submitted in partial fulfillment

of the requirements for the degree of

MASTER OF SCIENCE

(Mechanical Engineering)

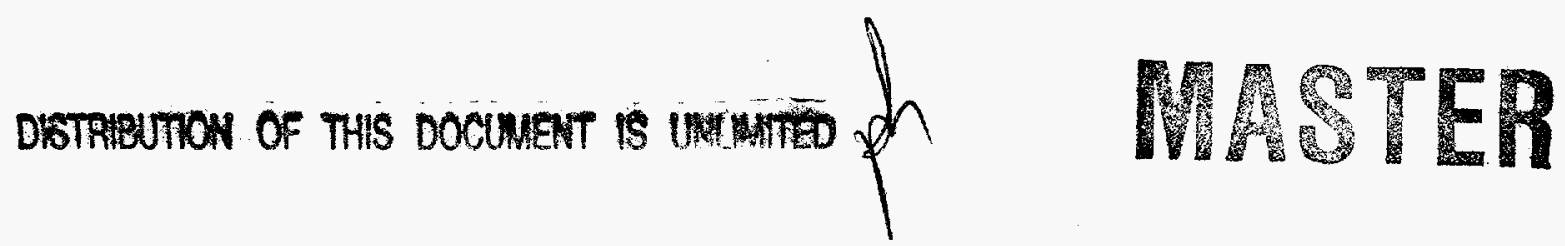
at the

UNIVERSITY OF WISCONSIN - MADISON

1997 


\section{DISCLAIMER}

This report was prepared as an account of work sponsored by an agency of the United States Government. Neither the United States Government nor any agency thereof, nor any of their employees, makes any warranty, express or implied, or assumes any legal liability or responsibility for the accuracy, completeness, or usefulness of any information, apparatus, product, or process disclosed, or represents that its use would not infringe privately owned rights. Reference herein to any specific commercial product, process, or service by trade name, trademark, manufacturer, or otherwise does not necessarily constitute or imply its endorsement, recommendation, or favoring by the United States Government or any agency thereof. The views and opinions of authors expressed herein do not necessarily state or reflect those of the United States Government or any agency thereof. 


\section{DISCLAIMER}

Portions of this document may be illegible electronic image products. Images are produced from the best available original document. 


\section{ABSTRACT}

Since the gains associated with solar thermal energy technologies are comparatively small in relation to the required capital investment, it is vital to maximize conversion efficiency. While providing the necessary function of freeze protection, the heat exchanger commonly included in solar domestic water heating systems represents a system inefficiency. There is either a significant energy loss due to a rise in collector operating temperature and subsequent decrease in collector efficiency or a significant return on investment loss due to the requirement of a very large heat exchanger. This thesis explores two alternate methods of providing freeze protection without resorting to a heat exchanger.

Commonly, collectors are made of rigid copper tubes separated by copper or aluminum fins. Cracking damage can occur when water is allowed to freeze and expand inside the non compliant tubes. The possibility of making collectors out of an elastic material was investigated and shown to be effective. Since unlike copper, elastomers typically have low thermal conductivities, the standard collector performance prediction equations do not apply. Modified thermal performance prediction equations were developed which can be used for both low and high thermal conductivity materials to provide accurate predictions within a limited range of plate geometries. An elastomeric collector plate was then designed and shown to have comparable performance to a copper plate collector whose aperture area is approximately $33 \%$ smaller. 
Another option for providing freeze protection to an SDHW system is to turn it off during the winter. Choosing a three-season operating period means two things. First, the system will have different optimums such as slope and collector area. Second, the wintertime solar energy incident on the collector is unavailable for meeting a heating load. However, the system's heat exchanger becomes unnecessary and removing it increases the amount of energy that arrives at the storage tank during those periods in which the system is operating. Both economic and thermal performance predictions were made for a number of locations across the United States, which show that the threeseason system is a viable alternative in some locations. In most locations the threeseason system provides a lower annual solar fraction. In locations along the coasts and specifically in the southeastern United States, the three-season system actually has a higher solar fraction than the four-season system. In mountainous regions the thermal penalty associated with the three-season system makes it an undesirable alternative. Furthermore, comparatively small penalties are associated with smaller system sizes. The economic analysis of three-season systems showed that they are no more sensitive to economic parameter or design changes than the four-season system.

Because the solar fraction is decreased in most locations by shutting an SDHW system down for the winter, it is beneficial to make the "winter" as short as possible by taking measures to prevent the collector from freezing. During the first and last month of winter, it was found that for most locations, the amount of energy that can be collected during daylight hours is significantly more than is lost if hot tank water is circulated through the collector during the night to prevent freezing. Such a control strategy is 
inexpensive to implement and significantly improves the solar fraction of the threeseason system.

As a final step to the analysis, the three-season system ensemble impact on an electric utility was studied. The utility benefits during peak demand times because the SDHW system ensemble meets the water heating requirements of the service district. Four-season systems are of benefit to the utility as well but since peak demand occurs during the summer, the three-season system is better adapted to the utility's needs. The Milwaukee, WI utility analyzed can expect a substantial increase in return on investment for a 1000 unit three-season system ensemble as compared to a 1000 unit four-season system ensemble under current economic conditions. 


\section{ACKNOWLEDGEMENTS}

As with any endeavor, there are a great many people without whose help this thesis would never have come to fruition. They of course deserve many more thanks than can be conveyed in such a short paragraph as this.

First, my advisors Bill Beckman and Sandy Klein who have provided both friendship and guidance to me during this past year and a half. I have the utmost respect for their intelligence, achievements, and dedication. It is their unwavering confidence that makes this lab one of the best learning environments in which I have ever been. Many thanks are also due to Jack Duffie and John Mitchell for their dedication to making the Solar Energy Lab a highly respected research site and not a fad that waxes and wanes with popular interest in renewable energy.

I would also like to thank my parents and sister who have instilled in me a love of learning that will never fade. Dad, you have shown me that engineering is an art which draws its material from every reach of science. It is never sufficient to examine a problem without regard to the bigger picture. I admire and strive to achieve your level of patience and understanding. Mom, you have provided the framework and world view which makes engineering mean something. You have imbued me with the understanding that if I can't explain it clearly to someone else, then it was hardly worth doing in the first 
place. If only I could explain things as well as you. Ariane, it is your attitude towards technology that keeps me humble. If you can't make it work, it isn't designed well enough. Through our many cherished late night conversations I continue to question the uses of technology and have come to appreciate and partially understand its impact upon our lives. I admire your knowledge of this world and your understanding of its cultures.

Finally, I would like to thank Jennifer whose has borne the brunt of my frustrations with grace and good nature for many years. Were it not for your ability to listen and quietly encourage I would have given up long ago. Thank you for everything. 


\section{LIST OF TABLES}

$\underline{\text { TABLE }}$

TABLE DESCRIPTION

PAGE

1.4.1 Power Requirements for Electric Resistance Freeze

Protection in Various Locations

8

2.7.1 Collector Geometries

36

3.4.3.1 Collector Parameters

61

3.4.4.1 The Partial Derivatives of $P_{1}$ and $P_{2}$ for Commonly

Changing Variables

67

4.5.1 Three-Season Thermal Penalties for Various Locations

98

5.4.1 Comparison of TRNSYS and f-Chart Results for Madison, WI

122

5.4.2 Benefits of Recirculation in Various Locations

122

5.4.3 Effects of Increasing the Length of Recirculation Period

123

6.4.1 Three and Four-Season System Parameters

134

6.4.2 Highlighted Results of EUSESIA Anlaysis

137 


\section{LIST OF FIGURES}

FIGURE

FIGURE DESCRIPTION

$\underline{\text { PAGE }}$

1.2.1 Typical Solar Domestic Hot Water System 3

1.3.1 Collector Efficiency 5

$\begin{array}{lll}\text { 1.4.1 Evacuated Tube Collector } & 10\end{array}$

$\begin{array}{lll}2.2 .1 & \text { Heat Exchanger Penalty } & 13\end{array}$

2.2.2 Temperature Distribution in a Copper Fin (End View) 15

$\begin{array}{lll}\text { 2.2.3 Molecular Structure of a Thermo-Elastomer } & 16\end{array}$

$\begin{array}{lll}\text { 2.3.1 Energy Balance on Fins } & 17\end{array}$

$\begin{array}{lll}\text { 2.3.2 One-Dimensional Model Configuration } & 18\end{array}$

$\begin{array}{lll}\text { 2.3.3 Energy Transferred to Water } & 24\end{array}$

2.3.4 Reduction in Integration Length due to Fin and Tube Thickness 25

$\begin{array}{lll}2.4 .1 & \text { Temperature Distribution } & 27\end{array}$

2.4.2a Temperature Distribution with $\mathrm{k}=1 \mathrm{~W} / \mathrm{m}-\mathrm{K}$

2.4.2b Temperature Distribution with $\mathrm{k}=10 \mathrm{~W} / \mathrm{m}-\mathrm{K}$

2.4.2c Temperature Distribution with $\mathrm{k}=400 \mathrm{~W} / \mathrm{m}-\mathrm{K} \quad 28$

2.4.2d Temperature Distribution with $\mathrm{k}=\infty \mathrm{W} / \mathrm{m}-\mathrm{K} \quad 29$

2.5.1 Comparison between One and Two Dimensional Models

$(0.1-0.5 \mathrm{~cm}) \quad 30$

2.5.2 Comparison between One and Two Dimensional Models

$(0.1-0.9 \mathrm{~cm}) \quad 31$ 
viii

2.6.1 Collector Efficiency Factor for a Range of $k \delta$

2.6.2 Collector Heat Removal Factor for a Range of $k \delta$

2.6.3 Model Verification for Standard Configuration 35

2.7.1 Monthly Solar Fraction for $2.6 \mathrm{~m}^{2}$ Thermo-Elastic

Versus $1.76 \mathrm{~m} 2$ Model AE-21 Collector 37

2.7.2 Square Tube Thermo-Elastic Collector Plate Design 40

3.3.1 Economic Parameters (from $f$-Chart version 5.88W) 48

3.4.1.1a Four-Season System Sensitivity to Slope in Madison, WI 51

3.4.1.1b Four-Season System Sensitivity to Slope in Miami, FL 51

3.4.1.1c Four-Season System Sensitivity to Slope in Seattle, WA 52

3.4.1.1d Four-Season System Sensitivity to Slope in Albuquerque, NM 52

3.4.1.2a Three-Season System Sensitivity to Slope in Madison, WI 54

3.4.1.2b Three-Season System Sensitivity to Slope in Miami, FL 54

3.4.1.2c Three-Season System Sensitivity to Slope in Seattle, WA 55

3.4.1.2d Three-Season System Sensitivity to Slope in Albuquerque, NM 55

3.4.2.1 Life Cycle Savings Sensitivity to Collector Azimuth for

Various SDHW Configurations $\quad 58$

3.4.2.2 Annual Solar Fraction Sensitivity to Collector Azimuth for Various SDHW Configurations $\quad 59$

$\begin{array}{lll}\text { 3.4.3.1 Collector Efficiency Curves } & 60\end{array}$

3.4.3.2a Three-Season LCS Sensitivity to Slope and Area in Madison, WI, (AE-32 Collector, $\mathrm{C}_{\mathrm{A}}=220 \$ / \mathrm{m}^{2}$ )

3.4.3.2b Three-Season LCS Sensitivity to Slope and Area in Madison, WI, (ASN-45A Collector, $C_{A}=170 \$ / \mathrm{m}^{2}$ ) 62

3.4.3.3a Three-Season LCS Sensitivity to Slope and Area in Miami, FL, $\left(\mathrm{AE}-32\right.$ Collector, $\left.\mathrm{C}_{\mathrm{A}}=220 \$ / \mathrm{m}^{2}\right)$ 
3.4.3.3b Three-Season LCS Sensitivity to Slope and Area in Madison, WI, (ASN-45 Collector, $\mathrm{C}_{\mathrm{A}}=170 \$ / \mathrm{m}^{2}$ )

3.4.3.4a Four-Season LCS Sensitivity to Slope and Area in Albuquerque, $\mathrm{NM},\left(\mathrm{AE}-32\right.$ Collector, $\mathrm{C}_{\mathrm{A}}=220 \$ / \mathrm{m}^{2}$ )

3.4.3.4b Four-Season LCS Sensitivity to Slope and Area in Albuquerque, $\mathrm{NM},\left(\mathrm{ASN}-45\right.$ Collector, $\left.\mathrm{C}_{\mathrm{A}}=170 \$ / \mathrm{m}^{2}\right)$

3.5.1 Effect of Altering Area Independent Cost 69

3.5.2 Three-Season System Design Methodology 70

3.5.3 LCS System Design for Madison, WI 71

3.5.4 LCS System Design for Seattle, WA 72

3.5.5 LCS System Design for Miami, FL 72

3.5.6 LCS System Design for Albuquerque, NM 73

3.6.1 Payback Period System Design for Madison, WI 76

3.6.2 LCS System Design for Seattle, WA 76

$\begin{array}{lll}\text { 3.6.3 LCS System Design for Miami, FL } & 77\end{array}$

3.6.4 LCS System Design for Albuquerque, NM 77

3.6.5 The Effect of System Prices upon Critical Area $\quad 79$

3.6.6 The Effect of Various Electricity Prices upon Critical Area $\quad 80$

4.2.1 Water Heating System Schematic Modeled by $f$-Chart 85

$\begin{array}{lll}\text { 4.2.2 } f \text {-Chart Correlation } & 89\end{array}$

4.4.1a Four-Season System $f$-Chart Inputs $\quad 94$

4.4.1b Three-Season System $f$-Chart Inputs 95

4.4.2 Comparison between Equation Solver Results and $f$-Chart Results 96

4.6.1 Thermal Performance of a Three-Season System Based on

A Four-Season System Meeting $25 \%$ of the Annual Load 
4.6.2 Thermal Performance of a Three-Season System Based on A Four-Season System Meeting 25\% of the Annual Load (Eastern United States)

4.6.3 Thermal Performance of a Three-Season System Based on A Four-Season System Meeting $50 \%$ of the Annual Load (Western United States)

4.6.4 Thermal Performance of a Three-Season System Based on A Four-Season System Meeting 50\% of the Annual Load (Eastern United States)

4.6.5 Thermal Performance of a Three-Season System Based on A Four-Season System Meeting $75 \%$ of the Annual Load (Western United States)

4.6.6 Thermal Performance of a Three-Season System Based on A Four-Season System Meeting $75 \%$ of the Annual Load (Eastern United States) 


\section{TABLE OF CONTENTS}

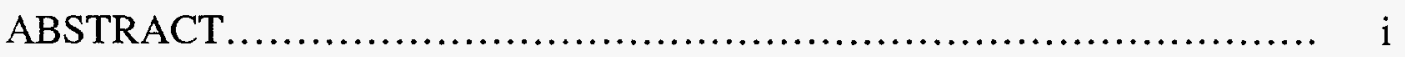

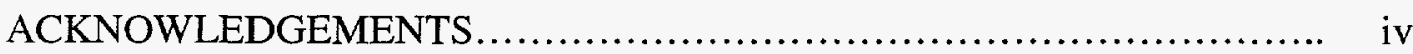

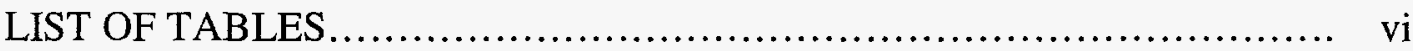

LIST OF FIGURES............................................... vii

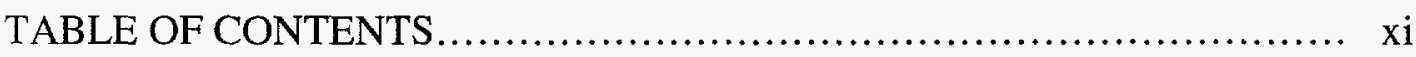

CHAPTER I: INTRODUCTION

1.1 The Current State of Solar Energy Technology.................... 1

1.2 Solar Domestic Hot Water Systems.............................. 2

1.3 Promising Alternatives........................................ 4

1.3.1 Thermo-Elastic Collectors.............................. 5

1.3.2 Three Season SDHW Systems........................ 6

1.4 Other Freeze Protection Alternatives............................. 7

1.5 Objectives and Research Scope.............................. 11

CHAPTER II: THERMO-ELASTIC COLLECTOR PLATE DESIGN

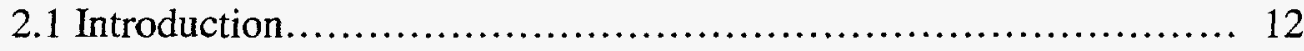

2.2 Background..................................................... 13

2.3 Development of a One Dimensional Model............................ 17

2.4 A Two Dimensional Model: Finite Element Analysis................ 26

2.5 Comparison of One and Two Dimensional Models..................... 29

2.6 Obtaining Useful Design Parameters from the Model............... 31

2.7 Designing a Thermo-Elastic Collector............................... 34

2.8 Further Research................................................... 38

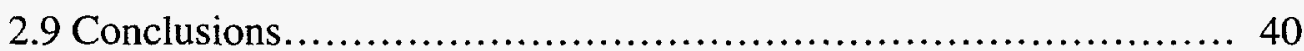

CHAPTER III: AN ECONOMIC ANALYSIS OF THREE-SEASON SDHW SYSTEMS

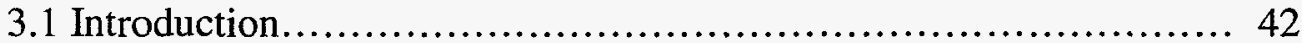

3.2 Economic Indicators and the $\mathrm{P}_{1} \mathrm{P}_{2}$ Method.......................... 43

3.3 The Economy Used in Analyzing Three-Season Systems............ 47

3.4 Three-Season System Sensitivity................................ 48

3.4.1 System Sensitivity to Collector Slope and Area.............. 50

3.4.2 System Sensitivity to Collector Azimuth Angle............. 57

3.4.3 System Sensitivity to Collector Quality......................59 
xii

3.4.4 System Sensitivity to Economic Parameters..................65

3.5 System Design Using the Life Cycle Savings Indicator................ 68

3.6 System Design Using the Simple Payback Period Indicator........... 75

3.7 Conclusions...................................................... 80

CHAPTER IV: A THERMAL ANALYSIS OF THREE SEASON SDHW SYSTEMS

4.1 Introduction................................................... 83

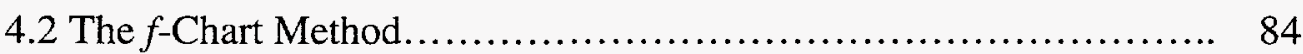

4.3 Weather Data................................................ 89

4.4 The $f$-Chart Applied to Three-Season System Analysis.............. 91

4.5 Three-Season System Thermal Penalties........................... 97

4.6 Three-Season System Thermal Penalty Maps.......................... 103

4.7 Discussion..................................................... 110

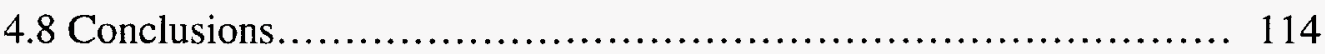

CHAPTER V: TRNSYS SIMULATION OF THREE SEASON SYSTEMS

5.1 Introduction.................................................... 116

5.2 TRNSYS Versus $f$-Chart..................................... 117

5.3 The TRNSYS File............................................. 118

5.4 Results.................................................... 121

5.5 Discussion.................................................... 123

5.6 Conclusions.................................................. 127

CHAPTER VI: CASE STUDY: WISCONSIN ELECTRIC POWER COMPANY

6.1 Introduction................................................... 129

6.2 The Three-Season System from a Utility's Point of View............ 131

6.3 EUSESIA...................................................... 133

6.4 WEPCO Impact Analysis....................................... 134

6.5 Modifications to EUSESIA....................................... 138

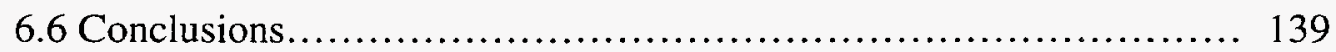

CHAPTER VII: CONLCUSIONS AND RECOMMENDATIONS

7.1 Summary................................................. 140

7.2 Conclusions.................................................. 143

7.3 Recommendations for Further Study........................ 147

APPENDIX A: THERMO-ELASTIC COLLECTOR DESIGN EES PROGRAMS

Thermo-Elastic Collector Design Program......................... 150

APPENDIX B: THREE-SEASON SYSTEM EES PROGRAMS

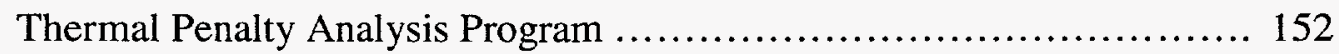

Economic Analysis Program ...................................... 156

APPENDIX C: FOUR SEASON SYSTEM TRNSYS DECK

Four-Season System TRNSYS Deck................................. 161 
APPENDIX D: THREE-SEASON SYSTEM TRNSYS DECKS

Three-Season System without Recirculation TRNSYS Deck............ 165

Three-Season System with Recurculation TRNSYS Deck............... 169

APPENDIX E: EUSESIA TRNSED DECK

Three or Four Season TRNSED Deck............................. 173

REFERENCES

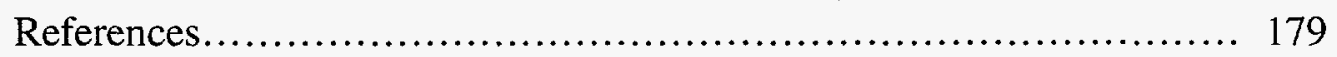




\subsection{The Current State of Solar Energy Technology}

A great deal of research has been carried out on solar energy alternatives to heating by conventional means. The conclusion of a great part of this research is that solar energy is a viable, clean and sustainable source. Yet 17 years after the energy scare of the early 1970s, solar energy's market share remains disappointing. In fact, solar accounts for less than $1 \%$ of water heating systems in the United States (Fanney and Dougherty, 1996). In order to propose remedies that will increase the acceptance of solar energy technology, it is first necessary to understand the reason for the poor market penetration. A number of these reasons are illuminated in a Public Service Commission of Wisconsin market study carried out between August 1996 and March 1997. Primary among the obstacles that they noted are: lack of knowledge about solar, concerns about system reliability, concerns about the effect of Wisconsin weather on performance, concerns about dealer credibility and competence, high system cost and redundancy with other heating options (Peters, Robison, and Winch, 1997). Essentially it seems that a customer would be more willing to consider solar if it were less expensive and there were someone to whom they could turn for maintenance issues and to be assured that the system was operating properly. 
One proposed solution to both of these problems is to encourage the involvement of electric utilities. If a utility were to buy a large quantity of solar systems and rent them to homeowners there would be a number of benefits to all involved. The utility could buy systems at a volume discount rate, recuperating their cost through a leasing program. Furthermore, there are business tax incentives for solar options that are available to corporations, such as utilities, but are unavailable to individual consumers. The other benefit to the utility is that of avoided generation cost. Most utilities are summer peaking meaning that the highest demand occurs during the summer when a large number of air conditioners are in operation. Because this is a problem for almost all utilities, simple rerouting of power from one utility district to another is not a sufficient solution. Many utilities maintain extra generating capacity year round so that they can meet their summertime load, a costly undertaking. If however, a large number of houses in the utility's service area heat water without creating an increased load on the utility, the utility's extra generating capacity could be reduced at great economic and environmental benefit. The benefit to the customer is that solar energy collection becomes much less expensive and that the utility would be in charge of maintenance. Furthermore, the customer would pay a fixed monthly lease on the collector, and would be charged a reduced electricity rate, hopefully decreasing the overall bill.

\subsection{Solar Domestic Hot Water Systems}

Solar thermal energy can, of course, be used for many purposes. The vast majority, however is used in heating water, especially for residential homes. The majority of solar domestic water hot water (SDHW) systems make use of thermal energy collectors that 
convert radiant solar energy into thermal energy in a fluid by exposing the collector to the sun. The working fluid is circulated from the bottom of a storage tank by means of a pump, through the collector, and is deposited at the top of the tank. The pumps are operated by means of a differential temperature controller. In the simplest case, the pumps circulate fluid when the fluid temperature at the collector outlet is greater than the fluid temperature at the bottom of the tank. In locations where freezing is an issue, a heat exchanger is placed between the tank and the collector, allowing propylene glycol (antifreeze) to be circulated in the collector, and potable water to be circulated in the tank, separate from the glycol. Figure 1.2.1 shows a typical SDHW system configuration.

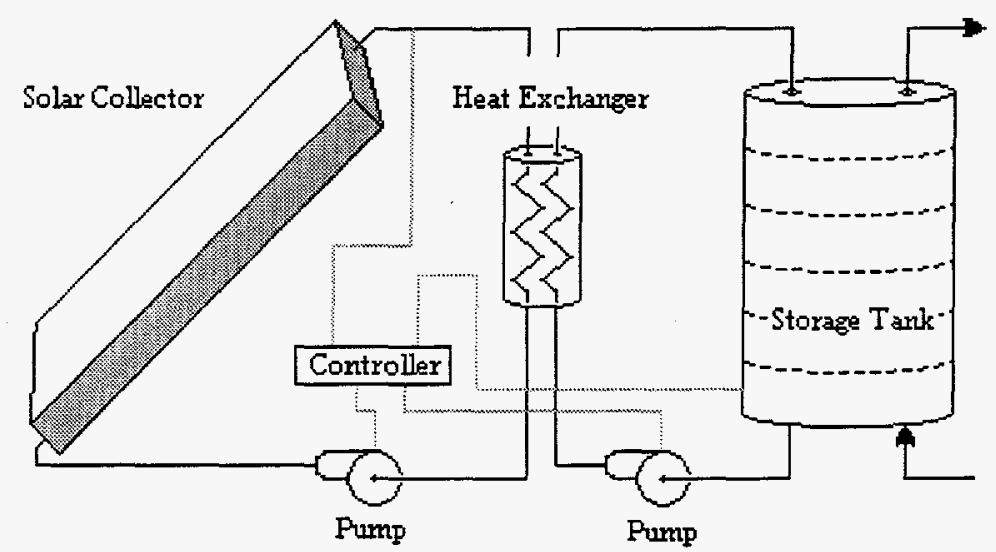

Figure 1.2.1 Typical Solar Domestic Hot Water System

There are numerous variations on the basic system in figure 1.2.1, including those that have a second storage tank, the first one being used as a solar preheat tank and the second being a standard water heater. Recently, systems have been integrated with 
4

photovoltaic (PV) panels that power the pumps (Jahnig, 1997) or that directly heat the water (Williams, 1996). The advantage of such systems is a reduction in parasitic energy cost. The PV panel also replaces the controller since the pumps circulate fluid only when the radiation input is above a certain critical level. Other systems are designed with a coil heat exchanger that wraps around the inside of the storage tank, and are sometimes designed without a heat exchanger at all. The heat exchanger is something of a doubleedged sword, providing freeze protection but decreasing the overall performance of the system while increasing the system cost.

\subsection{Promising Alternatives}

One of the problems with solar collectors in northern climates is that of freezing. SDHW systems necessarily bring water outside through pipes to the collector where the water is heated before being returned indoors. The scheme works well as long as the sun is shining and the water temperature is never allowed to fall below freezing. However, if the water does freeze, then chances are that the collector, and possibly the structure supporting it, will be damaged or destroyed.

The most common solution to the freezing problem is to place a heat exchanger between the tank and the collector, and to run antifreeze through the collector loop. This, however, is a wasteful method of transferring heat from one fluid to the other. Because of comparatively low flow rates and small temperature differences, the heat exchanger effectiveness in a typical solar collector system will vary between 0.1 and 0.5 , causing the solar collector to operate at a higher temperature and lower efficiency (Buckles, 
1983). Figure 1.3.1 shows that the collector's efficiency decreases with higher operating temperatures. $T_{i}$ is the inlet temperature to the collector, $T_{a}$ is the ambient temperature and $\mathrm{G}_{\mathrm{T}}$ is the incident radiation. Increasing $\mathrm{T}_{\mathrm{i}}$ acts to shift the collector operating point to the right, decreasing the efficiency.

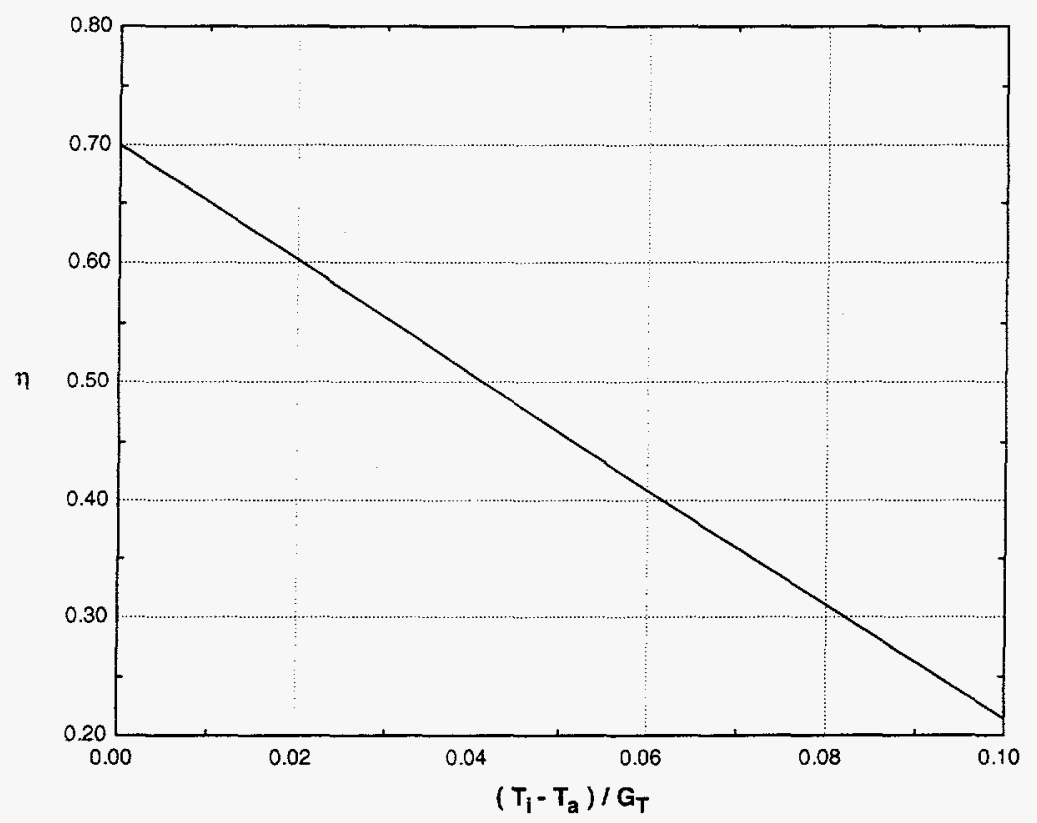

Figure 1.3.1: Collector Efficiency

It would be extremely beneficial to be able to provide freeze protection without paying the efficiency penalty associated with a heat exchanger. This thesis explores two such freeze protection possibilities.

\subsubsection{Thermo-Elastic Collectors}

The fluid in a standard collector is carried into a header where it is distributed throughout small diameter (typically about $0.75 \mathrm{~cm}$ ) copper tubes. These tubes are separated by thin copper fins approximately $7 \mathrm{~cm}$ in width and $0.5 \mathrm{~mm}$ in thickness. 
6

Solar energy incident on the fin is conducted towards the tubes (which are at a slightly lower temperature due to the internal fluid flow) and is delivered to the working fluid. Being a solid material that becomes more brittle when exposed to low temperatures, the header and copper tubes can crack with the expansion of freezing internal fluid.

In a thermo-elastic collector, the copper tubes and absorber plate are replaced with tubes made of some compliant material that does not deform permanently when water freezes inside them. Instead, they deform elastically, and regain their original shape once the water begins to flow again. Thermo-elastic materials provide built in freeze protection but have their own disadvantages since they tend to be good thermal insulators and do not conduct heat well. Is it possible, however, to design a collector plate geometry that overcomes the low thermal conductivity problem?

\subsubsection{Three-Season SDHW Systems}

Another option for freeze protection without resorting to a heat exchanger is to simply turn the system off and drain it during those months when freezing temperatures occur. Because the system would operate during a fraction of the year, its performance would be reduced, giving a lower annual solar fraction (the fraction of a heating load met by solar energy). However, removing the heat exchanger would increase the performance of the system during those times when it is in operation. Furthermore, the collector system would be optimized for summer collection, having a different slope and perhaps a different collector area. Would the benefit of removing the heat exchanger be great enough that the overall performance would not be degraded by leaving the system 
inoperational for some portion of the year? The answer depends upon the local weather conditions such as length of winter and the winter's relative cloudiness.

While the thermal benefits or penalties of a three-season system are easily quantified, there are also economic concerns that must be addressed. Even if there is a reduction in annual solar fraction associated with the three-season system, such a system also costs less to install and operate. Choosing a three-season system saves the customer the up-front cost of the heat exchanger, one of the pumps, and the antifreeze charge.

The idea of a three-season system also ties in to the utility ownership concept. Since the utility's greatest need for extra generating capacity occurs during the summer when the three-season system is operational, the economic benefit to the utility may be greater for a three-season system than for a four-season system that requires more maintenance.

\subsection{Other Freeze Protection Alternatives}

Inventing freeze protection methods requires a fair amount of imagination, but the technology often already exists. Consequently there are a great number of freeze protection methods available to SDHW system designers. While none of these methods were investigated within the scope of this project, they are worth mentioning.

One common freeze protection method is to attach a strip of electric resistance heating tape to the pipes that are in danger of freezing. To implement such a method, a controller would also be required to turn on the heater upon sensing a low fluid temperature. The main advantage of such a scheme lies in its simplicity. However, it is 
not appropriate for all situations. First, any SDHW system that relies upon electricity for freeze protection is in danger during periods of concurrent freezing and power failure.

Second, electric resistance heating is not appropriate in all locations. In a climate where freezing temperatures are a rarity, such a method works well. However, in a place such as Colorado, the heater would need to be on during a significant portion of the year and the cost of running such a heater might outweigh any benefit that the SDHW system could have delivered. Table 1.4.1 shows a number of locations and the amount of energy required to power an electric resistance type freeze protection scheme (Barnaby and Wilcox, 1977). The second column in Table 1.4.1 reports degree hours. One degreehour is added to the annual sum for each hour that the temperature is one degree less than an arbitrary base temperature. Two degree-hours would be added if the temperature were two degrees below the base temperature during a given hour.

Table 1.4.1 Power Requirements for Electric Resistance Freeze Protection in Various Locations

\begin{tabular}{|c|c|c|c|}
\hline Location & $\begin{array}{c}\text { Annual Degree } \\
\left.\text { Hours (base } 1.7^{\circ} \mathrm{C}\right) \\
{\left[{ }^{\circ} \mathrm{C}-\mathrm{hr}\right]}\end{array}$ & $\begin{array}{c}\text { Freeze Protection } \\
\text { Energy }\left[\mathrm{kWhr} / \mathrm{m}^{2}\right]\end{array}$ & $\begin{array}{c}\text { Percentage of 315 } \\
\mathrm{kW}-\mathrm{hr} / \mathrm{m}^{2} \text { annual } \\
\text { output [\%] }\end{array}$ \\
\hline Oakland, CA & 33 & 0.23 & 0.07 \\
\hline Sacramento, CA & 191 & 1.34 & 0.4 \\
\hline Portland, OR & 1574 & 11.02 & 3.5 \\
\hline Denver, CO & 12473 & 87.31 & 27.7 \\
\hline
\end{tabular}

Another method of active freeze protection is to include a controller, which upon sensing a low ambient temperature, opens a valve and allows the fluid contained within the collector to drain into a small expansion tank. These so-called drainback systems suffer from the problem of simultaneous freezing and power failure. There are also the 
added equipment costs of a more complex controller and of the solenoids used to control the valves as well. One method used to prevent problems that arise from simultaneous freezing and power failure is to design the system such that power is used to hold the solenoid open. Upon interruption of power the system would drain, regardless of the outdoor temperature.

Passive freeze protection schemes also exist which do not suffer from the drawbacks of the electric resistance heater or the drainback system. A freeze protection scheme has been analyzed in which the water in a tube is allowed to freeze briefly. However, as the water freezes, it expands into a compliant region such as an air filled tube, preventing the water tube itself from being damaged (Bickle, 1975). The disadvantage of such a system is that ice may form which blocks further expansion into the compliant zone in which case, there is essentially no freeze protection. A further disadvantage is that the required pumping power of the collector system will be increased (leading to increased operating costs) by the inclusion of a rubber tube or foam core contained within the copper pipes. The rubber tube or foam core will increase the friction factor of the pipe significantly.

Evacuated tube collectors also provide passive freeze protection. In such a collector, water is passed through an inner glass tube containing a low emmitance absorber plate. A second tube surrounds the first and the gap between the two is evacuated. The vacuum provides excellent insulation and the major losses from the collector occur in the header. Experiments have shown that such a collector tube can 
10

remain surrounded by dry ice (a temperature of $-78{ }^{\circ} \mathrm{C}$ ) for 120 hours without damage (Craig and Harding, 1987). In these experiments, the water in the header (which is directly attached to the collector tubes) was not subjected to freezing temperatures and it is theorized that any ice forming in the collector tube floated up into the header and melted (Figure 1.4.1). Since the header of the collector was unrealistically protected from freezing conditions, the validity of the experiment's results is debatable. Certainly, however, an evacuated tube collector has only radiation losses from the tubes themselves, and some passive freeze protection is inherent in the design. The disadvantages to evacuated tubes are that they are expensive, fragile, and that most of them have a glass to metal seal at the header the integrity of which is difficult to maintain over a long period of time.

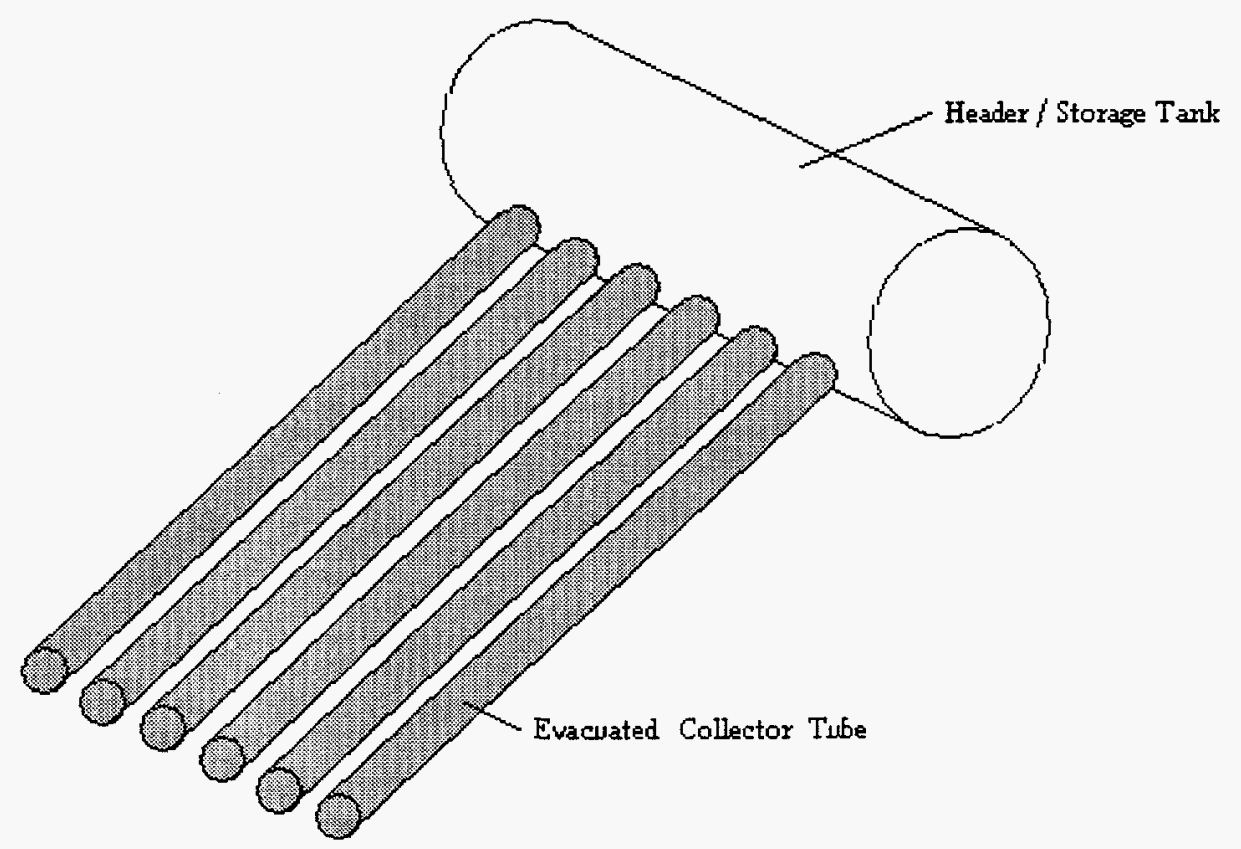

Figure 1.4.1: Evacuated Tube Collector 


\subsection{Objectives and Research Scope}

The overall goal of this project was to assess the feasibility of two heat exchangerless SDHW system alternatives: the thermo-elastic collector and the threeseason collector. The project included a number of tasks.

1. Create and validate a model for collector/plate geometries that make use of low thermal conductivity materials.

2. Design a thermo-elastic collector plate that gives similar performance to a standard collector.

3. Analyze the idea of an SDHW system that operates only when the outdoor temperature is above freezing.

4. Create guidelines for designing three-season systems, and for deciding whether a three-season or a four-season system is best suited to a given location.

5. Assess the impact of a three-season system ensemble on an electric utility as compared to that of a four-season system ensemble. 


\section{CHAPTER II}

\section{Thermo-Elastic Collector Plate Design}

\subsection{Introduction}

The gains associated with solar thermal energy collectors are comparatively small in relation to the required capital investment, so it is vital to maximize conversion efficiency. A typical active solar hot water heating system has a collector through which a working fluid is pumped and a tank for water storage. In cold climates, a heat exchanger is typically placed between the collector and the tank so that antifreeze solution may be circulated in the collector, providing freeze protection to the system. However, the addition of a heat exchanger, reduces the collector's useful energy output. It would greatly increase the viability of solar energy as a water-heating alternative if the heat exchanger loss could be eliminated since the energy output would be greater and the capital investment would be smaller.

This chapter examines one proposed remedy to the heat exchanger energy loss problem. If the collector tubes were made of a material that allowed the working fluid to expand and contract, then freeze protection would be built into the system and the heat exchanger would be unnecessary. After a brief discussion of previous experiments in this area and a description of a standard collector configuration, various mathematical models of the expandable collector will be analyzed and compared. 


\subsection{Background}

Before examining possibilities for remedying the heat exchanger penalty it is important to understand the circumstances under which the penalty is minimal and under what circumstances it becomes significant. Figure 2.2.1 shows the dependence of the annual solar fraction (the fraction of a heating load met by solar) on the effectiveness of the heat exchanger in the system. There is a great benefit to increasing the effectiveness of the heat exchanger if it is very low to begin with but the benefit decreases as the effectiveness increases.

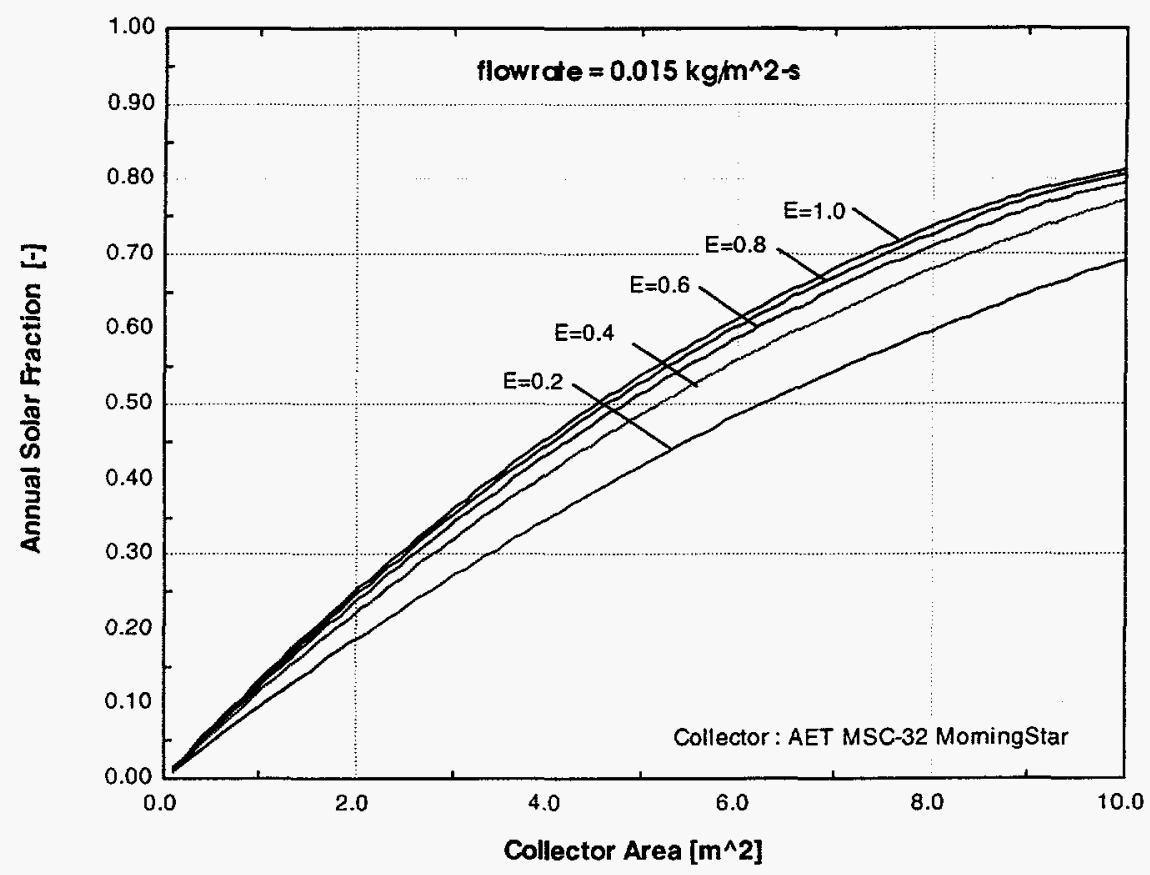

Figure 2.2.1: Heat Exchanger Penalty

One proposed remedy to the freezing problem is to make the collector tubes out of an elastic material that would allow the water to expand on freezing without damaging 
the collector itself. A literature search has shown that this method has met with limited success. All of the work on the subject has been purely experimental. An experiment at the Solar Energy Research Institute evaluated water filled polybutylene piping under repeated freeze thaw cycles (Farrington, 1987). While the piping can withstand temperatures only to $93^{\circ} \mathrm{C}$, it survived repeated freezing for 700 cycles before a crack appeared. Freezing problems were more common at the couplings between pipe sections.

Another experiment involved the manufacture of a carbon black reinforced crosslinked polyethylene collector whose absorber plate consisted of a 400-foot length of flat, spiraled tubing. Tube specimens were subjected to 100 freeze thaw cycles and, for some polyethylene formulations, they fared well (Bradley, 1977). It was found that the material had to be quite resilient (less reinforcement) because the stiffer formulations deformed plastically, creating ballooning problems at sections of the tubing where the wall was comparatively thin due to manufacturing imperfections. As water froze, stress concentrations occurred at these points and caused rupture. The reported $F_{R}(\tau \alpha)$ (intercept factor) for this collector was approximately 0.8 and the $F_{R} U_{L}$ was $1.03 \mathrm{~W} / \mathrm{m}^{2}$ C. These numbers are somewhat suspect as the intercept efficiency is high and the loss coefficient is low even for a modern copper plate collector.

The standard flat-plate collector is made up of a series of parallel copper tubes separated by thin, copper or aluminum fins that run along the length of the tube. The bottom part of figure 2.2.2 shows the end view of one of these fin tube arrangements. Radiant energy incident on the fins is conducted towards the tubes where it is transferred 
to a working fluid. Because the copper has a high thermal conductivity and because the fin thickness is small in comparison to its width, the transfer of energy to the water can be thought of as one-dimensional along the width of the fin and around the tube wall. In the analysis of this problem, two assumptions are made concerning temperatures. First, the temperature around the circumference of the tube is assumed to be constant. Second, there is a small increase in temperature along the length of the fin due to the fin material's finite heat transfer coefficient. A typical temperature profile is shown in figure 2.2.2.

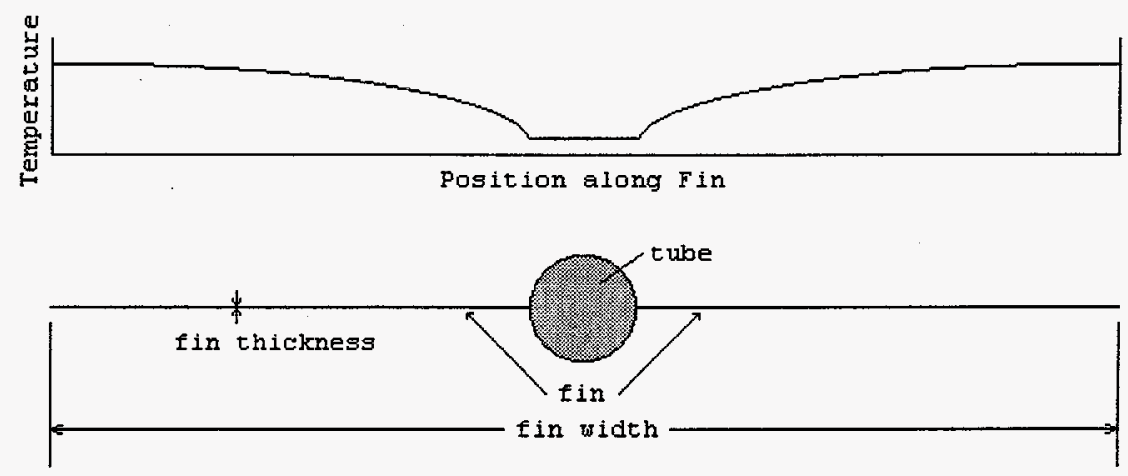

Figure 2.2.2: Temperature Distribution in a Copper Fin and Tube (End View)

In a regular elastic material, long chains of polymer are tangled together and attached to one another by crosslinks. The process of vulcanization makes use of sulfur atoms to crosslink polymer chains. Applying a force to a non-crosslinked polymer causes plastic deformation in the material. If, however, there are crosslinks, the polymer chains are brought back to their original shape after the force is removed. The problem with elastomers is that when heated, the crosslinks tend to break and the material deforms plastically. Thermo-elastomers, on the other hand do not rely upon crosslinks for their 
16

elastic properties. Instead, the polymer chains are capped and attached to one another by rigid regions. Figure 2.2 .3 shows a thermo-elastomer called styrene-butadiene in which butadiene chains, having a low glass transition temperature are rubbery at room temperature. Between these chains are rigid areas of high glass transition temperature styrene (Askeland, 1994).

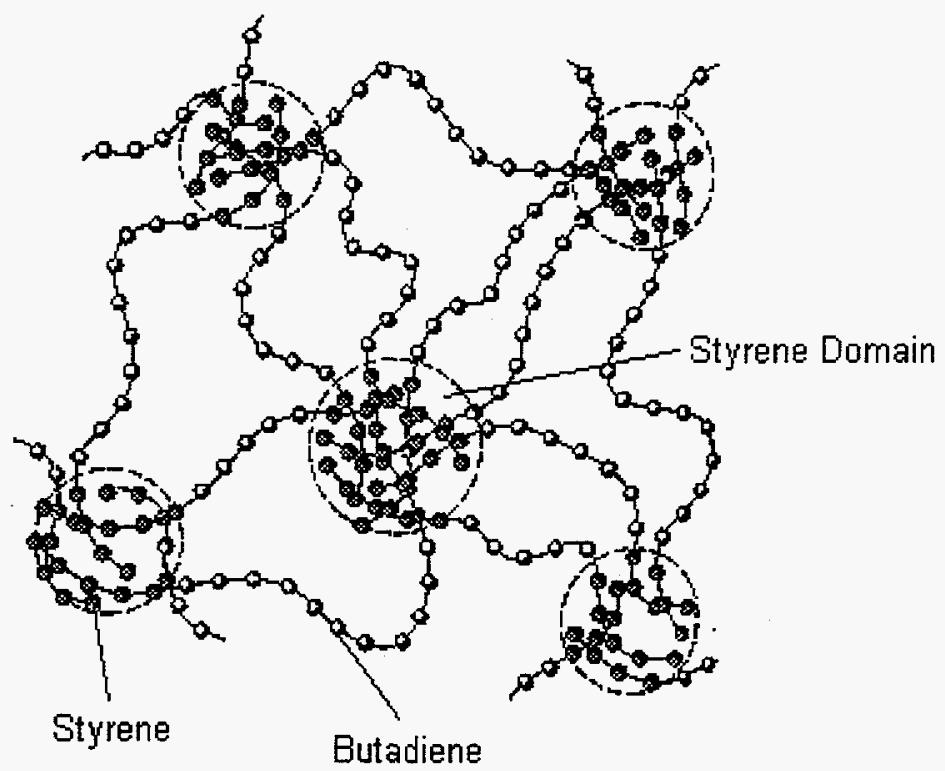

Figure 2.2.3: Molecular Structure of a Thermo-Elastomer

Unfortunately, along with their elastic properties, thermo-elastomers have low thermal conductivities meaning that energy incident on the fin would have a difficult time getting conducted to the fluid. Consequently, there would be significant temperature rise in the fins. To aid in the energy transfer along the fin and to prevent the high temperatures, a thermo-elastic collector would probably have short thick fins. For these reasons, neither the constant temperature around the tube assumption nor the onedimensional heat transfer along the fin assumption holds true. In order to assess the idea 
of a thermo-elastic collector, a one-dimensional model was created (Appendix A). This model allowed a temperature distribution along the circumference of the tube as well as along the length of the fin. The results of this model were validated by use of a finite element analysis program that modeled the problem in two dimensions.

\subsection{Development of a One Dimensional Model}

It is important to notice that the collector fin shown in figure 2.2 .2 has an axis of symmetry about the center of the tube. The problem can therefore be broken up into three fins attached at a center point as shown in figure 2.3.1. The original fin has an energy input along its top face, and loses energy from both its top and its bottom faces. The second fin is a quarter of the circumference of the tube with a radiative input, convective loss on its top face, and a convective loss to the fluid on its back face. The third fin consists of the tube bottom quarter, with convective losses both to the environment off its back face and to the fluid.

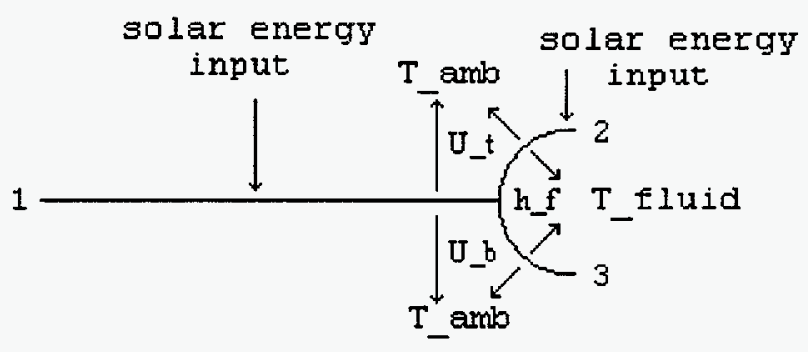

Figure 2.3.1: Energy Balance on Fins 
In the one-dimensional analysis, the second and third fins were assumed to be straight so that the configuration was that of a $T$ shape. The fact that only half the tube is being analyzed means that the ends of each fin can be assumed to be perfectly insulated (Figure 2.3.2).

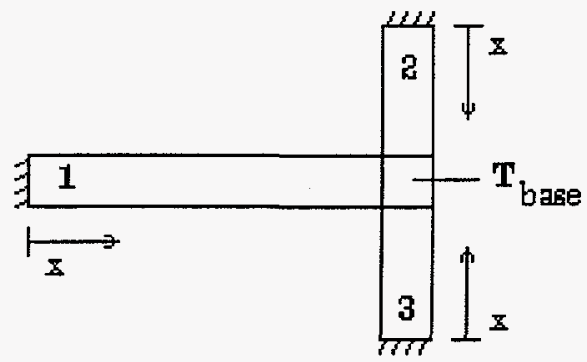

Figure 2.3.2: One-dimensional Model Configuration

In evaluating the amount of energy transferred to the working fluid, it was first necessary to find the temperature at the intersection of the three fins (labeled $T_{\text {base }}$ in figure 2.3.2). Energy balances were performed on each of the three fins assuming that the free ends were perfectly insulated due to symmetry and that the point of intersection had a temperature of $T_{\text {base. }}$ The energy balance for an element of length $\Delta x$ of along fin 1 , is given by equation 2.3.1.

$$
S \Delta x-U_{t} \Delta x\left(T-T_{a m b}\right)+\left(-\left.k \delta \frac{d T}{d x}\right|_{x}\right)-\left(-\left.k \delta \frac{d T}{d x}\right|_{x+\Delta x}\right)-U_{b} \Delta x\left(T-T_{a m b}\right)=0
$$

Where $S$ is the incident radiation per unit area, $U_{t}$ is the convective heat loss coefficient per unit area for the top of the fin, $U_{b}$ is the heat loss coefficient for the back of the fin, $k$ is the thermal conductivity of the fin material, $\delta$ is the thickness of the fin, and T is the local temperature of the element. The signs of each term are determined by the 
coordinate system shown in figure 2.3.2. The energy balance can be rewritten as a differential equation by dividing equation 2.3.1 through by $\Delta \mathrm{x}$ and finding the limit as $\Delta \mathrm{x}$ approaches zero.

$$
S-\left(U_{t}+U_{b}\right)\left(T-T_{a}\right)-k \delta \frac{d T}{d x}+k \delta \frac{d T}{d x}+k \delta \frac{d^{2} T}{d x^{2}}=0
$$

The equation can then be rewritten as

$$
\frac{d^{2} T}{d x^{2}}=\frac{U_{t}+U_{b}}{k \delta}\left[T-T_{a}-\frac{S}{U_{t}+U_{b}}\right]
$$

Two boundary conditions are used in solving the above equation. First, the base temperature must be known, and second, the derivative of temperature with respect to location is zero at the insulated end of the fin. (Equation 2.3.4)

$$
\left.T\right|_{x=(W-D / 2)}=\left.T_{b} \quad \frac{d T}{d x}\right|_{x=0}=0
$$

In order to simplify the algebra, two variables are defined as shown in equation 2.3 .5

$$
m=\sqrt{\frac{U_{t}+U_{b}}{k \delta}} \quad \Psi=T-T_{a}-\frac{S}{U_{t}+U_{b}}
$$

Equation 2.3.2 can thus be rewritten as

$$
\frac{d^{2} \Psi}{d x^{2}}-m^{2} \Psi=0
$$


20

Having the boundary conditions

$$
\left.\frac{d \Psi}{d x}\right|_{x=0}=\left.0 \quad \Psi\right|_{x=(W-D / 2)}=T_{b}-T_{a}-\frac{S}{U_{t}+U_{b}}
$$

The general solution to the differential equation is

$$
\Psi=C_{1} \sinh (m x)+C_{2} \cosh (m x)
$$

Constants $C_{1}$ and $C_{2}$ are found by substitution of the boundary conditions. The resulting solution is

$$
\frac{T-T_{a}-\frac{S}{U_{t}+U_{b}}}{T_{b}-T_{a}-\frac{S}{U_{t}+U_{b}}}=\frac{\cosh (m x)}{\cosh \left(m \frac{W-D}{2}\right)}
$$

Since the energy balances of each fin differ slightly, the equations for $\Psi$ and $m$ are also different. Equation 2.3.10 shows the energy balance on fin 2 .

$$
S \Delta x-U_{t} \Delta x\left(T-T_{a}\right)-h_{f}\left(T-T_{f}\right)+\left(-\left.k \delta \frac{d T}{d x}\right|_{x}\right)-\left(-\left.k \delta \frac{d T}{d x}\right|_{x+\Delta x}\right)-U_{b} \Delta x\left(T-T_{a}\right)=0
$$

$\Psi$ and $\mathrm{m}$ for fin 2 are given in equation 2.3.11.

$$
m_{t}=\sqrt{\frac{U_{t}+h_{f}}{k \delta_{t}}} \quad \Psi=T-\frac{1}{U_{t}+h_{f}}\left(U_{t} T_{a}+h_{f} T_{f}+S\right)
$$

And the solution is given in 2.3.12. 


$$
\frac{T_{\text {top }}-\left[\left(\frac{1}{U_{t}+h_{f}}\right)\left(U_{t} T_{a}+h_{f} T_{f}+S\right)\right]}{T_{b}-\left[\left(\frac{1}{U_{t}+h_{f}}\right)\left(U_{t} T_{a}+h_{f} T_{f}+S\right)\right]}=\frac{\cosh \left(m_{t} x_{f}\right)}{\cosh \left[m_{t} \pi \frac{D}{4}\right]}
$$

The energy balance for fin 3 is much the same as that of fin 2 except that there is no solar energy input.

$$
-U_{t} \Delta x\left(T-T_{a}\right)-h_{f}\left(T-T_{f}\right)+\left(-\left.k \delta \frac{d T}{d x}\right|_{x}\right)-\left(-\left.k \delta \frac{d T}{d x}\right|_{x+\Delta x}\right)-U_{b} \Delta x\left(T-T_{a}\right)=0
$$

The equations for $\Psi$ and $\mathrm{m}$ follow.

$$
m_{b}=\sqrt{\frac{U_{b}+h_{f}}{k \delta_{b}}} \quad \Psi=T-\frac{1}{U_{b}+h_{f}}\left(U_{b} T_{a}+h_{f} T_{f}\right)
$$

Which generates the solution

$$
\frac{T_{b o t}-\left[\left(\frac{1}{U_{b}+h_{f}}\right)\left(U_{b} T_{a}+h_{f} T_{f}\right)\right]}{T_{b}-\left[\left(\frac{1}{U_{b}+h_{f}}\right)\left(U_{b} T_{a}+h_{f} T_{f}\right)\right]}=\frac{\cosh \left(m_{b} x_{b}\right)}{\cosh \left[m_{b} \pi \frac{D}{4}\right]}
$$

Equations $2.3 .9,2.3 .12$, and 2.3 .15 provide the local temperature as a function of distance along each fin. However, the base temperature where the fins meet must also be known. The energy conducted to the base point can be found by evaluating Fourier's law at the base point where $x=L$ on fin 1 and where $x=\pi D / 4$ on fins 2 and 3 . 


$$
q_{f i n}=-\left.k \delta \frac{d T}{d x}\right|_{x=L}
$$

The resulting equations for each fin are shown in equations 2.3.17 through 2.3.19.

$\mathrm{Q}_{\mathrm{fin}}$ is the total energy transferred to the base point from the fin one.

$$
\begin{gathered}
q_{f i n}=-m_{f} k \delta_{t}\left[T_{b}-T_{a}-\left(\frac{S}{U_{t}+U_{b}}\right)\right] \tanh \left[m_{f}\left(\frac{W-D}{2}\right)\right] \\
\text { where } m_{f}=\sqrt{\frac{U_{t}+U_{b}}{k \delta_{t}}}
\end{gathered}
$$

In the above equation, $W$ is the fin width, $D$ is the diameter of the tube as defined in figure 2.2.1, and $T_{b}$ is the base temperature. $Q_{\text {top }}$ is the energy transferred to the base point from the top quarter circumference of the tube and $h_{f}$ is the convective heat transfer coefficient between the tube wall and the working fluid.

$$
\begin{gathered}
q_{t o p}=-m_{t} k \delta_{t}\left[T_{b}-\left[\frac{1}{U_{t}+h_{f}}\right]\left(U_{t} T_{a}+h_{f} T_{f}+S\right)\right] \tanh \left[m_{t} \pi \frac{D}{4}\right] \\
\text { where } m_{t}=\sqrt{\frac{U_{t}+h_{f}}{k \delta_{t}}}
\end{gathered}
$$

Q_bot is the energy transferred to the base point from the bottom half of the tube.

$$
\begin{gathered}
q_{b o t}=-m_{b} k \delta_{b}\left[T_{b}-\left[\frac{1}{U_{b}+h_{f}}\right]\left(U_{b} T_{a}+h_{f} T_{f}\right)\right] \tanh \left[m_{b} \pi \frac{D}{4}\right] \\
\text { where } m_{b}=\sqrt{\frac{U_{b}+h_{f}}{k \delta_{b}}}
\end{gathered}
$$


There is also an amount of energy that flows directly from the base point to the water.

$$
q_{\text {end }}=h_{f} \delta_{f}\left(T_{b}-T_{f}\right)
$$

To solve for the temperature at the intersection point, it is necessary to perform an energy balance on the base point itself.

$$
q_{\text {fin }}+q_{\text {top }}+q_{\text {bot }}=q_{\text {end }}
$$

The desired result is an estimate of the energy transferred to the water from the fin so it is necessary to integrate the energy flow along the length of the tube top and bottom. Since the tube was broken at its axis of symmetry for this analysis, the length of integration would normally be one quarter of the tube circumference for each of the top and bottom portions of the tube. Equation 2.3.22 is used twice, once for fin 2, and again for fin 3. The local temperatures are determined by evaluating equations $2.3 .9,2.3 .12$ and 2.3 .15

$$
q_{\text {water }}=\int_{0}^{x \max } h_{f}\left(T-T_{f}\right) d x
$$

The energy transferred to the water is the sum of $\mathrm{q}_{\text {water }}$ for the top portion of the tube, $q_{\text {water }}$ for the bottom portion of the tube and $q_{\text {end }}$ (figure 2.3.3) 


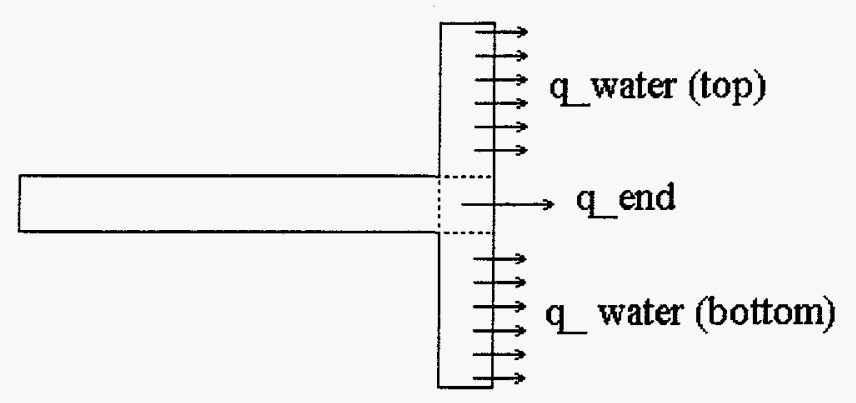

Figure 2.3.3: Energy Transferred to Water

In the next section, various fin tube configurations will be analyzed. In these configurations, the thickness of the tube wall and the thickness of the fin will be varied. There are a few complications in analyzing certain fin tube configurations. In evaluating the integral in equation 2.3 .22 , a length of integration must be chosen. As previously mentioned, when the tube wall thickness is small in relation to the diameter such as in the standard configuration, then a quarter of the circumference (the length of fin 2 or fin 3 ) is used. However, when the tube wall is thick then the base point is no longer a point and has some area associated with it. Thus there are a number of different tube dimensions that can be used in evaluating the circumference and therefore the integration length. Energy is collected along the outer surface and is transferred to the water along the inner surface. These surfaces can differ significantly in length. When evaluating heat transfer in such thick walled cylinder situations, an equivalent diameter is used that may be half or two thirds of the way through the cylinder wall. In this case, however, there is the added complication of fin 1 to deal with. When fin 1 is thick, the base point becomes large and the equivalent tube circumference is further reduced. To choose the integration length, the method illustrated in figure 2.3.4 was used. 


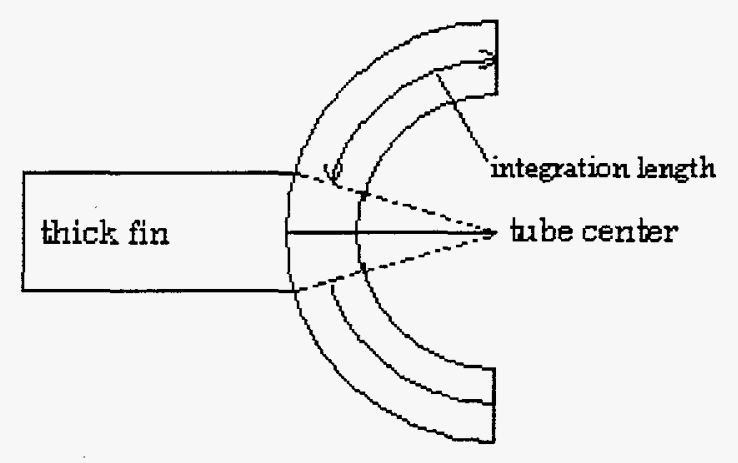

Figure 2.3.4: Reduction in Integration Length due to Fin and Tube Thickness

Radial lines are drawn from the center of the tube to the points where fin one meets either fin two or fin three. The trapezoidal area where the three fins meet is assumed to be the base point and the integration length is taken as the remaining length of the centerline of either fin two or three.

The performance prediction results of the one-dimensional analysis appeared to be reasonable. But lacking experimental data for comparison, they cannot be validated. Two assumptions had been made that needed validation. First, does the one-dimensional model approach reality or are the two-dimensional heat transfer effects important? Second, the choice of integration length was somewhat arbitrary and needed to be justified by a more realistic model such as a finite element analysis. 


\subsection{A Two Dimensional Model: Finite Element Analysis}

In general, a one-dimensional model can be used in analyzing a fin if the thickness to length ratio is less than 0.1 (Holman, 1995). The initial results of the one-dimensional model showed that the collector would have tubes separated by a fin $1 \mathrm{~cm}$ wide and 0.5 $\mathrm{cm}$ thick, a configuration which does not meet the above criteria. Thus, two-dimensional effects are important. However, the desired end result of this analysis is an estimation of the amount of energy transferred to the water. Thus if the one-dimensional model and a two-dimensional model agree, then the simpler of the two may be used. Since creating two-dimensional models is time consuming, while one-dimensional models can be created by simply changing the input values to a few equations, it would be convenient if the one-dimensional model were useable. Using finite element heat transfer analysis software, FEHT (Klein, 1990), collector configurations similar to those analyzed using the one-dimensional model were run in an effort to determine whether these two dimensional effects were important. The temperature distribution shown in figure 2.4.1 definitely shows some two-dimensional effects especially near the end of fin one, furthest from the intersection point. Furthermore, there are significant temperature distributions around the circumference of the tube. The lines in the figure are lines of constant temperature over a range of $38^{\circ} \mathrm{C}$ to $122^{\circ} \mathrm{C}$. The effect of the low thermal conductivity is evident here; a standard copper collector has a much smaller temperature rise along the length of the fins. 


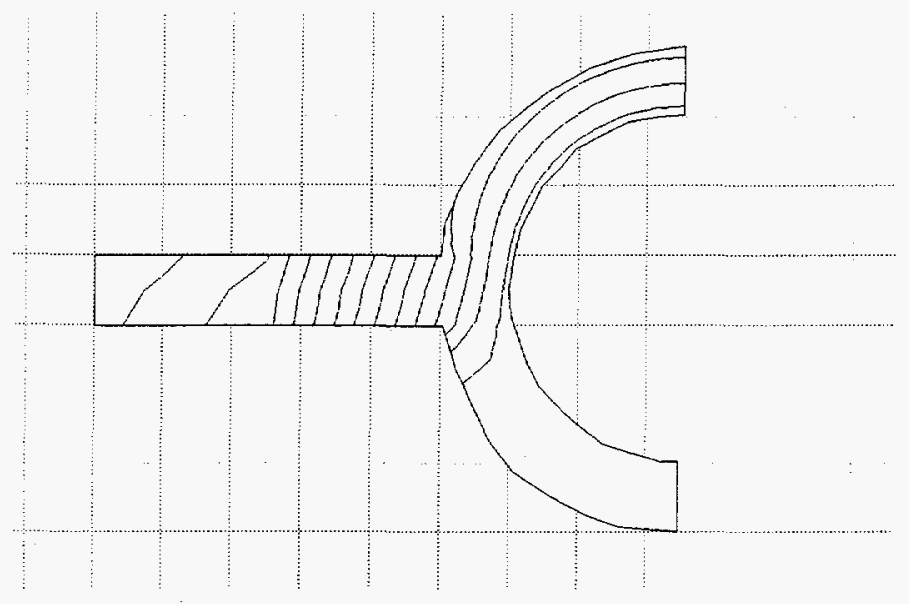

Figure 2.4.1: Temperature Distribution

In an effort to separate the low thermal conductivity contribution to the twodimensional temperature distribution from the thick fin contribution, figures $2.4 .2(\mathrm{a}-\mathrm{d})$ show the same plate geometry with various thermal conductivities.

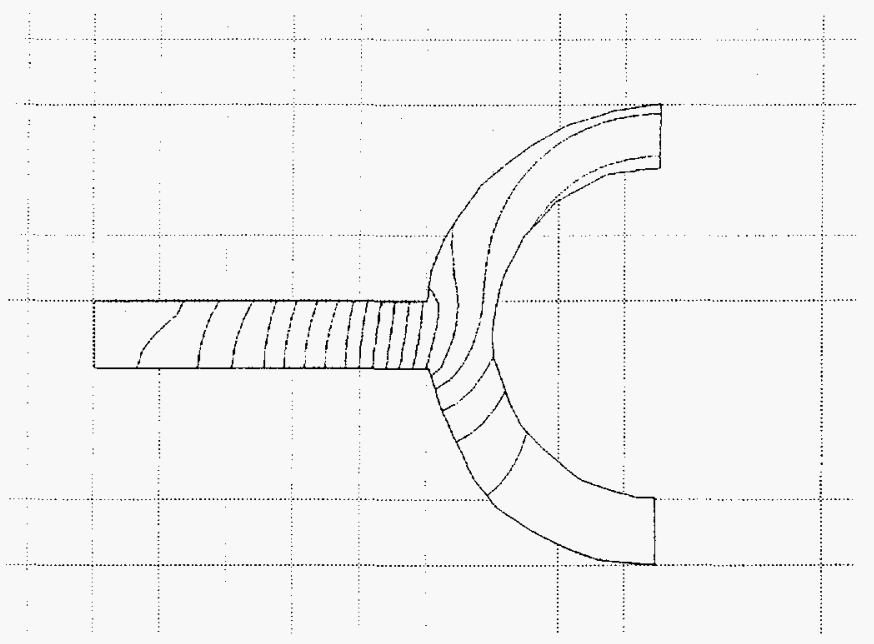

Figure 2.4.2a: Temperature Distribution with $\mathrm{k}=1 \mathrm{~W} / \mathrm{m}-\mathrm{K}$ Temperature Rise along fin: $26^{\circ} \mathrm{C}$ 


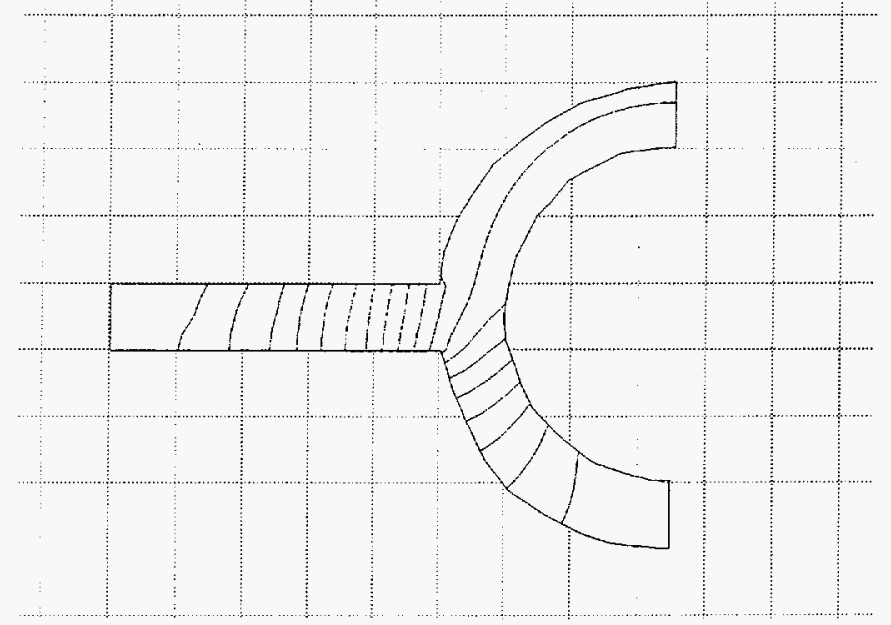

Figure 2.4.2b: Temperature Distribution with $\mathrm{k}=10 \mathrm{~W} / \mathrm{m}-\mathrm{K}$ Temperature Rise along fin: $5^{\circ} \mathrm{C}$

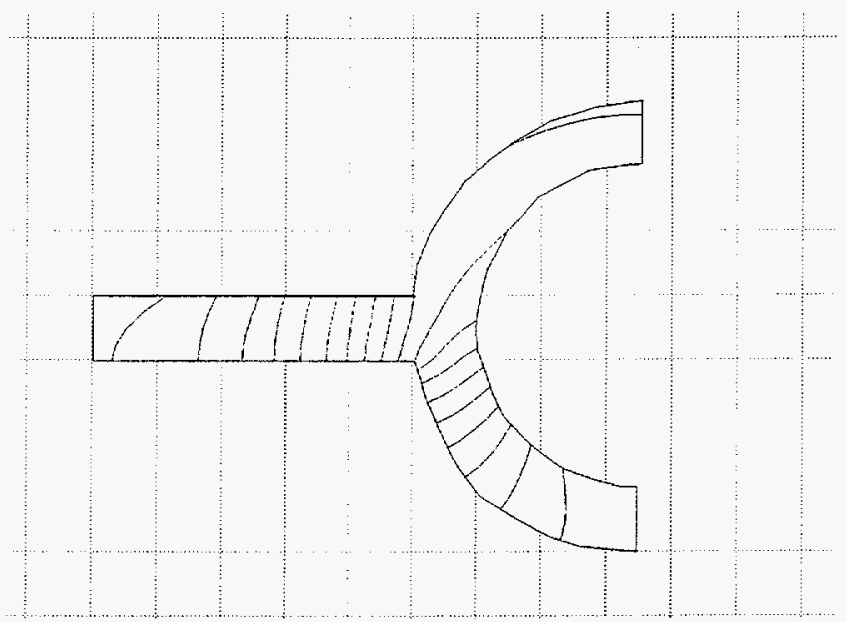

Figure 2.4.2c: Temperature Distribution with $k=400 \mathrm{~W} / \mathrm{m}-\mathrm{K}$ Temperature Rise along fin: $0.5^{\circ} \mathrm{C}$ 


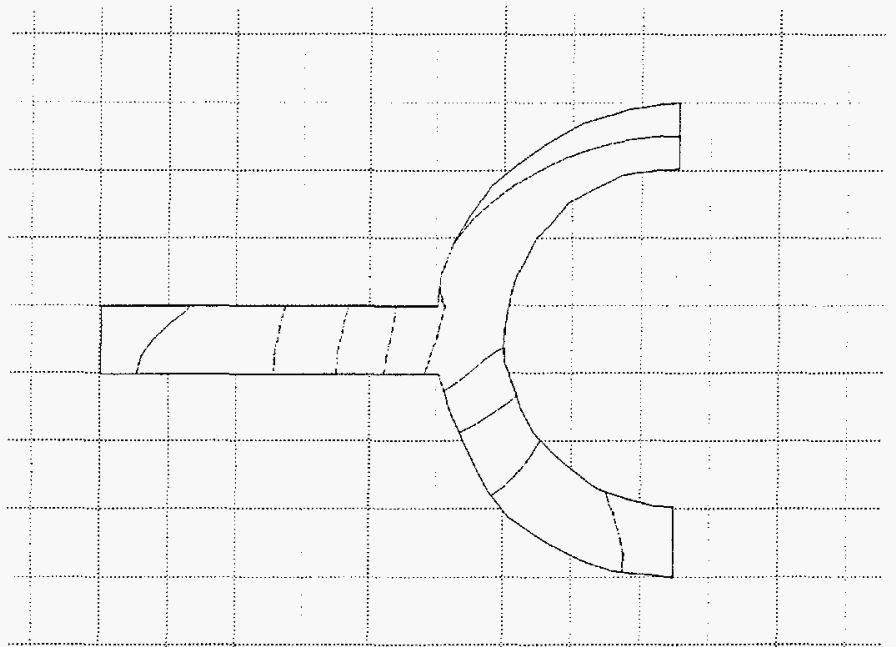

\section{Figure 2.4.2d: Temperature Distribution with $\mathrm{k}=\infty \mathrm{W} / \mathrm{mK}$ Temperature Rise along fin: $0.1^{\circ} \mathrm{C}$}

Evidently, the thickness of the fin does contribute to the two-dimensionality of the results. However, a high thermal conductivity means that the temperature difference through the thickness of the fin is miniscule that the two-dimensional effects do not matter. Another problem becomes apparent through these figures. Because of the thickness of the tube wall, the temperature distribution is in the wrong direction for a fin and therefore cannot be analvzed as such. Since the temperature profile is parallel to the length of the fin, it must be anaiyzed as a wall. The problem is described in greater detail in section 2.8

\subsection{Comparison of One and Two Dimensional Models}

Twenty-seven models were analyzed using both the one and two-dimensional models with fin and tube wall thicknesses varying between 0.1 and 0.9 centimeters. In all cases, the fin was one centimeter long. The fin length was chosen to provide some surface area for incident radiation while limiting the temperature rise along the fin. The 
30

solar input was $1000 \mathrm{~W} / \mathrm{m}^{2}-\mathrm{K}$, the plate top convective heat loss coefficient was $7 \mathrm{~W} / \mathrm{m}^{2}$ and the back loss coefficient was $1 \mathrm{~W} / \mathrm{m}^{2}-\mathrm{K}$. These numbers are typical for a single cover collector with a non selective surface plate and an insulated back. The tube inside diameter was always 1 centimeter. The results for the models are encouraging. For the range between 0.1 and $0.5 \mathrm{~cm}$ thickness, there is less than $10 \%$ difference in the prediction of energy transferred to the water between the two models (Figure 2.5.1). Predictably the agreement is better when the tube wall thickness and the fin thickness are nearly equal (ratio $=1$ ) and becomes worse as one or the other gets comparatively thicker.

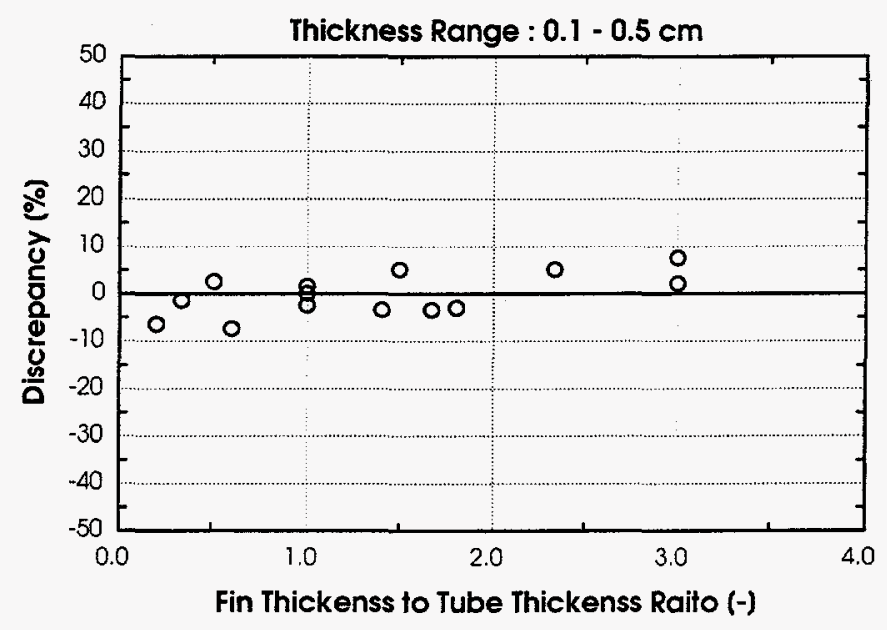

Figure 2.5.1: Comparison between One and Two-Dimensional Models $(0.1-0.5 \mathrm{~cm})$

As thicker fins are added to the evaluation, results between the one and twodimensional models diverge further, even when the fin and tube thicknesses are equal (figure 2.5.2) 


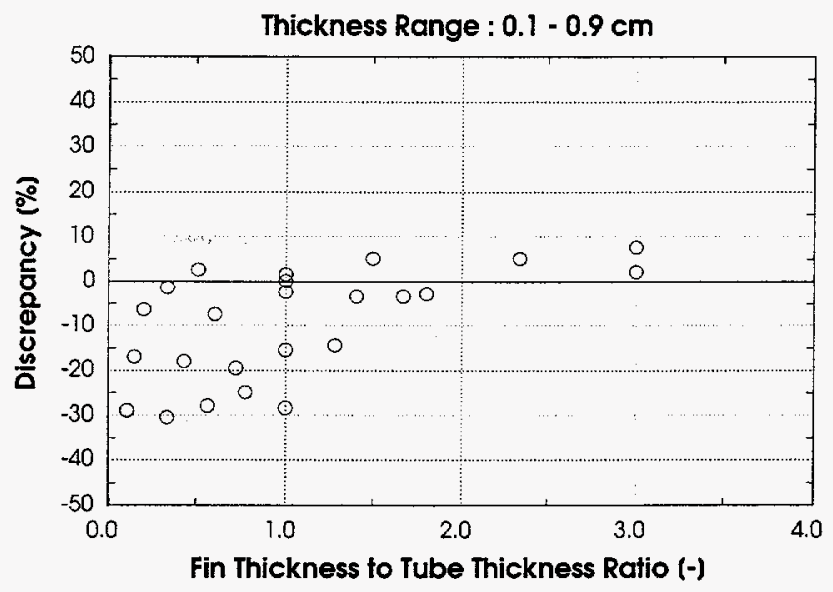

Figure 2.5.2: Comparison between One and Two Dimensional Models $(0.1-0.9 \mathrm{~cm})$

\subsection{Obtaining Useful Design Parameters from the Model}

Once the one-dimensional model had been validated for thicknesses ranging from 0.1 to $0.5 \mathrm{~cm}$, it was possible to use the model in predicting the performance of a thermoelastic collector. Collector performance can be described by equation 2.6.1 (Duffie and Beckman, 1991).

$$
Q_{u}=A_{c} F_{R}\left(I_{T} \tau \alpha-U_{L}\left(T_{i}-T_{a}\right)\right)
$$

In the above equation, $F_{R}$ is the collector heat removal factor, $\tau \alpha$ is the transmitance absorptance product, and $\mathrm{U}_{\mathrm{L}}$ is the loss coefficient. The one-dimensional model was used to determine values of $F_{R}$ for various possible collector designs. Both $F$ and $F_{R}$ vary between 0 and 1 .

The first step in estimating $F_{R}$ is to determine $F$, the collector efficiency factor. $F^{\prime}$ is the amount of energy transferred to the fluid divided by the amount of energy 
32

incident on the collector surface. The plot in figure 2.6.1 shows the F' curves for various collector configurations created using the one dimensional model. In all of these cases, the tube diameter was 1 centimeter, collector losses $\left(\mathrm{U}_{\mathrm{L}}\right)$ were $8 \mathrm{~W} / \mathrm{m}^{2} \mathrm{~K}$, and the tube wall thickness was $3 \mathrm{~mm}$. Each curve corresponds to a different $\mathrm{k} \delta$ product (fin thickness times thermal conductivity).

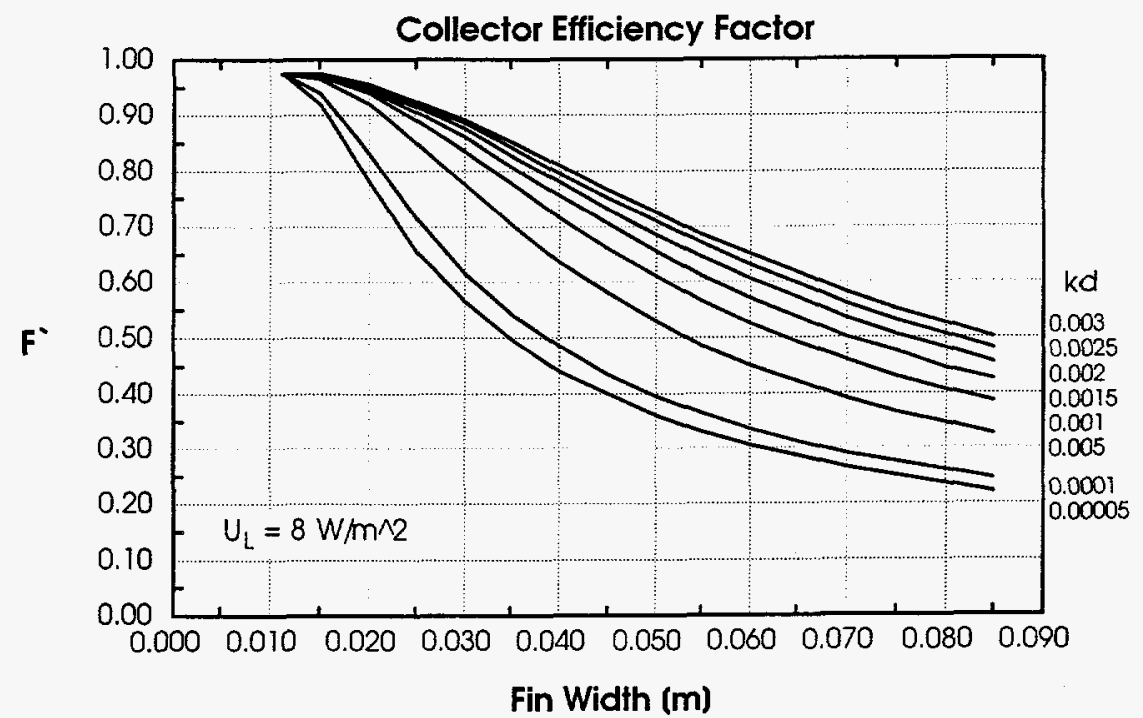

Figure 2.6.1: Collector Efficiency Factor for a Range of $k \delta$

The collector heat removal factor $\left(F_{R}\right)$ is defined as follows (Duffie and Beckman, 1991).

$$
F_{R}=\frac{\dot{m} C_{p}}{A_{c}\left(U_{t}+U_{b}\right)}\left[1-\exp \left(\frac{-A_{c} F^{\prime}\left(U_{t}+U_{b}\right)}{\dot{m} C_{p}}\right)\right]
$$


Equation 2.6 .2 assumes that the specific heat $\left(C_{p}\right)$, collector efficiency factor $\left(F^{\prime}\right)$, top losses $\left(\mathrm{U}_{\mathrm{t}}\right)$, and back losses $\left(\mathrm{U}_{\mathrm{b}}\right)$ are fairly constant over the operating temperature range (Duffie and Beckman, 1991).

The estimation of $F_{\mathrm{R}}$ requires the mass flow rate of the fluid which figures into the internal convective heat transfer coefficient through a Nusselt number and Reynolds number correlation (Equation 2.6.3).

$$
\begin{gathered}
h_{f}=\frac{N u k}{D} \\
N u=3.66 \quad \text { for laminar flow } \\
N u=0.023 \operatorname{Re}^{4 / 5} \operatorname{Pr}^{1 / 3} \text { for turbulent flow }
\end{gathered}
$$

In figure 2.6.2, the jump in $F_{R}$ seen at a mass flow rate per area of 0.005 to 0.0055 is a result of the change from laminar to turbulent flow inside the tubes. It should be noted here that the graph in figure 10 is for a fin width of three centimeters. As W decreases, the effect of the $k \delta$ product is a far less pronounced. The lower $k \delta$ curves are shifted upwards while the higher $\mathrm{k} \delta$ curves remain essentially unchanged. 


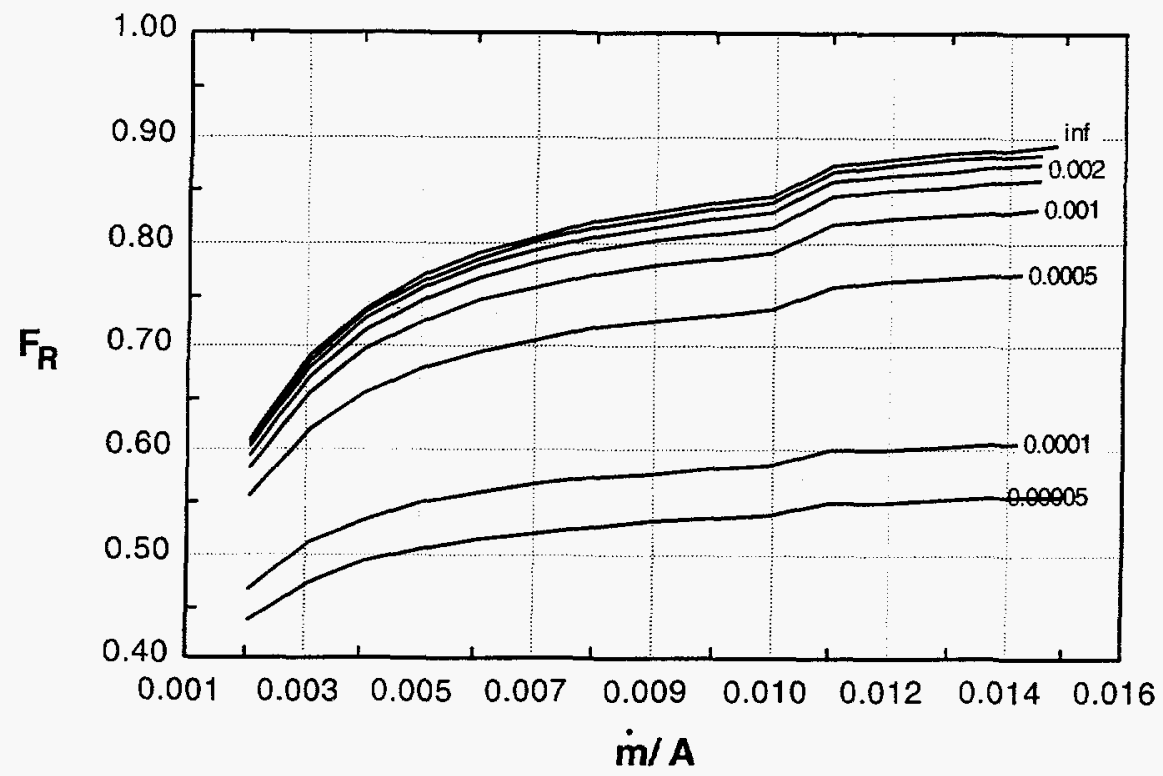

Figure 2.6.2: Collector Heat Removal Factor for a Range of $k \delta$

As a final check of model validity, a copper plate collector with typical dimensions was analyzed using both the one-dimensional model developed in section 2.3 and the accepted equations as presented by Duffie and Beckman (1991). The plot of F' for a copper collector using both the one-dimensional model and the standard design equation appears in figure 2.6.3. 


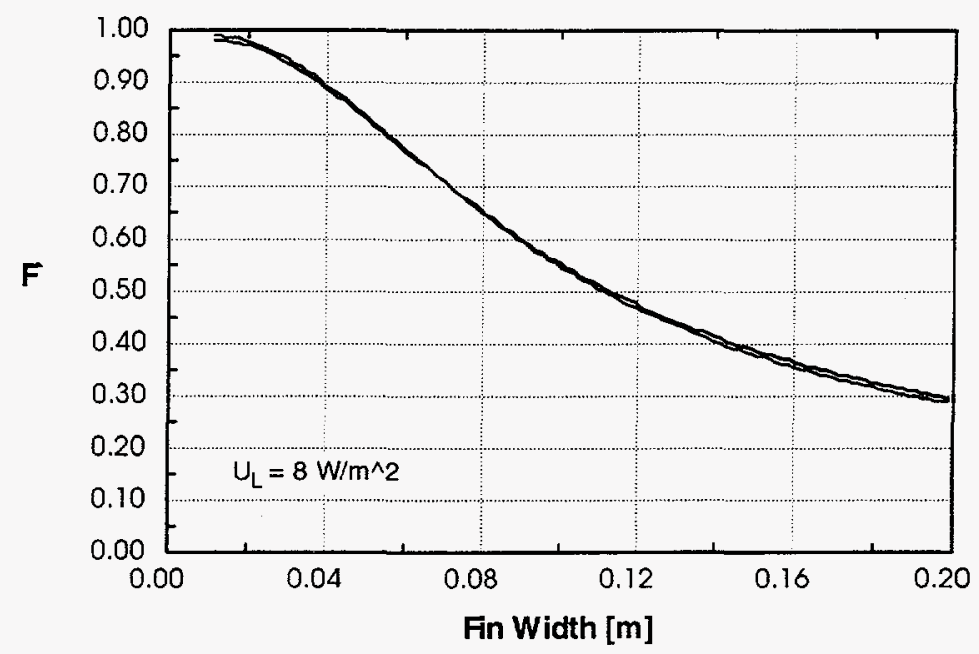

Figure 2.6.3: Model Verification for Standard Configuration

\subsection{Designing a Thermo-Elastic Collector}

With the one-dimensional model, it is possible to choose a reasonable design for a thermo-elastic collector. The restriction imposed by the use of the one-dimensional model is that the thickness of the plate and tube can be no greater than half a centimeter. Furthermore, the predicted $F^{*}$ and $F_{R}$ values will be most accurate if the ratio of fin thickness to tube wall thickness is nearly unity. The end result of this design will be a comparison between the energy performance of the thermo-elastic collector and a standard copper collector. A useful indicator is the amount of thermo-elastic plate area required to match the amount of energy delivered by a standard copper collector. The solar simulation program $f$-Chart (Klein, 1993) was used in evaluating various designs.

$F$-Chart allows the user to specify various parameters concerning the collector and system, and then performs a thermal and an economic analysis, reporting monthly values. 
36

As a preliminary comparison, a thermo-elastic collector of tube thickness $0.5 \mathrm{~cm}$ and fin thickness $0.5 \mathrm{~cm}$ was determined to have an $F_{R}$ of 0.78 using the chart in figure 2.6.2.

The mass flow rate was chosen to be $0.021 / \mathrm{m}^{2} \mathrm{~s}$. Using information from Duffie and Beckman (1991), a $\tau \alpha$ product of 0.7 and a $U_{L}$ value of $8 \mathrm{~W} / \mathrm{m}^{2}$ were chosen to be representative of a non selective surface material. The resulting thermal analysis was compared to the results of a standard American Energy Technologies collector Model AE-21 (SRCC, 1994). The relevant geometric data for the two collectors is shown below in Table 2.7.1.

Table 2.7.1: Collector Geometries

\begin{tabular}{|c||c|c|}
\hline & $\begin{array}{c}\text { AET Model AE-21 Copper } \\
\text { Collector }\end{array}$ & Thermo-Elastic Collector \\
\hline \hline $\mathrm{m} \_$dot $\left(\mathrm{kg} / \mathrm{s} \mathrm{m}^{2}\right)$ & 0.02 & 0.02 \\
\hline $\mathrm{U}_{\mathrm{L}}\left(\mathrm{W} / \mathrm{m}^{2}\right)$ & not reported individually & 8 \\
\hline$\tau \alpha$ & not reported individually & 0.75 \\
\hline $\mathrm{F}_{\mathrm{R}}$ & not reported individually & 0.78 \\
\hline $\mathrm{F}_{\mathrm{R}}(\tau \alpha)$ & 0.674 & 0.59 \\
\hline $\mathrm{F}_{\mathrm{R}} \mathrm{U}_{\mathrm{L}}\left(\mathrm{W} / \mathrm{m}^{2} \mathrm{C}\right)$ & 4.25 & 6.24 \\
\hline
\end{tabular}

The tube diameter was chosen to be 1 centimeter. Care must be taken in choosing a tube diameter and wall thickness not to exceed the maximum hoop strength of the material. The hoop strength is determined as the maximum allowable stress (force/area) that can be internally applied to a thin walled pressure vessel made of the material without worry of material failure. For example cross-linked polyethylene can withstand a hoop stress of 241 psi. Equation 2.7.1 can be used to determine the maximum tube diameter for a given wall thickness (Beer and Johnston, 1992). 


$$
H=\frac{p(D-t)}{2 t}
$$

$\mathrm{H}$ is the hoop stress, $\mathrm{p}$ is the internal hydrostatic pressure, $\mathrm{D}$ is the outside diameter of the tube and $\mathrm{t}$ is the wall thickness.

The comparison showed that, as expected, the thermo-elastic collector did not perform as well per unit area as the standard copper collector. Consequently, the aperture area of the thermo-elastic collector was increased until its annual solar fraction was equal to that of the copper collector.

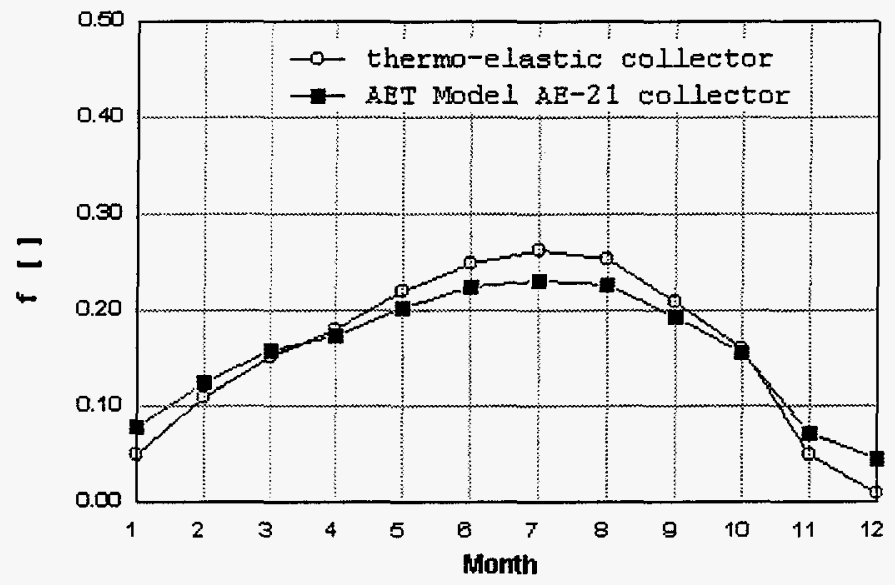

\section{Figure 2.7.1: Monthly Solar Fraction for $2.6 \mathrm{~m}^{2}$ Thermo-Elastic Versus $1.76 \mathrm{~m}^{2}$ Model AE-21 Collector}

The increase of area necessary to achieve a standard collector's energy output was chosen as a method of assessing the performance of the thermo-elastic collector. The AET collector had an aperture area of $1.76 \mathrm{~m}^{2}$ that corresponded to an annual solar fraction of 0.156 . The low solar fraction is due to only one collector panel being used in 
the system. With the same aperture area, the thermo-elastic collector has a solar fraction of 0.109 . An aperture area of $2.6 \mathrm{~m}^{2}$ is needed to achieve a solar fraction of 0.156 .

In can be seen from figure 2.7.1 that although the annual solar fraction is the same for the two collector types (0.157), that the thermo-elastic collector works better during the summer months (from an energy standpoint) and not as well during the winter. It must be kept in mind that this $f$-Chart analysis is purely thermal and does not take into account any benefits of freeze protection or reduced cost that a thermo-elastic collector might also include. It may appear odd that the plots of solar fraction cross when the thermo-elastic collector has both a lower intercept efficiency and a higher loss coefficient. However, it must be kept in mind that each plot was generated separately and that the collector areas were subsequently altered to obtain the same overall solar fraction. Were it not for the different areas the thermo-elastic collector plot would be almost coincident with the ordinate axis.

There are a number of points that have not been studied in this analysis, which are important to the design of a freeze tolerant collector. No work has been done in this analysis on material properties. In order to build a thermo-elastic collector, a material would have to be chosen that is able to withstand high temperature and high pressure without ballooning. According to Bradley (1977) carbon black reinforced cross-linked polyethylene is a promising alternative. His analysis goes into a fair amount of detail concerning the doping of polyethylene to obtain desired material properties. Furthermore, the header and footer of the collector pose a problem and need to be designed with a 
freeze protection scheme of their own because forming ice could crack them or damage the joints between header and riser. A significant number of the failures mentioned in both the Farrington (1987) and the Bradley (1977) experiments were caused by a compression fitting working its way loose during repeated freeze thaw cycles.

\subsection{Further Research}

To be honest, there are a lot of gaps in the thermo-elastic collector analysis. A one-dimensional model was sought in order to speed up the design process simply because two dimensional models are time consuming to create; each new configuration needs to be redrawn and redefined completely from scratch. But since the conclusion of the design work has been that the tube walls need to be thick in order to provide structural integrity to the collector plate, the problem is without a doubt, two-dimensional. This is not to say that the work to date is invalid. Collectors can be designed from onedimensional model equations as long as they have nearly the same geometries as those studied here $(\sim 1 \mathrm{~cm}$ fins and $\sim 1 \mathrm{~cm}$ diameter tubes). Furthermore the research to date has proven that thermo-elastic collectors are a viable alternative and bear further investigation.

The next thing that needs to happen if thermo-elastic collectors are to be pursued is to create a method of predicting F' using a two-dimensional model. Since F' is simply the ratio of energy in to energy out, it is an easy procedure of summing the total energy flow into the top of the collector and summing the total energy flow into the fluid. Given 
40

$F^{\prime}$, a designer could then predict $F_{R}$ and use it in equation 2.6 .1 as before. Then a prototype needs to be built in order to assess whether the fin separated tube design is best. It may well be that two thermo-elastic plates separated by vertical thermo-elastic risers as shown in figure 2.7 .2 would be a simpler and more efficient collector.

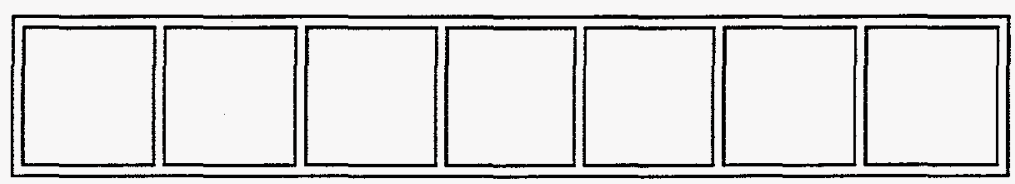

Figure 2.7.2: Square Tube Thermo-Elastic Collector Plate Design

\subsection{Conclusions}

A one dimensional model of a low thermal conductivity collector plate was developed in order to assess the possibility of providing a fail safe, built in freeze protection scheme. Because preliminary results indicated that short, thick fins would be desirable, two dimensional heat conduction effects were examined. A series of twodimensional models were developed and results were compared to those of the single dimensional model. The models give comparable results for fin and tube thicknesses under 0.5 centimeters. Results are further improved if the fin and tube thicknesses are nearly the same.

The one-dimensional model was then used to provide design tools from which a collector geometry and mass flow rate can be chosen. Standard collector performance measures such as the collector efficiency factor and the heat removal factor were developed and used to design a thermo-elastic collector plate. Because of its low thermal 
conductivity, the thermo-elastic collector did not perform as well as a standard copper plate collector. Thus, the aperture area was increased until a similar performance was achieved. To provide the same amount of energy on an annual basis, the thermo-elastic collector must be approximately 1.5 times as large as a standard collector must. Increasing the area will increase the amount of material required to build the collector. However, the manufacture of a copper collector involves bending a copper sheet around the tubes and then braising or welding the tubes into place to provide a good thermal bond. The thermo-elastic collector plate could be extruded in a single sheet, possibly significantly decreasing the manufacturing cost.

The suggested design of a thermo-elastic plate collector is that of one centimeter tubes with half centimeter thick walls separated by fins that are one centimeter long and again half a centimeter thick. The thickness of the plate gives a higher $\mathrm{k} \delta$ product in figure 9 meaning that the collector efficiency is less dependent on tube spacing. Next, a flow rate of $0.021 / \mathrm{m}^{2}$-s was chosen to give a high collector heat removal factor. With this configuration, an area 1.5 times greater than a typical copper collector will give comparable annual performance. 


\section{CHAPTER III}

\section{An Economic Analysis of Three-Season SDHW Systems}

\subsection{Introduction}

Economics play a central role in any customer's decision to purchase an SDHW system. The customer, whether a homeowner or a corporation, is unlikely to buy a solar energy system if they know from the start that its only benefit is to the environment. While the renewability of the energy source is certainly attractive, it is not a sufficient selling point. Part of the reason behind the popularity of SDHW systems during the 1980's was the availability of tax credits for renewable energy installations. The tax incentives are no longer available to individual homeowners and the current selling point of SDHW systems is the amount of money that the customer will save on future fuel bills. However, normal business tax credits are still available to electric utilities interested in solar. Obviously, any utility considering solar power generation is going to look very carefully at economics to ensure that such a project will be profitable to themselves and to their shareholders.

Another reason to consider an economic analysis of freeze protection alternatives is that some have the potential of reducing the cost of the SDHW system, although there may be an associated reduction in thermal performance. Eventually it must be decided whether the reduction is justified by the more favorable economics. In the case of the 
thermo-elastic collector, the cost reduction comes from eliminating the heat exchanger, a pump, the glycol charge, and from the possibility of the collector itself being much more inexpensively manufactured. For the three-season system, the collector would remain standard but the heat exchanger, pump and glycol charge would be unnecessary.

\subsection{Economic Indicators and the $P_{1}, P_{2}$ Method}

An economic analysis takes into account a great number of variables that describe the strength of the current market. These variables are combined to form a figure of merit that allows comparison of investment alternatives. In the case of solar energy alternatives, figures of merit are typically used in two ways. First, they provide a useful comparison between the SDHW system a conventional method of heating such as electricity or natural gas. Second, they allow designers to evaluate and optimize SDHW systems.

Many figures of merit are available for comparison of SDHW systems and there is no single correct choice; different figures of merit are appropriate to different economic situations. Two such figures of merit have been employed in analyzing the three-season SDHW system: that of life cycle savings, and that of payback period. Life cycle savings, or net present worth is defined as the difference in life cycle costs of a conventional system, and life cycle cost of the SDHW plus auxiliary system. The life cycle cost is the sum of all the costs associated with a system over a chosen analysis period, and is adjusted for inflation so that it is reported in today's dollars. The payback period is the 
44

number of years required for the annual fuel savings (undiscounted or discounted to today's dollars) to equal the initial system cost.

The payback period is calculated in the following manner. The fuel savings for the $j^{\text {th }}$ year, $\mathrm{Cs}_{\mathrm{j}}$, are defined in equation 3.2 .1 in which $F L$ is the energy saved, $\mathrm{C}_{\mathrm{F}}$ is the unit cost of fuel, and $i_{F}$ is the fuel cost inflation rate.

$$
C s_{j}=F L C_{F}\left(1+i_{F}\right)^{j-1}
$$

Summing this expression over the time required for payback yields equation 3.2.2

$$
C s=\sum_{j=1}^{N_{p}} F L C_{F}\left(1+i_{F}\right)^{j-1}
$$

Summing the geometric series results in equation 3.2 .3

$$
C s=\frac{F L C_{F}\left[\left(1+i_{F}\right)^{N_{p}}-1\right]}{i_{F}}
$$

Solving for $\mathrm{N}_{\mathrm{P}}$, the payback period:

$$
N_{P}=\frac{\ln \left[\frac{C_{S} i_{F}}{F L C_{F}}+1\right]}{\ln \left(1+i_{F}\right)}
$$

The above analysis includes the discounting of fuel savings so that they are reported in today's dollars. It is common to neglect the fuel savings discounting in which case the payback period is given by equation 3.2 .5 and is referred to as simple payback period. $\mathrm{N}$ is the number of years in the analysis and $\mathrm{C}_{\mathrm{SYS}}$ is the initial system cost. 


$$
N_{P}=\frac{C_{S Y S}}{N F L C_{F}}
$$

Life cycle savings are calculated using equation 3.2.6 (Duffie and Beckman, 1991). $P_{1}$ is the ratio of the life cycle fuel cost savings to the first year fuel cost savings. $\mathrm{P}_{2}$ is the ratio of the life cycle expeditures incurred because of the investment to the initial investment amount. $\mathrm{C}_{\mathrm{A}}$ is the cost per unit area of the system, and $\mathrm{C}_{\mathrm{E}}$ is the area independent cost.

$$
L C S=P_{1} \sum_{i=1}^{12} C_{F_{i}} l_{i} f_{i}-P_{2}\left(C_{A} A_{C}+C_{E}\right)
$$

Writing equation 3.2.6 with the summation allows for monthly variation in the cost of fuel. $P_{1}$ is given by equation 3.2 .7

$$
P_{1}=\left(1-C^{-}\right) P W F\left(N_{e}, i_{F}, d\right)
$$

$\mathrm{P}_{2}$ is given by equation 3.2.8.

$$
\begin{gathered}
P_{2}=D+(1-D) \frac{P W F\left(N_{\min }, 0, d\right)}{P W F\left(N_{L}, 0, d\right)} \\
-\bar{t}(1-D)\left[P W F\left(N_{\min }, m, d\right)\left(1-\frac{1}{P W F\left(N_{L}, 0, m\right)}\right)+\frac{P W F\left(N_{\min }, 0, d\right)}{P W F\left(N_{L}, 0, m\right)}\right] \\
+M_{s}(1-\overline{C t}) P W F\left(N_{e}, i, d\right)+t V(1-\bar{t}) P W F\left(N_{e}, i, d\right) \\
-\frac{C \bar{t}}{N_{D}} P W F\left(N_{\min }^{\prime}, 0, d\right)-\frac{R_{v}}{(1+d)^{N_{e}}}(1-C \bar{t})
\end{gathered}
$$


46

$\mathrm{C}=$ income producing flag ( 1 for income producing installation, 0 otherwise)

$\mathrm{d}=$ market discount rate (best alternative investment)

$\mathrm{m}=$ annual mortgage rate

$i=$ general inflation rate

$\mathrm{N}_{\mathrm{e}}=$ period of economic analysis

$\mathrm{N}_{\mathrm{L}}=$ term of loan

$N_{\text {min }}=$ years over which mortgage payments contribute to the analysis

$\mathrm{N}_{\text {min }}=$ years over which depreciation contributes to the analysis

$N_{D}=$ depreciation lifetime in years

$t=$ property tax rate

$\bar{t}=$ effective income tax rate

$\mathrm{D}=$ ratio of downpayment to initial investment

$M_{s}=$ ratio of miscellanious costs to initial investment

$\mathrm{V}=$ ratio of assessed valuation of solar energy system in first year to initial investment of system

$R_{v}=$ ratio of resale value at end of period of analysis to initial investment

Each PWF(N,i,d) term is the present worth factor calculated from the three given parameters using equation 3.2.9. This factor is useful for calculating the present worth of a series of regular future payments, discounted at a rate of $\mathrm{d}$, over $\mathrm{N}$ years at an inflation rate of $\mathrm{i}$.

$$
P W F(N, i, d)=\sum_{j=1}^{N} \frac{(1+i)^{j-1}}{(1+d)^{j}}
$$

The sheer number of variables appearing in the preceding equations gives a good idea of the complexity and subjectivity of economic analyses. There is no source book that tells what the value of each variable is, and what sources do exist, will likely give conflicting answers to the same question. Furthermore, there is the implicit assumption that the variables (such as inflation rate) will not change over the course of the analysis, a reasonable assumption when the analysis lasts only a few years. However, for solar to be profitable, a much longer analysis must be employed. Further complicating the issue the 
values of the variables are highly dependent on location. If any new SDHW system is to be marketed successfully, its potential savings must be proven to be insensitive enough to economic changes that it remains an attractive alternative even in unfavorable conditions.

\subsection{The Economy Used in Analyzing Three-Season Systems}

Unless otherwise stated, the parameters shown in figure 3.3.1 have been used in analyzing the three-season system alternative regardless of location. The parameters were chosen to be reasonably representative of the economy in the late 1990 s. No credit was taken for tax incentives as they are currently unavailable and three-season system design should not depend upon them. The price of electricity was $0.074 \$ / \mathrm{kW}$-hr from June to September, and was $0.063 \$ / \mathrm{kW}$-hr throughout the rest of the year. These values are the current rates for Madison Gas and Electric in Madison, WI (MG\&E, 1997). There is significant variation throughout the United States with the highest prices being found in New England at an approximate rate of $0.12 \$ / \mathrm{kW}$-hr (CommElectric, 1997). The low Madison prices were chosen so that the three-season system would be shown to work well under sub-optimal conditions. 


\begin{tabular}{|c|c|c|}
\hline Gi= & 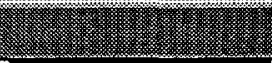 & 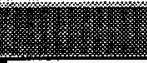 \\
\hline Economic analysis detail & Detailed & \\
\hline Cost per unit area & 150 & $\$ / m^{\wedge} 2$ \\
\hline Area independent cost & 2200 & $\$$ \\
\hline Price of electricity & Monthy & $\$ / k W-h r$ \\
\hline Annual \% increase in electricity & 6.0 & $\%$ \\
\hline Period of economic analysis & 20 & years \\
\hline$\%$ Down payment & 100 & $\%$ \\
\hline Annual mortgage interest rate & 0 & $\%$ \\
\hline Term of mortgage & 0 & years \\
\hline Annual market discount rate & 5.0 & $\%$ \\
\hline$\%$ Extra insur. and maint. in year 1 & 0.0 & $\%$ \\
\hline Annual \% increase in insur. and maint. & 0.0 & $\%$ \\
\hline Eff Fed. + State income tax rate & 30.0 & $\%$ \\
\hline True \% property tax rate & 0 & $\%$ \\
\hline Annual $\%$ increase in property tax & 0 & $\%$ \\
\hline$\%$ Resale value & 10 & $\%$ \\
\hline Commercial system? & No & \\
\hline Commercial depreciation schedule & 0 & $\%$ \\
\hline
\end{tabular}

Figure 3.3.1: Economic Parameters (from $f$-Chart version 5.88W)

\subsection{Three-Season System Sensitivity}

Two types of sensitivity matter in designing SDHW systems. The sensitivity to system design variables and the sensitivity to economic changes. Both contribute to the overall robustness of a design. A robust design is one in which no single variable changes the system performance to any great extent. 
The placement of collectors is obviously important in designing any SDHW system. The ideally placed four-season system in the Northern Hemisphere has collector panels facing due south (azimuth angle $=0^{\circ}$ ) and sloped at an angle $(\beta)$ equal to the latitude of the installation (Duffie and Beckman, 1991). In the Northern Hemisphere, the sun spends half of the day east of due south and half of the day west of due south. Thus a collector pointing directly south receives the most radiation throughout the day. Sloping the collector at an angle equal to the latitude means that beam radiation from the sun is normal to the collector surface (incidence angle $=0^{\circ}$ ) at solar noon on the autumnal and vernal equinoxes. Consequently, the incident radiation integrated over the entire year is maximized. Obviously, collector panels cannot always be placed in the optimum location since factors such as supporting structure orientation and local shading cannot be altered. The effects of sub optimal slope and azimuth are well known concerning four-season systems. Less is known, however, about their effects upon three-season systems.

In many of the graphs that follow, system sensitivities are compared using life cycle savings as the figure of merit because it is easily optimizable. The system designer has primary control over only one variable in equation 3.2.6, that of collector area. Both $P_{1}$ and $P_{2}$ are determined by the current economy, load and fuel cost are determined by the location of the system, and the system costs are driven by local availability of equipment. Thus the designer of an SDHW system can choose a collector area that maximizes the life cycle savings by taking the derivative of equation 3.2 .6 and setting it equal to zero to yield equation 3.4.1. 


$$
\frac{\partial L C S}{\partial A_{c}}=0=P_{1} C_{F} \frac{\partial F}{\partial A_{C}}-P_{2} C_{A}
$$

Solving this equation for $\partial F / \partial \mathrm{A}_{\mathrm{c}}$ and plotting, the optimal solar fraction and collector area can be read from a graph of life cycle savings versus collector area.

The following sensitivity analyses portray the possible benefits of a three-season system in four locations whose weather patterns are representative of the United States as a whole. Madison, WI which has a medium length, moderately clear winter, Seattle, WA which has a short, cloudy winter, Miami, FL which has essentially no winter at all, and Albuquerque, NM which has a long, clear winter.

\subsubsection{System Sensitivity to Collector Slope and Area}

The first set of four plots shows the effect that a non-optimum collector slope has upon both the total life cycle savings and the optimum area of a four-season system. In the plots and figures that follow, life cycle savings has been used as the economic figure of merit as it is optimizable and it allows easy comparison. 


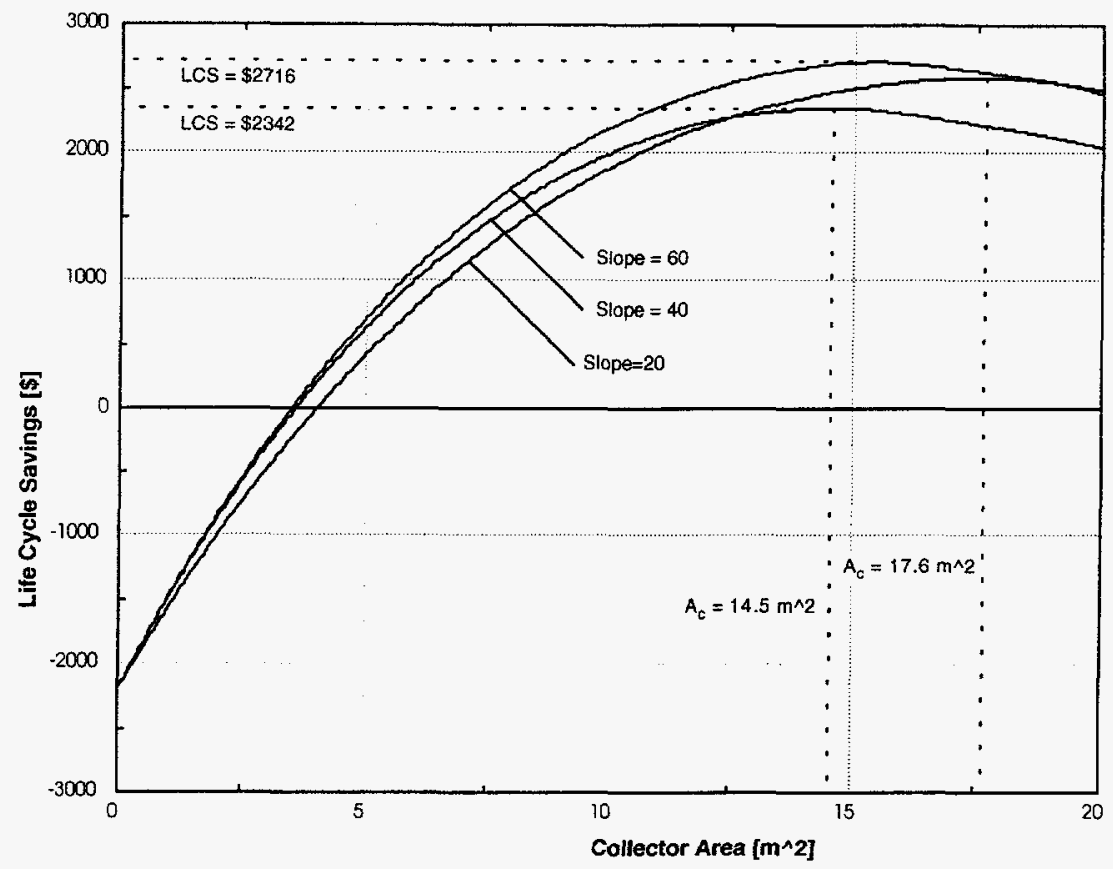

Figure 3.4.1.1a: Four-Season System Sensitivity to Slope in Madison, WI

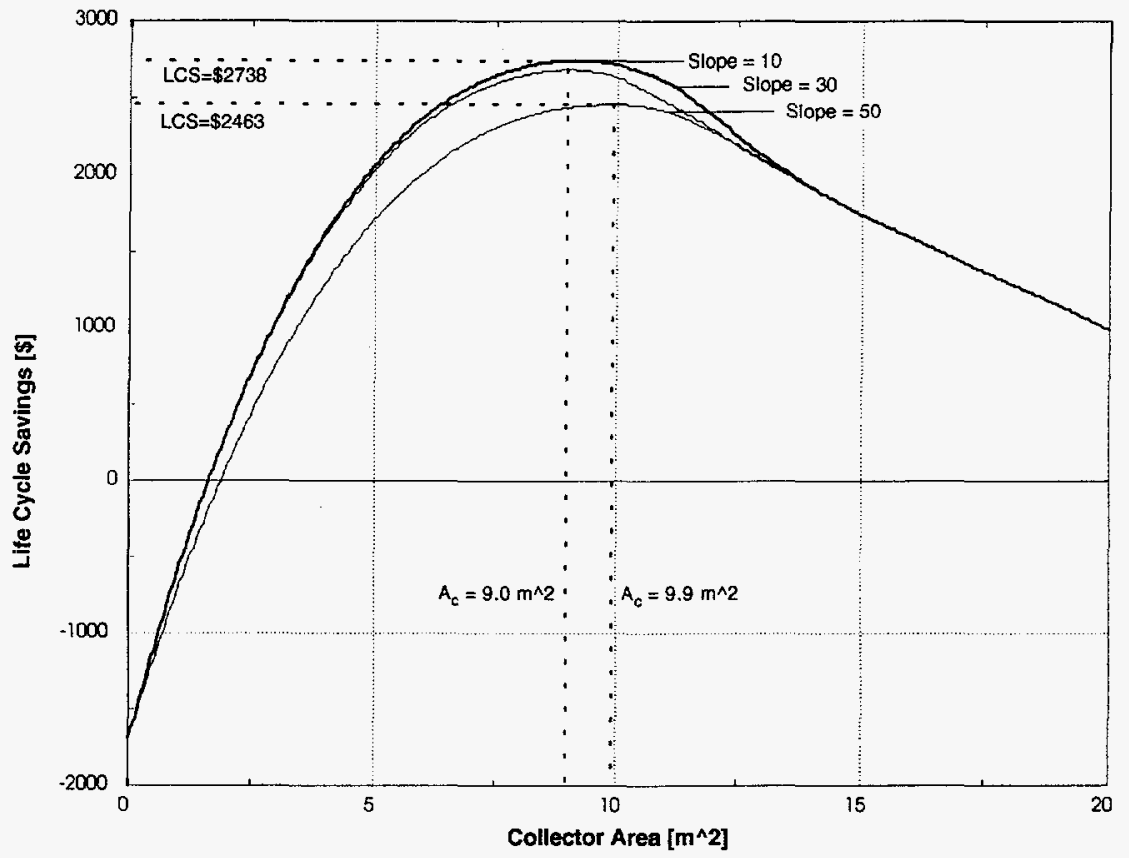

Figure 3.4.1.1b: Four-Season System Sensitivity to Slope in Miami, FL 


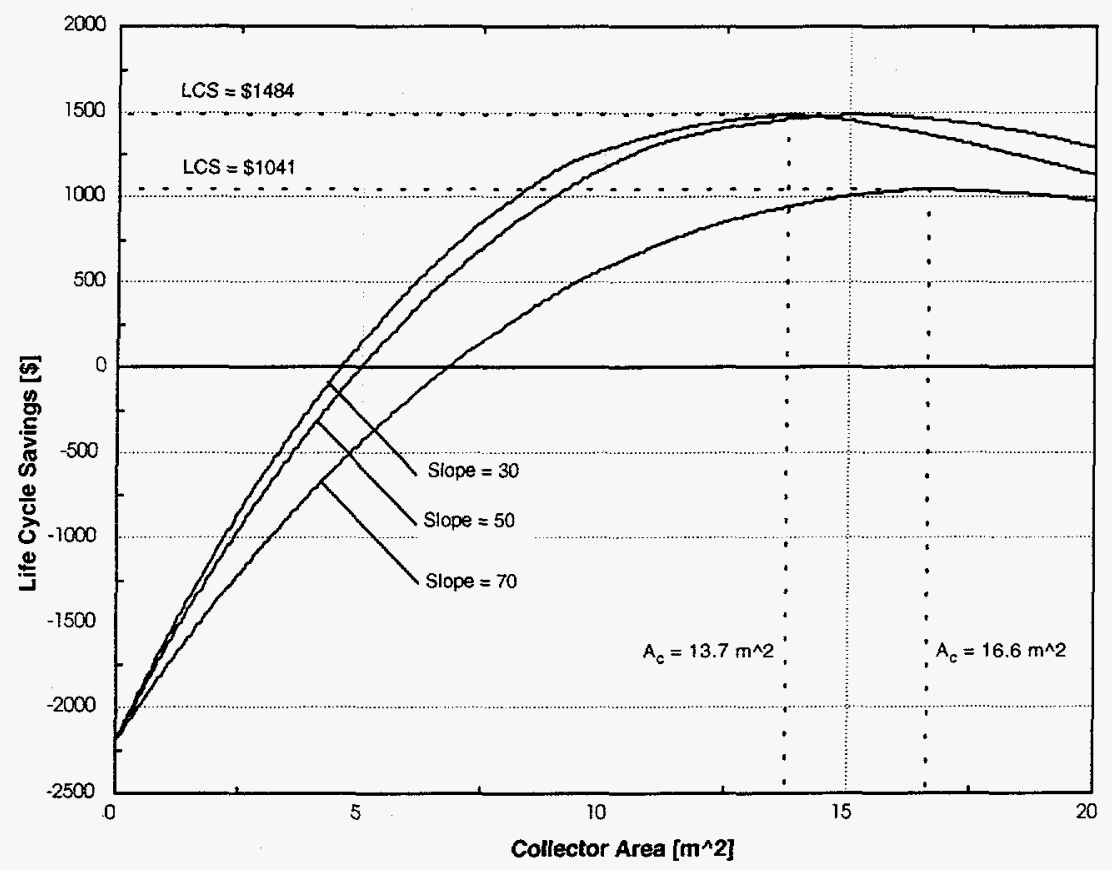

Figure 3.4.1.1c: Four-Season System Sensitivity to Slope in Seattle, WA

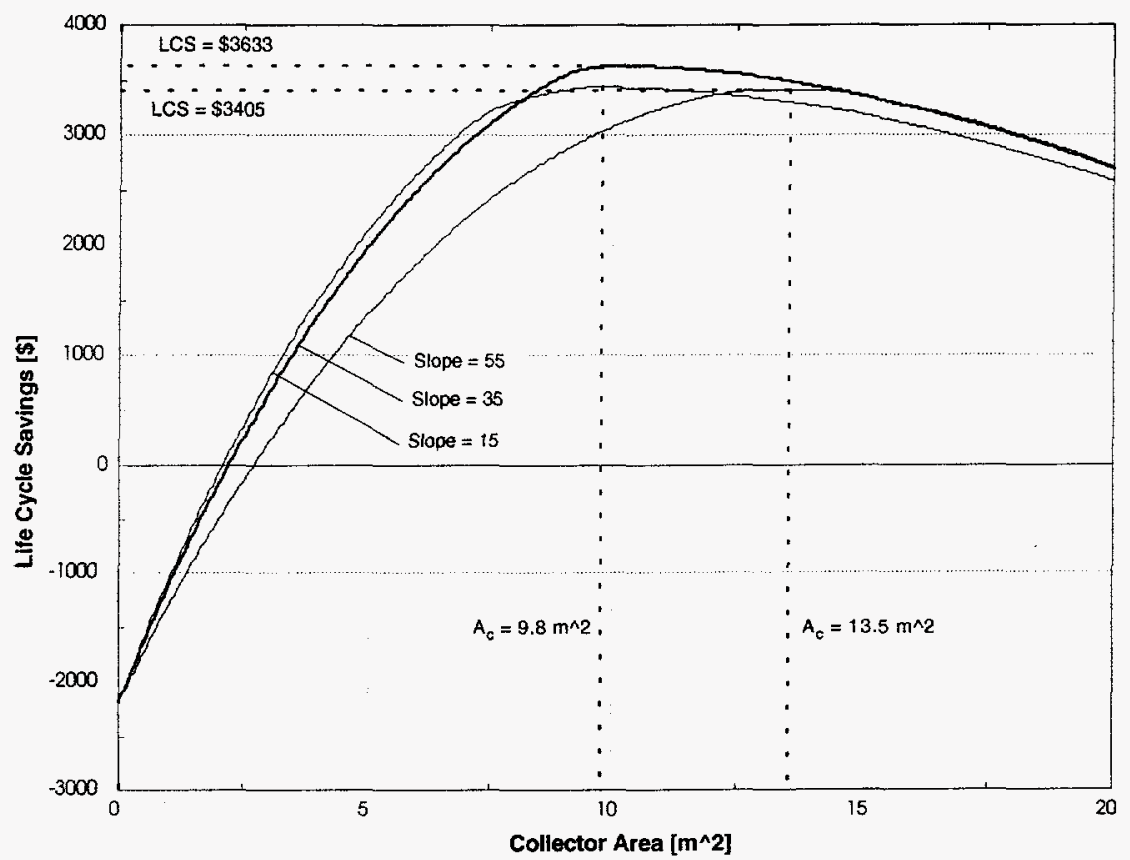

Figure 3.4.1.1d: Four-Season System Sensitivity to Slope in Albuquerque, NM 
It can be seen in Figure 3.4.1.1 that the slope nearest to the latitude of the location yields the highest life cycle savings. Both increasing and decreasing the collector slope not only reduces the life cycle savings but changes the optimum area of the system. If the system designer chooses the slope the collector at a non-ideal slope and does not alter the area, the life cycle savings decrease will be more pronounced. Furthermore, in all cases the steeper slope decreases the LCS by a greater extent than the shallower slope because the price of energy is higher in the summer. This means that for a location with seasonally varying electricity rates, the energy collected during the summer is worth more than that collected during the winter. It is also interesting to note that in all four cases, the change in LCS due to a $20^{\circ}$ amplitude change in collector slope hovers around $\$ 400$ over 20 years. There is no correlation between the level of the optimum life cycle savings and the decrease due to a change in slope. In each location, the change in optimal area is $2 \mathrm{~m}^{2}$ or less, approximately the area of one collector panel.

The next four plots are identical to those in Figure 3.4.1.1(a-d) but show the LCS sensitivity of a three-season system to changes in collector slope. 


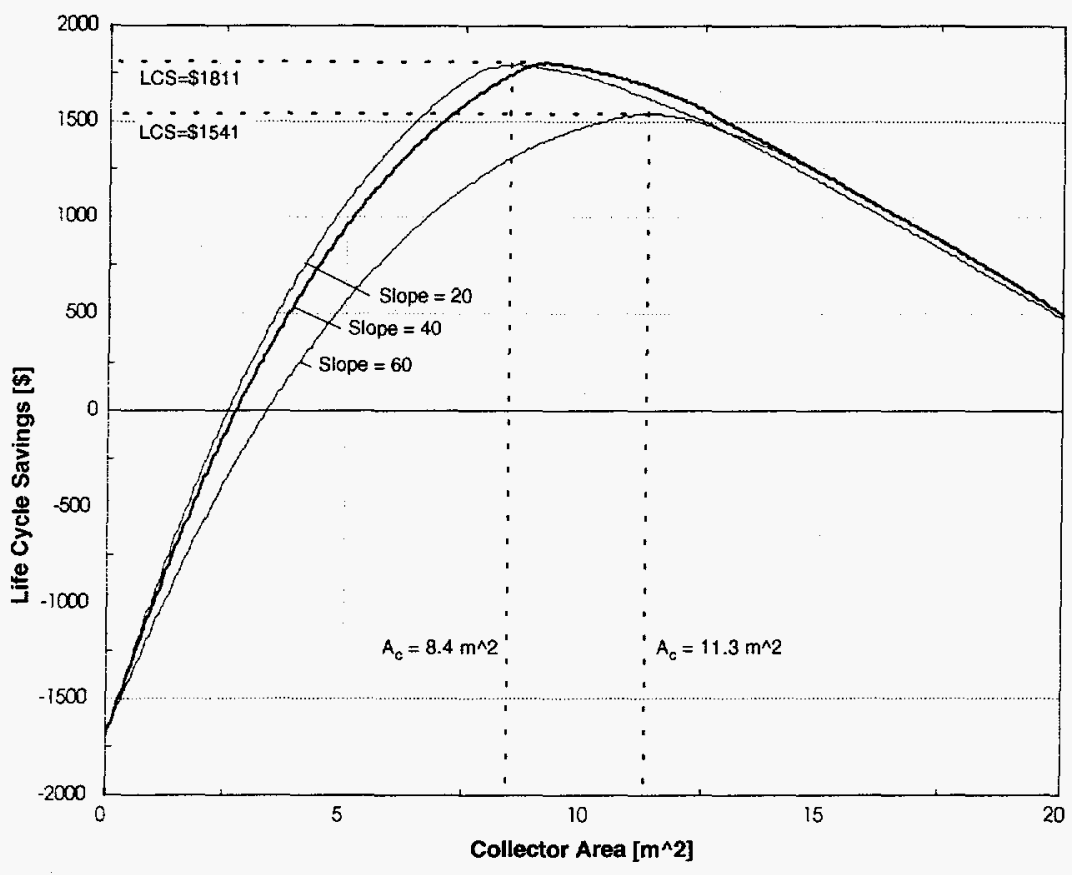

Figure 3.4.1.2a: Three -Season System Sensitivity to Slope in Madison, WI

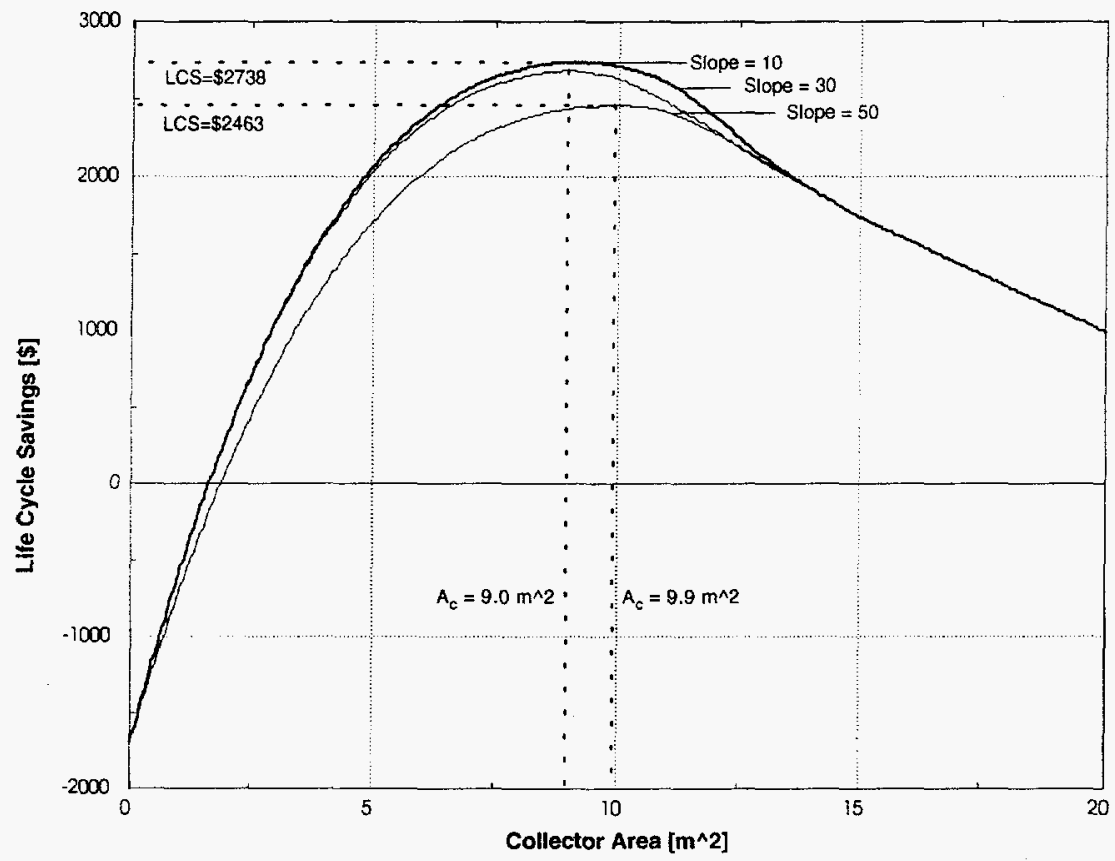

Figure 3.4.1.2b: Three -Season System Sensitivity to Slope in Miami, FL 


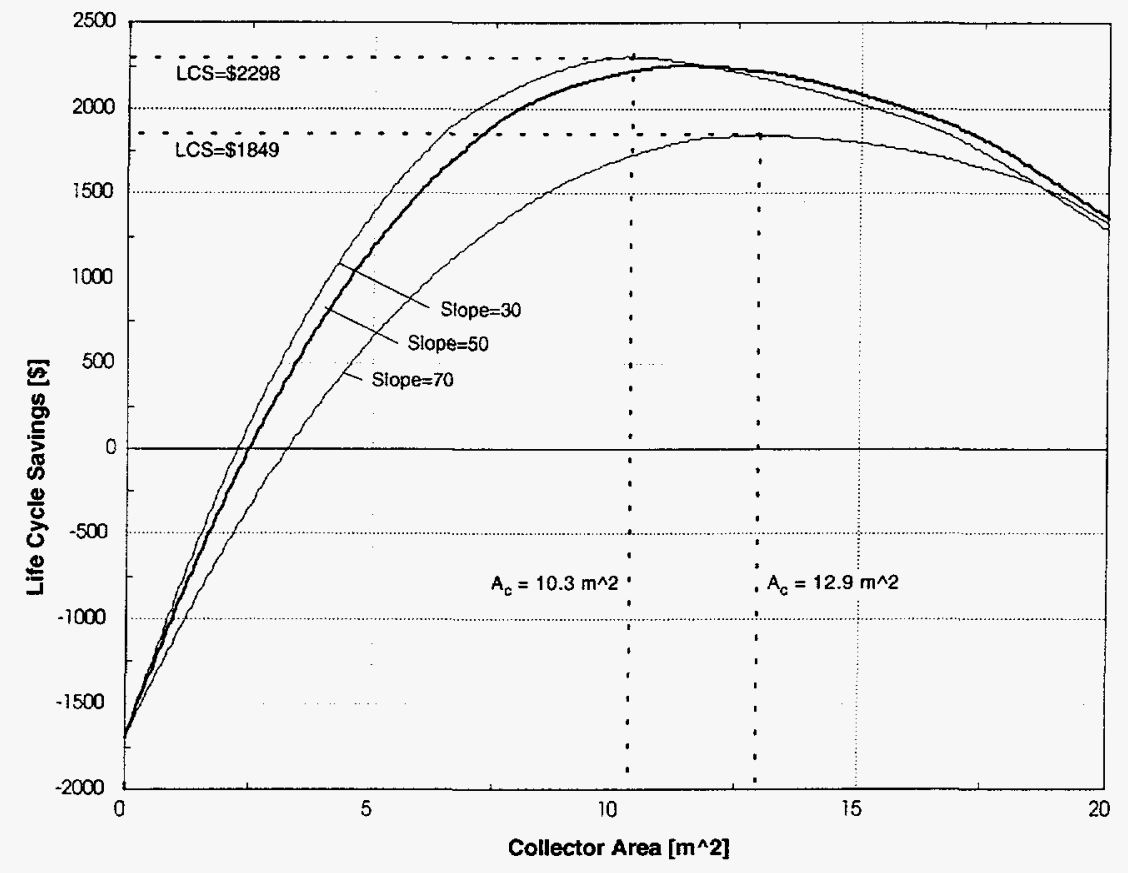

Figure 3.4.1.2c: Three -Season System Sensitivity to Slope in Seattle, WA

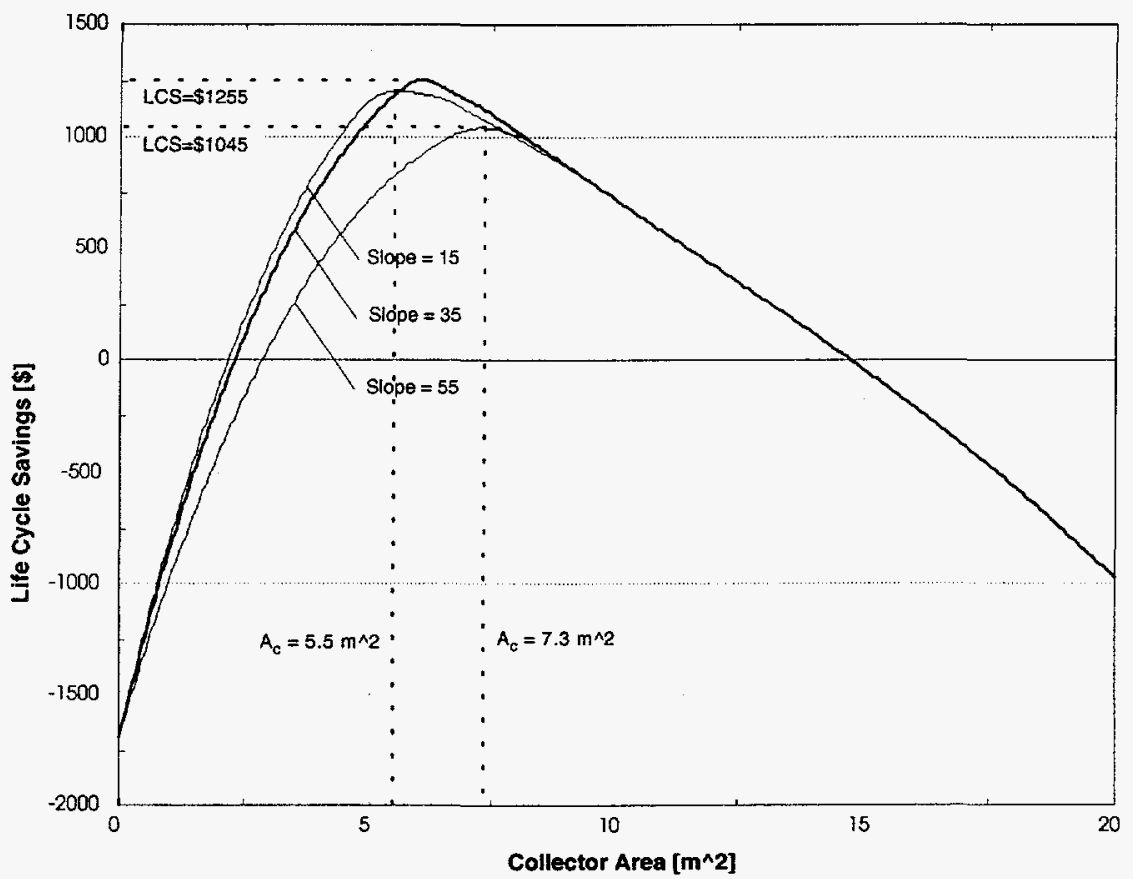

Figure 3.4.1.2d: Three-Season System Sensitivity to Slope in Albuquerque, NM 
Many of the features of the four-season system sensitivity reappear in the threeseason system, indicating that such a system is no less robust from the point of view of collector slope. Since Miami has no freezing period, plot 3.4.1.1b and 3.4.1.2b are precisely the same. In the other three locations, however, there are a few important differences. First, the life cycle savings are not nearly as high as for the four-season system, a problem that will be addressed at length in section 3.5. Typically, the threeseason system LCS values are more than $\$ 1000$ lower than those of the corresponding four-season system even after taking a $\$ 500$ credit for reduced equipment cost. The change in collector area is another important difference. In all cases except Miami, the optimum area $\left(\partial \mathrm{LCS} / \partial \mathrm{A}_{\mathrm{c}}=0\right)$ is a great deal lower than for the four-season system. Another interesting feature of the three-season system arises from the shape of the plots. The optimums on all the three-season plots (with the exception of Miami) are more pointed and while at first glance it would appear that the life cycle savings drop off more quickly indicating a more sensitive system, this is not the case. Granted it does indicate that the three-season system life cycle savings are more sensitive to area changes. However, the optimums resulting from various collector slopes are more tightly packed meaning that both the life cycle savings and the three-season system's critical areas are less sensitive to slope than those of the four-season system are. The three-season system LCS and optimal areas are less sensitive to changes in collector slope and more sensitive to changes in collector area than the four-season system.

The plots in figures 3.4.1.1 and 3.4.1.2 show that the three-season system does not compare favorably to a four-season system from a life cycle savings point of view. 
However, they also show that the system reacts to changes in collector slope in much the same manner as the four-season system.

\subsubsection{System Sensitivity to Collector Azimuth Angle}

An SDHW system's sensitivity to collector azimuth angle is much simpler to characterize than the sensitivity to slope since the question of optimums does not arise. Any collector that is faced away from due south is unable to collect some amount of energy incident either early in the morning or late in the afternoon. The energy lost to the collector is directly proportional to the azimuth angle. An investigation of sensitivity to azimuth angle is, however, warranted in order to ensure that the three-season system is not overly sensitive to changes in the variable. Figure 3.4.2.1 shows the decrease in life cycle savings due to changes in azimuth angle for various system configurations. 


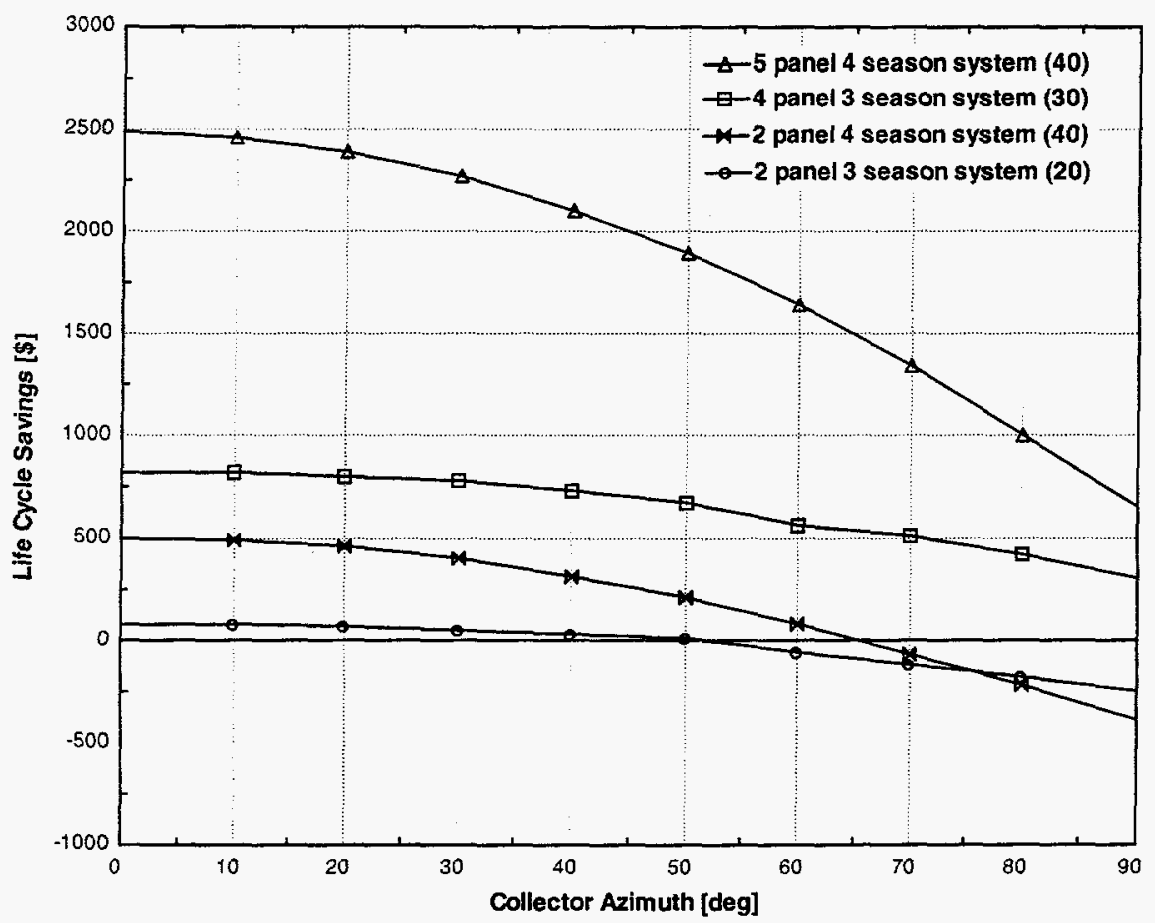

Figure 3.4.2.1 Life Cycle Savings Sensitivity to Collector Azimuth for Various SDHW Configurations

It can be seen from the figure that in fact the four-season systems are more sensitive to azimuth angle than the three-season systems. The phenomenon can be attributed to the fact that the three-season system is dependent only upon summer sunlight. In the Northern Hemisphere during the summer, the sun is up for a longer period of time, setting north of the collector's east-west axis. The four-season system, on the other hand, collects energy during the winter as well when the sun spends comparatively little time above the horizon. Therefore, to perform well, the four-season SDHW system had better collect as much energy as possible when the sun is up during the winter, and consequently needs to face due south. The three-season system has a bit more leeway since there is more sunlight available during its operating period. 
In an effort to divorce the economic effects from the system's thermal performance, figure 3.4.2.2 shows the annual solar fraction's sensitivity to collector azimuth. Although not as obvious, the four-season system again suffers more from nonsouth orientation.

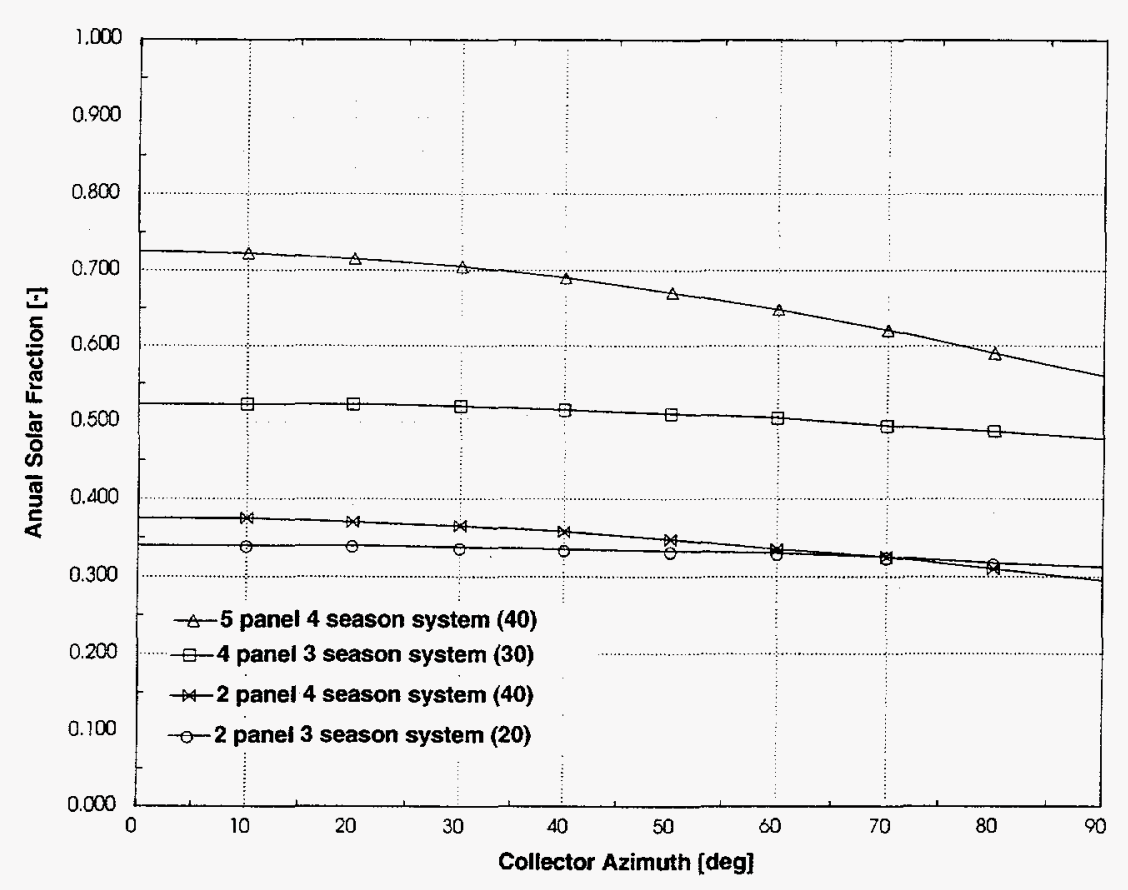

Figure 3.4.2.2 Annual Solar Fraction Sensitivity to Collector Azimuth for Various SDHW Configurations

\subsubsection{System Sensitivity to Collector Quality}

There are a great many solar collectors on the market, all of which vary in quality. Thankfully, the industry has agreed upon a standard method of describing a solar collector's efficiency that makes comparison between models and brands relatively simple. Essentially, flat-plate collectors are described by a linear efficiency curve for 
60

which two parameters are needed to predict performance; the intercept $\left(F_{R}(\tau \alpha)\right)$, and the curve's slope $\left(\mathrm{F}_{\mathrm{R}} \mathrm{U}_{\mathrm{L}}\right)$ (Duffie and Beckman, 1991). The intercept efficiency describes how much of the incident radiation is transferred to the working fluid, and the slope describes the losses of the collector. Figure 3.4.3.1 shows two different collector efficiency curves.

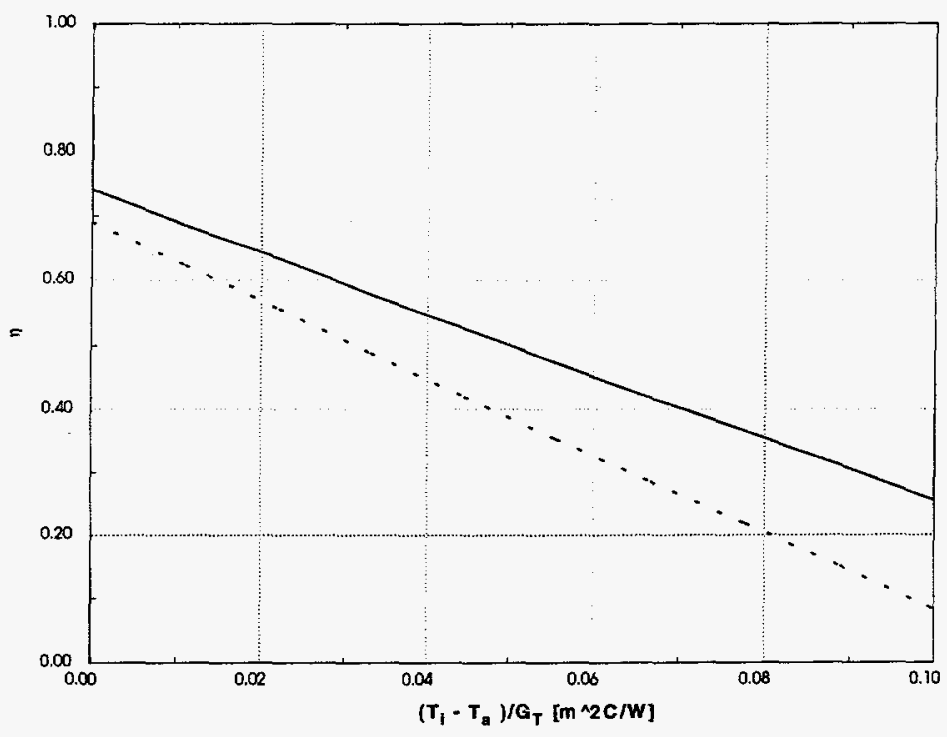

Figure 3.4.3.1: Collector Efficiency Curves

Both the thermal and economic analyses thus far have made use of a comparatively high efficiency collector, the American Energy brand, model AE-32 manufactured by American Energy Technologies (Meaken, 1994). The collector parameters are shown in Table 3.4.3.1 and the efficiency curve appears as the solid line in Figure 3.4.3.1. A number of sensitivity plots were created which investigate the effect of choosing a poorer performing, less expensive collector on the three-season system. The second collector's efficiency appears as the dotted line in Figure 3.4.3.1 and the parameters are shown in Table 3.4.3.1. All collector data was obtained from the Solar 
Ratings and Certification Corporation (SRCC) publication of OG-100 standards (Meaken, 1994).

Table 3.4.3.1: Collector Parameters

\begin{tabular}{|c|c|c|c|}
\hline Collector Model & $\begin{array}{c}\text { Efficiency Curve } \\
\text { Intercept }[-]\end{array}$ & $\begin{array}{c}\text { Efficiency Curve } \\
\text { Slope }\left[\mathrm{W} / \mathrm{m}^{2}-\mathrm{C}\right]\end{array}$ & $\begin{array}{c}\text { Collector Panel } \\
\text { Cost }\left[\$ / \mathrm{m}^{2}\right]\end{array}$ \\
\hline American Energy AE-32 & 0.74 & 4.86 & 220 \\
\hline Skylite ASN-45A & 0.69 & 6.08 & 170 \\
\hline
\end{tabular}

The first set of figures shows the plan view of a three-dimensional plot enabling an estimation of the life cycle savings sensitivity to changes in both area and collector slope of various system alternatives. Figure 3.4.3.2a repeats results already presented and can be used as a basis of comparison for later figures.

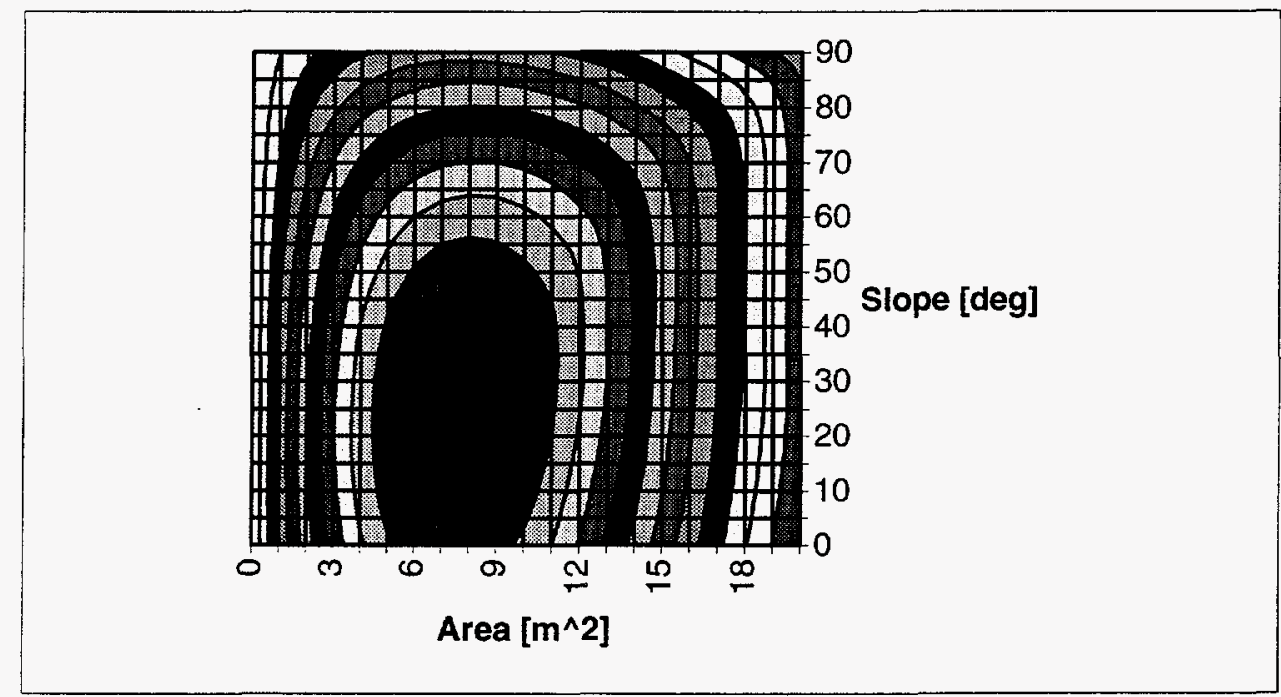

Figure 3.4.3.2a: Three-Season LCS Sensitivity to Slope and Area in Madison, WI (AE-32 Collector, $\mathrm{C}_{\mathrm{A}}=220 \$ / \mathrm{m}^{2}$ )

The actual values of the LCS are of secondary importance to the shape of the contours. Suffice it to say that the peak value in figure 3.4.3.2a is approximately $\$ 2000$ 
62

and the bands are $\$ 200$ wide. Figure 3.4.3.2b shows the same plot but using the lower quality collector. Credit has been taken for a lower cost per unit area.

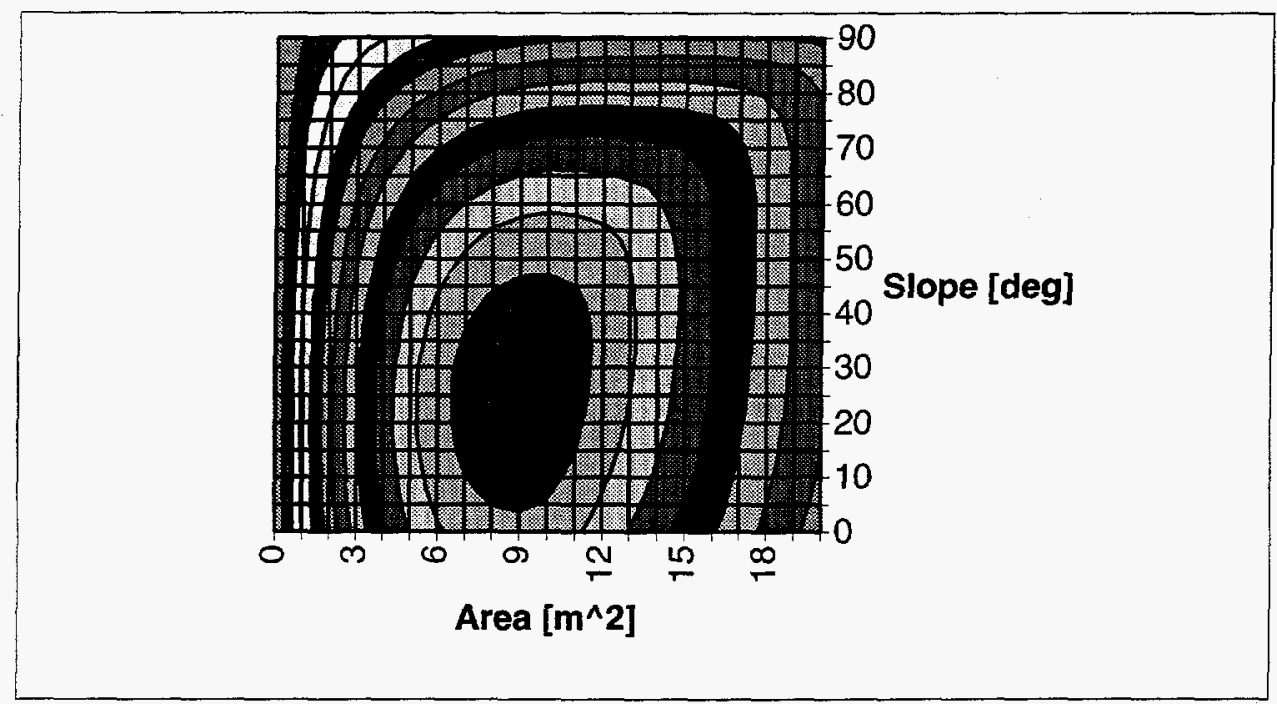

Figure 3.4.3.2b: Three-Season LCS Sensitivity to Slope and Area in Madison, WI (ASN-45A Collector, $\left.\mathrm{C}_{\mathrm{A}}=170 \$ / \mathrm{m}^{2}\right)$

While the peak value of this plot has dropped to about $\$ 800$, the shape has barely changed at all. Both the optimum area and the optimum slope have increased slightly, but the plot is flat enough near the optimum that the changes are inconsequential.

Other locations exhibit many of the same features. Figures 3.4.3.3a and 3.4.3.3b duplicate the plots in figures 3.4.3.2a and b except that the analysis was performed in Miami, FL instead of Madison, WI. 


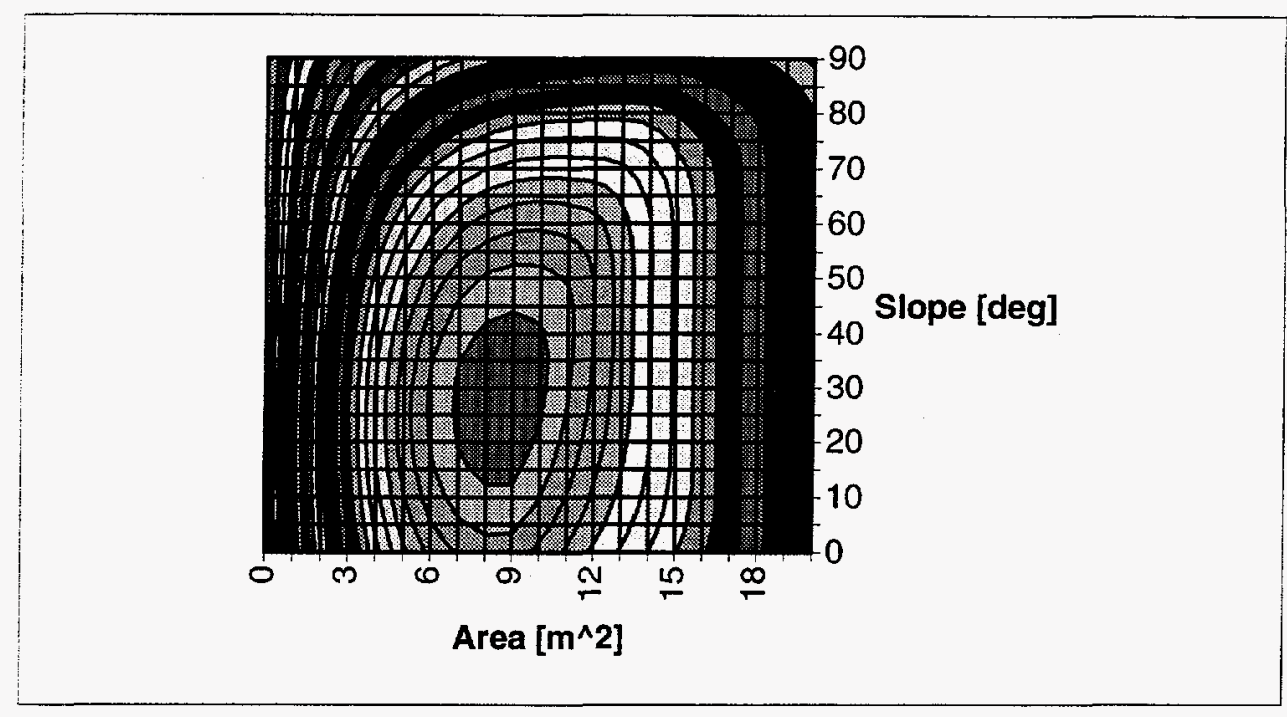

Figure 3.4.3.3a: Three-Season LCS Sensitivity to Slope and Area in Miami, FL (AE-32 Collector, $C_{A}=220 \$ / \mathrm{m}^{2}$ )

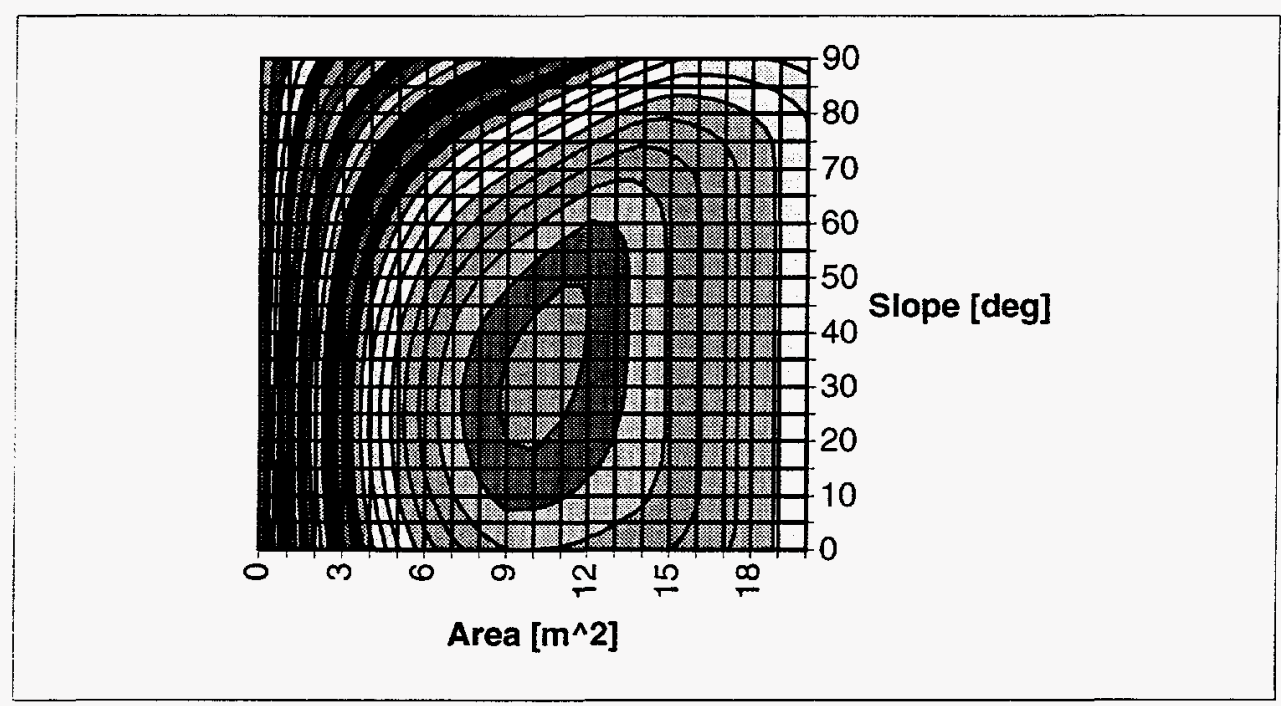

Figure 3.4.3.3b: Three-Season LCS Sensitivity to Slope and Area in Miami, FL (ASN-45A Collector, CA = $170 \$ / \mathrm{m} 2$ )

Again the shapes of the two plots are quite similar. Both exhibit low dependence on slope at high areas although the dependence does become more significant for the 
64

lower quality collector at steep collector angles. Again, the optimum shifts up slightly in both area and slope for the lower quality collector.

The above plots have shown that the three-season system life cycle savings is not very dependent upon collector quality. However, the actual value of the life cycle savings drops significantly with collector quality, which is true for four-season systems as well. Figures $3.4 .3 .3 \mathrm{a}$ and $4.4 .3 .4 \mathrm{~b}$ show the effect of collector quality on the life cycle savings of a four-season system in Albuquerque, NM.

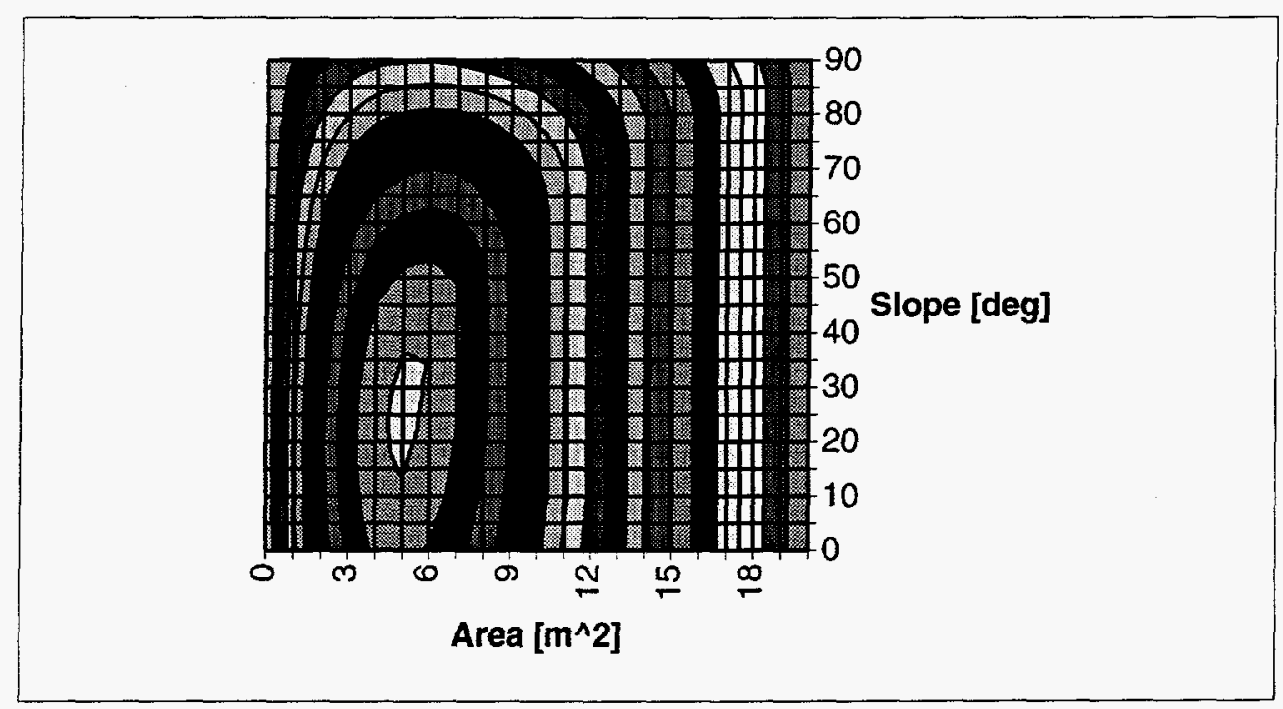

Figure 3.4.3.4a: Four-Season LCS Sensitivity to Slope and Area in Albuquerque, NM (AE-32 Collector, CA = $220 \$ / \mathrm{m} 2$ ) 


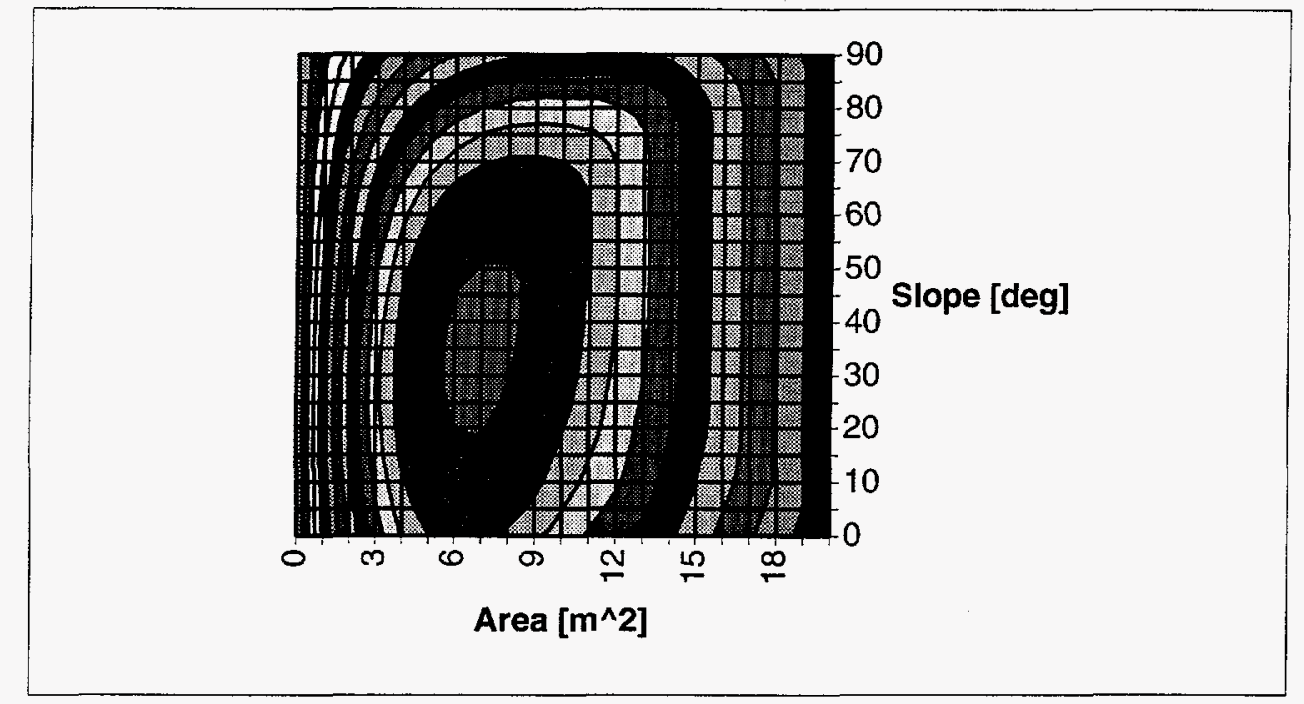

Figure 3.4.3.4b: Four-Season LCS Sensitivity to Slope and Area in Albuquerque, NM (ASN-45A Collector, CA = $170 \$ / \mathrm{m} 2)$

As in section 3.4.2, the four-season system life cycle savings appears to be more dependent upon slope and area. The above plots also show that the four-season system is more dependent upon collector quality as well. There are some features in common with the three-season system; the higher area systems are less dependent upon collector slope, and switching to a lower quality collector increases the optimum slope and area. The value of LCS at the optimum for the high quality collector is $\$ 4000$ and is $\$ 800$ for the low quality collector. As with the three-season system, the LCS values are highly dependent upon collector quality, but the shape of the plot is not.

\subsubsection{System Sensitivity to Economic Parameters}

Thus far, the sensitivities examined impact the design of three-season systems. It is also important to understand how the economic predictor will hold up over the course of its lifetime. Since the economic parameters shown in figure 3.3 .1 are by no means 
66

guaranteed to remain constant over the course of 20 years, the three-season system should be shown to save the customer money even when the economy is performing strongly and there are attractive alternative investments.

The study of sensitivity to economic parameters can be cast as a study in uncertainty propagation. Both changes in and uncertainty in economic indicators have the same impact upon the life cycle savings of an SDHW system. Based upon equation 3.2.6, the change in life cycle savings due to a change in a given parameter can be approximated by equation 3.4.4.1 (Duffie and Beckman, 1991).

$$
\Delta L C S=\frac{\partial L C S}{\partial X_{j}} \Delta x_{j}=\frac{\partial}{\partial x_{j}}\left[P_{1} C_{F} L F-P_{2}\left(C_{A} A_{C}+C_{E}\right)\right] \Delta x_{j}
$$

Rewriting part of the above equation yields equation 3.4.4.2

$$
\frac{\partial L C S}{\partial x_{j}}=\frac{\partial\left(P_{1} C_{F} L F\right)}{\partial x_{j}}-\frac{\partial P_{2}\left(C_{A} A_{C}+C_{E}\right)}{\partial x_{j}}
$$

It suffices now to calculate the partial derivatives of $P_{1}$ and $P_{2}$ for the changing variable in question. The derivatives appear in table 3.4.4.1 below for a number of commonly changing variables. 
Table 3.4.4.1: The Partial Derivatives of $P 1$ and $P 2$ for Commonly Changing Variables (Duffie and Beckman, 1991)

\begin{tabular}{|c|c|c|}
\hline $\begin{array}{c}\text { Variable } \\
\left(x_{j}\right)\end{array}$ & $\frac{\partial P_{1}}{\partial x_{j}}$ & $\frac{\partial P_{2}}{\partial x_{j}}$ \\
\hline$i_{f}$ & $(1-\bar{C} \bar{t}) \frac{\partial P W F\left(N_{e}, i_{F}, d\right)}{\partial i_{F}}$ & - \\
\hline$i$ & - & {$\left[(1-C \bar{t}) M_{s}+(1-\bar{t}) V V\right] \frac{\partial P W F\left(N_{e}, i, d\right)}{\partial i}$} \\
\hline$t$ & - & $V(1-\bar{t}) P W F\left(N_{e}, i, d\right)$ \\
\hline$R_{r}$ & - & $\frac{1-C \bar{t}}{(1+d)^{N_{e}}}$ \\
\hline
\end{tabular}

The partial derivatives of various present worth factors are also required.

Equations 3.4.4.3 through 3.4.4.5 show such partials.

$$
\begin{gathered}
\frac{\partial}{\partial N} P W F(N, i, d)=-\frac{1}{d-i}\left(\frac{1+i}{1+d}\right)^{N} \ln \left(\frac{1+i}{1+d}\right) \\
\frac{\partial}{\partial i} P W F(N, i, d)=\frac{1}{d-i}\left[P W F(N, i, d)-\frac{N}{1+i}\left(\frac{1+i}{1+d}\right)^{N}\right] \\
\frac{\partial}{\partial d} P W F(N, i, d)=\frac{1}{d-i}\left[\frac{N}{1+d}\left(\frac{1+i}{1+d}\right)^{N}-P W F(N, i, d)\right]
\end{gathered}
$$


As an example, say that the fuel inflation for a system in Madison, which was taken as $6 \%$, changes to $8 \%$. Equation 3.4.4.4 and table 3.4.4.1 entry 1 are used to compute that the partial derivative of $P_{1}$ with respect to fuel inflation rate is $\$ 194$. The uncertainty in life cycle savings is calculated to be $\$ 2567$ from terms from equation 3.4.4.1 and rewriting as equation 3.4.4.6. $\$ 2567$ is well over half of the projected savings of the SDHW system.

$$
\Delta L C S=C_{F} L F \frac{\partial P_{1}}{\partial i_{F}} \Delta i_{F}
$$

The last two multipliers in this equation are independent of whether the system is a three or a four-season design. Since the cost of fuel and the load also remain unchanged by the difference in system type, only the annual solar fraction matters in computing the difference in life cycle savings due to a change in an economic parameter. Furthermore, the three-season systems tend to have lower solar fractions so that the change in life cycle savings of a three-season system would actually be less than for a four-season system. It would appear that the three-season system is therefore less sensitive to economic change. However, it must be kept in mind that the life cycle savings of each system are different and that the amount of change in LCS might be smaller, but the percentage of the total might be larger depending upon the location.

\subsection{System Design Using the Life Cycle Savings Indicator}

The life cycle savings of an SDHW alternative have been useful so far in comparing system sensitivities for a number of reasons, the first of which is that there is 
an optimum point obtained by plotting equation 3.4.1. However, to use this equation in a design capacity, there is another important dynamic that should be mentioned. On the plot, the $y$-intercept is equal to the initial cost of area independent equipment $\left(C_{E}\right)$. At this point, the collector area is zero, the customer has not spent any money on collectors and other area dependent equipment but has purchased the rest of the system. An investment has been made but since no energy is collected, the system will never save any fuel cost and the life cycle savings is negative. Altering the area independent cost not only shifts the y-intercept, but shifts the entire plot evenly up and down as shown by the dotted lines in figure 3.5.1.

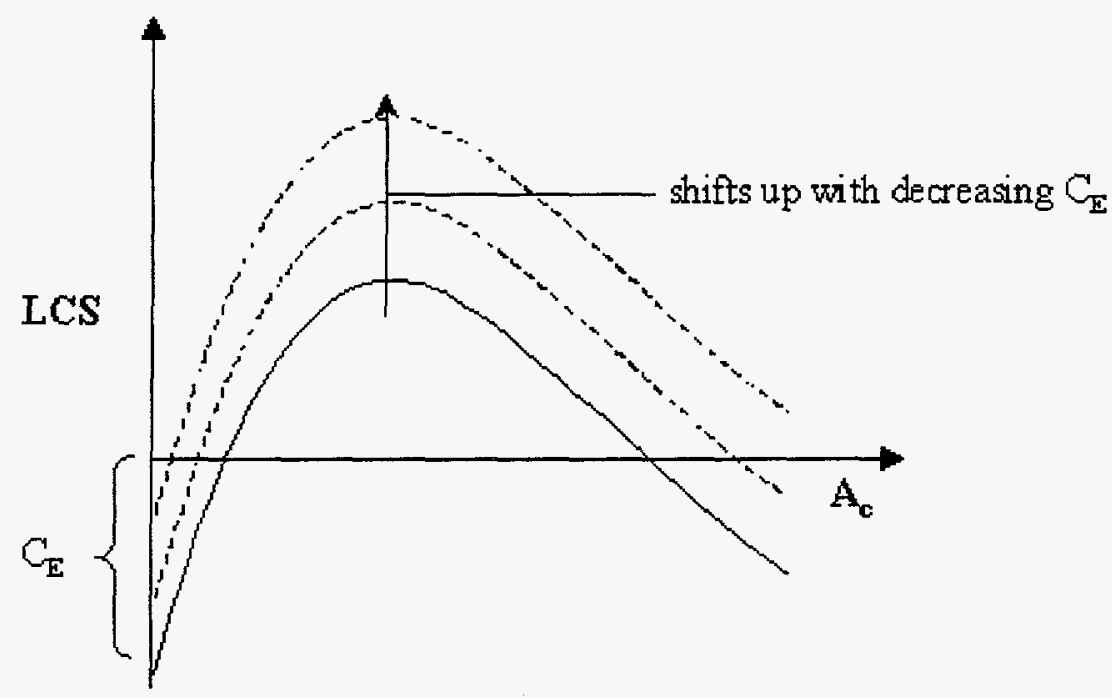

Figure 3.5.1: Effect of Altering Area Independent Cost

The goal of this analysis is to design three-season systems in various locations that are as economically attractive as a four-season system would be. To achieve this, the life cycle savings of the three-season system will be set equal to that of the four-season system by adjusting the three-season initial cost as shown in figure 3.5.2. The difference 
between the three and four-season initial costs correspond to the purchase price of the equipment that is unnecessary to the three-season system: the heat exchanger, the glycol and a pump. If these three pieces of equipment cost more than the projected cost difference, then the three-season system is the more attractive alternative and will save the customer more money over the course of its lifetime.

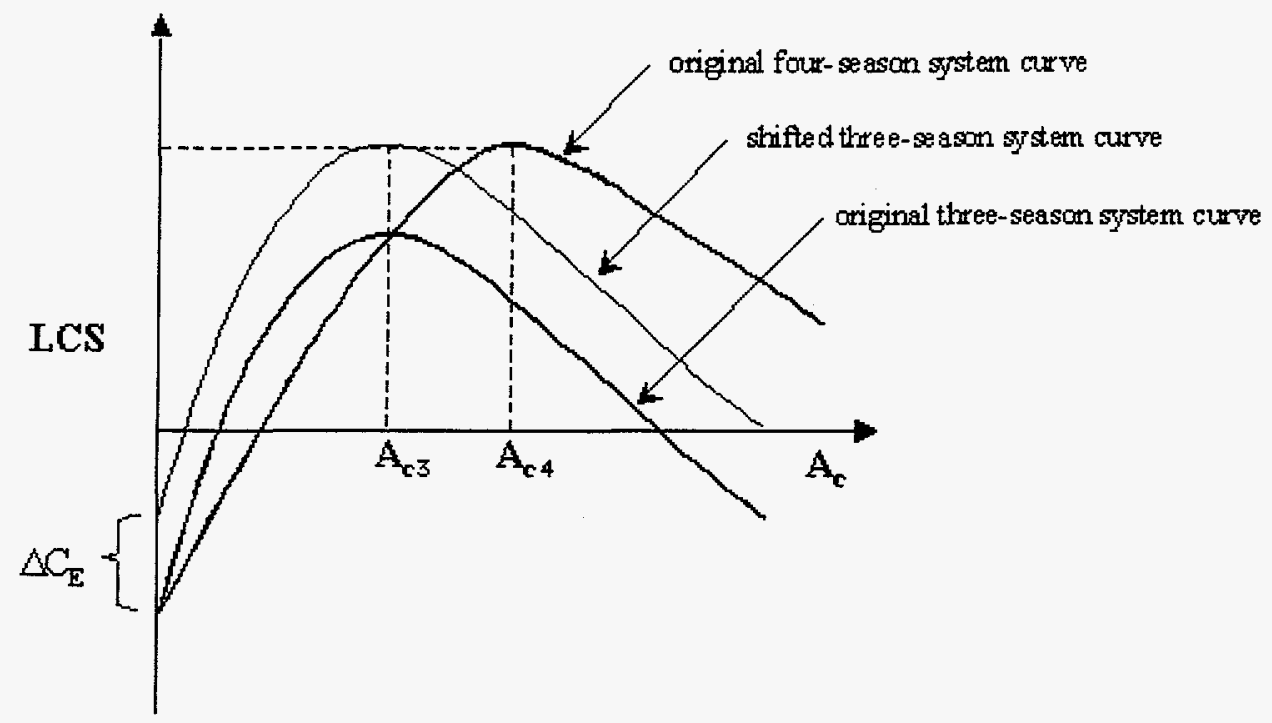

Figure 3.5.2: Three-Season System Design Methodology

The three-season system design proceeded as follows. First, the optimum slope for a four-season system in a given location is found and the plot of LCS versus collector area for that slope is created. Second, the optimum slope for a three-season system in the same location is found, and its plot of LCS versus collector area is created. Next, the two plots are superimposed and the area independent initial cost of the three-season system is adjusted until the optimum life cycle savings of the two systems are equal. The designer may then compare the cost of the four-season system specific equipment (pump, heat 
exchanger and glycol) with the cost reduction required to obtain equal life cycle savings, and may make the decision of whether a three or four-season system will save more money.

Figures 3.5.3 through 3.5.6 show the superimposed plots and the required threeseason system initial cost reduction for four cities that have diverse weather conditions.

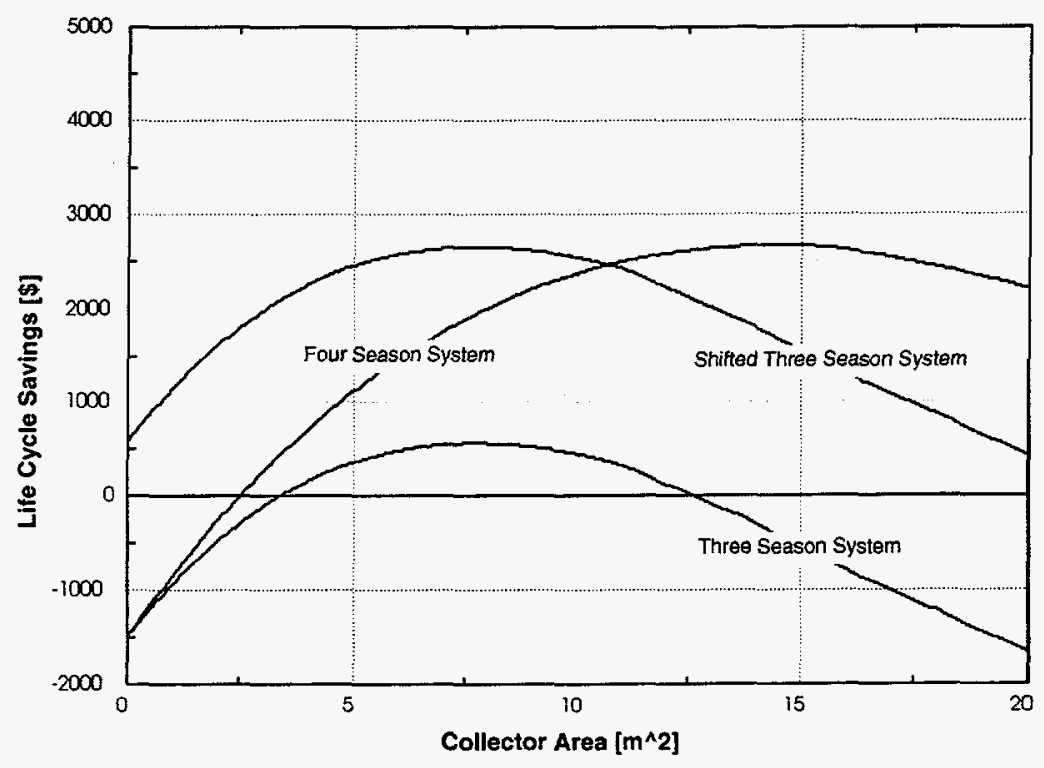

Figure 3.5.3: LCS System Design for Madison, WI 


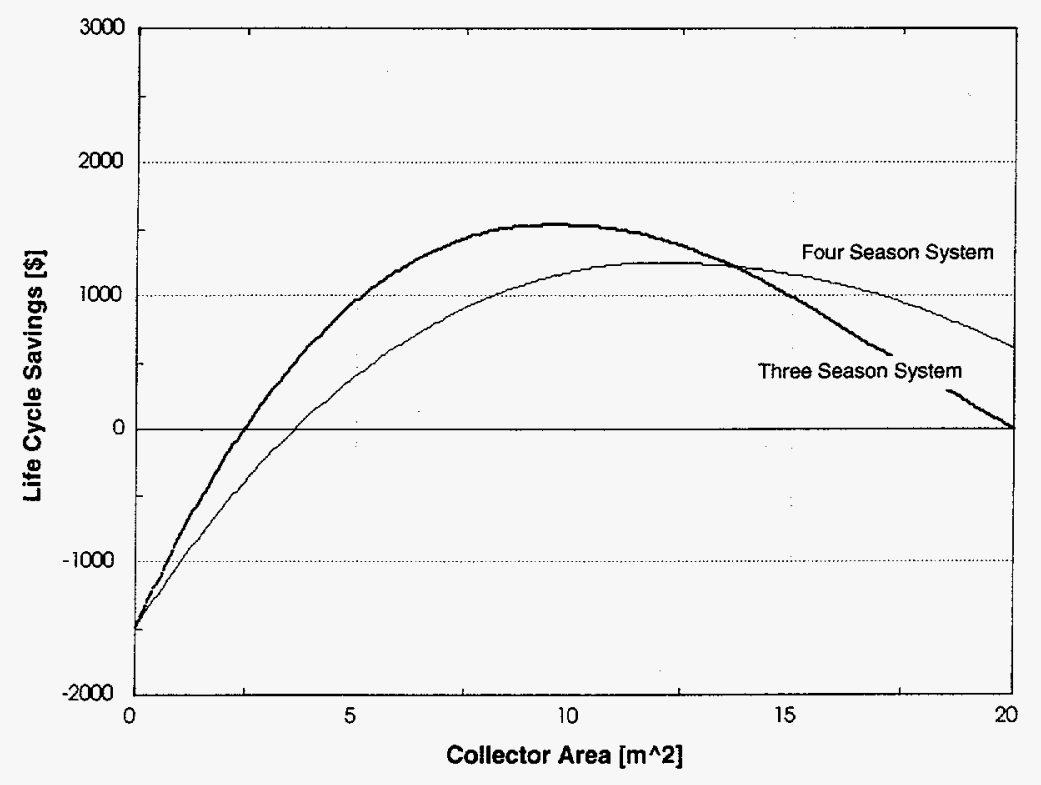

Figure 3.5.4: LCS System Design for Seattle, WA

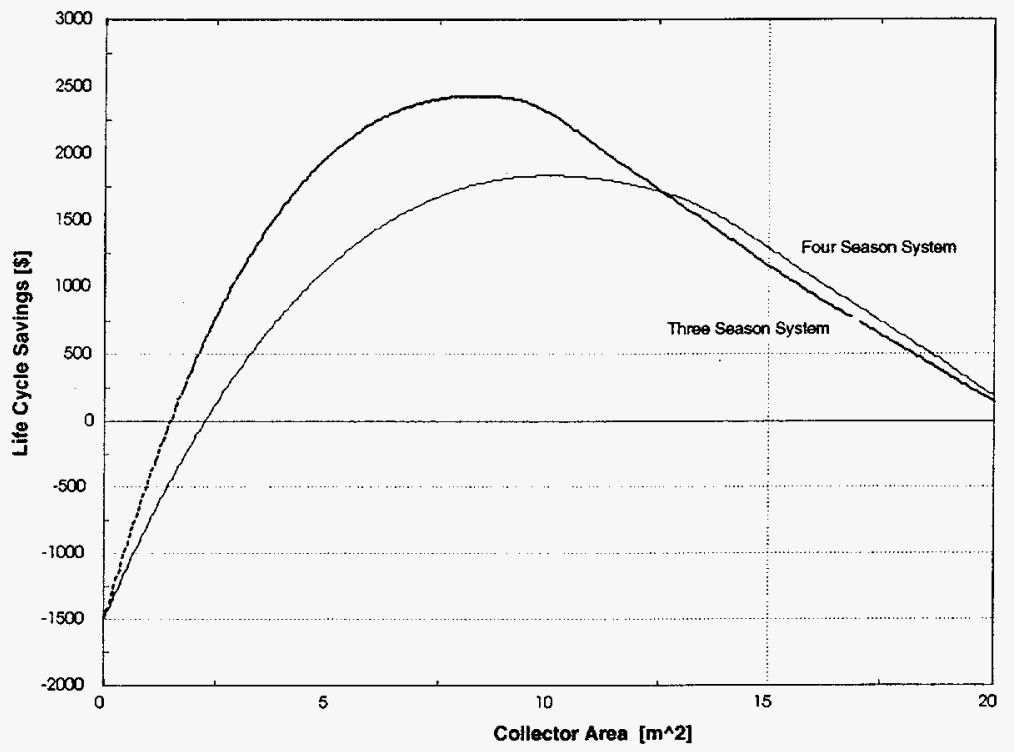

Figure 3.5.5: LCS System Design for Miami, FL 


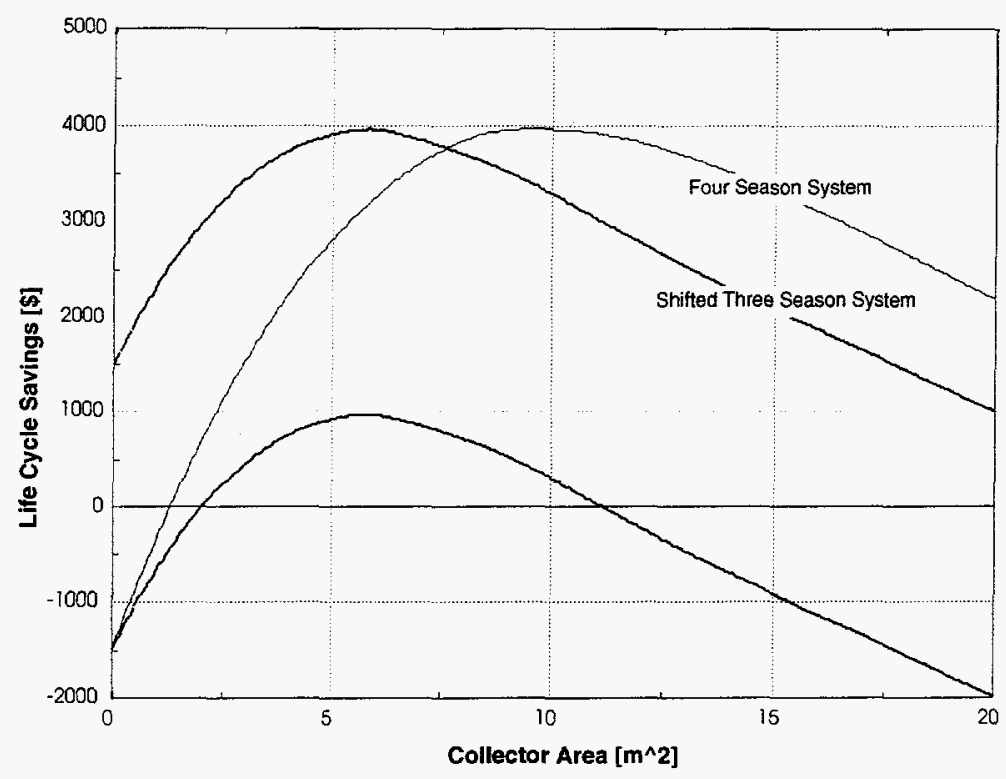

Figure 3.5.6: LCS System Design for Albuquerque, NM

The above figures show two different situations. In Miami and Seattle, the threeseason system is preferable from an economic point of view as the three-season life cycle savings is higher than that of the four-season system even without a difference in initial cost. In Madison and Albuquerque, on the other hand, the three-season LCS is nowhere near as high as that of the four-season system. In fact, the required reduction in threeseason system cost is greater than the four-season system cost. In other words, the system provider would have to actually pay the customer to install a three-season system. Unfortunately, Miami and Seattle are the exceptions to the norm and almost all the cities across the United States fall into the other category of places where the three-season system is unattractive from an economic point of view. 
The results of designing three-season systems by calulating a required cost reduction were both disappointing and contrary to intuition. Eventually, it was determined that the life cycle savings indicator was preferentially penalizing the threeseason system in a number of ways. First, the optimum areas for the four-season systems were coming out to be much higher than those of the three-season systems. Because of this, the four-season systems were collecting far more energy and meeting a much higher proportion of the load. The larger amount of collected energy meant that the annual fuel savings (in dollars) were far greater and therefore the life cycle savings were higher. The two square meter collector area operating for a fraction of the year was obviously having a difficult time economically outperforming fifteen square meters of collector operating year round, all be it at a lower efficiency.

The other reason for the poor results is more subtle and has to do with the fact that a comparison of life cycle savings is only valid when it compares the same initial investment. In the case of this analysis, two different investmets were being compared. To correct it, the life cycle savings of the initial cost difference would have to be added to the three-season system savings. The problem can be better visualised using a banking analogy. A customer has the option of either either investing $\$ 1000$ at a $5 \%$ rate of return or $\$ 500$ at a $7 \%$ rate of return. Obviously the latter choice is preferable even though the first investment option earns $\$ 50$ in the first year as opposed to $\$ 35$ for the second. The important economic indicator is the return on the investment, not the amount of the dividend. Based upon the fact that life cycle savings gives preferential results it was discarded as a design indicator in favor of return on investment. 


\subsection{System Design Using the Simple Payback Period Indicator}

The number of years that it takes for the cumulative fuel savings to equal the purchase price of the SDHW system is referred to as the payback period as described in section 3.3. Because annual residential fuel bills tend to be comparatively small, because SDHW systems are only designed to meet a fraction of the total load, and because the SDHW system purchase price tends to be high, the payback period is often on the order of 10 years. Simple payback period is also the inverse of return on investment. If a system pays for itself in 10 years then $1 / 10$ of it is paid off each year and the return on investment is $10 \%$. The relationship between payback period and return on investment is not valid if the fuel savings are discounted to today's dollars.

Plots of payback period versus area at optimum slopes for the four representative locations are shown in figures 3.6.1 through 3.6.4. Unlike the plots of LCS versus area, a $\$ 500$ difference in system price has been built into these plots. 


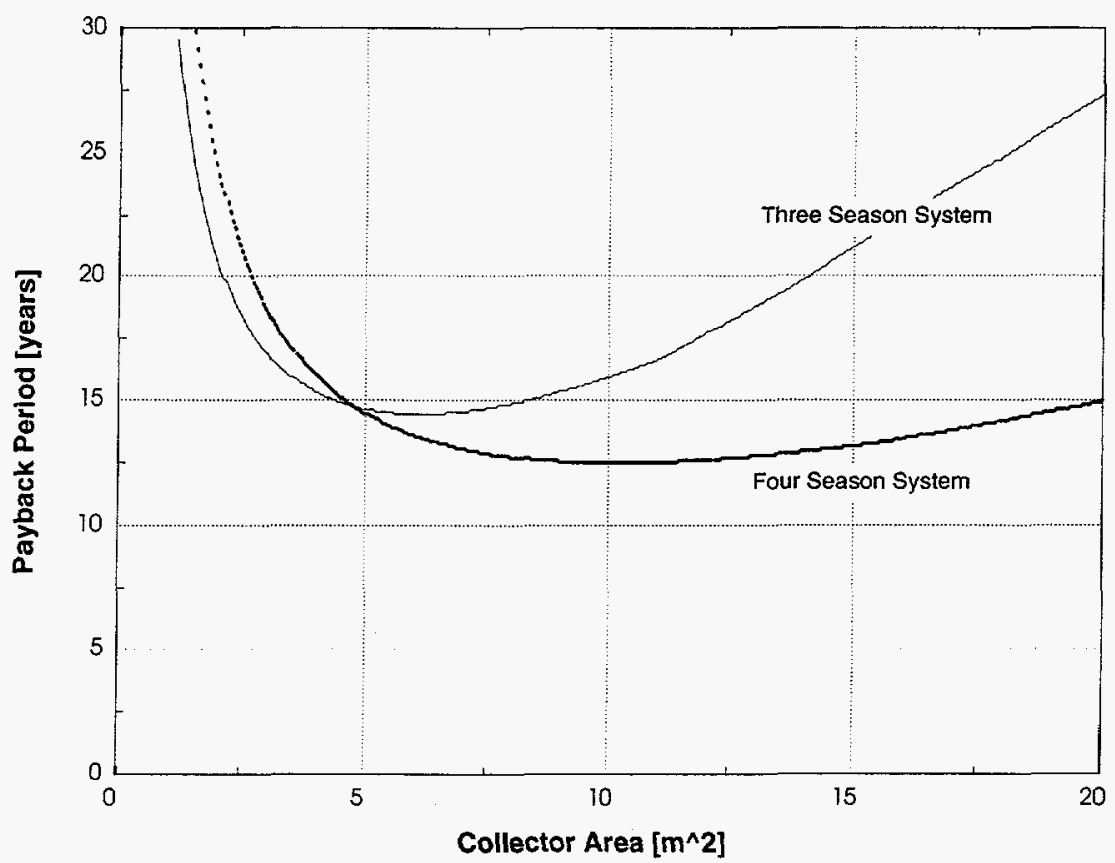

Figure 3.6.1: Payback Period System Design for Madison, WI

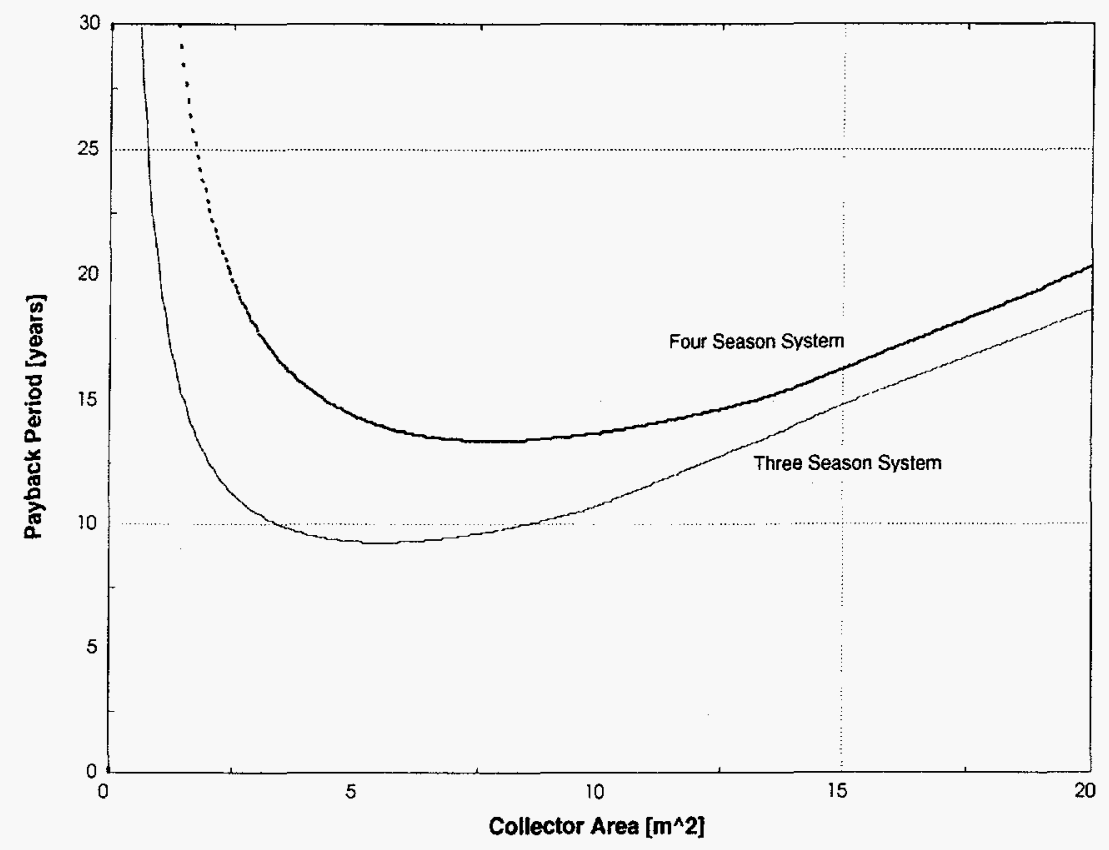

Figure 3.6.2: Payback Period System Design for Miami, FL 


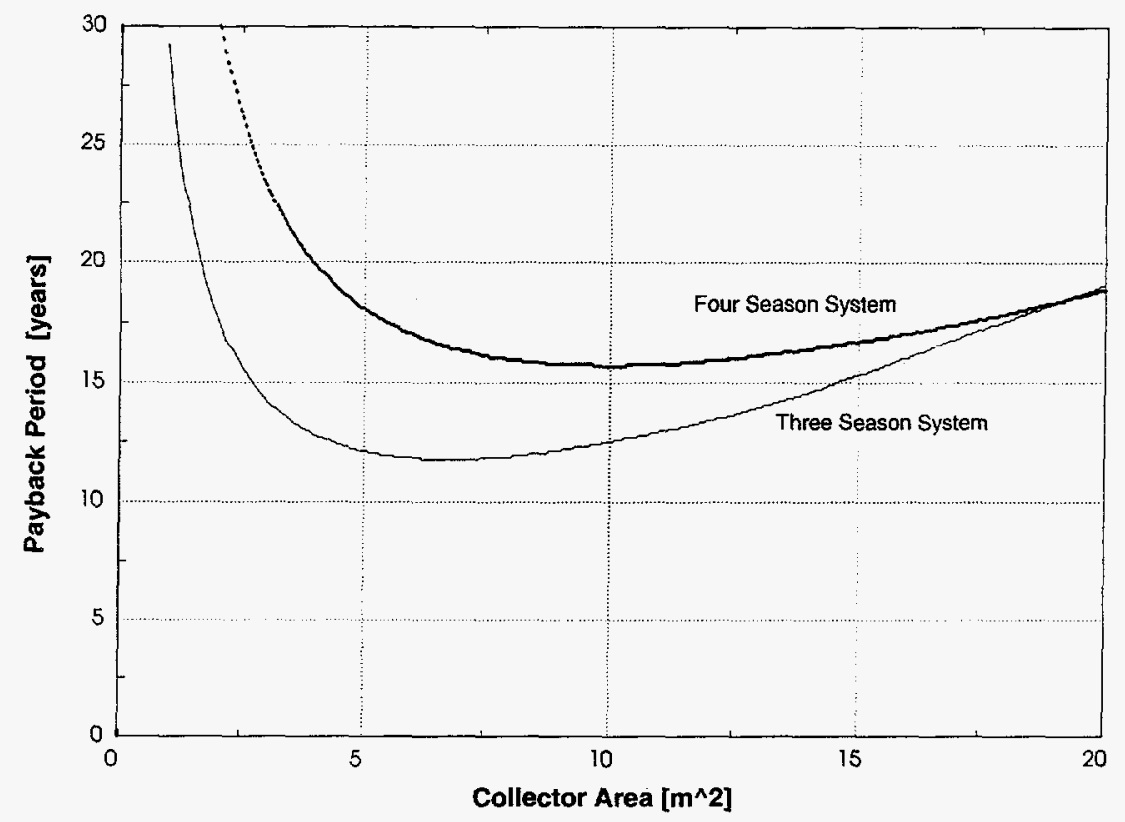

Figure 3.6.3: Payback Period System Design for Seattle, WA

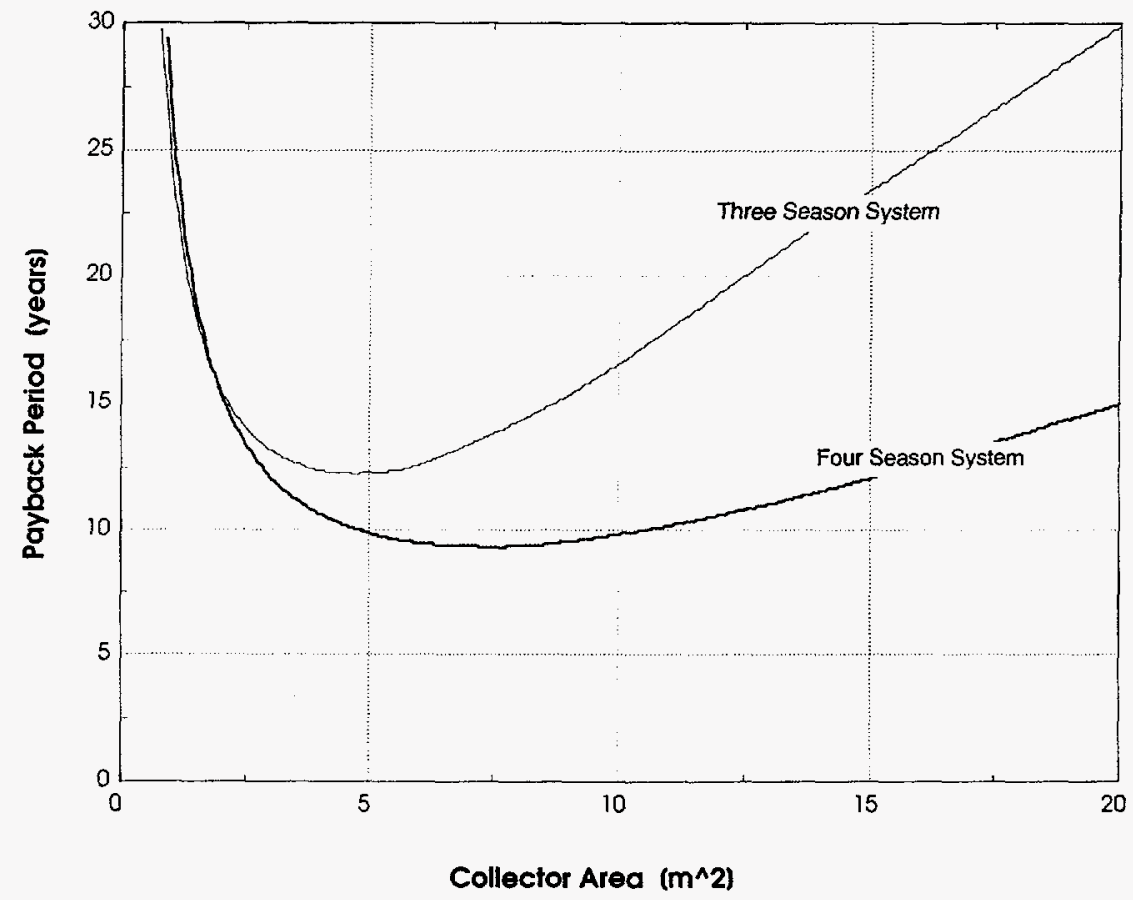

Figure 3.6.4: Payback Period System Design for Albuquerque, NM 
As with the life cycle savings analysis, Miami and Seattle are favorable locations for three-season systems from a return on investment point of view. Madison and Albuquerque are also favorable locations under certain circumstances. Examination of figure 3.6.1 shows that below a certain collector area, the three-season system has a shorter payback period. One method of designing three-season systems would then be to calculate this critical area for each location. Then if the system designed to meet the customer's budget has an area smaller than the critical area, the three-season alternative should be chosen. For Madison, WI, the critical area is approximately $5 \mathrm{~m}^{2}$ of collector area, or about 2 collector panels.

There are a number of variables that have an effect upon the critical area. Obviously the difference in system cost plays an important role; the greater the initial savings of the three-season system, the shorter time it will take for the cumulative fuel savings to reach the purchase price. Since the four-season cost does not change, and thus the four-season curve does not change, the critical area is shifted upwards (Figure 3.6.5). 


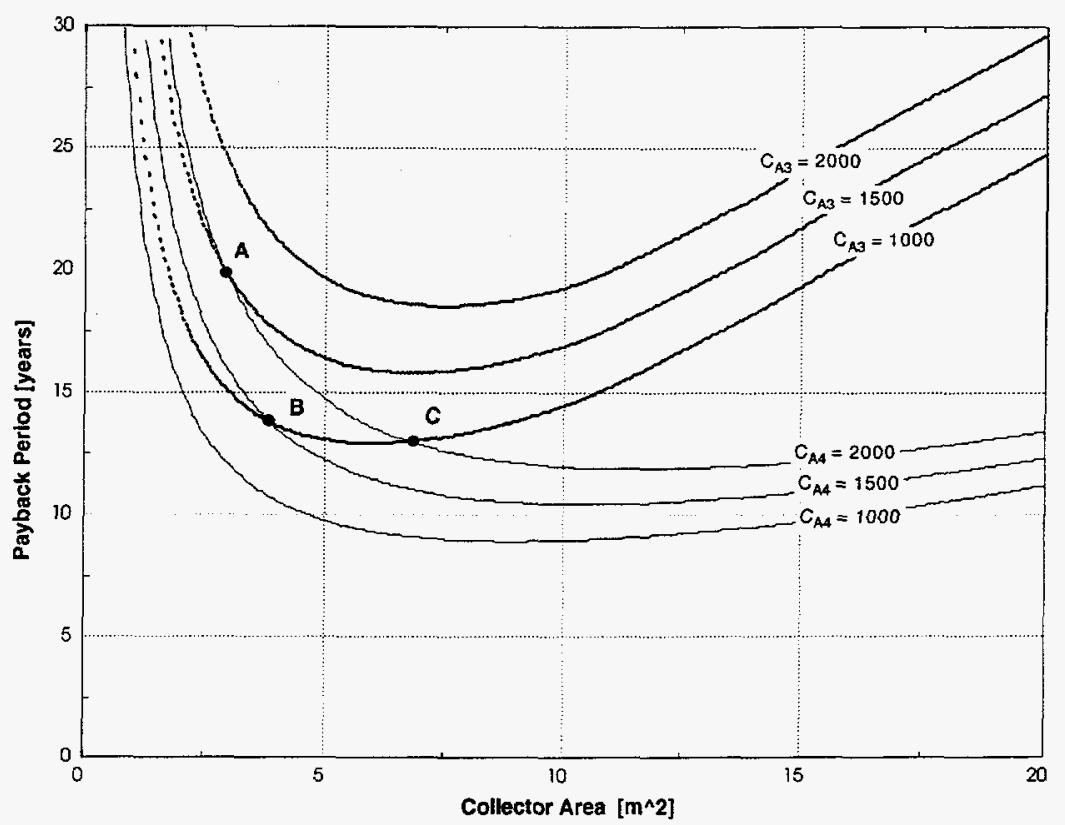

Figure 3.6.5: The Effect of System Prices upon Critical Area

As evident in figure 3.6.5, not only is the cost difference between the two systems important, but the base price is important as well. Point $\mathrm{A}$ shows the critical area for a three-season system costing $\$ 1500$ and a four-season system costing $\$ 2000$. Point B shows the same for a three-season system costing $\$ 1000$ and a four-season system costing $\$ 1500$. Both cost differences are $\$ 500$, but the less expensive systems have a shorter payback period and therefore a higher rate of return.

The critical area is not influenced by changes in cost of electricity (Figure 3.6.6). This makes some logical sense as the change in electricity rates affect both systems equally from the customer's point of view. No analysis was performed with electricity rates varrying within the month. 


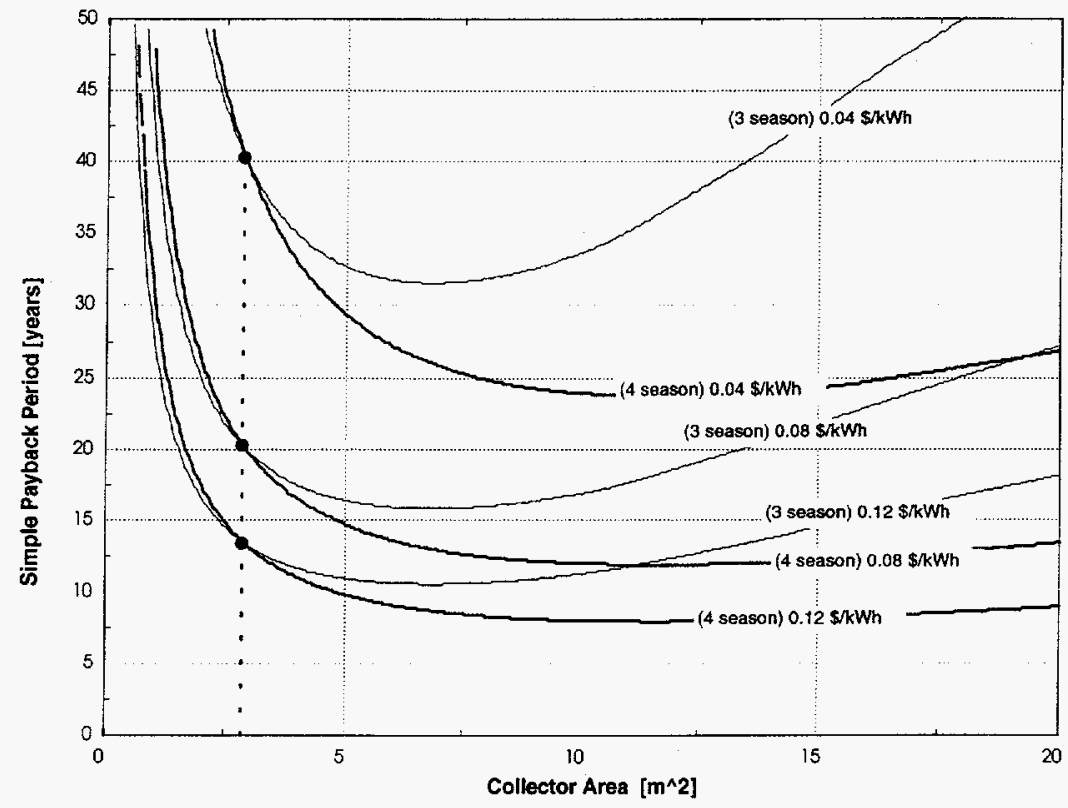

Figure 3.6.6: The Effect of Various Electricity Prices upon Critical Area

While using the payback period indicator has solved the problem of examining the amount of savings versus the return on investment; the collector area problem still exists. Plots 3.6.1 through 3.6.4 again indicate that the optimal area (lowest point on the payback period curve) for the four-season system is much higher than that of the threeseason system and that the system will therefore collect more energy and pay for itself more rapidly.

\subsection{Conclusions}

A great deal has been learned through performing an economic analysis of threeseason and four-season systems. Encouragingly, it has been shown that both system types are similarly sensitive to changes in various variables. Thus choosing a threeseason system does not entail a sacrifice in system robustness. More disappointingly, the 
results of the analysis show that the three-season alternative is a poor one from an economic point of view. The optimum three-season system is simply unable to match the economic performance of the optimum four-season system. However, before abandoning the idea, the whole concept of an economic analysis should be examined.

First, an economic analysis is fraught with estimation. For example, the reported inflation rate is derived from the price increases of a "market basket" of commonly purchased goods. The list of goods is standard but there is no guarantee that different areas of the country rely upon the same goods. Consequently there are a number of inflation rates reported; the consumer price index for all urban consumers (CPI-U) and the consumer price index for Urban Wage Earners and Clerical Workers (CPI-W) are just two in a long list. (http://stats.bls.gov/news.release/cpi.nws.htm) The problem is that someone needs to decide what items urban wage earners and clerical workers are buying in order to report upon inflation. Such decisions are, at the heart, somewhat arbitrary.

Another example of estimation in economic analysis is the market discount rate. The market discount rate is supposed to reflect the rate of return of the best alternative investment. In other words, how much money would the consumer have made had he/she invested it in some other manner? The problem is choosing what this value should be. If invested in a savings account, the money might return $3 \%$ currently. If invested in a stock that happened to do well, it might return 50\%. If the best alternative investment is chosen to be $50 \%$, it is guaranteed that no SDHW system would ever be profitable. 
Basically, the lesson learned from this economic analysis is that the results are interesting but should not be used to design SDHW systems; there are simply too many variables which, when tweaked, can preferentially benefit one option. Since ultimately a list of locations and their friendliness to three-season systems is desired, some performance indicator is needed and economic analysis is simply too uncertain to be of any use. 


\section{A Thermal Analysis of Three-Season SDHW Systems}

\subsection{Introduction}

It became apparent in the preceding chapter that performing economic analyses is something of a game. Because numerous variables have a significant effect upon the final outcome of the analysis, it is easy to tweak a few to obtain the desired answer. Furthermore, it is necessary to estimate the values of all the variables, which may vary significantly from location to location. For these reasons, generalized findings are difficult to report with any certainty. The benefit of an economic analysis is that the associated performance indicators are easily understood and compared. However, it was found that a purely thermal analysis is much less dependent on variable estimation and gives results that are easily comparable.

The basic idea of a thermal analysis is that turning off the SDHW system during the winter reduces the amount of energy collected annually. On the other hand, removing the heat exchanger from the system raises the operating efficiency of the collectors, meaning that more energy is collected annually. This chapter describes a series of performance predictions that were carried out in order to generate a map of the entire United States showing the penalty paid in annual solar fraction due to choosing a threeseason operating period. 


\subsection{The $f$-Chart Method}

Most residential sized solar collector systems fall into a few standard configuration categories that have been studied in great detail. Because of this wealth of information, it is possible to design such systems using short-cut methods such as $f$-Chart (Klein and Beckman, 1993) instead of by running numerous hourly simulations. The $f$ Chart method is essentially a curve fit of solar water heating system performance data and it is used in predicting the fraction of a total heating load that will be supplied by solar energy in a given system. Its advantages are numerous, stemming primarily from its simplicity. The system parameters in the curve fit equation are easily obtainable from manufacturer specifications. The only weather data needed are the average monthly temperature and the monthly average daily solar radiation. Monthly average daily radiation is defined as monthly total radiation divided by the number of days in the month (Duffie and Beckman, 1991). Another advantage of the $f$-Chart method is that it does not require any understanding of the underlying thermal processes so that anyone can make use of it. Once set up, only twelve monthly calculations are needed to obtain the annual performance, allowing a number of system alternatives to be evaluated and compared. Lastly, the end result of an $f$-Chart analysis leads very neatly into an economic analysis.

There are also a number of disadvantages to $f$-Chart. It must be remembered that the final result is only an estimate of the monthly and annual performance. Two factors come into play. First, the weather data used is under 30 year average conditions and there is no guarantee that any given year will conform to the average. Second, $f$-Chart is itself is an estimation method. Furthermore, the curve fit is only valid over a limited 
range of parameters and is limited to standard system configurations on which the curve fit was based.

The $f$-Chart method was developed by correlating a large amount of solar thermal simulation data. The conditions in the simulations were varied over appropriate ranges and then reduced to an equation that predicts the fraction of a heating load met by solar as a function of two dimensionless parameters. The primary design variable used is collector area but secondary parameters such as collector type, fluid type and flowrates, heat exchanger size and load are also included.

F-Chart correlations are available for three system types; a system using liquid heat transfer and storage media, an air system, and a system for water heating only. The later system was used in evaluating the three-season SDHW alternative. (Figure 4.2.1).

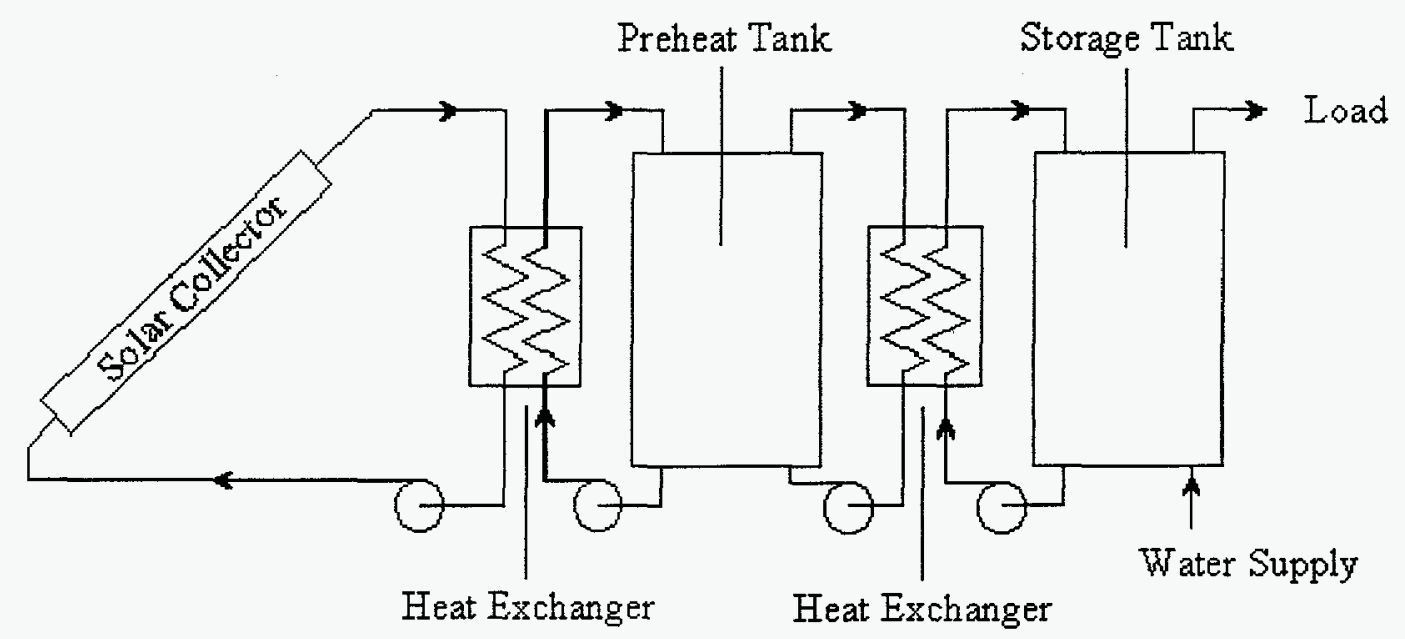

Figure 4.2.1: Water Heating System Schematic Modeled by $f$-Chart 
Only the water heating correlation has been used in this analysis, for which the dimensionless parameters as presented by Duffie and Beckman (1991) are shown in equations 4.2.1 and 4.2.2. The $X$ parameter is related to the ratio of collector losses to the heating loads while the $\mathrm{Y}$ parameter is related to the ratio of absorbed solar radiation to the heating load.

$$
\begin{gathered}
X=\frac{A_{C} F_{R}^{\prime} U_{L}\left(T_{\text {ref }}-\overline{T_{a}}\right) \Delta t}{L} \\
Y=\frac{A_{c} F_{R}^{\prime}(\overline{\tau \alpha}) \overline{H_{T}} N}{L}
\end{gathered}
$$

$A_{C}=$ collector area $\left(\mathrm{m}^{2}\right)$

$F_{R}^{\prime}=$ collector heat exchanger efficiency factor

$\mathrm{U}_{\mathrm{L}}=$ collector overall loss coefficient $\left(\mathrm{W} / \mathrm{m}^{2} \mathrm{C}\right)$

$\mathrm{T}_{\mathrm{REF}}=$ empirically derived reference temperature $(100 \mathrm{C})$

$\overline{T_{a}}=$ monthly average ambient temperature (C)

$\Delta t=$ total number of seconds in the month (s)

$\mathrm{L}=$ total monthly heating load $(\mathrm{J})$

$\tau \alpha=$ monthly average transmittance absorbtance product

$\mathrm{H}_{\mathrm{T}}=$ monthly average daily radiation incident on the collector surface per unit area $\left(\mathrm{J} / \mathrm{m}^{2}\right)$

$\mathrm{N}=$ number of days in the month (days)

A correction factor is normally applied to the $\mathrm{X}$ parameter for water heating systems (Beckman, Duffie and Klein, 1977). The $\left(T_{R E F}-T_{a}\right)$ factor in equation 4.2 .1 is multiplied by equation 4.2 .3 .

$$
\frac{\left(11.6+1.18 T_{W}+3.86 T_{m}-2.32 T_{a}\right)}{\left(100-T_{a}\right)}
$$

In which $T_{W}$ is the desired water temperature and $T_{m}$ is the temperature of mains water. 
The above equations can be rewritten as equations 4.2 .4 and 4.2 .5 respectively.

The format in these equations allows the user to directly read the parameters given in a manufacturer's literature and plug them into the formula.

$$
\begin{gathered}
X=F_{R} U_{L} \times \frac{F_{R}^{\prime}}{F_{R}} \times\left(T_{r e f}-\bar{T}_{a}\right) \times \Delta t \times \frac{A_{C}}{L} \\
Y=F_{R}(\tau \alpha)_{n} \times \frac{F_{R}^{\prime}}{F_{R}} \times \frac{(\tau \bar{\alpha})}{(\tau \alpha)_{n}} \times \bar{H}_{T} N \times \frac{A_{C}}{L}
\end{gathered}
$$

The overall $f$-chart correlation for liquid systems is shown in equation 4.2.6.

$$
f=1.029 Y-0.06 X+0.245 Y^{2}+0.0018 X^{2}+0.0215 Y^{3}
$$

The annual solar fraction $(f)$ can then be determined by the use of equation 4.2 .7

$$
\mathfrak{I}=\frac{\sum f_{i} L_{i}}{\sum L_{i}}
$$

As previously mentioned, the $f$-chart method is valid over a limited range of parameters as described in Table 4.2.2 
88

Table 4.2.2: Design Parameters Ranges Used in Developing $f$-Chart for Liquid Systems

\begin{tabular}{|cccccc|}
\hline 0.6 & $<$ & $(\tau \alpha)_{\mathrm{n}}$ & $<$ & 0.9 & - \\
5 & $<$ & $\mathrm{F}_{\mathrm{R}} \mathrm{A}_{\mathrm{C}}$ & $<$ & 120 & $\mathrm{~m}^{2}$ \\
2.1 & $<$ & $\mathrm{U}_{\mathrm{L}}$ & $<$ & 8.3 & $\mathrm{~W} / \mathrm{m} 2 \mathrm{C}$ \\
30 & $<$ & $\beta$ & $<$ & 90 & 0 \\
83 & $<$ & $\left(\mathrm{U}_{\mathrm{A}}\right)_{\mathrm{h}}$ & $<$ & 667 & $\mathrm{~W} / \mathrm{C}$ \\
\hline
\end{tabular}

By fixing the value of solar fraction $(f)$ and varying one of the two parameters to determine the other, a useful design plot can be created. Once the plot is obtained, a designer can determine the $\mathrm{X}$ and $\mathrm{Y}$ parameters for a suggested system, and quickly determine the expected solar fraction for the month. Twelve such calculations will yield the annual solar fraction. It can occur that the calculated parameters fall outside of the acceptable range. Beyond a value of $\mathrm{X}=15$, equation 4.2 .6 is no longer applicable, and an extremely incorrect answer will be given. The solid line in figure 4.2.2 shows equation 4.2.6 in both the acceptable and unacceptable regions. As a safeguard against such results, the equation was modified such that the dotted line predicts $f$ when $\mathrm{X}>15$. 


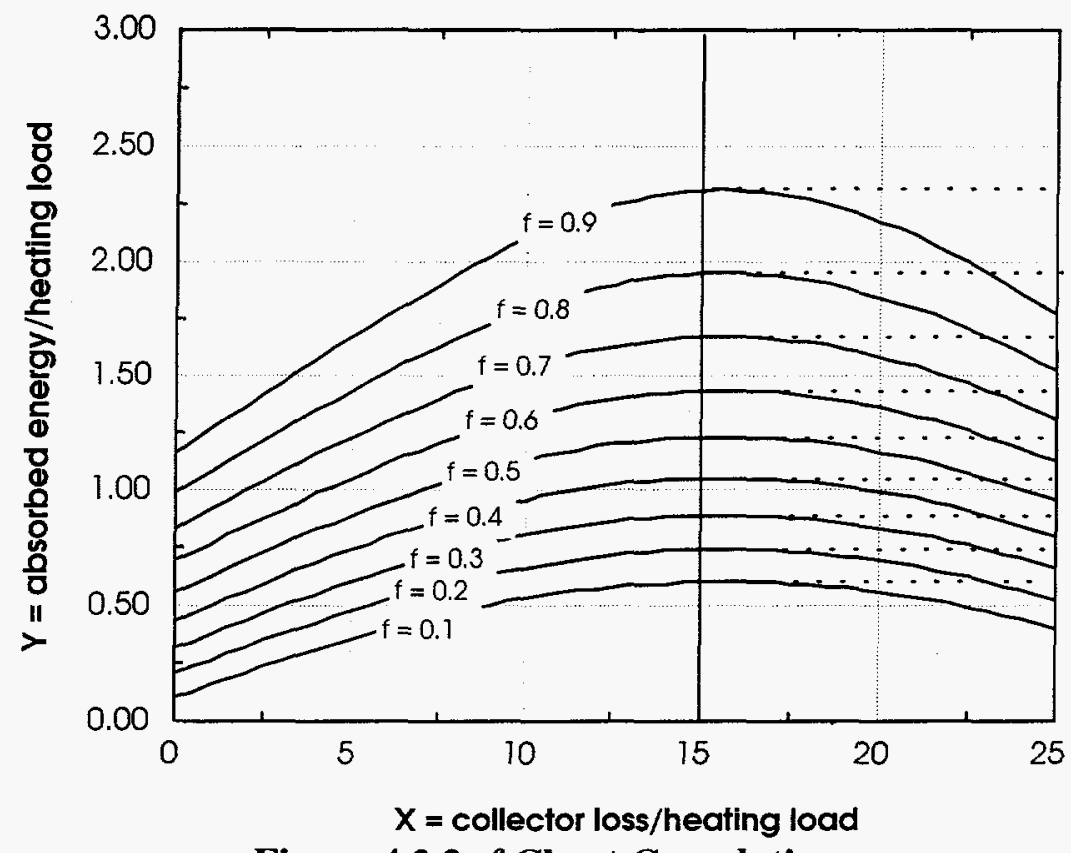

Figure 4.2.2: $f$-Chart Correlation

\subsection{Weather Data}

The $f$-Chart method bases its estimation of solar gain upon the monthly average daily radiation and the monthly average temperature. While such data are readily available, it was noticed that there are discrepancies between various sources. In some cases the difference was a great as $20 \%$ in solar radiation. The difference is a result of the data collection method. Solar irradiation data (global radiation on a horizontal surface) was taken over a period of 30 years between 1951 and 1975 at approximately 60 locations. The data were digitized at each station following instructions that changed over the collection period, and were sent to the National Climatic Data Center (NCDC). A host of problems arose during the course of the experiment stemming partly from each station being equipped differently. Some stations recorded continuous data on strip chart 
90

recorders while others only measured total daily radiation. Once the data had been reduced, only data from 26 of the locations were deemed accurate enough for inclusion in a database. During 1976, data collection ceased and the equipment underwent a recalibration overhaul. Data were again collected between 1977-1980 whereupon funding became inadequate to maintain the network and what data were collected, were not controlled for quality (NREL, 1992). Much of the equipment deteriorated during this period as well, including the pyranometers.

The simplest pyranometer consists of two concentric rings. The outer ring is coated with magnesium oxide that has a high reflectance of radiation in the solar energy spectrum. The inner ring is coated with a material such as Parson's Black that has a very high absorptance of radiation in the solar energy spectrum. Thermopiles are then used to measure the temperature difference between the two rings. At the end of the collection period, it was noticed that the Parson's Black coating had turned somewhat green so that the absorptance was no longer the same as the calibration indicated.

Since 1980 time, a great deal of effort has gone into salvaging the vast quantity of data and into making it useful. National Renewable Energy Labs now puts out a widely accepted data base of solar radiation data collected between 1961 and 1990 which is based upon a corrected interpolation of the NCDC data.

Other data necessary to the evaluation of three-season systems were estimates of the first and last date of freezing temperatures in each location. The first and last 
occurrences of freezing temperatures were obtained from the Weather Atlas of the United

States. No mention is made as to the source of the data but it is assumed that the dates and maps presented represent average conditions over some extended period of time.

In calculating the load, it is also necessary to choose a temperature for mains water entering the system. There is much variability in this temperature from location to location but two cases cover the entire spectrum of possibilities. If water is drawn from a deep source, such as a well, then its temperature is nearly equal to the average yearly ambient temperature. If, on the other hand it is drawn from a surface source, such as a reservoir, then it is nearly equal to the monthly average ambient temperature (Klein, 1997).

\subsection{The $f$-Chart Method Applied to Three-Season System Analysis}

Using the $f$-Chart method, the concept of a three-season system has been examined for various locations throughout the United States. In general, a solar energy collection system that operates year round is designed to meet a desired percentage of a heating load. A comparable system that operates during the freeze free months without a heat exchanger will have a different annual solar fraction. However, the reduction in solar fraction is not as simple as the ratio of time that the collector is shut off. One location for instance may have a long, clear winter (such as Albuquerque, NM) while another may have a short cloudy winter (Sault Saint Marie, MI). In the former case, a system without a heat exchanger cannot operate during six months of the year because of freezing, but the winter months are months in which a large amount of solar energy could 
92

have been collected, overcoming the losses associated with the heat exchanger. Thus the reduction in solar fraction would perhaps be more than simply half of the original design value. In the latter case, however, there is little radiation to be collected in the winter and operating during that period does not make up for the year round energy penalty paid by using a heat exchanger.

The overall goal is to answer the question: Given the location of an SDHW system, how much worse will a system operating for three seasons without a heat exchanger perform, than a standard system with a heat exchanger operating year round?

It is first necessary to design a four-season system that will meet a desired percentage of the heating load. The percentage met depends on a variety of factors such as the customer's desired investment level, the space available for installing the system, and the price of alternative methods of meeting the load. Taking all these factors into account, a four-season system can be designed with a collector area, a storage tank size, and a heat exchanger. The primary design variable is the collector area, which has a direct effect upon the annual solar fraction and system cost. A great deal of work has been carried out to analyze such systems and the optimum slope of the collector panels has been determined to be equal to the latitude of the collector location (Duffie and Beckman, 1991). Because of the earth sun geometry, this slope means that the beam radiation from the sun will be normal to the collector surface at solar noon on the equinoxes (September 21 and March 22) when the incidence angle of beam radiation is zero. Essentially, the collector is sloped at the sun's average annual declination angle. 
The four-season collector area is fixed such that the system meets a certain percentage of the annual load $(25 \%, 50 \%$ or $75 \%$ for our purposes).

The next step is to design a three-season system, and compare the two in order to determine the thermal penalty. The three-season system design is slightly more complicated. In order to compare the three-season system to the four-season system, the area of the three-season system was set to be equal to that of the corresponding fourseason system. The slope of the three-season collector was set to be the average solar declination during the system's operating period (see function slope3_(FF,LF,lat) in Appendix B). The rest of the system parameters were kept the same. The inputs to the $f$ Chart method are shown in figure 4.4.1a and 4.4.1b 


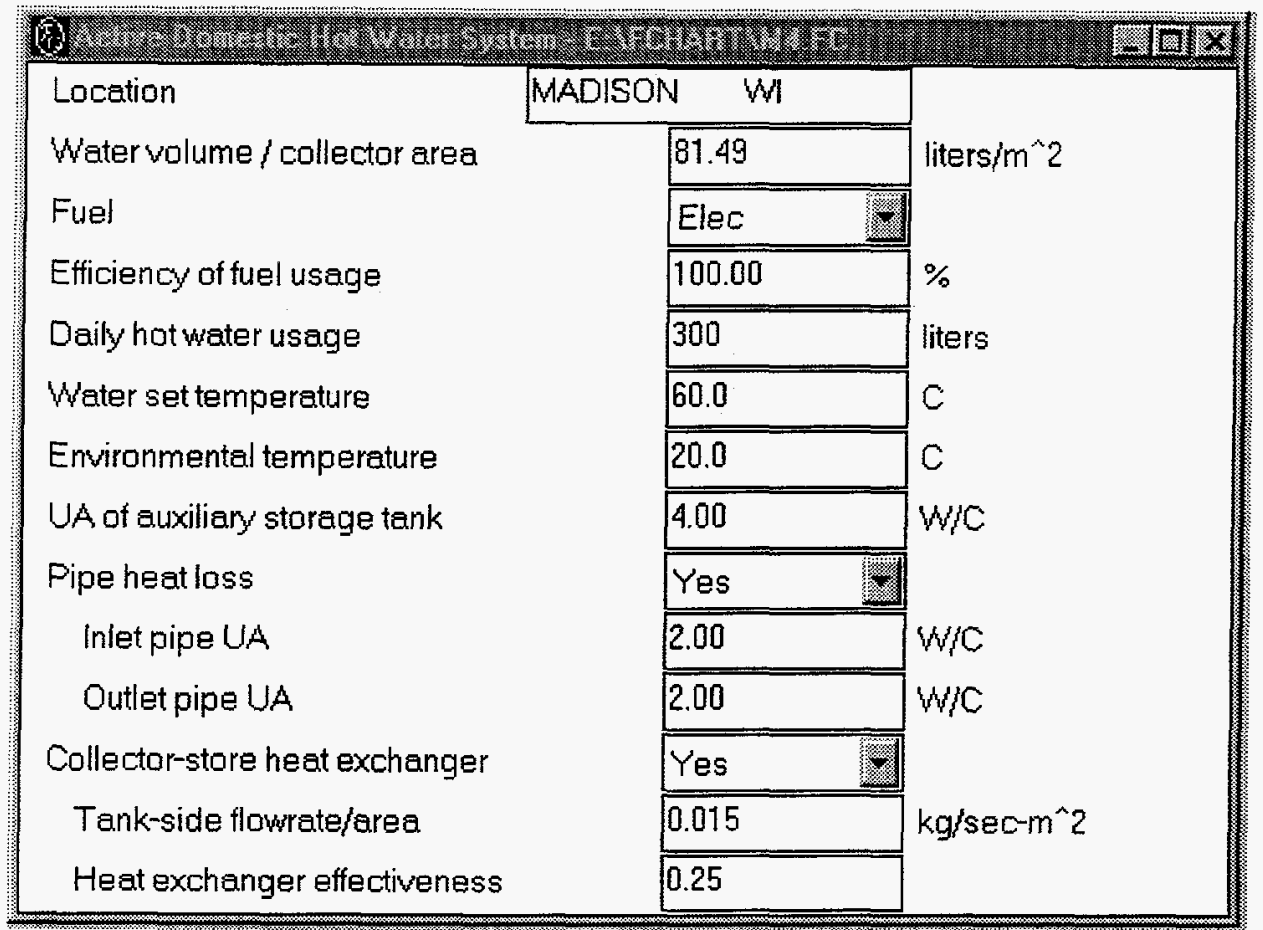

\begin{tabular}{|c|c|c|}
\hline \multicolumn{2}{|c|}{ 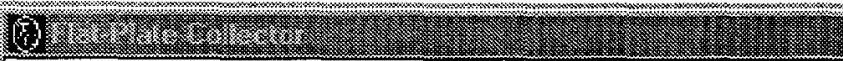 } & \multirow{5}{*}{$\begin{array}{l}m^{\wedge} 2 \\
W / m^{\wedge} 2-C\end{array}$} \\
\hline Number of collector panels & 2 & \\
\hline Collectar panel area & 2.75 & \\
\hline FR*UL (Test slope) & 4.860 & \\
\hline FR*TAU*ALPHA (Test intercept) & 0.741 & \\
\hline Callector slape & $\overline{43.1}$ & \multirow{6}{*}{$\begin{array}{l}\text { degrees } \\
\text { degrees }\end{array}$} \\
\hline Collector azimuth (South=0) & 0 & \\
\hline Incidence angle modifier calculation & Glazings & \\
\hline Number of glass covers & 1 & \\
\hline Inc angle modifier constant & 0.050 & \\
\hline Inc angle modifier value(s) & 0000 & \\
\hline Collector flowrate/area & 0.015 & \multirow{3}{*}{$\begin{array}{l}\mathrm{kg} / \mathrm{sec}-\mathrm{m}^{\wedge} 2 \\
\mathrm{k} \cdot \mathrm{J} / \mathrm{kg}-\mathrm{C}\end{array}$} \\
\hline Collectar fluid specific heat & 3.35 & \\
\hline Modify test values & No & \\
\hline Test collector flowratejarea & 0015 & \multirow{2}{*}{$\begin{array}{l}\mathrm{kg} / \mathrm{sec-m}{ }^{\wedge 2} \\
\mathrm{~kJ} / \mathrm{kg}-\mathrm{C}\end{array}$} \\
\hline Teat fll iir anecific heat & 4.19 & \\
\hline
\end{tabular}

Figure 4.4.1a: Four-Season System $f$-Chart Inputs 


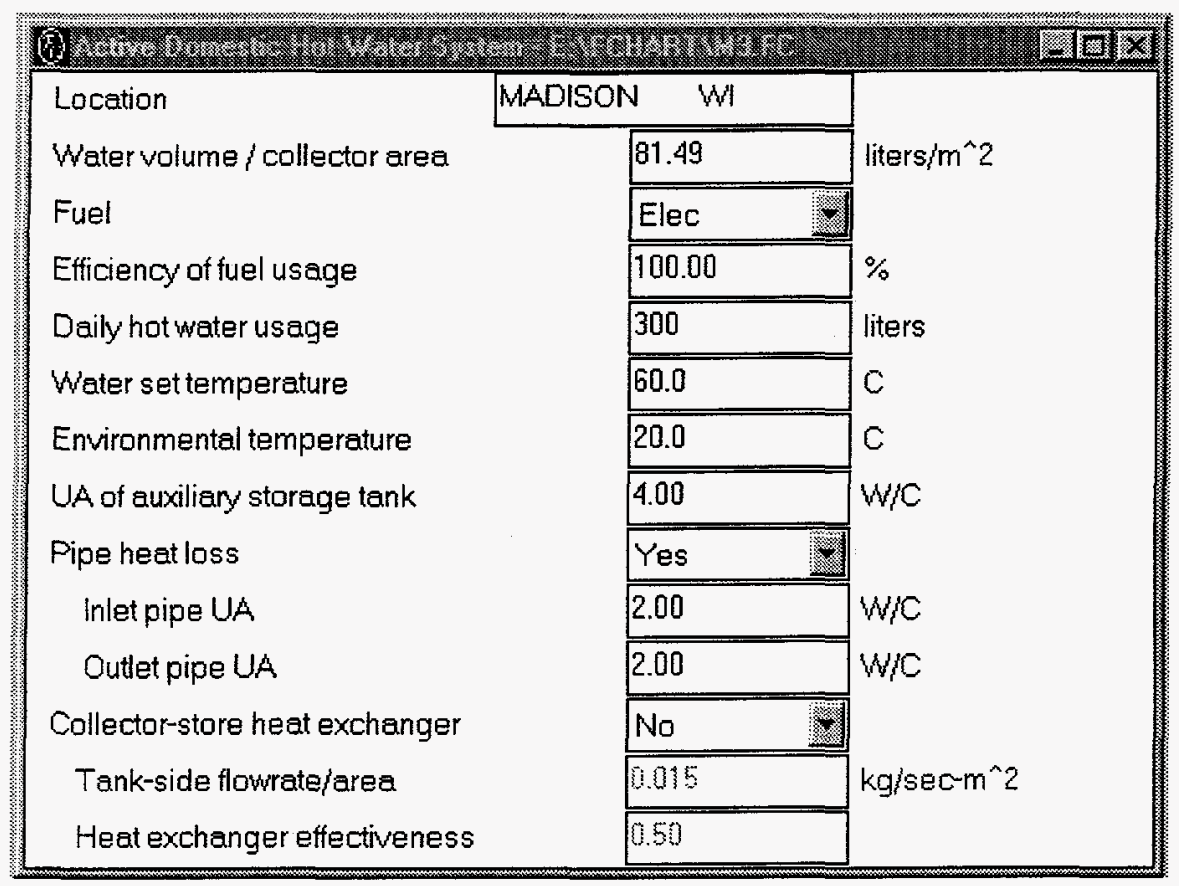

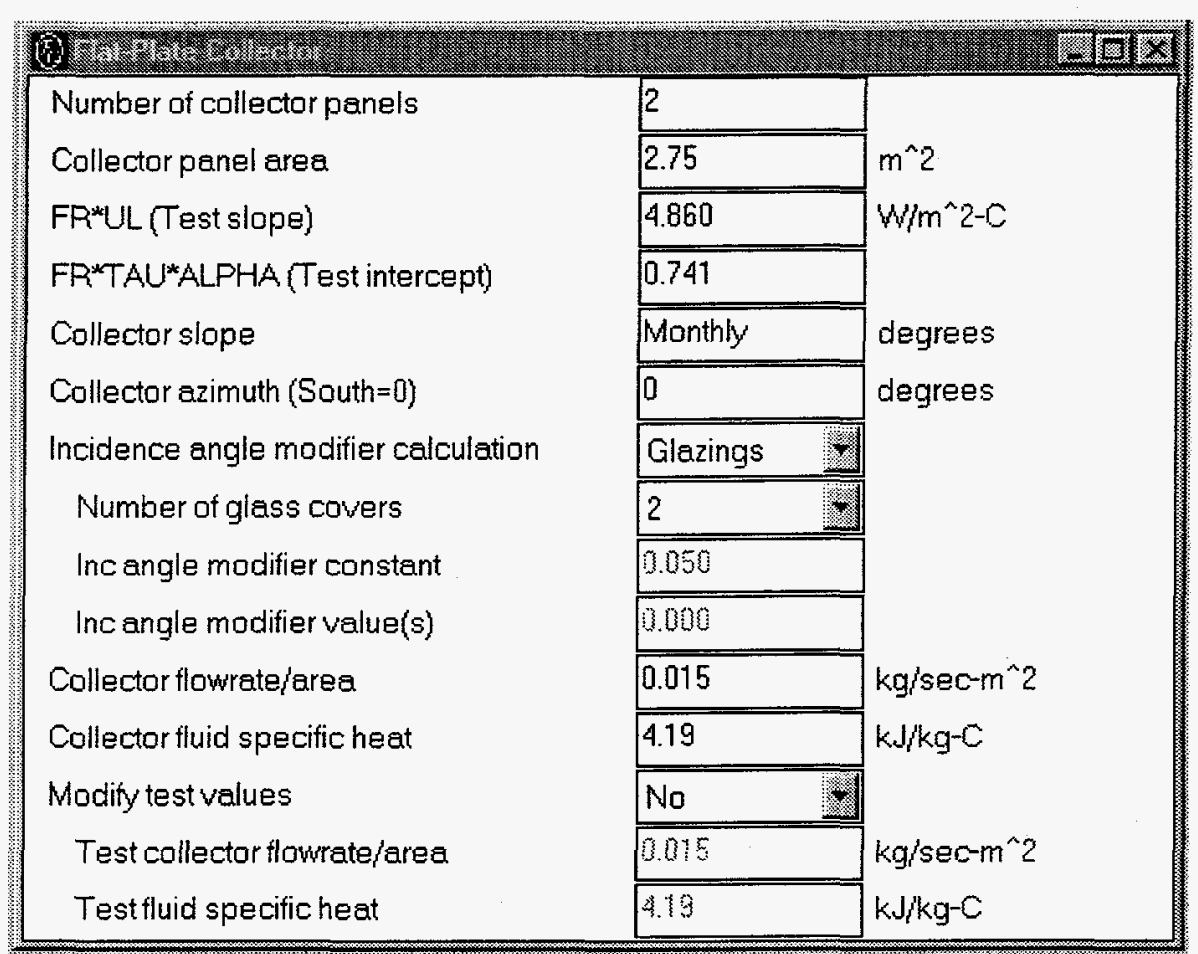

Figure 4.4.1b: Three-Season System $f$-Chart Inputs 
96

While the $f$-Chart method exists in a software form that combines worksheet style inputs with a simple summary and plotting tool output, it is limited in that it is designed to evaluate one system at a time (Klein and Beckman, 1993). Since, for the purposes of the three-season analysis, it is desirable to evaluate a large number of cities sequentially, it was deemed worthwhile to re-code the $f$-Chart equations into a program that could be tailored to the desired output. Engineering Equation Solver (EES), an equation solver software package (Klein, 1997) was used. The program appears in Appendix B at the end of this report. Figure 4.4.2 shows a comparison between $f$-Chart software results and the equation solver based program in Appendix B.

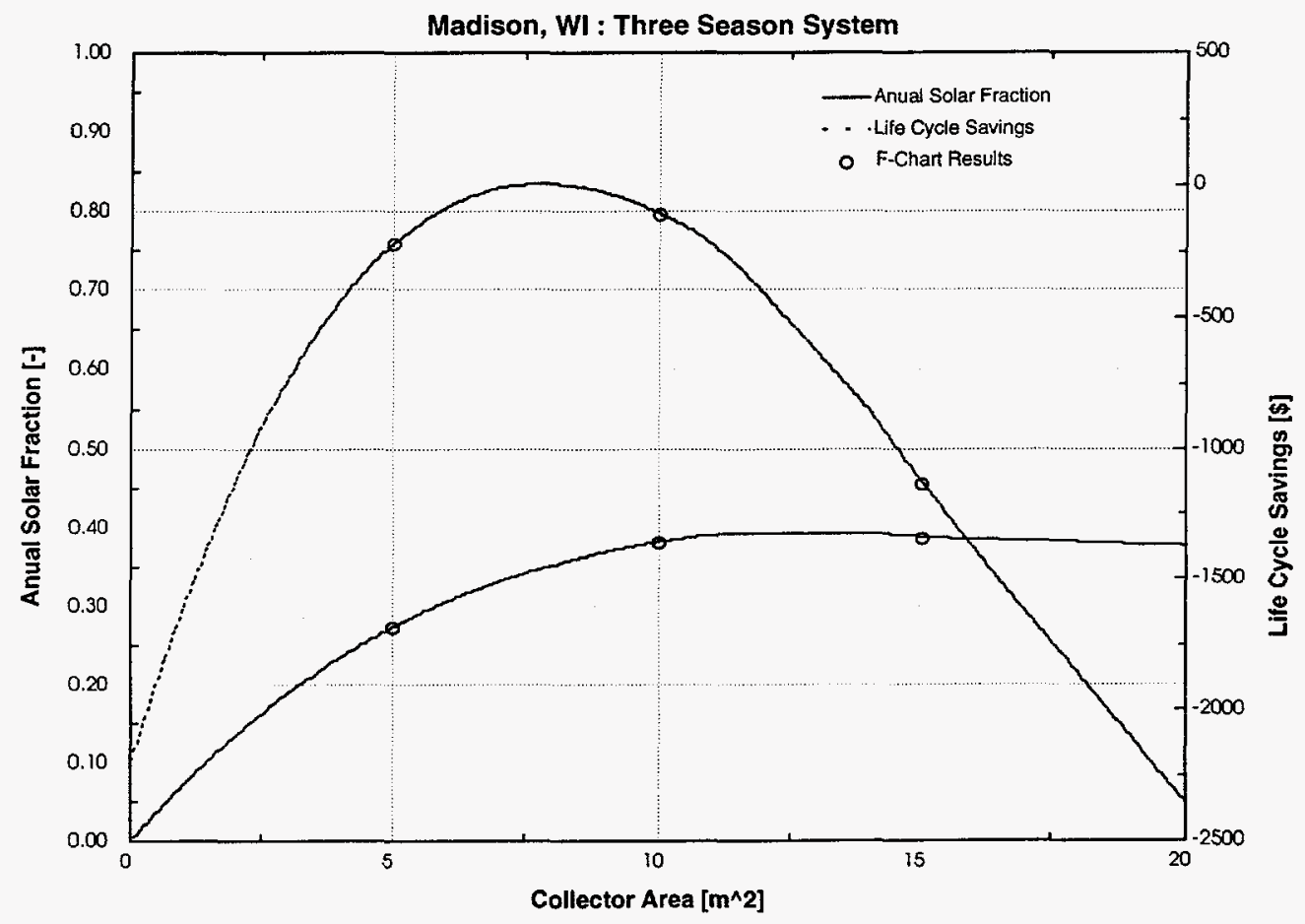

Figure 4.4.2: Comparison of Results between Equation Solver Results and $f$ Chart Software Results 


\subsection{Three Season Thermal Penalty}

A number of tables follow that show the thermal penalty associated with a threeseason system in various locations across the United States. Three systems were designed in each location, each based on a four-season system meeting 25,50 and $75 \%$ of an annual water heating load.

- City Number: A reference number identifying each city in the NREL data file

- City: City name and state of each location analyzed

- Location: latitude and longitude of each location

- Weather: the first (FF) and last (LF) month in which freezing is an issue are noted. A value of 0 in the LF category denotes the absence of a spring freeze and a value of 13 in the FF category indicates the lack of an autumn freeze.

- Collector Angles: The collector slopes of the four-season and three-season systems are noted. The four-season slope is equal to the latitude of the system, and the threeseason slope is equal to the average solar declination during the operating period.

- Three Season Solar Fraction: These columns show the three-season solar fraction for a system having the same area as a four-season system designed to meet the load shown in the column heading. For example, the first sub column is based upon a fourseason system that meets $25 \%$ of the load. 
98

Table 4.5.1 Three Season Thermal Penalties for Various Locations

\begin{tabular}{|c|c|c|c|c|c|c|c|c|c|c|c|}
\hline \multirow{2}{*}{ \# } & \multirow{2}{*}{\multicolumn{2}{|c|}{ City }} & \multicolumn{2}{|c|}{ location } & \multicolumn{2}{|c|}{ Weather } & \multicolumn{2}{|c|}{ Collector angles } & \multicolumn{3}{|c|}{ Three Season Solar Fraction } \\
\hline & & & latitude & longitude & LF & FF & slope 4 & slope 3 & $F=25 \%$ & $F=50 \%$ & $F=75 \%$ \\
\hline 1 & Abilene & $T X$ & 32.43 & 99.68 & 3 & 11 & 32.43 & 28.55 & 24.32 & 45.93 & 62.77 \\
\hline 2 & Akron & $\mathrm{OH}$ & 40.92 & 81.43 & 4 & 11 & 40.92 & 37.04 & 21.94 & 40.28 & 49.29 \\
\hline 3 & Albany & NY & 42.75 & 73.8 & 4 & 10 & 42.75 & 33.3 & 18.80 & 34.50 & 41.91 \\
\hline 4 & Albuquerque & NM & 35.05 & 106.62 & 5 & 11 & 35.05 & 31.01 & 15.65 & 29.70 & 40.82 \\
\hline 5 & Allentown & PA & 40.65 & 75.43 & 5 & 11 & 40.65 & 36.61 & 17.28 & 32.07 & 40.67 \\
\hline 6 & Alpena & MI & 45.07 & 83.43 & 5 & 10 & 45.07 & 35.45 & 15.12 & 27.79 & 33.19 \\
\hline 7 & Amarillo & $\mathrm{TX}$ & 35.23 & 101.7 & 4 & $\$ 1$ & 35.23 & 31.35 & 19.01 & 35.94 & 48.98 \\
\hline 8 & Annette & AK & 55.03 & 131.57 & 4 & 10 & 55.03 & 45.58 & 21.54 & 36.29 & 37.41 \\
\hline 9 & Apalachicola & FL & 29.73 & 85.2 & 1 & 13 & 29.73 & 29.89 & 31.51 & 59.45 & 81.33 \\
\hline 10 & Asheville & NC & 35.43 & 82.53 & 3 & 11 & 35.43 & 31.55 & 22.42 & 42.02 & 62.89 \\
\hline 11 & Astoria & OR & 46.15 & 123.88 & 3 & 12 & 46.15 & 45.64 & 26.78 & 48.94 & 65.34 \\
\hline 12 & Atlanta & GA & 33.65 & 84.43 & 3 & 12 & 33.65 & 33.14 & 24.69 & 46.44 & 68.63 \\
\hline 13 & Augusta & GA & 33.37 & 81.97 & 2 & 12 & 33.37 & 32.86 & 27.37 & 51.51 & 75.83 \\
\hline 14 & Austin & $\mathrm{TX}$ & 30.3 & 97.7 & 3 & 12 & 30.3 & 29.79 & 24.45 & 46.00 & 68.03 \\
\hline 15 & Bakersfield & $\mathrm{CA}$ & 35.42 & 119.05 & 1 & 12 & 35.42 & 35.37 & 30.65 & 57.68 & 80.62 \\
\hline 16 & Baltimore & $M D$ & 39.18 & 76.67 & 3 & 11 & 39.18 & 35.3 & 23.48 & 43.66 & 62.50 \\
\hline 17 & Barrow & AK & 71.3 & 156.78 & 6 & 7 & 71.3 & 48.56 & 0.00 & 0.00 & 0.00 \\
\hline 18 & Baton Rouge & LA & 30.53 & 91.15 & 2 & 12 & 30.53 & 30.02 & 29.39 & 51.68 & 75.40 \\
\hline 19 & Bethel & AK & 60.78 & 161.8 & 5 & 9 & 60.78 & 45.19 & 12.05 & 22.07 & 25.21 \\
\hline 20 & Bettles & AK & 66.92 & 151.52 & 6 & 8 & 66.92 & 46.24 & 1.97 & 7.18 & 8.49 \\
\hline 21 & Big Delta & AK & 64 & 145.73 & 5 & 9 & 64 & 48.41 & 13.40 & 24.24 & 25.21 \\
\hline 22 & Billings & MT & 45.8 & 108.53 & 4 & 10 & 45.8 & 36.35 & 18.39 & 33.99 & 41.92 \\
\hline 23 & Binghamton & NY & 42.22 & 75.98 & 4 & 10 & 42.22 & 32.77 & 18.93 & 34.63 & 41.84 \\
\hline 24 & Birmingham & AL & 33.57 & 86.75 & 3 & 11 & 33.57 & 29.69 & 22.88 & 42.68 & 57.05 \\
\hline 25 & Bismarck & ND & 46.77 & 100.75 & 4 & 10 & 46.77 & 37.32 & 18.33 & 34.05 & 41.84 \\
\hline 26 & Boise & ID & 43.57 & 116.22 & 4 & 11 & 43.57 & 39.69 & 22.18 & 40.95 & 49.80 \\
\hline 27 & Boston & MA & 42.37 & 71.3 & 4 & 11 & 42.37 & 38.49 & 20.64 & 38.35 & 49.29 \\
\hline 28 & Brownsville & TX & 25.9 & 97.43 & 1 & 13 & 25.9 & 26.06 & 31.51 & 59.36 & 81.01 \\
\hline 29 & Bryce Canyon & UT & 37.7 & 112 & 4 & 10 & 37.7 & 28.25 & 16.69 & 31.49 & 41.92 \\
\hline 30 & Buffalo & NY & 42.93 & 78.73 & 4 & 11 & 42.93 & 39.05 & 21.85 & 40.16 & 49.06 \\
\hline 31 & Burlington & IA & 40.78 & 91.2 & 4 & 10 & 40.78 & 31.33 & 20.18 & 36.59 & 41.92 \\
\hline 32 & Burlington & VT & 44.47 & 73.15 & 4 & 10 & 44.47 & 35.02 & 19.07 & 34.97 & 41.92 \\
\hline 33 & Bums & IA & 43.58 & 119.05 & 5 & 9 & 43.58 & 27.99 & 12.39 & 22.50 & 25.21 \\
\hline 34 & Cape Hatteras & NC & 35.27 & 75.55 & 2 & 12 & 35.27 & 34.76 & 27.60 & 51.85 & 70.40 \\
\hline 35 & Caribou & ME & 46.87 & 68.02 & 5 & 9 & 46.87 & 31.28 & 11.64 & 21.42 & 25.21 \\
\hline 36 & Casper & WY & 42.92 & 106.47 & 5 & 10 & 42.92 & 33.3 & 14.67 & 27.21 & 33.42 \\
\hline 37 & Cedar City & UT & 37.7 & 113.1 & 4 & 10 & 37.7 & 28.25 & 17.39 & 32.49 & 41.92 \\
\hline 38 & Charleston & SC & 32.9 & 79.97 & 2 & 12 & 32.9 & 32.39 & 29.24 & 54.22 & 69.49 \\
\hline 39 & Charleston & WV & 38.37 & 81.6 & 4 & 11 & 38.37 & 34.49 & 20.95 & 38.70 & 49.29 \\
\hline 40 & Charlotte & NC & 35.22 & 80.93 & 3 & 11 & 35.22 & 31.34 & 24.80 & 45.58 & 57.14 \\
\hline 41 & Chattanooga & TN & 35.03 & 85.2 & 3 & 11 & 35.03 & 31.15 & 23.25 & 43.27 & 57.08 \\
\hline 42 & Cheyenne & WY & 41.15 & 104.82 & 5 & 10 & 41.15 & 31.53 & 14.00 & 26.12 & 33.42 \\
\hline 43 & Chicago & IL & 41.78 & 87.75 & 4 & 11 & 41.78 & 37.9 & 21.51 & 39.74 & 49.39 \\
\hline 44 & Cincinnati & $\mathrm{OH}$ & 39.07 & 84.52 & 4 & 11 & 39.07 & 35.19 & 22.59 & 41.12 & 49.67 \\
\hline
\end{tabular}




\begin{tabular}{|c|c|c|c|c|c|c|c|c|c|c|c|}
\hline \multirow{2}{*}{$\#$} & \multirow{2}{*}{\multicolumn{2}{|c|}{ City }} & \multicolumn{2}{|c|}{ location } & \multicolumn{2}{|c|}{ weather } & \multicolumn{2}{|c|}{ Collector angies } & \multicolumn{3}{|c|}{ Three-Season Solar Fraction } \\
\hline & & & latitude & longitude & LF & FF & slope 4 & slope 3 & $F=25 \%$ & $F=50 \%$ & $F=75 \%$ \\
\hline 45 & Clayton & NM & 36.45 & 103.1 & 4 & 10 & 36.45 & 27 & 16.35 & 30.84 & 41.64 \\
\hline 46 & Cleveland & $\mathrm{OH}$ & 41.4 & 81.85 & 4 & 11 & 41.4 & 37.52 & 22.18 & 40.64 & 49.20 \\
\hline 47 & Colorado Springs & $\mathrm{CO}$ & 38.82 & 104.72 & 4 & 10 & 38.82 & 29.37 & 16.69 & 31.35 & 41.61 \\
\hline 48 & Columbia & Sc & 33.95 & 92.37 & 3 & 11 & 38.82 & 34.94 & 23.66 & 44.10 & 57.15 \\
\hline 49 & Columbia & MO & 38.82 & 79.97 & 2 & 12 & 33.95 & 33.44 & 28.68 & 53.62 & 69.49 \\
\hline 50 & Columbus & $\mathrm{OH}$ & 40 & 82.88 & 3 & 11 & 40 & 36.12 & 23.35 & 43.63 & 57.10 \\
\hline 51 & Concord & $\mathrm{NH}$ & 43.2 & 71.5 & 4 & 10 & 43.2 & 33.75 & 18.03 & 33.40 & 41.80 \\
\hline 52 & Corpus Christi & TX & 27.77 & 97.5 & 1 & 12 & 27.77 & 27.72 & 29.65 & 55.65 & 75.40 \\
\hline 53 & Cut Bank & MT & 48.6 & 122.37 & 5 & 9 & 48.6 & 33.01 & 12.27 & 22.33 & 25.21 \\
\hline 54 & Dagget & $\mathrm{CA}$ & 34.87 & 116.78 & 3 & 11 & 34.87 & 30.99 & 22.34 & 42.11 & 57.31 \\
\hline 55 & Dallas & $T X$ & 32.85 & 96.85 & 3 & 12 & 32.85 & 32.34 & 24.96 & 46.80 & 62.34 \\
\hline 56 & Dayton & $\mathrm{OH}$ & 39.9 & 84.22 & 4 & 11 & 39.9 & 36.02 & 21.52 & 39.71 & 49.41 \\
\hline 57 & Daytona Beach & $\mathrm{FL}$ & 29.18 & 81.05 & 1 & 12 & 29.18 & 29.13 & 31.53 & 58.52 & 74.32 \\
\hline 58 & Del Rio & $T X$ & 29.37 & 100.78 & 1 & 12 & 29.37 & 29.32 & 29.34 & 55.31 & 75.53 \\
\hline 59 & Denver & co & 39.75 & 104.87 & 4 & 10 & 39.75 & 30.3 & 16.73 & 31.45 & 41.79 \\
\hline 60 & Des Moines & IA & 41.53 & 93.65 & 4 & 11 & 41.53 & 37.65 & 20.86 & 38.86 & 49.48 \\
\hline 61 & Detroit & MI & 42.42 & 83.02 & 4 & 11 & 42.42 & 38.54 & 21.87 & 40.24 & 49.23 \\
\hline 62 & Dillon & MT & 45.25 & 112.8 & 6 & 9 & 45.25 & 29.66 & 8.40 & 15.28 & 16.99 \\
\hline 63 & Dodge City & KS & 37.77 & 99.97 & 4 & 11 & 37.77 & 33.89 & 19.49 & 36.74 & 49.06 \\
\hline 64 & Duluth & MN & 46.83 & 92.18 & 5 & 10 & 46.83 & 37.21 & 14.36 & 26.77 & 33.02 \\
\hline 65 & Eagle & CO & 39.65 & 106.92 & 6 & 9 & 39.65 & 24.06 & 7.39 & 13.78 & 16.99 \\
\hline 66 & Eau Claire & WI & 44.87 & 91.48 & 5 & 9 & 44.87 & 29.28 & 11.98 & 21.92 & 25.21 \\
\hline 67 & El Paso & TX & 31.8 & 115.78 & 5 & 9 & 40.83 & 25.24 & 11.89 & 21.79 & 25.21 \\
\hline 68 & Elko & NV & 40.83 & 106.4 & 3 & 11 & 31.8 & 27.92 & 21.79 & 41.22 & 56.69 \\
\hline 69 & Ely & NY & 39.28 & 114.85 & 5 & 9 & 39.28 & 23.69 & 11.00 & 20.46 & 25.21 \\
\hline 70 & Erie & PA & 42.08 & 80.18 & 4 & 11 & 42.08 & 38.2 & 22.17 & 40.65 & 49.19 \\
\hline 71 & Evansville & IN & 38.05 & 87.53 & 3 & 11 & 38.05 & 34.17 & 24.19 & 44.84 & 57.28 \\
\hline 72 & Fairbanks & AK & 64.82 & 147.87 & 5 & 9 & 64.82 & 49.23 & 13.68 & 24.23 & 25.21 \\
\hline 73 & Fargo & ND & 46.9 & 96.8 & 4 & 10 & 46.9 & 37.45 & 18.55 & 34.39 & 41.79 \\
\hline 74 & Farmington & NM & 36.75 & 108.23 & 5 & 10 & 36.75 & 27.13 & 13.51 & 25.42 & 33.42 \\
\hline 75 & Flint & Ml & 42.97 & 83.73 & 4 & 10 & 42.97 & 33.52 & 19.58 & 35.61 & 41.92 \\
\hline 76 & Fort Smith & AR & 35.33 & 94.37 & 3 & 11 & 35.33 & 31.45 & 22.86 & 42.77 & 56.64 \\
\hline 77 & Fort Wayne & IN & 41 & 85.2 & 4 & 11 & 41 & 37.12 & 18.55 & 35.12 & 48.35 \\
\hline 78 & Fort Worth & $T X$ & 32.83 & 97.05 & 3 & 11 & 32.83 & 28.95 & 23.40 & 43.57 & 56.85 \\
\hline 79 & Fresno & $\mathrm{CA}$ & 36.77 & 119.72 & 1 & 12 & 36.77 & 36.72 & 30.97 & 58.27 & 76.60 \\
\hline 80 & Glasgow & MT & 48.22 & 106.53 & 5 & 10 & 48.22 & 38.6 & 15.25 & 28.12 & 33.42 \\
\hline 81 & Goodland & KS & 39.37 & 101.7 & 4 & 10 & 39.37 & 29.92 & 17.19 & 32.17 & 41.68 \\
\hline 82 & Grand Island & NE & 40.97 & 98.32 & 4 & 10 & 40.97 & 31.52 & 17.81 & 33.13 & 41.78 \\
\hline 83 & Grand Junction & $\mathrm{CO}$ & 39.12 & 108.53 & 5 & 10 & 39.12 & 29.5 & 14.77 & 27.32 & 33.34 \\
\hline 84 & Grand Rapids & MI & 42.88 & 85.52 & 4 & 11 & 42.88 & 39 & 19.68 & 37.07 & 49.21 \\
\hline 85 & Great Falls & MT & 47.48 & 104.8 & 4 & 10 & 47.48 & 38.03 & 18.82 & 34.64 & 41.92 \\
\hline 86 & Green Bay & $W I$ & 44.48 & 88.13 & 4 & 10 & 44.48 & 35.03 & 18.67 & 34.40 & 41.73 \\
\hline 87 & Greensboro & NC & 36.08 & 79.95 & 3 & 11 & 36.08 & 32.2 & 26.01 & 47.64 & 57.00 \\
\hline 88 & Greensville & SC & 34.9 & 82.22 & 3 & 12 & 34.9 & 34.39 & 26.82 & 49.56 & 60.99 \\
\hline 89 & Gulkana & AK & 62.15 & 145.45 & 6 & 9 & 62.15 & 46.56 & 8.69 & 15.88 & 16.99 \\
\hline
\end{tabular}




\begin{tabular}{|c|c|c|c|c|c|c|c|c|c|c|c|}
\hline \multirow{2}{*}{$\#$} & \multirow{2}{*}{\multicolumn{2}{|c|}{ City }} & \multicolumn{2}{|c|}{ location } & \multicolumn{2}{|c|}{ weather } & \multicolumn{2}{|c|}{ collector angles } & \multicolumn{3}{|c|}{ Three-Season Solar Fraction } \\
\hline & & & latitude & longitude & LF & FF & slope 4 & slope 3 & $F=25 \%$ & $F=50 \%$ & $F=75 \%$ \\
\hline 90 & Harrisburg & PA & 40.22 & 76.77 & 3 & 11 & 40.22 & 36.34 & 23.79 & 44.17 & 56.92 \\
\hline 91 & Hartford & CT & 41.93 & 72.65 & 4 & 11 & 41.93 & 38.05 & 20.65 & 38.37 & 49.14 \\
\hline 92 & Helena & MT & 46.6 & 112 & 4 & 10 & 46.6 & 37.15 & 19.15 & 35.16 & 41.92 \\
\hline 93 & Hilo & $\mathrm{HI}$ & 19.72 & 155.08 & 0 & 13 & 19.72 & 19.88 & 33.28 & 62.93 & 86.44 \\
\hline 94 & Homer & AK & 59.63 & 151.5 & 5 & 10 & 59.63 & 50.01 & 16.06 & 28.92 & 33.17 \\
\hline 95 & Honolulu & $\mathrm{HI}$ & 21.33 & 157.92 & 0 & 13 & 21.33 & 21.49 & 33.36 & 63.32 & 87.69 \\
\hline 96 & Huntington & WV & 38.37 & 95.35 & 1 & 12 & 29.98 & 29.93 & 29.66 & 55.69 & 80.96 \\
\hline 97 & Huron & SD & 44.38 & 82.5 & 4 & 11 & 38.37 & 34.49 & 24.19 & 44.70 & 49.32 \\
\hline 98 & Houston & TX & 29.98 & 98.22 & 4 & 10 & 44.38 & 34.93 & 18.67 & 34.52 & 41.92 \\
\hline 99 & Indianapolis & $\mathbb{N}$ & 39.73 & 86.28 & 4 & 11 & 39.73 & 35.85 & 21.35 & 39.50 & 49.41 \\
\hline 100 & International Falls & MN & 48.57 & 93.38 & 5 & 9 & 48.57 & 32.98 & 11.87 & 21.86 & 32.97 \\
\hline 101 & Jackson & MS & 32.32 & 90.08 & 2 & 11 & 32.32 & 29.52 & 25.73 & 48.09 & 70.58 \\
\hline 102 & Jacksonville & $\mathrm{FL}$ & 30.5 & 81.7 & 1 & 12 & 30.5 & 30.45 & 29.92 & 56.26 & 81.39 \\
\hline 103 & Juneau & AK & 58.37 & 134.58 & 4 & 11 & 58.37 & 54.49 & 24.33 & 41.65 & 51.40 \\
\hline 104 & Kansas City & MO & 39.3 & 94.58 & 3 & 11 & 39.3 & 35.42 & 23.57 & 43.96 & 62.82 \\
\hline 105 & King Salmon & AK & 58.68 & 156.65 & 5 & 9 & 58.68 & 43.09 & 12.44 & 22.29 & 32.87 \\
\hline 106 & Knoxville & TN & 35.82 & 83.98 & 3 & 11 & 35.82 & 31.94 & 23.48 & 43.62 & 62.94 \\
\hline 107 & Kodiak & AK & 57.75 & 152.48 & 5 & 10 & 57.75 & 48.13 & 15.72 & 28.02 & 39.38 \\
\hline 108 & Korror Island & PN & 7.33 & 225 & 0 & 13 & 7.33 & 7.495 & 33.26 & 62.78 & 86.02 \\
\hline 109 & Kotzebue & AK & 66.87 & 162.63 & 6 & 9 & 66.87 & 51.28 & 5.48 & 13.07 & 16.99 \\
\hline 110 & Kwajelein Isiand & PN & 8.73 & 195 & 0 & 13 & 8.73 & 8.895 & 33.30 & 63.02 & 86.70 \\
\hline 111 & Lacrosse & WI & 43.87 & 91.25 & 4 & 10 & 43.87 & 34.42 & 21.80 & 40.26 & 49.64 \\
\hline 112 & Lake Charles & LA & 30.12 & 93.22 & 2 & 12 & 30.12 & 29.61 & 27.57 & 51.74 & 70.14 \\
\hline 113 & Laredo & $T X$ & 27.53 & 99.45 & 1 & 12 & 27.53 & 27.48 & 29.60 & 55.65 & 75.48 \\
\hline 114 & Las Vegas & UT & 36.08 & 115.17 & 2 & 11 & 36.08 & 33.28 & 25.25 & 47.66 & 64.97 \\
\hline 115 & Lewiston & ID & 46.38 & 117.02 & 5 & 10 & 46.38 & 36.76 & 15.46 & 28.32 & 33.42 \\
\hline 116 & Lewiston & MT & 47.05 & 109.45 & 5 & 9 & 47.05 & 31.46 & 12.34 & 22.40 & 25.21 \\
\hline 117 & Lexington & KY & 38.03 & 84.6 & 3 & 11 & 38.03 & 34.15 & 24.18 & 44.75 & 57.29 \\
\hline 118 & Lihue & $\mathrm{HI}$ & 21.98 & ${ }^{+} 59.35$ & 0 & 13 & 21.98 & 22.14 & 33.32 & 63.11 & 87.03 \\
\hline 119 & Little Rock & AR & 34.73 & 92.24 & 3 & 11 & 34.73 & 30.85 & 25.99 & 48.53 & 64.21 \\
\hline 120 & Long Beach & $\mathrm{CA}$ & 33.82 & 118.15 & 1 & 12 & 33.82 & 33.77 & 29.33 & 55.41 & 75.93 \\
\hline 121 & Los Angeles & $\mathrm{CA}$ & 33.93 & 118.4 & 0 & 13 & 33.93 & 34.09 & 33.38 & 63.47 & 88.19 \\
\hline 122 & Louisville & KY & 38.18 & 85.73 & 3 & 11 & 38.18 & 34.3 & 26.86 & 49.87 & 64.37 \\
\hline 123 & Lovelock & NV & 40.07 & 118.55 & 5 & 9 & 40.07 & 24.48 & 11.14 & 20.71 & 25.21 \\
\hline 124 & Lubbock & $T X$ & 33.65 & 101.82 & 3 & 11 & 33.65 & 29.77 & 22.01 & 41.54 & 56.77 \\
\hline 125 & Lufkin & TX & 31.23 & 94.8 & 3 & 11 & 31.23 & 27.35 & 22.89 & 42.66 & 56.68 \\
\hline 126 & Macon & GA & 32.7 & 83.65 & 2 & 12 & 32.7 & 32.19 & 27.44 & 51.61 & 70.31 \\
\hline 127 & Madison & WI & 43.13 & 89.33 & 4 & 11 & 43.13 & 39.25 & 20.81 & 38.75 & 48.91 \\
\hline 128 & Mason City & IA & 43.15 & 93.33 & 4 & 10 & 43.15 & 33.7 & 18.57 & 34.32 & 41.92 \\
\hline 129 & Massena & NY & 44.93 & 74.85 & 4 & 10 & 44.93 & 35.48 & 18.65 & 34.38 & 41.79 \\
\hline 130 & McGrath & AK & 62.97 & 155.62 & 5 & 9 & 62.97 & 47.38 & 12.57 & 23.16 & 25.21 \\
\hline 131 & Medford & OR & 42.37 & 122.87 & 4 & 11 & 42.37 & 38.49 & 23.21 & 42.38 & 49.80 \\
\hline 132 & Memphis & TN & 35.05 & 90 & 3 & 11 & 35.05 & 31.17 & 23.49 & 43.70 & 57.14 \\
\hline 133 & Meridian & MS & 32.33 & 88.75 & 2 & 11 & 32.33 & 29.53 & 25.62 & 47.85 & 64.31 \\
\hline 134 & Miami & $\mathrm{FL}$ & 25.8 & 80.27 & 0 & 13 & 25.8 & 25.96 & 33.32 & 63.11 & 87.02 \\
\hline
\end{tabular}




\begin{tabular}{|c|c|c|c|c|c|c|c|c|c|c|c|}
\hline \multirow{2}{*}{$\#$} & \multirow{2}{*}{\multicolumn{2}{|c|}{ City }} & \multicolumn{2}{|c|}{ location } & \multicolumn{2}{|c|}{ weather } & \multicolumn{2}{|c|}{ collector angles } & \multicolumn{3}{|c|}{ Three-Season Solar Fraction } \\
\hline & & & latitude & longitude & LF & $\mathrm{FF}$ & slope 4 & slope 3 & $F=25 \%$ & $F=50 \%$ & $F=75 \%$ \\
\hline 135 & Midland & $T X$ & 31.93 & 102.18 & 3 & 11 & 31.93 & 28.05 & 24.82 & 46.86 & 64.41 \\
\hline 136 & Miles City & MT & 46.43 & 105.87 & 4 & 10 & 46.43 & 36.98 & 18.57 & 34.37 & 41.92 \\
\hline 137 & Milwaukee & WI & 42.95 & 87.9 & 4 & 11 & 42.95 & 39.07 & 21.24 & 39.37 & 49.18 \\
\hline 138 & Minneapolis & $M N$ & 44.88 & 93.22 & 4 & 10 & 44.88 & 35.43 & 18.46 & 34.16 & 41.77 \\
\hline 139 & Minot & ND & 48.27 & 101.35 & 5 & 9 & 48.27 & 32.68 & 12.08 & 22.14 & 25.21 \\
\hline 140 & Missoula & MT & 46.92 & 114.08 & 5 & 9 & 46.92 & 31.33 & 13.39 & 23.82 & 25.21 \\
\hline 141 & Mobile & AL & 30.68 & 88.25 & 2 & 12 & 30.68 & 30.17 & 27.36 & 51.33 & 69.58 \\
\hline 142 & Moline & IL & 41.45 & 90.52 & 4 & 10 & 41.45 & 32 & 18.82 & 34.57 & 41.92 \\
\hline 143 & Montgomery & AL & 32.3 & 86.37 & 2 & 12 & 32.3 & 31.79 & 27.54 & 51.76 & 70.40 \\
\hline 144 & Mount Shasta & $\mathrm{CA}$ & 41.32 & 122.32 & 5 & 9 & 41.32 & 25.73 & $\$ 2.72$ & 22.90 & 25.21 \\
\hline 145 & Nashville & TN & 36.12 & 86.68 & 3 & 11 & 36.12 & 32.24 & 23.69 & 44.02 & 57.28 \\
\hline 146 & Needles & $\mathrm{CA}$ & 34.77 & $\$ 14.62$ & 2 & 12 & 34.77 & 34.26 & 27.38 & 51.82 & 71.38 \\
\hline 147 & Newark & NJ & 40.7 & 74.17 & 4 & 11 & 40.7 & 36.82 & 20.64 & 38.30 & 49.26 \\
\hline 148 & New Orleans & LA & 29.98 & 90.25 & 1 & 12 & 29.98 & 29.93 & 29.61 & 55.67 & 75.71 \\
\hline 149 & New York (central park) & NY & 40.78 & 73.97 & 3 & 11 & 40.78 & 36.9 & 23.79 & 44.17 & 57.07 \\
\hline 150 & New York (laguardia) & NY & 40.77 & 73.9 & 3 & 11 & 40.77 & 36.89 & 23.80 & 44.18 & 57.07 \\
\hline 151 & Nome & AK & 64.5 & 165.43 & 5 & 9 & 64.5 & 48.91 & 12.20 & 22.44 & 25.21 \\
\hline 152 & Norfolk & VA & 36.9 & 76.2 & 3 & 12 & 36.9 & 36.39 & 26.12 & 48.82 & 62.26 \\
\hline 153 & North Bend & OR & 43.42 & 124.25 & 6 & 9 & 43.42 & 27.83 & 8.37 & 14.88 & 16.99 \\
\hline 154 & North Omaha & NE & 41.37 & 96 & 3 & 11 & 41.37 & 37.49 & 25.23 & 46.05 & 57.22 \\
\hline 155 & North Platte & NE & 41.13 & 100.68 & 4 & 10 & 41.13 & 31.68 & 19.83 & 35.55 & 41.92 \\
\hline 156 & Oakland & $\mathrm{CA}$ & 37.73 & 122.32 & 0 & 13 & 37.73 & 37.89 & 33.36 & 63.35 & 87.46 \\
\hline 157 & Oklahoma City & OK & 46.97 & 97.6 & 3 & 11 & 35.4 & 31.52 & 25.43 & 47.79 & 64.00 \\
\hline 158 & Olympia & WA & 35.4 & 122.9 & 4 & 11 & 46.97 & 43.09 & 23.51 & 42.03 & 48.08 \\
\hline 159 & Orlando & $\mathrm{FL}$ & 28.55 & 81.38 & 1 & 13 & 28.55 & 28.71 & 31.06 & 58.71 & 75.00 \\
\hline 160 & Pendleton & OR & 45.68 & 118.85 & 4 & 10 & 45.68 & 36.23 & 20.46 & 36.96 & 49.65 \\
\hline 161 & Philadelphia & PA & 39.88 & 75.25 & 3 & 12 & 39.88 & 39.37 & 25.33 & 47.40 & 62.48 \\
\hline 162 & Phoenix & $A Z$ & $\cdot 33.43$ & 112.02 & 1 & 12 & 33.43 & 33.38 & 29.44 & 55.81 & 77.16 \\
\hline 163 & Pierre & SD & 44.38 & 100.28 & 4 & 10 & 44.38 & 34.93 & 18.50 & 34.25 & 41.92 \\
\hline 164 & Pittsburgh & PA & 40.5 & 80.22 & 4 & 11 & 40.5 & 36.62 & 21.71 & 39.93 & 49.34 \\
\hline 165 & Pocatello & ID & 42.92 & 112.6 & 4 & 10 & 42.92 & 33.47 & 19.25 & 35.35 & 41.92 \\
\hline 166 & Port Arthur & $T X$ & 29.95 & 94.02 & 2 & 12 & 29.95 & 29.44 & 29.68 & 54.79 & 69.04 \\
\hline 167 & Portland & OR & 43.65 & 70.32 & 4 & 10 & 43.65 & 34.2 & 17.89 & 33.17 & 41.87 \\
\hline 168 & Portland & ME & 45.6 & 122.6 & 2 & 12 & 45.6 & 45.09 & 26.91 & 50.95 & 69.42 \\
\hline 169 & Prescott & $A Z$ & 34.65 & 112.43 & 4 & 10 & 34.65 & 25.2 & 16.52 & 31.06 & 41.59 \\
\hline 170 & Providence & $\mathrm{RI}$ & 41.73 & 71.43 & 3 & 11 & 41.73 & 37.85 & 23.63 & 43.95 & 56.99 \\
\hline 171 & Pueblo & $\mathrm{CO}$ & 38.28 & 104.48 & 4 & 10 & 38.28 & 28.83 & 16.94 & 31.77 & 41.77 \\
\hline 172 & Raleigh & NC & 35.87 & 78.78 & 3 & 12 & 35.87 & 35.36 & 24.59 & 46.26 & 62.89 \\
\hline 173 & Rapid City & SD & 44.05 & 103.07 & 4 & 10 & 44.05 & 34.6 & 19.34 & 35.31 & 41.92 \\
\hline 174 & Red Bluff & $\mathrm{CA}$ & 40.15 & 122.3 & 2 & 12 & 40.15 & 39.64 & 29.45 & 55.01 & 70.14 \\
\hline 175 & Redmond & OR & 44.27 & 121.15 & 5 & 8 & 44.27 & 25.09 & 8.45 & 15.19 & 16.71 \\
\hline 176 & Reno & NV & 39.5 & 119.78 & 4 & 10 & 39.5 & 30.05 & 18.09 & 33.56 & 41.92 \\
\hline 177 & Richmond & VA & 37.5 & 77.33 & 3 & 11 & 37.5 & 33.62 & 23.08 & 43.02 & 56.82 \\
\hline 178 & Roanoke & VA & 37.32 & 79.97 & 4 & 11 & 37.32 & 33.44 & 19.79 & 36.99 & 49.08 \\
\hline 179 & Rochester & MN & 43.92 & 92.5 & 5 & 9 & 43.92 & 28.33 & 12.07 & 22.04 & 25.21 \\
\hline
\end{tabular}




\begin{tabular}{|c|c|c|c|c|c|c|c|c|c|c|c|}
\hline \multirow{2}{*}{$\#$} & \multirow{2}{*}{\multicolumn{2}{|c|}{ City }} & \multicolumn{2}{|c|}{ location } & \multicolumn{2}{|c|}{ weather } & \multicolumn{2}{|c|}{ collector angies } & \multicolumn{3}{|c|}{ Three-Season Solar Fraction } \\
\hline & & & latitude & longitude & LF & FF & slope 4 & slope 3 & $F=25 \%$ & $F=50 \%$ & $F=75 \%$ \\
\hline 180 & Rochester & NY & 43.12 & 77.67 & 4 & 11 & 43.12 & 39.24 & 20.98 & 39.08 & 49.07 \\
\hline 181 & Rock Springs & WY & 41.6 & 109.07 & 5 & 8 & 41.6 & 22.42 & 6.85 & 12.77 & 16.71 \\
\hline 182 & Roswell & NM & 33.4 & 104.53 & 3 & 11 & 33.4 & 29.52 & 22.15 & 41.87 & 57.27 \\
\hline 183 & Sacramento & $\mathrm{CA}$ & 38.52 & 121.5 & 1 & 12 & 38.52 & 38.47 & 30.90 & 58.07 & 76.16 \\
\hline 184 & Salem & OR & 44.92 & 123.02 & 3 & 11 & 44.92 & 41.04 & 26.23 & 47.63 & 57.30 \\
\hline 185 & Salt Lake City & UT & 40.77 & 111.97 & 3 & 11 & 40.77 & 36.89 & 24.47 & 45.53 & 57.44 \\
\hline 186 & San Angelo & TX & 31.37 & 100.4 & 3 & 12 & 31.37 & 30.86 & 23.98 & 45.39 & 62.62 \\
\hline 187 & San Antonio & TX & 29.53 & 98.47 & 2 & 11 & 29.53 & 26.73 & 25.12 & 47.25 & 64.13 \\
\hline 188 & San Diego & $\mathrm{CA}$ & 32.73 & 117.17 & 0 & 13 & 32.73 & 32.89 & 33.40 & 63.53 & 88.38 \\
\hline 189 & San Francisco & $\mathrm{CA}$ & 37.62 & 122.38 & 0 & 13 & 37.62 & 37.78 & 33.34 & 63.24 & 86.69 \\
\hline 190 & San Juan & PR & 18.43 & 66.12 & 0 & 13 & 18.43 & 18.59 & 33.34 & 63.22 & 87.35 \\
\hline 191 & Santa Maria & $\mathrm{CA}$ & 34.9 & 120.45 & 3 & 11 & 34.9 & 31.02 & 25.06 & 47.12 & 64.29 \\
\hline 192 & Sault Saint Marie & MI & 46.47 & 84.37 & 5 & 10 & 46.47 & 36.85 & 14.55 & 27.00 & 32.88 \\
\hline 193 & Savannah & GA & 32.13 & 81.2 & 2 & 12 & 32.13 & 31.62 & 27.28 & 51.31 & 69.89 \\
\hline 194 & Scottsbluff & NE & 41.87 & 103.6 & 5 & 10 & 41.87 & 32.25 & 11.57 & 22.24 & 31.53 \\
\hline 195 & Seattle & WA & 47.45 & 122.3 & 2 & 12 & 47.45 & 46.94 & 30.41 & 55.55 & 67.31 \\
\hline 196 & Sheridan & WY & 44.77 & 106.97 & 5 & 10 & 44.77 & 35.15 & 14.71 & 27.24 & 33.42 \\
\hline 197 & Sherman & $T X$ & 33.72 & 96.67 & 3 & 11 & 33.72 & 29.84 & 23.26 & 43.31 & 56.57 \\
\hline 198 & Shreveport & LA & 32.47 & 93.82 & 2 & 12 & 32.47 & 31.96 & 27.65 & 51.93 & 70.12 \\
\hline 199 & Sioux City & IA & 42.4 & 96.38 & 4 & 10 & 42.4 & 32.95 & 18.44 & 34.09 & 41.87 \\
\hline 200 & Sioux Falls & SD & 43.57 & 96.73 & 4 & 10 & 43.57 & 34.12 & 18.07 & 33.54 & 41.83 \\
\hline 201 & South Bend & IN & 41.7 & 86.32 & 4 & 11 & 41.7 & 37.82 & 21.80 & 40.12 & 49.25 \\
\hline 202 & Spokane & WA & 47.63 & 117.52 & 4 & 10 & 47.63 & 38.18 & 20.23 & 36.64 & 41.92 \\
\hline 203 & Springfield & IL & 39.83 & 89.67 & 3 & 11 & 39.83 & 35.95 & 21.98 & 41.57 & 56.90 \\
\hline 204 & Springfield & MO & 37.23 & 93.38 & 3 & 11 & 37.23 & 33.35 & 22.63 & 42.60 & 57.20 \\
\hline 205 & St. Louis & MO & 38.75 & 90.38 & 3 & 11 & 38.75 & 34.87 & 23.78 & 44.23 & 57.14 \\
\hline 206 & Summit & AK & 63.33 & 150 & 6 & 8 & 63.33 & 42.65 & 4.73 & 8.49 & 8.49 \\
\hline 207 & Syracuse & NY & 43.12 & 76.12 & 4 & 10 & 43.12 & 33.67 & 19.39 & 35.32 & 41.92 \\
\hline 208 & Tallahassee & $\mathrm{FL}$ & 30.38 & 84.37 & 2 & 12 & 30.38 & 29.87 & 27.16 & 51.12 & 75.53 \\
\hline 209 & Tampa & $\mathrm{FL}$ & 27.97 & 82.53 & 0 & 13 & 27.97 & 28.13 & 33.33 & 63.20 & 87.32 \\
\hline 210 & Toledo & $\mathrm{OH}$ & 41.6 & 83.8 & 4 & 11 & 41.6 & 37.72 & 24.95 & 46.06 & 57.20 \\
\hline 211 & Tonopah & NV & 38.07 & 117.08 & 5 & 10 & 38.07 & 28.45 & 14.08 & 26.30 & 33.42 \\
\hline 212 & Topeka & KS & 39.07 & 95.63 & 3 & 11 & 39.07 & 35.19 & 23.42 & 43.73 & 57.02 \\
\hline 213 & Traverse City & MI & 44.73 & 85.58 & 5 & 10 & 44.73 & 35.11 & 15.62 & 28.49 & 33.31 \\
\hline 214 & Truth or Consequences & NM & 33.23 & 107.2 & 4 & 11 & 33.23 & 29.35 & 18.45 & 35.08 & 48.70 \\
\hline 215 & Tucson & $A Z$ & 32.12 & 110.93 & 2 & 12 & 32.12 & 31.61 & 26.90 & 51.00 & 70.60 \\
\hline 216 & Tucumcari & NM & 35.18 & 103.6 & 4 & 11 & 35.18 & 31.3 & 19.07 & 36.04 & 49.15 \\
\hline 217 & Tulsa & OK & 36.2 & 95.9 & 3 & 11 & 36.2 & 32.32 & 22.99 & 42.97 & 56.59 \\
\hline 218 & Waco & TX & 31.62 & 97.22 & 3 & 11 & 31.62 & 27.74 & 22.59 & 42.27 & 56.29 \\
\hline 219 & Wake Island & PN & 19.28 & 200 & 0 & 13 & 19.28 & 19.44 & 33.35 & 63.30 & 87.59 \\
\hline 220 & Washington & DC & 38.95 & 77.03 & 3 & 11 & 38.95 & 35.07 & 27.33 & 50.48 & 64.29 \\
\hline 221 & West Palm Beach & $\mathrm{FL}$ & 26.68 & 80.1 & 0 & 13 & 26.68 & 26.84 & 33.35 & 63.26 & 87.49 \\
\hline 222 & Wichita & KS & 37.65 & 97.42 & 4 & 10 & 37.65 & 28.2 & 20.67 & 38.47 & 49.50 \\
\hline 223 & Wichita Falls & TX & 33.97 & 98.48 & 3 & 11 & 33.97 & 30.09 & 23.83 & 44.37 & 57.09 \\
\hline
\end{tabular}




\begin{tabular}{|c|c|c|c|c|c|c|c|c|c|c|c|}
\hline \multirow{2}{*}{ \# } & \multirow{2}{*}{\multicolumn{2}{|c|}{ City }} & \multicolumn{2}{|c|}{ location } & \multicolumn{2}{|c|}{ weather } & \multicolumn{2}{|c|}{ collector angles } & \multicolumn{3}{|c|}{ Three-Season Solar Fraction } \\
\hline & & & latitude & longitude & LF & FF & slope 4 & slope 3 & $F=25 \%$ & $F=50 \%$ & $F=75 \%$ \\
\hline 224 & Willkes-Barre & PA & 41.33 & 75.73 & 5 & 10 & 41.33 & 31.71 & 15.33 & 27.97 & 33.40 \\
\hline 225 & Wilmington & DE & 39.67 & 75.6 & 4 & 11 & 39.67 & 35.79 & 20.47 & 38.07 & 49.17 \\
\hline 226 & Winnemucca & NV & 40.9 & 117.8 & 5 & 10 & 40.9 & 31.28 & 15.17 & 27.94 & 33.42 \\
\hline 227 & Winslow & $A Z$ & 35.02 & 110.73 & 4 & 11 & 35.02 & 31.14 & 19.05 & 36.11 & 49.41 \\
\hline 228 & Yakima & WA & 46.57 & 120.53 & 4 & 11 & 46.57 & 42.69 & .22 .29 & 41.02 & 49.58 \\
\hline 229 & Yakutat & AK & 59.52 & 139.67 & 4 & 10 & 59.52 & 50.07 & 20.06 & 35.38 & 38.82 \\
\hline 230 & Youngstown & $\mathrm{OH}$ & 41.27 & 80.67 & 4 & 10 & 41.27 & 31.82 & 19.81 & 35.82 & 41.92 \\
\hline
\end{tabular}

\subsection{Three-Season System Thermal Penalty Maps}

Since the above tables are somewhat cumbersome to use and do not show geographic trends in three-season system performance, a number of cities have been selected and placed on maps for clarity. The figures on the following pages show the three-season system annual solar fraction that can be expected by duplicating the area of a four-season system meeting 25,50 and $75 \%$ of an annual water heating load. The system parameters are as shown in 4.4.1a and 4.4.1b. 
Thermal Performance of a Three-Season System Based on a Four Season System Meeting 25\% of the Annual Load

(Western United States)

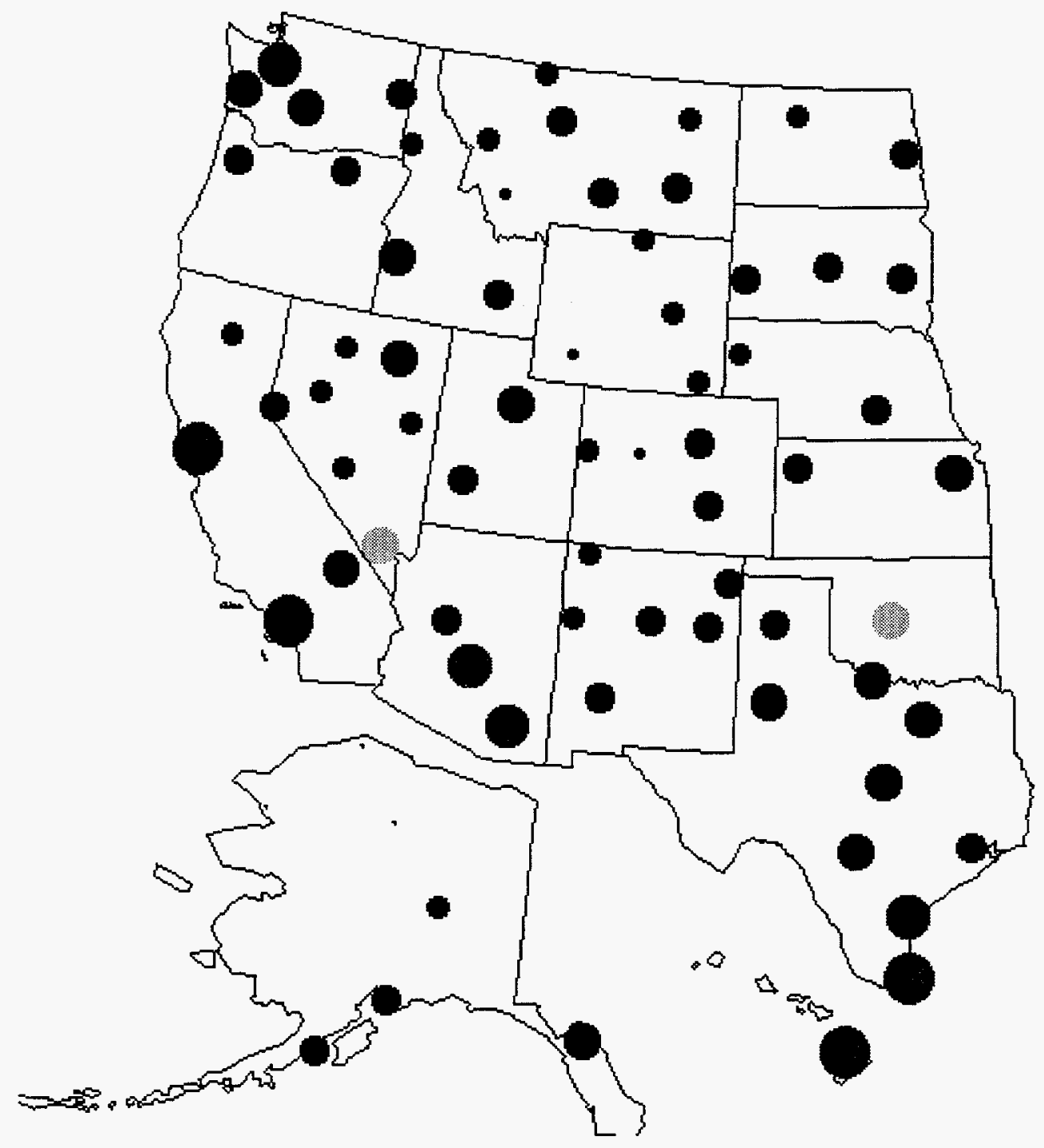


Thermal Performance of a Three-Season System Based on a Four Season System Meeting 25\% of the Annual Load (Eastern United States)
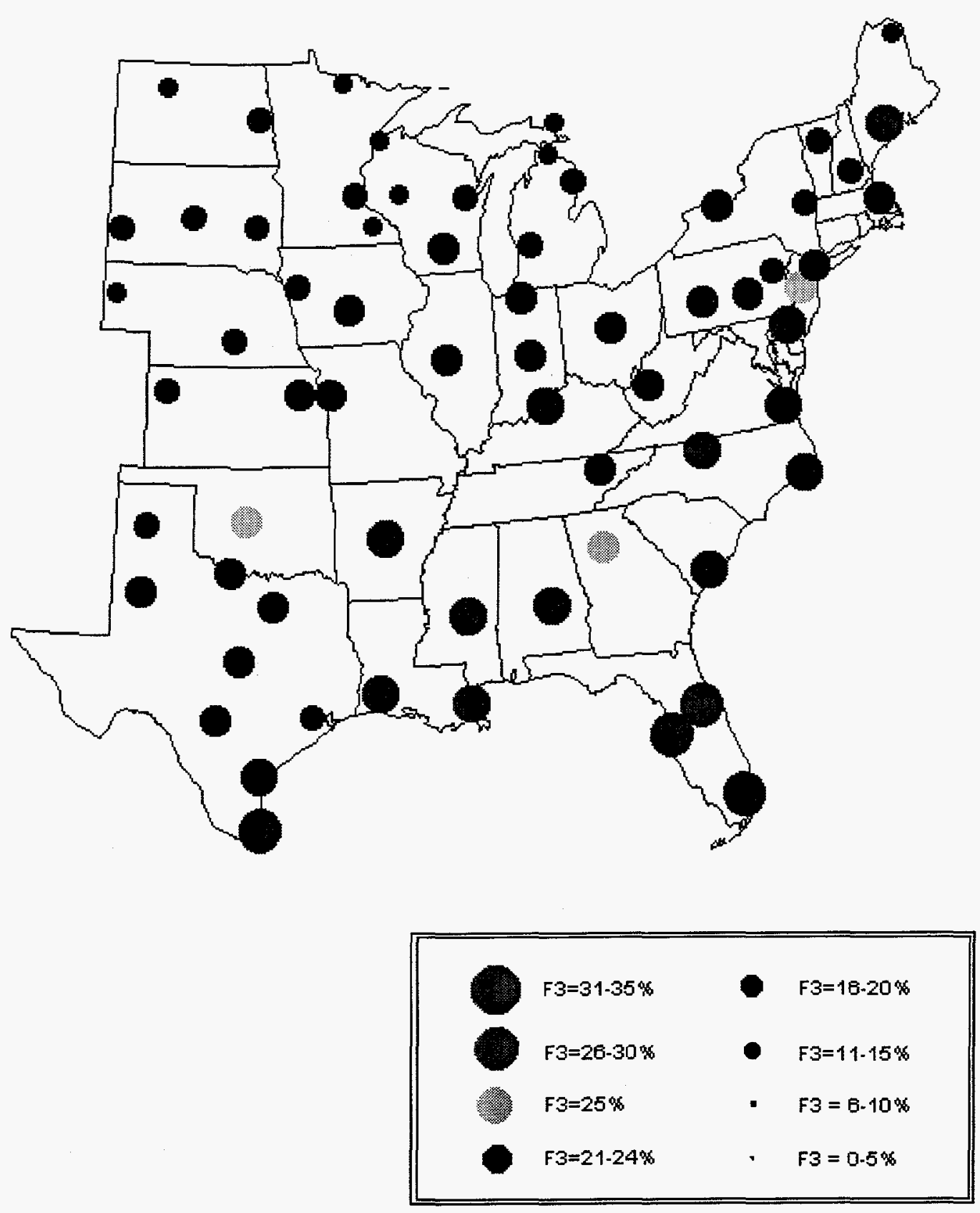
Thermal Performance of a Three-Season System Based on a Four Season System Meeting $50 \%$ of the Annual Load (Western United States)

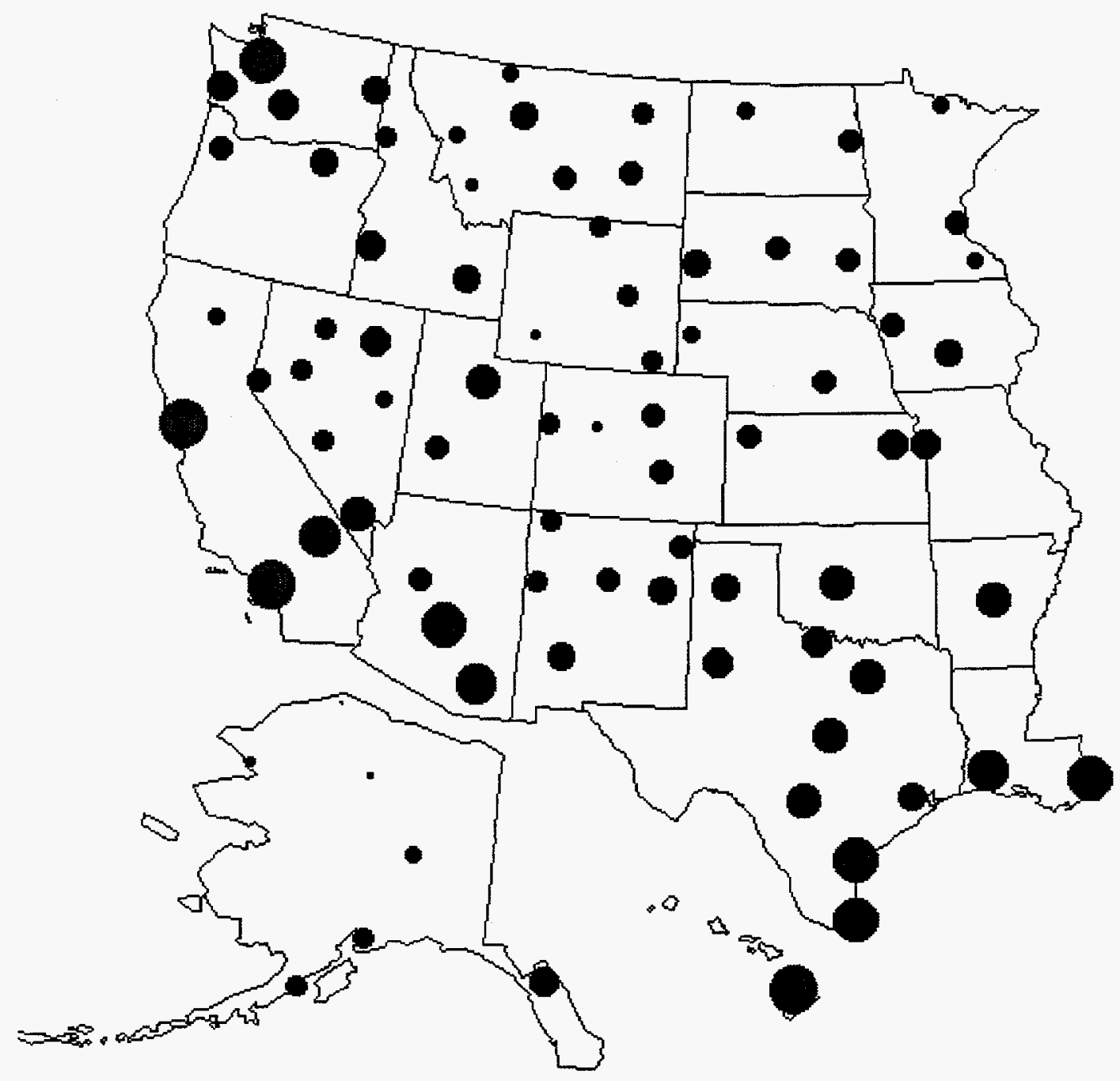


Thermal Performance of a Three-Season System Based on a Four Season System Meeting $50 \%$ of the Annual Load (Eastern United States)
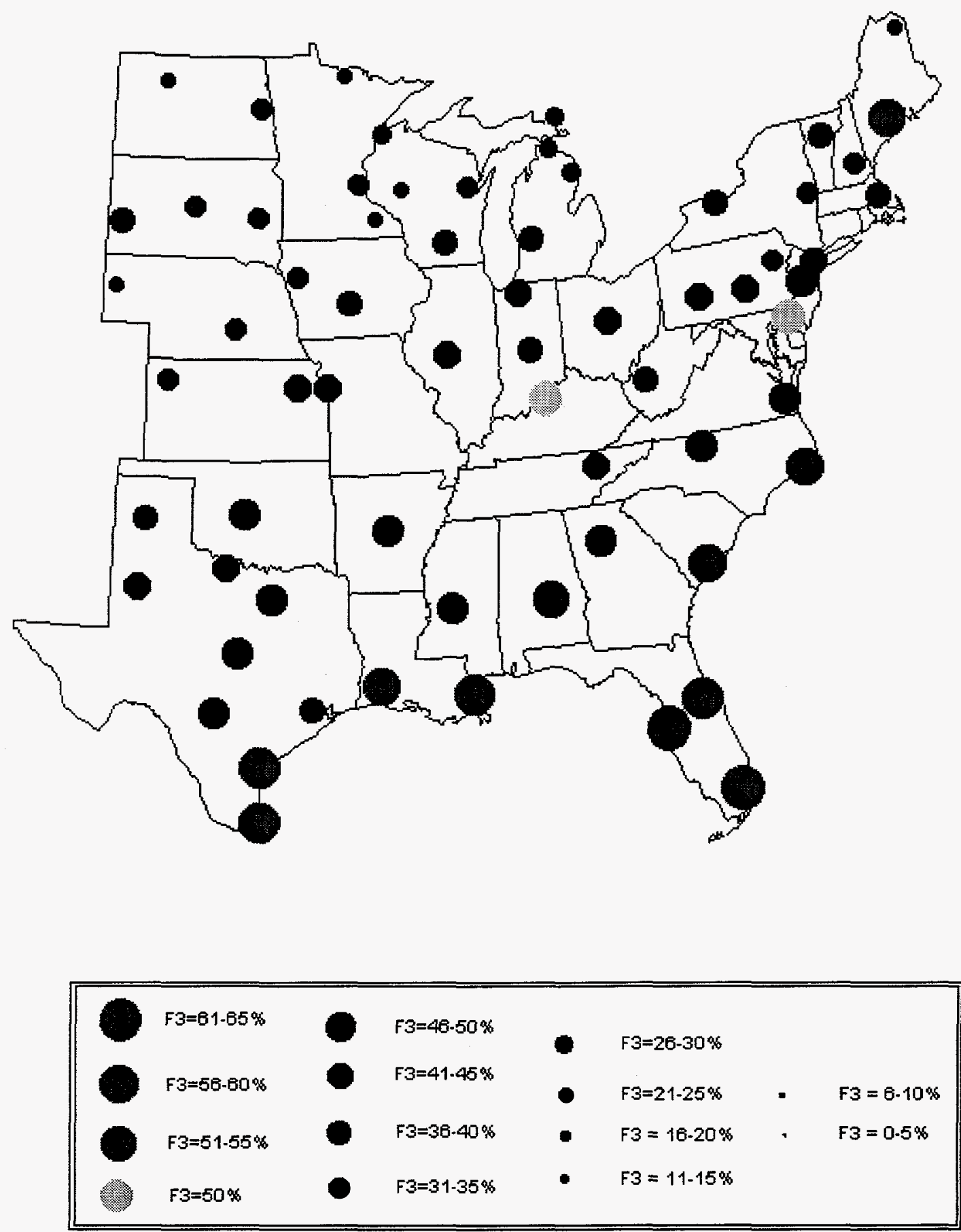
Thermal Performance of a Three-Season System Based on a Four Season System Meeting 75\% of the Annual Load (Western United States)

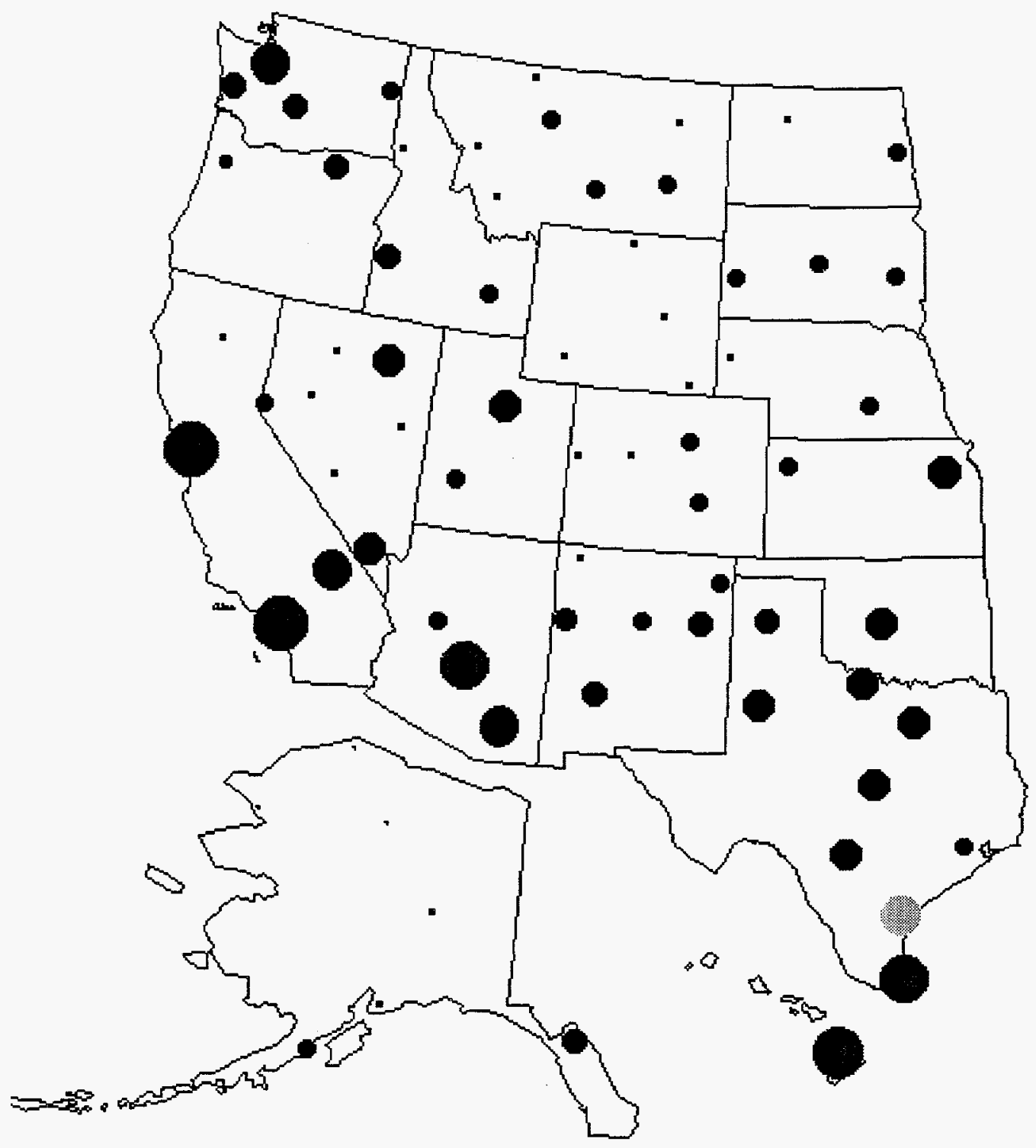


Thermal Performance of a Three-Season System Based on a Four Season System Meeting $75 \%$ of the Annual Load

(Eastern United States)
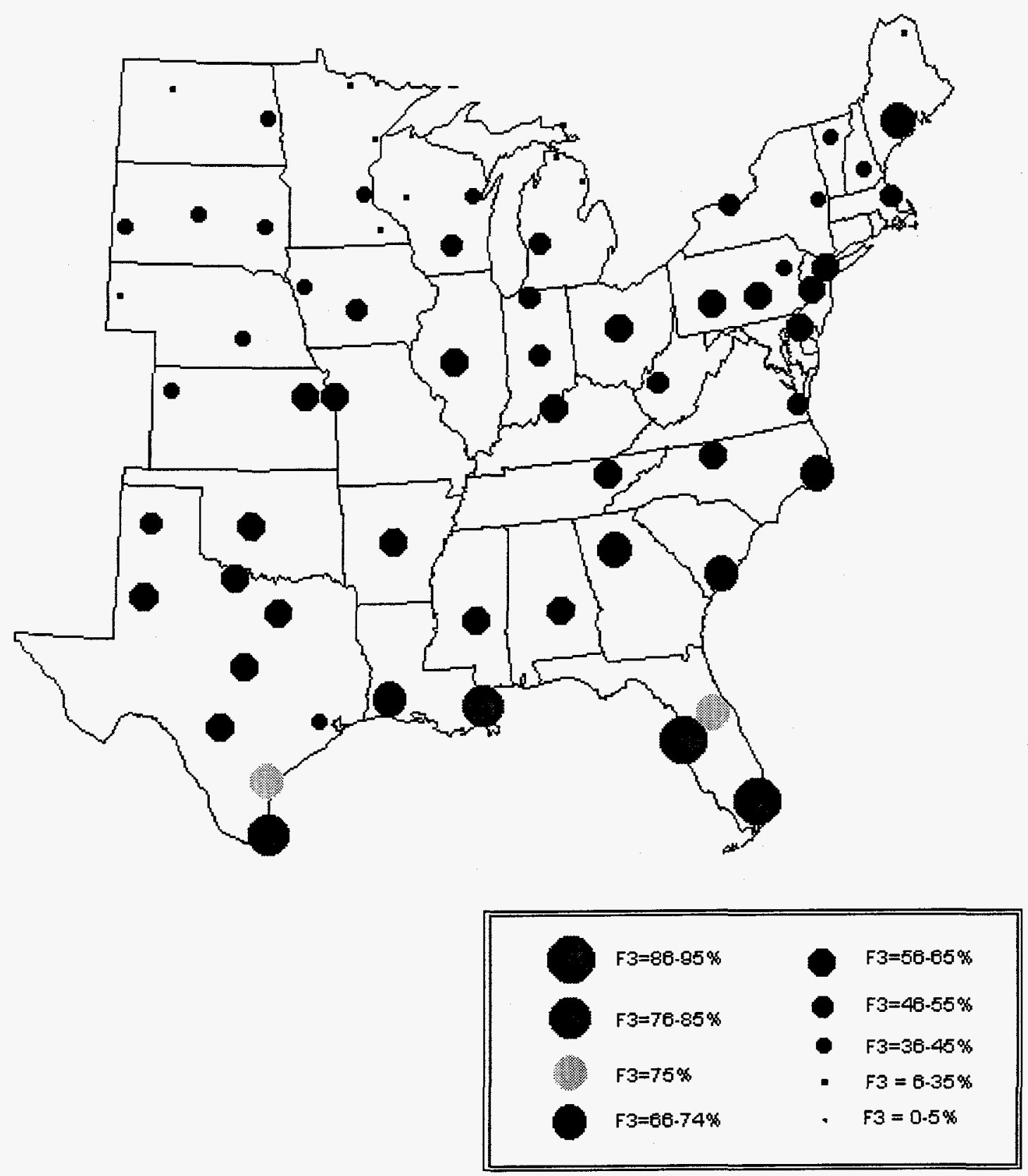


\subsection{Discussion}

There were no huge surprises in the thermal analysis of three-season systems.

There was, as expected, a decrease in annual solar fraction for most locations associated with shutting down the system for a certain portion of the year. Furthermore, the penalty was closely related to the length of shutdown, modified somewhat by the relative cloudiness of the location during the shutdown time. The cloudier a region during the winter, the less solar energy is available for collection to the four-season system and the smaller the penalty to shutting down. In a clear winter location there is a lot of energy to be collected during the off months, and the four-season system comes out ahead.

Examination of the thermal penalty maps, however, indicates some interesting trends. Three-season system solar fractions in maritime and southern locations tend to be either slightly less than or slightly greater than the four-season system solar fractions. This trend makes some sense in that freezing is rare in southern locations, and the energy lost by shutting down the system for the one month when freezing is a problem, is preferable to losing energy in a heat exchanger all year long. As to the maritime locations, the ocean provides temperature regulation, which means warmer winter temperatures. Furthermore, as cold inland air meets the warmer moist air near the ocean, clouds form and keep the winter clearness indices low (Lutgens and Tarbuck, 1995). The total amount of energy collected during the winter months by the four-season system is almost the same as the energy lost in the heat exchanger throughout the entire year. Thus removing the heat exchanger and shutting down the system for a portion of the year has 
little or no adverse effect upon the thermal performance of the system and has a positive effect upon the cost of the system.

The second category of locations are those in which the three-season system alternative is undesirable due to a significant thermal penalty. Predictably inland locations in Alaska fall into this category. In these locations, the freeze free period is so short (sometimes as short as a single month) that the three-season system has no hope of comparing favorably. Coincidentally, the same locations are poor candidates for SDHW anyway and the question of whether to install a three or four-season system is somewhat overshadowed by the decision whether or not to install an SDHW system at all. It should be stated that the results for any location with latitude of greater than $66^{\circ}$ should be taken with a grain of salt as the equations for absorbed solar radiation begin to break down at this point. The complication arises from the fact that above the Arctic Circle, the sun never sets during part of the summer and never rises during part of the winter. The other locations in which three-season systems are a bad choice tend to be high altitude locations in the Rocky Mountains. Again the sheer length of the winter severely limits the ability of the three-season system to perform.

The final category is by far the largest and contains those locations in which there is a significant but not detrimental penalty to running a three-season system. The category can be divided into two subcategories. The first subcategory contains locations in which the thermal penalty is slight enough that you would definitely choose a threeseason system with its lower first cost. In the second, the thermal penalty is significant 
112

enough that a system designer would have to look carefully at local economics to make a decision. Favorable economic conditions such as high summertime electricity prices could make an otherwise thermally poor choice work well.

The thermal penalty maps also shed light on some interesting features of the three-season system alternative. In the maps based upon a four-season $25 \%$ system, general weather trends are visible in the performance of the three-season systems. The high altitude Rocky Mountains can be seen as a diagonal line of poorly performing locations stretching from Montana southeast into Colorado. The warm southeastern United States can also clearly be seen. In a great number of locations, these small area three-season systems perform better than their four-season counterparts, and would cost less to install. If there is a thermal penalty associated with the three-season system, it tends to be small.

As the system size increases to meeting near $50 \%$ of the annual heating load, local weather conditions become more important than general geographic areas. It is more difficult to divide the country into a few well-defined zones because there are outlying results scattered throughout. Another noticeable trend is that the size of the three-season thermal benefit zone in the southeastern United States has begun to shrink.

As system size passes $F=50 \%$, the three season alternative becomes less and less attractive and the thermal penalties are accentuated. Of course the locations in which freezing is a rarity will still perform well but it can be plainly seen from the map that the 
three-season system penalty is detrimental in all but the southeast. The reason behind the accentuated penalty is that the larger the collector area, the more energy is collected. Since the load remains unchanged, the four-season system is able to overcome the heat exchanger penalty essentially by collecting a surplus of energy and then throwing away the unnecessary portion through the heat exchanger. Were it not for the heat exchanger, the tank water would be continually above the set point temperature. Increasing the area of the three-season system, on the other hand, means that the winter down time becomes more costly from a thermal point of view.

There are a number of sources of error involved with the $f$-Chart results that bear mention. First, the results are only as good as the confidence in the radiation data, which is somewhat shaky (see section 4.3). However, since this analysis is primarily a comparison of SDHW system alternatives, both of which were subjected to the same (perhaps incorrect) weather conditions, this source of error is less important. Second, most of the locations used were in urban areas that tend to be slightly warmer than the surrounding countryside. This heat island effect means that the results indicated for Chicago, IL may not apply well just outside of Chicago. Lacking environmental data for the surrounding areas, there is really no cure for this source of error. The designer should, however, be aware of its existence and should allow for some safety factor in predicting three-season performance near large urban areas. Lastly, the $f$-Chart performance prediction results are intended to be 10 -year average results and there may be some significant variation from year to year depending on current conditions. 


\subsection{Conclusions}

The $f$-Chart method has left us with a thorough analysis of the thermal penalty incurred by choosing to run an SDHW system without a heat exchanger for only those months during which freezing is not a worry. A system designer is able to use the generated maps in section 4.6to get a good feeling for the practicality of installing a three-season system in a given location. The locations on the map divide themselves into approximately three categories. First, there are a number of southern and maritime locations in which a three-season system has a higher annual solar fraction. At the other end of the spectrum, there are high latitude and high altitude locations in which the threeseason system is barely turned on at all and performs abysmally. The large majority of locations fall into the third category, which is made up of locations in which the thermal penalty is an issue, but is not huge. In these locations the designer would probably need to examine local economics to determine whether the thermal penalty is warranted by the potential decrease in system initial cost and in system operating cost.

For all the success that was met using the $f$-Chart method, there are some important shortcomings. First, it would be helpful if the $f$-Chart results could be confirmed by some other means short of a ten-year experiment in order to increase the confidence with which the results are presented. Second, $f$-Chart is limited to modeling a few standard system configurations and there are a number of variations to the general three-season system design which are worth investigating. A third problem is the confidence level in the weather data. These data were not measured; they are based upon measurements at a few locations and were then interpolated using related data in order to 
obtain the final set for 230 locations. Recent radiation measurements have shown the data set to have some serious inaccuracies, however, it is the best weather data available. In order to draw conclusions confidently from the results presented in this chapter, it is necessary to repeat them using a method different from $f$-Chart. 


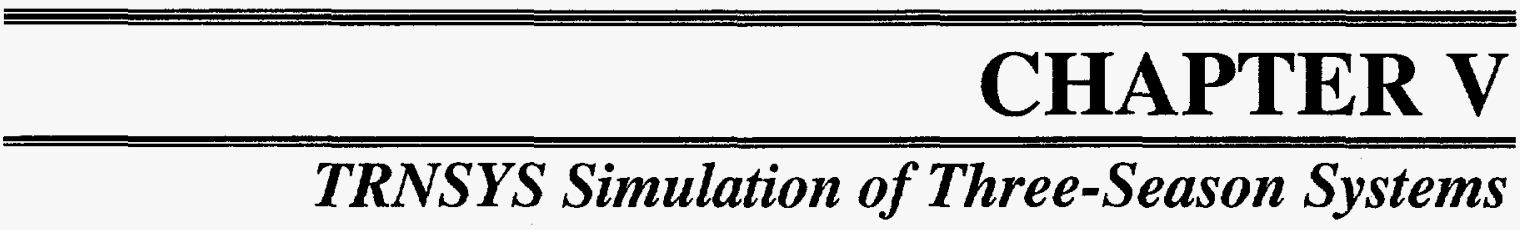

\subsection{Introduction}

The thermal penalty maps previously presented give a general feel for the performance that can be expected from a three-season system. However, they are limited in part by the method used to create them. A number of hourly simulations were carried out using TRNSYS in order to both confirm and extend the conclusions drawn from the maps. Specifically, the benefit of recirculating storage tank water through the collector in order to gain an extra month at either end of the operating period was examined. The idea is that a place such as Madison, WI has a six-month down time (November through April) in which freezing may occur. During the two swing months, one at either end of the freezing period, the days may well be warm and sunny enough to collect a sizeable amount of solar energy while the nights are still freezing. Under the assumptions made in the previous chapter, these months are unacceptable for a three-season because of the nighttime freezing. Yet if substantially more energy can be collected during the daytime than is needed to keep the collector free of ice at night, then the performance would benefit from the more complex control strategy. 


\subsection{TRNSYS versus $f$-Chart}

To this point, the $f$-Chart method of estimating thermal performance has been adequate. However, it is unable to model the effects of freeze protection by recirculating tank water. The $f$-Chart method was developed at a time when computers were of limited availability. Its strength lay in its ability to accurately estimate annual performance with only twelve calculations, one for each month. Because of this, however, there are limitations as to the systems that can be modeled. Because the $f$-Chart method is based on the correlation of a large amount of calculated thermal performance data, the type of system that generated the data is intrinsically embedded in any estimations that are made using the method. Thus there is an $f$-Chart correlation to be used for liquid systems, a correlation for air systems, and a correlation for space heating systems. Each system is set up to operate in some manner and none of the basic correlations include recirculated tank water as a method of freeze protection.

With the current power and availability of computers, it is no longer as necessary to look for estimation methods. TRNSYS software, for example, allows hourly simulation and can run a year of thermal performance in less than five minutes (Klein, S.A. et al., 1997). Such a program also allows greater flexibility in the type of system to be modeled. In this case, TRNSYS was used to model a system that can be turned on or off at any hour during the year. It both backed up the conclusions drawn from using the $f$-Chart method and allowed examination of systems controlled in a more complex manner than simply "on" during summer or "off" during winter. 
118

\subsection{The TRNSYS Deck}

TRNSYS is an hourly simulation tool in which various existing FORTRAN subroutines are linked together in order to model a thermal system, in this case, an SDHW system (Klein, S.A. et al., 1997). Each subroutine is called from a block of code called a TYPE which includes a list of parameters (constants describing the piece of equipment), and a list of inputs to that equipment (which tend to be the outputs of another TYPE.) The entire list of subroutine calls is created in an interface program called TRNSHELL and makes up the input statements to TRNSYS. The list of input statements is referred to as a DECK. The deck used in this simulation consisted of a TYPE 1 Solar Collector, a TYPE 5 Heat Exchanger, a TYPE 60 Stratified Fluid Storage Tank, two TYPE 3 pumps, and a TYPE 2 controller (Figure 5.3.1).

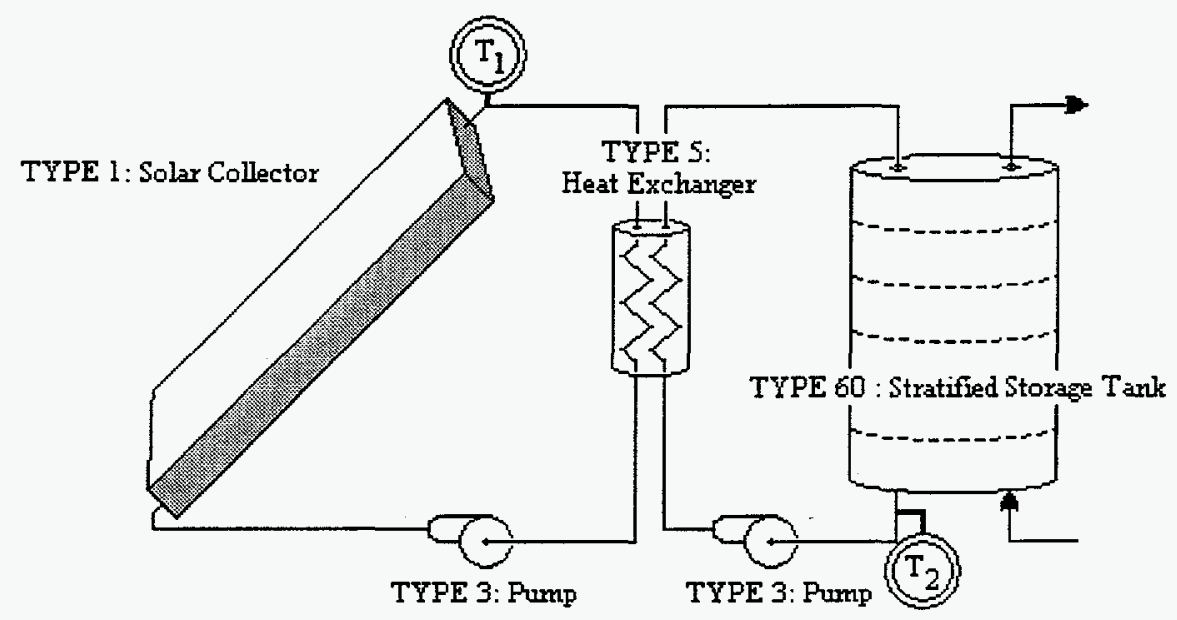

Figure 5.3.1: TRNSYS System Model

For clarity, the TYPE 2 controller is not shown in the figure but it compares the temperature at the outlet of the collector $\left(\mathrm{T}_{1}\right)$ with the temperature at the bottom of the 
storage tank $\left(\mathrm{T}_{2}\right)$ and turns on the TYPE 3 pumps if useful energy can be collected. In order to model the four season system, the heat exchanger was assumed to have a constant effectiveness of 0.2 (Buckles, 1983), and the $F_{R} U_{L}$ and $F_{R}(\tau \alpha)$ parameters of the collector were chosen to be 4.68 and 0.741 respectively, as in the case of the $f$-Chart model. Propylene glycol was circulated in the collector loop while water circulated in the tank loop (see Appendix C).

The three-season system was built on much the same model as the four-season system. The significant changes included: running water in the collector loop, removing the heat exchanger, changing the slope of the collector to the same three-season slope used in the $f$-Chart analysis, and adding a forcing function to the controller output that prevented the pumps from activating during the location's freezing season (see Appendix D).

The third deck, shown in appendix D, modeled a three-season system with recirculation. In this case, the down time was reduced by one month at either end over the nominal freeze period. Also, a second controller was added which looks at the outdoor ambient temperature and sends an "on" signal to the pumps if it falls below $5{ }^{\circ} \mathrm{C}$. The TYPE 3 controller sends an output of 1 for "on" and an output of 0 for "off." The specifics of making this work were slightly different as the TYPE 3 controller is only able to compare two temperatures and send a single output signal. Thus, one controller is set up to output a 1 if the temperature of water exiting the collector is higher than the temperature of water at the bottom of the tank. The other controller compares ambient 
temperature to $5{ }^{\circ} \mathrm{C}$ and outputs a 0 when the temperature falls below $5{ }^{\circ} \mathrm{C}$. The signal from the second controller is then inverted (made 0 if it was 1 and vice versa), and added to the signal of the first controller. The output is inverted because you want a temperature lower than $5^{\circ} \mathrm{C}$ to turn the pump on, not off. The output signal then carries a value of 0,1 , or 2 . The pumps are designed to turn on if this signal is greater than or equal to 1 , meaning that either a freezing condition, or above critical solar radiation is sufficient condition to turn on the pumps (Figure 5.3.2). There is a TRNSYS microprocessor controller type, which could have been used in this case, but it requires a complex set up and was discarded in favor of the simpler, two differential controller model. 


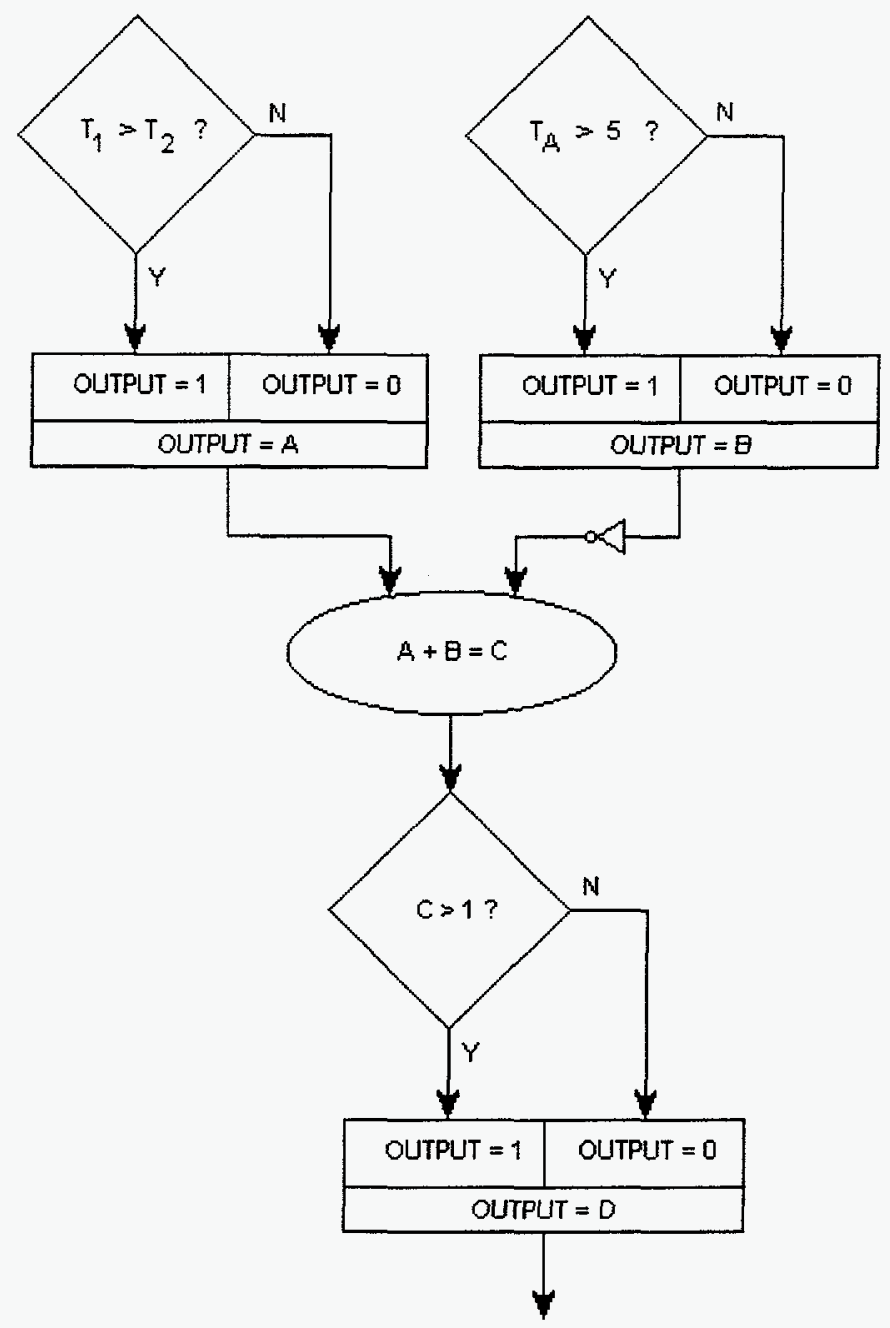

Figure 5.3.2: Two Controller Decision Making Process

\subsection{Results}

Simulation of the three and four-season systems using TRNSYS yielded a number of important results. Table 5.4.1 shows a comparison between $f$-Chart and TRNSYS results, indicating both that the $f$-Chart method used in producing the thermal penalty maps is valid and that the TRNSYS deck is properly modeling the desired system. 
Table 5.4.1: Comparison of TRNSYS and F-Chart Results for Madison, WI

\begin{tabular}{|c|c|c|c|c|}
\hline & \multicolumn{2}{|c|}{ F-Chart Results } & \multicolumn{2}{c|}{ TRNSYS Results } \\
\cline { 2 - 5 } & Four Season & $\begin{array}{c}\text { Three } \\
\text { Season }\end{array}$ & Four Season & $\begin{array}{c}\text { Three } \\
\text { Season }\end{array}$ \\
\hline Load [GJ/year] & 24 & 24 & 23.92 & 23.92 \\
\hline Auxiliary Energy [GJ/year] & 12 & 14.7 & 13.64 & 16.20 \\
\hline Annual Solar Fraction [-] & 0.5 & 0.39 & 0.43 & 0.32 \\
\hline Decrease [points] & \multicolumn{2}{|c|}{11} & \multicolumn{2}{c|}{11} \\
\hline
\end{tabular}

The second result of the TRNSYS simulation was an indication that recirculating tank water through the collector as a method of freeze protection in order to shorten the three season system's "off season" can have a number of different effects depending upon location (Table 5.4.2).

Table 5.4.2: Benefits of Recirculation in Various Locations

\begin{tabular}{|c|c|c|c|}
\hline Location & $\begin{array}{c}\text { Four Season } \\
\text { System Solar } \\
\text { Fraction }[-]\end{array}$ & $\begin{array}{c}\text { Three Season } \\
\text { System Solar } \\
\text { Fraction }[-]\end{array}$ & $\begin{array}{c}\text { Three Season } \\
\text { Recirculation } \\
\text { System Solar } \\
\text { Fraction }[-]\end{array}$ \\
\hline Madison, WI & 0.43 & 0.32 & 0.40 \\
\hline Caribou, ME & 0.48 & 0.24 & 0.36 \\
\hline Sault Sainte Marie, MI & 0.49 & 0.27 & 0.24 \\
\hline Denver, CO & 0.51 & 0.32 & 0.52 \\
\hline
\end{tabular}

Finally, TRNSYS was able to show that further shortening the "off season" gives diminishing returns in terms of annual solar fraction (Table 5.4.3). 
Table 5.4.3: Effects of Increasing the Length of the Recirculation Period

\begin{tabular}{|c|c|}
\hline System Type (Albuquerque, NM) & Annual Solar Fraction \\
\hline Four Season System & 0.57 \\
\hline Three Season System: June 1 - October 31 (no recirculation) & 0.32 \\
\hline Three Season System: May 1 - November 30 (recirculation) & 0.41 \\
\hline Tree Season System: April 1 - November 30 (recirculation) & 0.47 \\
\hline Three Season System: March 1 - November 31 (recirculation) & 0.51 \\
\hline
\end{tabular}

\subsection{Discussion}

One of the first difficulties encountered in corroborating and extending the conclusions drawn from using $f$-Chart lay in creating a TRNSYS model that yielded the same result as the $f$-Chart analysis. It must be kept in mind that $f$-Chart is a curve fit with a limited range of applicability while TRNSYS performs energy balances on each component at specified timesteps (usually one hour or less). Furthermore, the system configuration is built into the $f$-Chart model and cannot be changed without creating a different curve fit. However, it is important to compare the two results because they should be approximately equivalent. In table 5.4.1, it can be seen that for Madison $f$ Chart predicts a four-season annual solar fraction of 0.5 while TRNSYS gives a result of 0.43 for the same system. There are a number of possible reasons for such discrepancies.

The differences that arise between TRNSYS and $f$-Chart are numerous. First, there are some important differences in the two systems modeled. F-Chart assumes that there is a second storage tank (referred to as the solar preheat tank) and that the tank shown in figure 5.4.1 has no heating elements and simply feeds a standard water heater. 
124

Such a system has additional losses from the piping between the tanks and from the second tank itself. Furthermore, $f$-Chart assumes that both tanks are fully mixed, having no thermal gradient along the vertical axis. The TRNSYS system, however, includes a stratified storage tank. It is possible to use a fully mixed tank in TRNSYS but the benefit of a stratified tank is that the hottest water is delivered to the load while the coldest water is returned to the collector. Such a strategy increases the efficiency of the collector and decreases the load on the auxiliary heaters.

Another difference between TRNSYS and $f$-Chart arises in the calculation of losses and loads. The governing equation for energy loss from a tank is shown below in equation 5.5.1. F-Chart conservatively calculates the temperature difference as the set point temperature of the heater minus the environmental temperature of the tank. TRNSYS, on the other hand, calculates the temperature difference as the average of the inlet and outlet temperatures minus the environmental temperature. TRNSYS allows that if the temperature of fluid near the top of the tank exceeds the set point, the losses will be greater while $f$-Chart assumes there to be an upper bound on losses. Since the heaters in the tank maintain the set point temperature, there is never a situation in which TRNSYS calculates a lower energy loss from the tank.

$$
E=U A \Delta T
$$

Furthermore, $f$-Chart allows the user to change the losses from only the waterheating tank. The losses from the solar preheat tank cannot be changed. Since the TRNSYS model only contained one tank, the losses for the two models are different. 
Loads are also calculated with similar differences. In $f$-Chart, the load is defined as the difference between the temperature set point and the temperature of the mains water multiplied by the specific heat of the fluid (Equation 5.5.2). In TRNSYS however, the load is the difference in energy levels of the mains water and the water exiting to the load. If the fluid near the top of the tank is hotter than the set point temperature, then the load is increased, which makes sense as it represents the actual amount of energy delivered to the load. The hotter water may have to be mixed with cold water in order to avoid scalding in which case it appears to be thrown away. However, the hotter temperature means that the draw from the tank will be proportionally decreased.

$$
\mathrm{L}=\mathrm{C}_{\mathrm{p}} \Delta \mathrm{T}
$$

Creating the TRNSYS models had two benefits. First, it made sure that the $f$ Chart results were reasonable and obtainable through other, similar means. However, the true purpose of this exercise was to examine the effects of more complicated control strategies. The maps of thermal penalty can be loosely divided up into three categories. Locations in which a three-season system actually performs better than a four-season system, locations where the thermal penalty is very large, and locations where it could go either way depending on a number of externalities such as economics or clever control strategies. One such control strategy is tank water recirculation.

The reason for having to shut down the system during the winter is obviously that freezing can damage the collector or the piping. The downtime, as previously mentioned 
is highly dependent upon the length of the freezing season. However, the beginning and end of the freezing season do not occur all at once, meaning that the system does not go from a constantly positive temperature to a constantly negative temperature environment all at once. For a time, the nights may be cold and the system freeze prone while the days may still be warm and sunny. At these times shutting the system down because of nighttime freezing may waste a great deal of potentially collectable energy. One method of avoiding this problem is to circulate comparatively warm water from the bottom of the storage tank through the collector whenever the environmental temperature is lower than freezing plus some factor of safety $\left(5^{\circ} \mathrm{C}\right.$ in this case). The recirculation prevents ice from forming assuming that the freezing danger isn't so great that the warmer water is cooled down to zero. If the amount of solar energy collected by the system during the day significantly exceeds the amount lost at night, then the control strategy will recuperate some of the thermal penalty paid by removing the heat exchanger from the system and running for only three seasons.

A number of different situations can arise, as shown in Table 5.4.2. In most locations, running the three-season system for an extra two months will greatly improve the system's annual solar fraction. In some cases, it may even improve the three-season system performance beyond that of the corresponding four-season system. One might expect a place such as Denver, $\mathrm{CO}$, which has a high winter clearness index but a long freeze period, to be a good example. TRNSYS indicates that a four-season system installed in Denver and meeting $51 \%$ of the annual load has a three-season solar fraction of $32 \%$. Adding recirculation to the three-season system increases the annual three- 
season system solar fraction to $52 \%$, slightly higher than that of the four-season system. In such a case, it may be worthwhile to add a second month on either end of the freeze period in the hopes of further increasing the solar fraction.

At some point, however, the ambient temperature will drop low enough for an extended period of time such that the losses would be greater than the benefit. While the recirculating system does not actually perform better than its four-season counterpart in Albuquerque, New Mexico, the diminishing return of decreasing the freeze period can be seen in Table 5.4.3. In March and April, the losses to the cold environment are increasingly large in comparison to the amount of energy that can be collected during the days.

The last situation occurs in locations that have cloudy, cold winters. In this case, the recirculation will further degrade the solar fraction. Such places tend to be extremely poor candidates for solar anyway and only extremely favorable economic incentives can make solar profitable. Table 5.4.2 indicates that in Sault Saint Marie, Michigan, adding extra months to the system's running time further degrade the annual performance. If solar is to be considered at all, a three-season system with a shorter on time might be considered.

\subsection{Conclusions}

A number of important results arise from analyzing the three-season system concept using an hourly simulation tool such as TRNSYS. First, it can be seen that the $f$ - 
Chart method is an acceptable tool to use in predicting the basic thermal performance of a three-season system. Since $f$-Chart predicts the annual performance of an SDHW system in a given location within a few seconds, it lends itself well to analysis of a large quantity of locations. TRNSYS, which takes on the order of minutes to complete an analysis, would be a much more cumbersome tool to use.

Second, TRNSYS allows the analysis of more complex control schemes than are included in $f$-Chart. Specifically it has been used to examine the effect of using storage tank water recirculated through the collector during freezing periods in order to extend the system's operating period. From the results it can be seen that this strategy has both benefits and drawbacks, depending primarily on location. In some cases, extending the operating time will reduce the penalty paid in annual solar fraction because enough energy is collected during daylight to more than offset the losses associated with cooling tank water by exposure to ambient during freeze periods. In a very few locations, collecting during two extra months adds enough energy to offset both the losses during the months and the losses associated with the four-season system's heat exchanger. In these cases, the three-season solar fraction is higher than that of the four-season system. There are also locations in which three-season systems do not benefit from recirculation and exhibit further penalty in annual solar fraction. In these locations, the operating period of the three-season system can be shortened in order to decrease the annual solar fraction penalty. 
$\frac{\text { CHAPTER VI }}{\text { CHAse Study: Wisconsin Electric Power Company }}$

\subsection{Introduction}

As yet, very little mention has been made of utility involvement or interest in SDHW systems. Part of this project's motivation, however, was to examine such a possibility. With the increase in popularity of residential air conditioning, electric utilities often experience their highest demand in the summer on the third or fourth consecutive hot day. The utility needs to be able to meet the peak demand by having enough generating plants available or by being able to purchase power from another utility. Since almost all utilities in the country are summer peaking however, not all of them can purchase the extra power needed to meet the peak demand (Cragan, 1994). At some point in the chain, there needs to be extra generating capacity that is used during the summer and sits idle during the rest of the year. While idle, however, these plants still need to be maintained, which costs the utility money and leads to the increased cost of electricity during the summer.

If, however, a large number of houses in the utility's service district have solar water heating systems installed then there is in essence a diversified power generator capable of reducing the peak demand seen by the utility. Peak demand reduction is 
130

accomplished by the SDHW systems meeting the service area's water heating demand and allowing the utility to concentrate on the air conditioning demand.

The benefit of utility involvement in SDHW is not limited to the utility itself. As previously mentioned, one of the obstacles to solar energy's market penetration has been high initial costs and the nonexistence of a maintenance network (Peters, Robison and Winch, 1997). Since the utility would benefit from a large-scale SDHW initiative however, they stand in a position to promote it as well. The utility could purchase a large number of SDHW systems and lease them to customers for a monthly fee. Ideally, the customer would see a decrease in electric bill, would not have to spend a large amount of money to install an SDHW system, and would be able to call upon the utility for maintenance issues. There are also obvious benefits to the environment as well stemming from reduced $\mathrm{CO}_{2}, \mathrm{SO}_{2}$ and many other chemical emissions.

A fair amount of research has been done to date concerning the idea of a large scale SDHW initiative by a utility. Cragan investigated a number of economic issues involved with the problem and worked out the basics of modeling the economic and energy impact on the utility (Cragan, 1994). Trzesniewski then extended the work and wrote a TRNSYS based program called EUSESIA which performs an impact evaluation (Trzesniewski, 1995). Because of its basis in TRNSYS, EUSESIA can be used to characterize the impact of any SDHW system design. It was used to investigate the impact of photovoltaic heated water systems on a utility (Williams, 1996) and it lends itself perfectly to investigating the impact of three-season systems as well. 
For the purposes of this analysis, a utility in Milwaukee, Wisconsin was chosen. A Wisconsin location offers a number of advantages. First, it is not an area of the country that is likely to be thought of as a great place for solar. Furthermore, it has a significant thermal penalty associated with choosing a three-season system. Showing that a three-season system works well from an economic standpoint in such a location therefore carries more weight. Milwaukee was also chosen because of data availability. Data files containing actual (not generated) 1991 weather data and utility load data were available for the Wisconsin Electric Power Company (WEPCO), located in Milwaukee.

\subsection{The Three-Season System from a Utility's Point of View}

To this point, the three-season system has been analyzed and evaluated from a single consumer's point of view. The economic analysis showed the dynamics of an SDHW recuperating its initial cost by saving the homeowner money on monthly fuel bills. These dynamics change when the system is owned by a utility. First, the income producing flag $\mathrm{C}$ in equations 3.2 .7 and 3.2 .8 changes from 0 to 1 , adding more terms to and decreasing the values of both $\mathrm{P}_{1}$ and $\mathrm{P}_{2}$. The life cycle savings will go up or down depending on whether $\mathrm{P}_{1}$ or $\mathrm{P}_{2}$ decreases more. Second, while tax incentives for solar installations are no longer available to individuals, they are still available to businesses, including utilities, further increasing solar's attractiveness. These economic factors affect both the three and four-season SDHW systems. However, there are important differences that may make one system a more attractive alternative. 
Three-season systems offer a utility a number of benefits over four-season systems. Interestingly the benefits are much the same as for individual customers but since many systems are involved, have much higher value. Foremost, the three-season system costs less to install, having less equipment. Saving $\$ 500$ per system on 1000 systems in the service district is a very big incentive. Second, the systems run solely on water and therefore the glycol charge never has to be checked or topped up, saving the utility one service call per system each year. Maintenance costs on the three-season system will also theoretically be lower as the system is off for half the year. All the while, there is no reason that the utility would decrease the monthly lease rate on the system. The overall effect is that the utility's profit margin is higher for a three-season system than for a four-season system. Another advantage of the three-season system is that most utilities need extra generating capacity only during the summer. Since the three-season system only operates during these times, its output is more tailored to the utility's needs.

The disadvantage of a three-season system is that it requires at least two service calls each year: once in the spring to turn it on, and once in the fall to shut it down. Theoretically, the four-season system would only require a check up service once a year to ensure that it is operating as intended. 


\subsection{EUSESIA}

EUSESIA performs an economic impact analysis of a diversified energy generator on either a single utility or on a consortium of utilities. The second option takes into account the fact that a utility is one of a group and can purchase power to meet its energy demand from neighboring utilities.

Performing an EUSESIA analysis involves a number of steps. First, a TRNSYS deck is created that models the solar alternative currently under investigation. The output of this deck must be a file that shows the hour of the year, and the electric demand of the solar alternative. Second, a deck must be run that will provide the basis of comparison. The deck edhw.trd models an electric domestic water heater with which any solar alternative can be compared (Trzesniewski, 1995). Its output file also shows each hour of the year and the system's energy demand.

The next step in performing an EUSESIA analysis is to characterize the utility by examining its load and determining the order in which it will turn on their various generating facilities. To do so, marplant.trd is run to determine the marginal plant at each hour of the year (Trzesniewski, 1995). The marginal plant is a schedule that determines the order in which plants will be brought on line to meet the demand. It takes into account the total demand upon the utility at each hour of the year, the operating costs of each generating plant in the area, and all the scheduled plant outages due to maintenance. The marginal plant is determined to be the next least expensive plant to operate that is not already running. 
Once the marginal plant schedule has been created for the location in question, another TRNSED deck (utility.trd) is used to determine the energy contribution from a large number of SDHW systems. Utility.trd (Trzesniewski, 1995) calculates the difference in demand between the solar alternative and the electric heated base case, and determines the amount of money that the solar alternative saves the utility. The savings are then used in a $\mathrm{P}_{1} \mathrm{P}_{2}$ analysis that takes into account the utility's required capital investment in order to offer the SDHW program. An output file shows a detailed analysis of the energy saving and economic benefits of the SDHW alternative.

\subsection{WEPCO Impact Analysis Results}

The EUSESIA analyses compared both a four-season and a three-season SDHW system ensemble with conventional EDHW systems. There were assumed to be 1000 such SDHW ensembles in the WEPCO service area. Table 6.4.1 shows the differences between the two installations.

Table 6.4.1: Three and Four-Season System Parameters

\begin{tabular}{|c|c|c|}
\hline & Three-Season System & Four-Season System \\
\hline Collector Slope (degrees) & 35 & 40 \\
\hline System Installed Cost $(\$)$ & 1500 & 2000 \\
\hline System Maintenance Cost (\$yr-system) & 15 & 30 \\
\hline
\end{tabular}

Figures 6.4.2 and 6.4.3 show the EUSESIA results for both the three and fourseason system. The three-season system had the same collector area but was sloped at $35^{\circ}$ in accordance with the three-season optimum. 
Electric Utility Solar Energy System Impact Analysis:

Impact of a Large Scale Impiemention of a Solar Energy System on an Electric Utility

$\star \star \star \star * *$ Energy and Environmental Impact Summary for the First Year $* * * * *$ Resuits based on: 1000 solar systems

$\begin{array}{ccc} & \text { Energy Reduction }(\mathrm{kWh}) & \text { Energy Savings }(\$) \\ & 4006710 . & 64672 . \\ \text { CO2 } & \text { Emission Reduction }(\mathrm{Ibm}) & \text { Enission Savings }(\$) \\ \text { SO2 } & 4679570 . & 0 . \\ \text { NOX } & 34608 . & 692 . \\ \text { N20 } & 22594 . & 0 . \\ \text { Parts } & 74 . & 0 . \\ \text { CH4 } & 1943 . & 0 . \\ \text { HG } & 48 . & 0 . \\ \text { NUKES } & 0 . & 0 . \\ & 0 . & 0 .\end{array}$

Demand Reduction ( $k w$ ) Demand savings ( $\$$ )

619.

Total Savings $(\$)$

86604 .

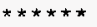 \\ Economic Analysis Summary}

Present Worth of Investment

Present Worth of OM\&A

Present worth of Energy Savings

present Worth of Emission Savings

Present Worth of Demand Savings

Present worth of Depreciation

Present Worth of Downpayments

Eresent worth of Lease Payments

Present worth of Tax Credit

Present worth of Energy Subsidy

Present Worth of Customer Retention

Present Worth of Delay Value

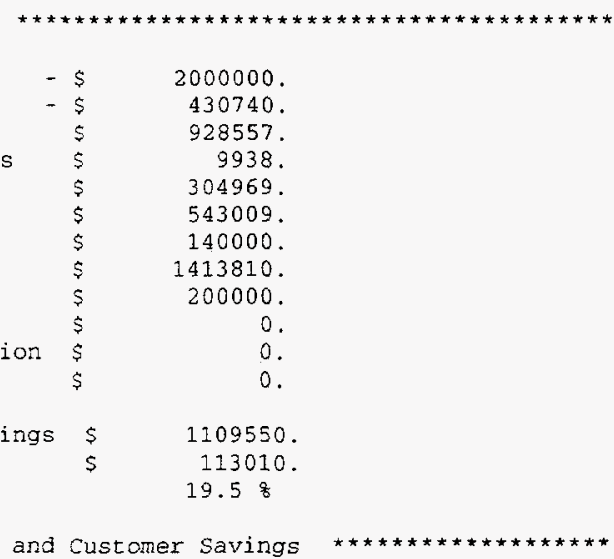

Present worth of Life Cycle Savings $\$ 1109550$.

Levelized Savings of Option $\$ 113010$.

Rate of Return of option

****** System Performance Summary and Customer Savings

Results based on average system performance

$\begin{array}{lccccr} & \text { Elc (kWh) } & \text { Sol }(\mathrm{kWh}) & \text { Dei }(\mathrm{kWh}) & \text { SF } & \text { Savings }(\$) \\ \text { JAN } & 489 . & 247 . & 242 . & .495 & 15.49 \\ \text { FEB } & 437 . & 148 . & 289 . & .660 & 18.46 \\ \text { MAR } & 475 . & 164 . & 311 . & .655 & 19.92 \\ \text { APR } & 446 . & 84 . & 363 . & .813 & 23.21 \\ \text { MAY } & 438 . & 68 . & 370 . & .844 & 23.66 \\ \text { JUN } & 414 . & 17 . & 397 . & .959 & 29.60 \\ \text { JUL } & 415 . & 20 . & 395 . & .952 & 29.46 \\ \text { AUG } & 419 . & 34 . & 385 . & .919 & 28.71 \\ \text { SEP } & 428 . & 56 . & 372 . & .869 & 27.73 \\ \text { OCT } & 460 . & 161 . & 299 . & .650 & 19.12 \\ \text { NOV } & 459 . & 276 . & 182 . & .397 & 11.65 \\ \text { DEC } & 478 . & 275 . & 204 . & .426 & 13.03 \\ & & & & & \\ \text { YEAR } & 5358 . & 1550 . & 3809 . & .711 & 260.04\end{array}$




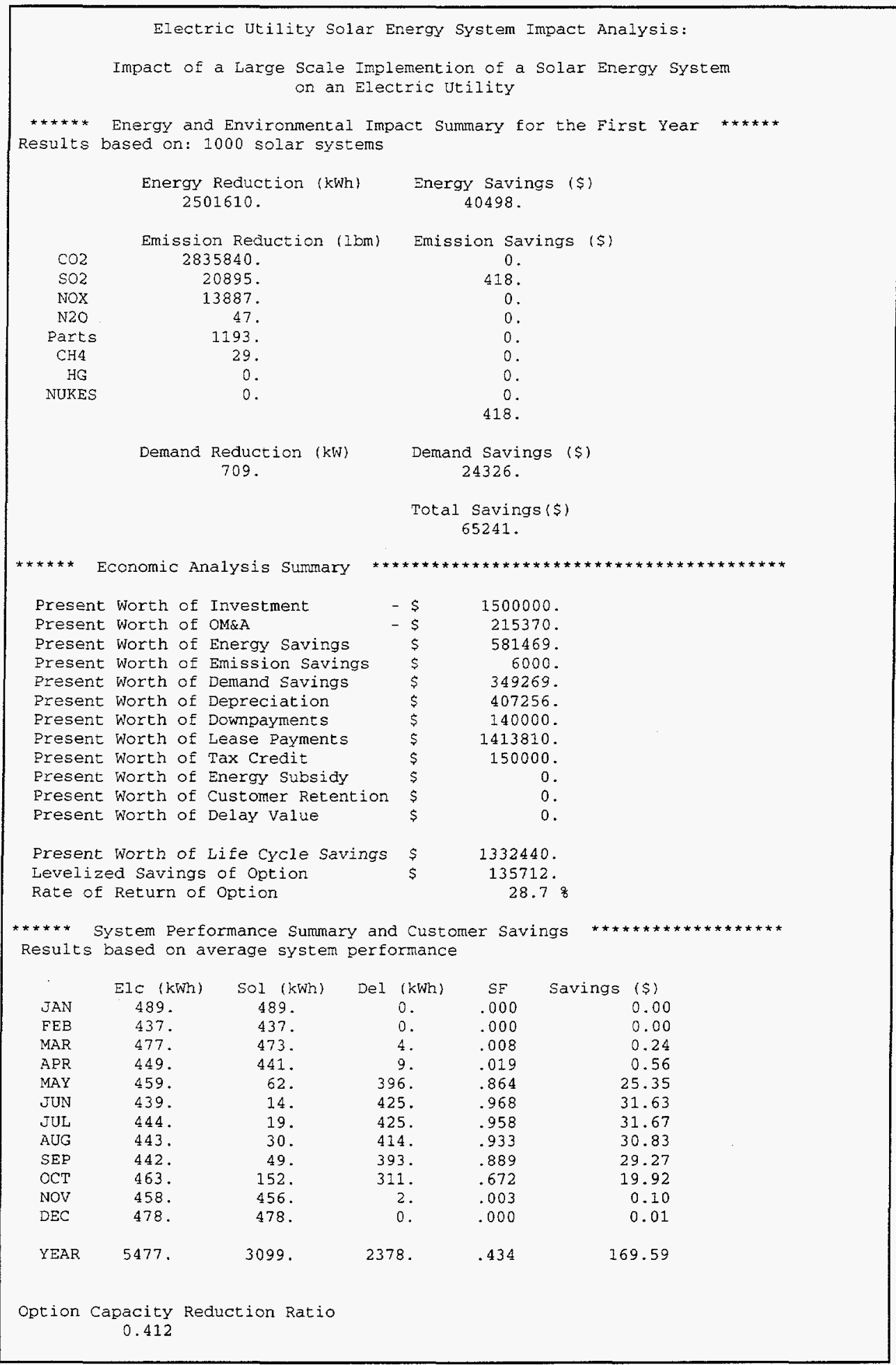

Figure 6.4.3: EUSESIA Analysis Output for a Three-Season SDHW Installation 
Table 6.4.1 highlights some of the important results of the EUSESIA analysis.

Table 6.4.1: Highlighted Results of EUSESIA Analysis

\begin{tabular}{|c|c|c|}
\hline & Four-Season System & Three-Season System \\
\hline Energy Reduction (kW-hr) & $4.0 \times 10^{6}$ & $2.5 \times 10^{6}$ \\
\hline $\mathrm{SO}_{2}$ Emissions Reduction (lbm) & 34608 & 20895 \\
\hline Demand Reduction (kW) & 619 & 709 \\
\hline Rate of Return (\%) & 19.5 & 28.7 \\
\hline Capacity Contribution Index (-) & 0.363 & 0.412 \\
\hline
\end{tabular}

There are a number of interesting results to the EUSESIA analysis, which highlight the comparative benefits of the three-season system. From an energy standpoint, the four-season system ensemble reduces the annual energy requirement on the utility more than the three-season system ensemble. If, however, only the peak demand periods are examined, then the three-season system has a greater benefit to the utility. This result confirms that the three-season system meets the utility's generation demands better than the four-season system. Along with a greater overall demand reduction, the four-season system also provides greater sulfur dioxide emission reduction. In fact, the four-season system has greater emission reductions all around but $\mathrm{SO}_{2}$ emissions are the only ones for which the utility gets monetary credit.

From an economic standpoint, the three-season system is of greater benefit to the utility. The reduced installation and maintenance costs associated with the three-season system result in a higher rate of return on the utility's investment. Furthermore, the capacity contribution index is higher for the three-season system. The capacity 
contribution index $(\mathrm{CCI})$ compares the relative capacity contributions to overall utility reliability. An important feature of the $\mathrm{CCI}$ is that it takes into account the effect of the demand-side project on an interconnected utility system, not just an isolated system (Arny, 1994). The three-season SDHW initiative contributes more to the area utilities' ability to meet their peak demand than does the four-season system.

\subsection{Modifications to EUSESIA}

EUSESIA makes an assumption, which while justifiable and undoubtedly correct was deemed inappropriate to this analysis. In generating a base case, a domestic water heating system is modeled using the file edhw.trd (Trzesniewski, 1995). The storage tank in this model contains two heating elements at one third and two-thirds the height of the tank. The SDHW system on the other hand contains a tank with only one heater. It was found that running the SDHW system with the solar radiation set to zero (representing an Electric Domestic Hot Water system (EDHW)) yielded a solar fraction when compared with the EDHW system. EUSESIA calculates the solar fraction as the difference in demand between the SDHW and EDHW systems. The difference in heater configurations was causing a difference in demand between the two systems, and therefore a non-zero solar fraction.

It should be stated that the models are correct and that comparing a four-season SDHW system and the EDHW system with two tank heaters will yield valid results. However, the three-season SDHW system needs to have the same demand as the EDHW system during the off season so the comparison becomes invalid. Therefore, the base case for comparison was modified to be the SDHW system with no solar radiation all 
year long. Alternatively, a second heater could have been added to the SDHW system but doing so would disturb the stratification of the tank and erase this benefit from the SDHW system. In order to model the three-season system, the solar radiation was set to zero during the freezing months to ensure that the demand of the system was equal to that of the EDWH system.

\subsection{Conclusions}

Because of its reduced installation and maintenance costs, a three-season system ensemble is of greater benefit to Wisconsin Electric Power Company by a significant margin. The utility can expect almost a $30 \%$ return on their investment as opposed to a $20 \%$ return for a four-season system. Since the four-season ensemble runs throughout the year, its overall energy reduction is greater in Milwaukee. However the utility has little use for the diversified generator during the winter so in reality the four-season ensemble is a burden during off peak times when it heats water at perhaps greater expense than the utility generated electricity. Say for example, that the utility has plenty of generating capacity on a winter day and could shut down a number of their power plants, thereby generating electricity at a very low cost and gaining a high profit margin. At this time, the four-season system ensemble would still be operating, conceivably generating energy at much higher cost to the utility, reducing the utility's profit margin. 


\section{CHAPTER VII}

Conclusions

\subsection{Summary}

Since the inclusion of a heat exchanger in a solar domestic water heating system incurs a thermal penalty and increases the cost of the system, there would be obvious benefits to its removal. However, the heat exchanger provides important freeze protection to the system, a function which must be carried out by another component if the exchanger is to be removed. While many freeze protection schemes exist, they have been shown to be inappropriate in certain locations. Two alternate freeze protection schemes have been proposed in this thesis; that of designing a collector plate that is not damaged by freezing, and that of running the heat exchangerless system only when the ambient temperature is above $0{ }^{\circ} \mathrm{C}$.

Designing a collector plate from a thermo-elastic material that does not deform plastically on freezing poses interesting problems due to its low thermal conductivity. A model was developed that assumed that heat transfer occurs only in one dimension along the length of the fin. The model was used to predict the amount of energy delivered to the collector fluid. The results were then validated by comparison with a finite element analysis that considered two-dimensional effects caused by low thermal conductivity and thick fins. A thermo-elastic collector plate was designed using the one-dimensional 
model in a range for which two-dimensional effects were shown to be unimportant. Its performance was then matched to a standard copper collector by increasing the collector area. Tools useful for graphically designing thermo-elastic collector plates were developed. Furthermore, the one-dimensional model was shown to model standaard copper plate collectors extremely well, making it an extremely versatile model while validating the assumptions used in developing the standard copper collector design equations.

The second freeze protection scheme involves shutting down the SDHW system during the winter months resulting in a changed performance and in different optimum system set points. At first, economics were used in an effort to design three-season systems that would have a life cycle savings equal to that of an optimum four-season system in the same location. The first step in designing three-season systems involved learning about the system's sensitivity to various variable changes. Three-season systems were then designed for four locations whose weather patterns are representative of the United States as a whole using life cycle savings. Next, three-season systems were designed for the same locations using simple payback period as the indicator. Various system dynamics were identified.

A thermal analysis was then carried out in an effort to divorce the three-season system economic performance results from the thermal penalty incurred by shutting the system down for a number of months. All economic factors were discarded and the thermal penalty of a three-season system was determined for 230 locations across the 
142

United States. In each location, three three-season systems were analyzed. The first had the same area as a four-season system meeting $25 \%$ of the annual heating load. The second had an area equal to that of the four-season system meeting $50 \%$ of the load, and the third was based upon a four-season system meeting $75 \%$ of the load.

Because the initial method used in determining the three-season thermal penalty was limited to analyzing standard system configurations, an hourly simulation tool was used to investigate alterations to the basic three-season concept. Specifically, the result of recirculating warm storage tank water through the collector during freezing periods in the swing months at either end of the system's down time was investigated. Such a scheme would increase the amount of energy collected but would also add an energy loss to the system.

Lastly, an investigation of the impact on an electric utility of a large-scale threeseason system implementation was carried out. The idea is that a large number of SDHW systems in the utility's service area will cut the peak electricity demand seen by the utility. In so doing, the utility is able to delay building further generation capacity and gets credits for reduced emissions. The electric customers benefit by paying a monthly lease rate for the collector and very little for their electricity thus receiving a lower monthly bill. Furthermore, customers are able to install SDHW systems without having to lay out a lot of money and have an authority to whom to turn for maintenance issues. The impact of a three-season system ensemble upon a Milwaukee utility was assessed and compared to the impact of four-season systems. 


\subsection{Conclusions}

Both the thermo-elastic collector and the three-season system have been proven to be viable freeze protection alternatives. Of course both alternatives also have important disadvantages which must be understood when designing solar domestic hot water systems that make use of them.

The tubes in the thermo-elastic provide freeze protection by expanding to accommodate any freezing water. Once the ambient temperature rises above freezing, the ice in the tubes melts and the tubes return to their original size and shape. The results of the Chapter 2 analysis show that such a collector can be designed that has comparable performance to a standard copper collector. Such a collector would need to be approximately 1.5 times as large as a standard flat plate collector is in order to maintain the desired annual solar fraction. An increase in area is undesirable in that it puts further limitations on where the collectors can be mounted. Perhaps more important than the actual design, however is that equations were developed which are more generally useful in designing collectors of all designs. The current collector design equations and plots are created using the assumption that the temperature around the circumference of the collector tube is constant. While this is a valid assumption for collector geometries that involve thin walled tubes and high thermal conductivity materials, it breaks down with thick walled tubes and low thermal conductivities.

Breaking the fin and tube into a three fin problem and allowing the temperature to vary around the tube circumference generated collector design equations that are valid for 
144

a wider range of collector plate materials. However, these equations are valid somewhat out of luck and only for configurations similar to those studied in this thesis. The upper "fin" has a temperature distribution running parallel to its length which means that heat flows directly through its width and not along its length. Because of this, it is incorrect to assume that the upper portion of the tube is a fin. It should be instead analyzed as a wall. Moreover, the one-dimensional model is of limited use as the problem is truly twodimensional. Anyone wishing to actually design thermo-elastic plate collectors would want to use a two-dimensional model.

The other freeze protection alternative investigated was that of an SDHW system that is shut down during the winter and so does not need to include a heat exchanger. A number of important conclusions can be drawn from the investigation. Obviously, the three-season alternative reduces the annual solar fraction in most locations. There are some locations however, where the freezing season is extremely short or extremely cloudy in which the four-season system barely collects any more total energy than the three-season system. In these locations, the thermal penalty paid with a heat exchanger throughout the year is greater than the energy collected by operating during the winter months. A three-season system is the obvious choice in these locations as it yields a higher annual solar fraction than the corresponding four-season system.

As previously mentioned, the majority of locations suffer some decrease in thermal performance due to shutting down the system. Various areas of the country are affected differently but in general, for a small system, the thermal penalty is not 
debilitating unless the system is located high in the mountains or in Alaska. As the system is designed to meet more of the annual load, however, the penalty becomes much more significant.

An economic analysis of three-season systems indicated that such a system is no more sensitive to parameter changes than a four-season system. Such a result is valuable because it means that three-season system design is no more complicated than fourseason system design. The main lesson learned in the economic analysis was that economics are fickle and great care should be taken when using them to make threeseason SDHW design decisions. A standard economic indicator, life cycle savings, indicated that a three-season system would never be profitable and that a customer would have to be paid to install one if the same life cycle savings as a four-season system are desired. In retrospect, it is obvious that a four-season system with a larger optimum area would save the customer more money than the smaller system operating for only a fraction of the year. The proper indicator is instead the return on investment as a smaller capital outlay is required for the three-season system.

Designing three-season SDHW systems using return on investment as the indicator is possible. However, the geographic dependence of economic variables and the subjectivity involved with choosing their values makes it a poor method for assessing the viability of three-season systems across the United States. 
There are a great number of modifications that can be made to a three-season system which can help it to perform almost as well as a four-season system thermally while still costing less. Recirculating warm storage tank water through the collector at night during the first and last month of the freeze period was shown to greatly increase the three-season system's thermal performance. There are two extremes in results however. In some locations such as Denver, $\mathrm{CO}$, recirculation can increase the threeseason solar fraction beyond that of the four-season system. At the opposite end of the spectrum, recirculation in Saulte Saint Marie, MI further degrages the three-season solar fraction. Again, the majority of locations across the United States fall into a middle category in which the three-season system performance is increased, but not so much that it overtakes that of the four-season system.

The final step in the analysis of three-season systems involved an examination of their impact on a Wisconsin electric utility. It was found that because of a lower installation cost, a theoretically lower maintenance cost, and the same lease rate as a fourseason system, the three-season system ensemble benefited the utility more from an economic point of view. The four-season system ensemble, on the other hand, reduced annual energy demand on the utility by a greater amount. If, however, only the peak demand periods are examined, the three-season system ensemble is more beneficial, annually reducing peak demand by $90 \mathrm{~kW}$ more than the four-season system ensemble. Evidently, the three-season system ensemble is better suited to meeting the utility's demand. In fact the four-season system ensemble operating during the winter may be producing energy at a higher cost than the utility's marginal plant. At such a time, the 
utility would normally want to shut down the higher cost SDHW electricity generator. Unfortunately, the ensemble is impossible to shut down all at once. The three-season system ensemble, which only operates when the marginal plant generates electricity at a high cost, may have an added benefit to the utility that was not accounted for in the EUSESIA analysis.

\subsection{Recommendations for Further Research}

At the outset of this project, a utility in Green Bay, WI had an $f$-Chart model of an SDHW system that would have provided them with acceptable returns to make the project profitable. They were, at the end of 1996 prepared to begin performance experiments of two systems and hoped to begin offering a solar alternative to their customers by the end of 1997 . Because of various setbacks the project was discarded before experimentation began.

Previous work has shown that such programs can be profitable to utilities (Trzesniewski, 1995) and (Williams, 1996). The best use of this thesis would be to redesign the SDHW system so that it could be used in Green Bay. It may turn out that while the four-season system did not seem profitable that the three-season system with its reduced operating costs would. Such research would make use of the EUSESIA software in order to model system alternatives. 
Perhaps the most enlightening further research into three-season systems would involve an analysis of the cost at which three and four-season systems produce energy throughout the year. If, because of maintenance costs, the four-season system ensemble heats water very expensively during winter when there are plenty power plants which can be run inexpensively, then it has an adverse economic effect upon the utility that the three-season system does not share.

The next step in investigating the thermo-elastic collector is to begin choosing a material for the plate. This task is not easy, as there are many requirements of stiffness, resistance to high temperatures and low cost. Building and testing a prototype thermoelastic collector would also lend immeasurable credence to the presented model.

Experimentation would also validate the results of the three-season system thermal penalty analysis. A number of SDHW systems across the country could be outfitted for data collection and run in both three and four-season modes. After collecting data the annual solar fractions could be easily calculated and compared with the predicted results.

One of the major shortcomings of the three-season system analysis is the definition of the freezing season. An investigation of the time required for a collector to freeze up under various conditions would lead to a much more accurate estimation of the start up and shut down times in each location analyzed. 
Lastly, in all the analyses thus far the flow rates of fluid on the tank side and on the collector side of the four-season system has been kept equal. Previous work has shown that significant benefits can be met using lower flow rates (Dayan, 1997). It could be that the four-season system is not operating at its optimum in terms of flow rate and it therefore being unfairly penalized. 


\section{APPENDIX A: THERMO-ELASTIC COLLECTOR DESIGN PROGRAM}

"h_fi $=300 \mathrm{~W} / \mathrm{m}^{\wedge} 2 \mathrm{C}$

this program generates FR graphs for turbulent flow"

Procedure Nusselt(Re, Pr : Nus)

If $(\operatorname{Re}<2100)$ Then

Nus := 3.66

Else

EndIf

Nus $:=0.023 * \operatorname{Re}^{\wedge}(4 / 5) * \operatorname{Pr}^{\wedge}(1 / 3)$

End Nusselt

$\mathrm{k}=0.1$ "W/m^2 $\mathrm{C}$; thermal conductivity"

T_a $=20$ "C; ambient temperature"

$\mathrm{T}_{-} \mathrm{f}=35$ "C; fluid temperature"

$\mathrm{S}=1000$ "W/m^2; absorbed radiation"

$U_{-} \mathrm{t}=7$ "W/m^2; top heat transfer coefficient"

$\mathrm{U}_{-} \mathrm{b}=1$ "W/m^ 2 ; back heat transfer coefficient"

$\left\{\mathrm{h} \_\mathrm{f}=300\right.$ "W/m^2 ; heat transfer coefficent to fluid at wall" $\}$

$\mathrm{W}=0.03$ "m; fin width"

$\mathrm{D}=0.01$ " $\mathrm{m}$; tube diameter"

$\{$ delta_f $=0.01$ "m; fin thickness" $\}$

delta_t $=0.005$ "m; tube wall thickness"

A_c $=1$ " $\mathrm{m}^{\wedge} 2$; collector area"

$\left\{\mathrm{m}_{-}\right.$dot $=0.015 \mathrm{~kg} / \mathrm{s}$; fluid mass flow rate" $\}$

$\mathrm{C}_{-} \mathrm{p}=4180$ "J/kg C; water specific heat"

k_fluid $=0.628$

$\mathrm{mu}=0.000655$ "Pa s; absolute viscosity of water at $40 \mathrm{C} "$

$\operatorname{Pr}=4.34$

$\operatorname{Re}=4^{*} \mathrm{~m} \_\mathrm{dot} /\left(\mathrm{pi}^{*} \mathrm{D}^{*} \mathrm{mu}\right)$

call Nusselt(Re, Pr : Nus)

h_f $=$ Nus $* k$ kfluid/D

$m_{-} f=\operatorname{sqrt}\left(\left(U_{-} t+U_{-} b\right) /\left(k^{*}\right.\right.$ delta_f $\left.)\right)$

$m \_t=\operatorname{sqrt}\left(\left(U_{-} t+h \_f\right) /(k *\right.$ delta_t $\left.)\right)$

$m \_b=\operatorname{sqrt}\left(\left(U_{-} b+h \_f\right) /(k *\right.$ delta_t $\left.)\right)$ 
"energy transfer from fin to base point"

q_fin $=-m_{-} f^{*} k^{*}$ delta_f*(T_b - T_a $-\left(S /\left(U_{-} t+U_{-} b\right)\right) * \tanh \left(m_{-} f *(W-D) / 2\right)$

"energy transfer from tube top half to base point"

q_top $=-m_{-} t^{*} k^{*}$ delta_t* $\left(T \_b-\left(1 /\left(U_{-} t+h \_f\right) *\left(U_{-} t^{*} T \_a+h \_f * T \_f+\right.\right.\right.$

$\mathrm{S}))^{*} \tanh \left(\mathrm{m}_{-} \mathrm{t} * \mathrm{pi}\right.$ i D/4)

"energy transfer from tube bottom half to base point"

q_bot $=-\mathrm{m}_{-} \mathrm{b}^{*} \mathrm{k}^{*}$ delta_t $*\left(T \_b-\left(1 /\left(\mathrm{U} \_\mathrm{b}+\mathrm{h} \_\mathrm{f}\right)\right)^{*}\left(\mathrm{U} \_\mathrm{b} * \mathrm{~T} \_\mathrm{a}+\right.\right.$

h_f*T_f $) * \tanh \left(m_{-} b^{*}\right.$ pi*D/4)

"energy transfer from base point to fliud"

q_end $=h \_f *$ delta_t $*\left(T \_b-T \_f\right)$

"energy balance on base point"

q_fin + q_top $+q \_$bot $=$q_end

"energy transfered from top half of tube to water"

q_u_top = integral(q_flux_t,x_t,0,pi*D/4)

$q_{-}$flux_t $=h_{-} f *\left(T \_t o p-T \_f\right)$

$\left(T \_t o p-\left(1 /\left(U_{-} t+h \_f\right)\right) *\left(U_{-} t^{*} T \_a+h \_f * T \_f+S\right)\right) /\left(T \_b-\left(1 /\left(U_{-} t+h \_f\right)\right) *\left(U_{-} t * T \_a+\right.\right.$ $\left.\left.h_{-}{ }^{*} T_{-} f+S\right)\right)=\cosh \left(m_{-} t^{*} x_{-} t\right) / \cosh \left(m_{-} t^{*} i^{*} \mathrm{D} / 4\right)$

"energy transfered from bottom half of tube to water"

q_u_bot $=$ integral(q_flux_b,x_b,0,pi*D/4)

q_flux_b $=$ h_f* $\left(T \_b o t-T \_f\right)$

$\left(T_{-} b o t-\left(1 /\left(\bar{U} \_b+h \_f\right)\right) *\left(U_{-} b^{*} T \_a+h \_f * T \_f\right)\right) /\left(T \_b-\left(1 /\left(U_{-} b+h \_f\right)\right) *\left(U_{-} b^{*} T \_a+\right.\right.$ $\left.\left.h \_f * T \_f\right)\right)=\cosh \left(m \_b * x \_b\right) / \cosh \left(m \_b * p i * D / 4\right)$

"total energy transfered from fin and tube to water"

$q^{\prime}$ _w $=$ q_end + q_u_top + q_u_bot

"gains if everything is at Tf : gains $=\mathrm{S}-$ losses"

q_u_tf $=S *((W-D) / 2+p i * D / 4)-((W-D) / 2+p i * D / 4) *\left(U_{-} t+U \_b\right) *\left(T \_f-T \_a\right)$

"incident radiation"

incident $=\mathrm{S}^{*}((\mathrm{~W}-\mathrm{D}) / 2+\mathrm{pi} * \mathrm{D} / 4)$

$" F^{\prime}=q_{-}$actual $/ q_{-} T=T f^{\prime \prime}$

$F^{\prime}=q^{\prime}$-w/q_u_tf

$\mathrm{FR}=\left(\mathrm{m} \_\right.$dot $\left.* \mathrm{C} \_\mathrm{p}\right) /\left(\mathrm{A} \_\mathrm{c} *\left(\mathrm{U}_{-} \mathrm{t}+\mathrm{U}_{-} \mathrm{b}\right)\right) *\left(1-\exp \left(\left(-\mathrm{A}_{-} \mathrm{c} * \mathrm{~F} *\left(\mathrm{U}_{-} \mathrm{t}+\mathrm{U} \_\mathrm{b}\right)\right) /\left(\mathrm{m} \_\mathrm{dot} * \mathrm{C} \_\mathrm{p}\right)\right)\right)$

$\left\{\left(m_{-}\right.\right.$dot $*$ C_p $\left.) /\left(A_{-} c^{*}\left(U_{-} t+U_{-} b\right)\right)^{*}\left(1-\exp \left(A \_c * F *\left(U_{-} t+U_{-} b\right) /\left(m_{-} \operatorname{dot}^{*} C_{-} p\right)\right)\right)\right\}$

$\mathrm{x} \_\mathrm{ax}=\mathrm{m} \_\mathrm{dot} / \mathrm{A} \_\mathrm{c}$ 


\section{APPENDIX B: THERMAL AND ECONOMIC ANALYSIS PROGRAMS}

"This program is used to calculate the thermal penalty associated with a three-season system"

FUNCTION DoY_(Month)

Month $=$ round $($ Month $)$

If Month $=0$ Then DoY $=355$

If Month $=1$ Then DoY $=1$

If Month $=2$ Then DoY $=32$

If Month $=3$ Then DoY $=60$

If Month $=4$ Then DoY_ $=91$

If Month $=5$ Then DoY $=121$

If Month $=6$ Then DoY $=152$

If Month $=7$ Then DoY $=182$

If Month $=8$ Then DoY $=213$

If Month $=9$ Then DoY $=244$

If Month $=10$ Then DoY $_{-}=274$

If Month $=11$ Then DoY $=305$

If Month $=12$ Then DoY $=335$

END

If Month $=13$ Then DoY $=355$

FUNCTION slope3_(FF,LF,lat)

$F F n=D_{1}(F F)$ "day of year corresponding to first fall freeze"

LFn = DoY_(LF) "day of year corresponding to last spring freeze"

springdec $=$ Dec_(LFn) "declination at last spring freeze"

falldec $=$ Dec $\_(F F n)$ "declination at first fall freeze"

mindec $=\min ($ falldec,springdec $)$ "calculates the minimum of these two"

If $(5>\mathrm{LF})$ Then

$$
\text { maxdec }=\text { Dec } \_(182)
$$

Else

$$
\operatorname{maxdec}=23.45
$$

EndIf END

slope $3_{-}=$lat $-((\operatorname{maxdec}+\operatorname{mindec}) / 2)$ 
Function

F_R'F_R_(A_c,FrUl,MassFR_col,C_p’col,MassFR_tk,C_p`tk,Effect_CHX)

\{Equation 10.2.3\}

CollCapRate=MassFR_col*C_p'col

TankCapRate $=$ MassFR_tk*C_p`tk

CapRateMin=min(CollCapRate,TankCapRate)

$\mathrm{X}=\mathrm{A} \_\mathrm{c} * \mathrm{FrU1} / \mathrm{CollCapRate}$

$\mathrm{Y}=$ CollCapRate $/$ (Effect_CHX $*$ CapRateMin)

F_R $I F \_R \_=\left(1+X^{*}(Y-1)\right)^{\wedge}(-1)$

END

FUNCTION MonthFlag_(i,FF,LF)

If $(\mathrm{i}>\mathrm{LF})$ and $(\mathrm{i}<\mathrm{FF})$ then

MonthFlag_: $=1$

Else

MonthFlag_: $=0$

EndIf

END

StoreCap $=81.49$

"data specific to three season system"

\{slope $3=28$ "collector slope"

C_p'col3 = 4190 "J/kgC; specific heat of collector loop fluid"

Effect_CHX3 = 1 "heat exchanger effectiveness:"

$\{$ A_c $3=7.5$ "m^2; collector area" $\}$

"data specific to four season system"

slope4 = lat "collector slope"

C_p ${ }^{\prime}$ col $4=3350$ "J/kgC; specific heat of collector loop fluid"

Effect_CHX $4=0.2$ "heat exchanger effectiveness"

A_c4 = A_c3 " $\mathrm{m}^{\wedge} 2$; collector area"

"system parameters"

$T$ _set $=60$ "tank temperature set point"

draw = 300 "1; daily water draw"

UA_tk $=0$ "W/C; tank losses THESE AREN' INCLUDED YET"

GrRef $=0.2$ "ground reflectance"

"collector parameters"

$\mathrm{FrUl}=4.86$ "W/m^2C; efficiency curve slope"

Frta_n $=0.741$ "efficiency curve intercept"

C_p tk $=4190$ "J/kgC; specific heat of tank loop fluid"

MassFR_col3 $=0.015^{*} \mathrm{~A} \_\mathrm{c} 3$ "kg/s; collector loop flow rate" 
154

MassFR_tk3 $=0.015^{*} \mathrm{~A} \_\mathrm{c} 3$ "kg/s; tank loop flow rate"

MassFR_col4 $=0.015^{*} \mathrm{~A} \_\mathrm{c} 4$ " $\mathrm{kg} / \mathrm{s}$; collector loop flow rate"

MassFR_tk4 $=0.015 * \mathrm{~A} \_\mathrm{c} 4$ "kg/s; tank loop flow rate"

$\mathrm{T}_{\text {_ref }}=100$ "C; empirically derived reference temperature"

tabarlta_n = 0.96 "TauAlphaIncAng_(Ncov,IncAng,KL,RefrInd,Alpha_n) "

F_R 'F_R3 =

F_R \F_R_(A_c3,FrUl,MassFR_col3,C_p`col3,MassFR_tk3,C_p`tk,Effect_CHX3)

F_R'F_R4 =

F_R'F_R_(A_c4,FrUl,MassFR_col4,C_p’col4,MassFR_tk4,C_p'tk,Effect_CHX4)

Lat $=$ lookup(TableRun\#,\#latitude $)$

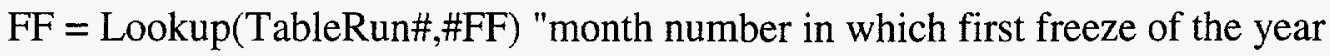
occurs (Fall)"

$\mathrm{LF}=$ Lookup(TableRun\#,\#LF) "month number in which last freeze of the year occurs (Spring)"

"the slope of the three season system is the average declination during its operating period"

slope3 = slope3_(FF,LF,lat)

duplicate $i=1,12$ "repeat for each month of the year"

"weather data"

$\mathrm{n}[\mathrm{i}]=$ AveDay_(i) "mean day of the month"

DIM[i] = NumDay_(i) "number of days in the month"

Nhim $[\mathrm{i}]=\mathrm{DIM}[\mathrm{i}] * 24$ "hr; number of hours in the month"

Time[i] $=$ Nhim [i] $* 3600$ "s; number of seconds in the month"

Hbar[i] $=$ Lookup $(\text { TableRun\#, }(2+\mathrm{i}))^{*}$ convert $(\mathrm{kJ}, \mathrm{MJ})$ "MJ/m^2; monthly average daily radiation incident on horizontal"

Tbar_a[i] = Lookup(TableRun\#,(14+i)) "C; monthly average ambient temperature"

T_mains $[\mathrm{i}]=\left(\operatorname{sum}\left(T \mathrm{Tbar} \_a[\mathrm{i}], \mathrm{i}=1,12\right)\right) / 12$ "C; mains water temperature for well water"

$\left\{T \_\right.$mains $[i]=T b a r \_a[i]$ "C; mains water temperature for surface source water" $\}$

flag[i] = MonthFlag_(i,FF,LF)

"load data"

Load[i] $=\left(T_{-}\right.$set - T_mains[i] $) *$ C_p'tk*draw*DIM[i] $\{+$ losses $\}$ "J"

"incident radiation" "J"

H_Tbar3_LJ[i] = H_TBAR'LJ_(Hbar[i],Lat,n[i],slope3,GrRef)*convert(MJ,J) 
H_Tbar3_total[i] $=$ H_Tbar3_LJ[i] ${ }^{*}$ A_c $3 *$ DIM $[i]$ "J"

H_Tbar4_LJ[i] = H_TBAR'LJ_(Hbar[i],Lat,n[i],slope4,GrRef)*convert(MJ,J)

H_Tbar4_total[i] $=$ H_Tbar4_LJ[i] ${ }^{* A}$ _c $4 *$ DIM $[\mathrm{i}]$

"monthly solar fraction"

$\mathrm{f} 3[\mathrm{i}]=$

SolFract'HW_(FrUl,F_R'IF_R3,T_ref,Tbar_a[i],Time[i],A_c3,Load[i],Frta_n,tabarlt a_n,H_Tbar3_LJ[i],DIM[i],StoreCap,T_set,T_mains[i])*Flag[i]

$\mathrm{f} 4[\mathrm{i}]=$

SolFract'HW_(FrUl,F_R'F_R4,T_ref,Tbar_a[i],Time[i],A_c4,Load[i],Frta_n,tabarlt a_n,H_Tbar4_LJ[i],DIM[i],StoreCap,T_set,T_mains[i])

"auxiliary energy requirement"

aux3[i] $=(1-f 3[i]) *$ Load[i] "J"

$\operatorname{aux} 4[\mathrm{i}]=(1-\mathrm{f} 4[\mathrm{i}]) * \operatorname{Load}[\mathrm{i}] \quad$ "J"

end

aux_anual $3=\operatorname{sum}(\operatorname{aux} 3[\mathrm{i}], \mathrm{i}=1,12)$

aux_anual $4=\operatorname{sum}(\operatorname{aux} 4[\mathrm{i}], \mathrm{i}=1,12)$

L_anual $=\operatorname{sum}(\operatorname{Load}[\mathrm{i}], \mathrm{i}=1,12)$

F_anual3 $=\operatorname{sum}(\mathbf{f} 3[\mathrm{i}] * \operatorname{Load}[\mathrm{i}], \mathrm{i}=1,12) / \operatorname{sum}(\operatorname{Load}[\mathrm{i}], \mathrm{i}=1,12)$

F_anual $4=\operatorname{sum}(\mathbf{f} 4[\mathrm{i}] * \operatorname{Load}[\mathrm{i}], \mathrm{i}=1,12) / \operatorname{sum}(\operatorname{Load}[\mathrm{i}], \mathrm{i}=1,12)$

F_anual $4=0.75$

penalty $=100 *\left(\mathrm{~F} \_\right.$anual4 $-\mathrm{F} \_$anual3 $)$ 
"This program is used to calculate economic sensitivities for both three and fourseason systems."

$$
\begin{aligned}
& \text { FUNCTION DoY_(Month) } \\
& \text { Month }=\text { round(Month) } \\
& \text { If Month }=0 \text { Then DoY_ }=355 \\
& \text { If Month }=1 \text { Then DoY_ }=1 \\
& \text { If Month }=2 \text { Then DoY }=32 \\
& \text { If Month }=3 \text { Then DoY }=60 \\
& \text { If Month }=4 \text { Then DoY }=91 \\
& \text { If Month }=5 \text { Then DoY }=121 \\
& \text { If Month }=6 \text { Then DoY }=152 \\
& \text { If Month }=7 \text { Then DoY }=182 \\
& \text { If Month }=8 \text { Then DoY }=213 \\
& \text { If Month }=9 \text { Then DoY }=244 \\
& \text { If Month }=10 \text { Then DoY }=274 \\
& \text { If Month }=11 \text { Then DoY_- }=305 \\
& \text { If Month }=12 \text { Then DoY }=335 \\
& \text { If Month }=13 \text { Then DoY }=355 \\
& \text { END }
\end{aligned}
$$

FUNCTION slope3_(FF,LF,lat)

$\mathrm{FFn}=$ DoY_$_{-}(\mathrm{FF})$ "day of year corresponding to first fall freeze"

LFn $=$ DoY_(LF) "day of year corresponding to last spring freeze"

springdec $=$ Dec_(LFn) "declination at last spring freeze"

falldec $=$ Dec_(FFn) "declination at first fall freeze"

mindec $=\min ($ falldec,springdec) "calculates the minimum of these two"

If $(5>\mathrm{LF})$ Then

$$
\text { maxdec }=\text { Dec } \_(182)
$$

Else

$$
\operatorname{maxdec}=23.45
$$

EndIf

END

$$
\text { slope } 3 \text { - }=\text { lat }-((\operatorname{maxdec}+\operatorname{mindec}) / 2)
$$

\section{Function}

F_R'IF_R_(A_c,FrUl,MassFR_col,C_p`col,MassFR_tk,C_p`tk,Effect_CHX) \{Equation 10.2.3\}

CollCapRate=MassFR_col*C_p'col

TankCapRate $=$ MassFR_tk*C_p`tk

CapRateMin=min(CollCapRate,TankCapRate)

$\mathrm{X}=\mathrm{A} \_\mathrm{c} * \mathrm{FrUl} / \mathrm{CollCapRate}$

$\mathrm{Y}=$ CollCapRate/(Effect_CHX ${ }^{*}$ CapRateMin)

$F_{-} R^{\prime} \backslash F \_R \_=\left(1+X^{*}(Y-1)\right)^{\wedge}(-1)$

\section{END}


FUNCTION MonthFlag_(i,FF,LF)

If $(\mathrm{i}>\mathrm{LF})$ and $(\mathrm{i}<\mathrm{FF})$ then

MonthFlag_: $=1$

Else

MonthFlag $:=0$

EndIf

END

StoreCap $=81.49$

"data specific to three season system"

\{slope $3=28$ "collector slope"

C_p'col3 $=4190 \mathrm{~J} / \mathrm{kgC}$; specific heat of collector loop fluid"

Effect_CHX3 = 1 "heat exchanger effectiveness:"

$\left\{\right.$ A_c3 $=7.5$ " $\mathrm{m}^{\wedge} 2$; collector area" $\}$

"data specific to four season system"

slope 4 = lat "collector slope"

C_p'col4 = 3350 "J $/ \mathrm{kgC}$; specific heat of collector loop fluid"

Effect_CHX4 $=0.2$ "heat exchanger effectiveness"

A_c4 = A_c3 "m^2; collector area"

"system parameters"

T_set $=60$ "tank temperature set point"

draw $=300$ "1; daily water draw"

UA_tk $=0$ "W/C; tank losses THESE AREN' INCLUDED YET"

GrRef $=0.2$ "ground reflectance"

"collector parameters"

$\mathrm{FrU1}=4.86$ "W/ $/ \mathrm{m}^{\wedge} 2 \mathrm{C}$; efficiency curve slope"

Frta_n $=0.741$ "efficiency curve intercept"

C_p'tk $=4190$ "J/kgC; specific heat of tank loop fluid"

MassFR_col3 $=0.015^{*} \mathrm{~A} \_\mathrm{c} 3 \mathrm{~kg} / \mathrm{s}$; collector loop flow rate"

MassFR_tk3 $=0.015 *$ A_c3 "kg/s; tank loop flow rate"

MassFR_col4 $=0.015 * A \_c 4 " \mathrm{~kg} / \mathrm{s}$; collector loop flow rate"

MassFR_tk $4=0.015^{*}$ A_c4 "kg/s; tank loop flow rate"

T_ref $=100$ "C; empirically derived reference temperature"

"economic parameters"

$\{$ C_A $=200$ "\$; area dependent costs"

C_E3 = 1000 "\$; area independent costs"

C_E4 = 1100 "\$; area independent costs"

P_Eww $=0.0668$ 
158

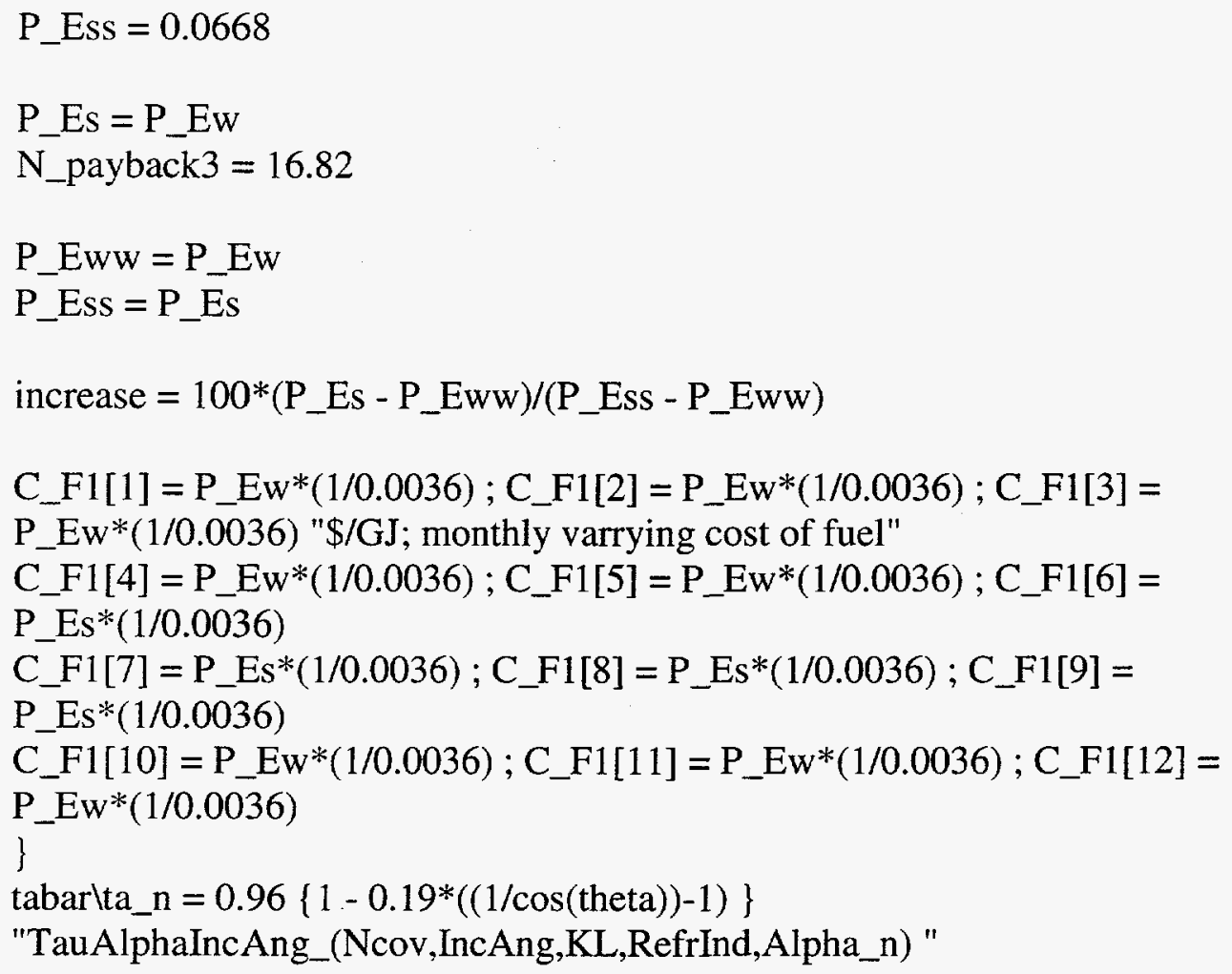

$\mathrm{FF}=$ Lookup (59,\#FF) "month number in which first freeze of the year occurs (Fall)" $\mathrm{LF}=\mathrm{Lookup}(59, \# \mathrm{LF})$ "month number in which last freeze of the year occurs (Spring)"

"the slope of the three season system is the average declination during its operating period"

slope3 = slope3_(FF,LF,lat)

duplicate $i=1,12$ "repeat for each month of the year"

"weather data"

$\mathrm{n}[\mathrm{i}]=$ AveDay_(i) "mean day of the month"

DIM[i] = NumDay_(i) "number of days in the month"

Nhim[i] = DIM[i] $* 24$ "hr; number of hours in the month"

Time[i] = Nhim[i] $* 3600$ "s; number of seconds in the month"

$\mathrm{Hbar}[\mathrm{i}]=\operatorname{Lookup}(59,(2+\mathrm{i}))^{*}$ convert $(\mathrm{kJ}, \mathrm{MJ})$ "MJ $/ \mathrm{m}^{\wedge} 2$; monthly average daily radiation incident on horizontal" 
Tbar_a[i] $=\operatorname{Lookup}(59,(14+\mathrm{i}))$ "C; monthly average ambient temperature"

$\mathrm{T} \_$mains $[\mathrm{i}]=\left(\operatorname{sum}\left(\mathrm{Tbar} \_\mathrm{a}[\mathrm{i}], \mathrm{i}=1,12\right)\right) / 12 \mathrm{C} \mathrm{C}$; mains water temperature for well water"

$\left\{\mathrm{T} \_\right.$mains $[\mathrm{i}]=$ Tbar_a[i] "C; mains water temperature for surface source water" $\}$ flag[i] = MonthFlag_(i,FF,LF)

"load data"

Load[i] $=(\text { T_set }- \text { T_mains }[\mathrm{i}])^{*} \mathrm{C}_{-} \mathrm{p}^{`} \mathrm{tk} * \mathrm{draw} * \mathrm{DIM}[\mathrm{i}]\{+$ losses $\}$ "J"

"incident radiation" "J"

H_Tbar3_LJ[i] = H_TBAR'LJ_(Hbar[i],Lat,n[i],slope3,GrRef)*convert(MJ,J)

H_Tbar3_total[i] $=$ H_Tbar3_LJ [i] ${ }^{* A} A \_c 3 * D I M[i]$ "J"

H_Tbar4_LJ $[\mathrm{i}]=$ H_TBAR LJ_(Hbar[i],Lat,n[i],slope4,GrRef) ${ }^{*}$ convert(MJ,J)

H_Tbar4_total[i] = H_Tbar4_LJ[i]*A_c4*DIM[i]

"monthly solar fraction"

$\mathrm{f} 3[\mathrm{i}]=$

SolFract'HW_(FrUl,F_R'IF_R3,T_ref,Tbar_a[i],Time[i],A_c3,Load[i],Frta_n,tabarlt a_n,H_Tbar3_LJ[i],DIM[i],StoreCap,T_set,T_mains[i])*Flag[i]

$\mathrm{f} 4[\mathrm{i}]=$

SolFract'HW_(FrUl,F_R'VF_R4,T_ref,Tbar_a[i],Time[i],A_c4,Load[i],Frta_n,tabarlt a_n,H_Tbar4_LJ[i],DIM[i],StoreCap,T_set,T_mains[i])

"auxiliary energy requirement"

$\operatorname{aux} 3[\mathrm{i}]=(1-\mathrm{f} 3[\mathrm{i}]) * \operatorname{Load}[\mathrm{i}] " \mathrm{~J} "$

$\{\operatorname{cost} 3[\mathrm{i}]=$ aux3[i] $*$ C_F $1[\mathrm{i}] / 1 \mathrm{E} 9$ "cost of electricity with solar collector system" $\}$ $\operatorname{aux} 4[\mathrm{i}]=(1-\mathrm{f} 4[\mathrm{i}]) * \operatorname{Load}[\mathrm{i}] \quad$ "J"

$\left\{\operatorname{cost} 4[\mathrm{i}]=\right.$ aux $4[\mathrm{i}]{ }^{*}$ C_F1 [i]/1E9 "cost of electricity with solar collector system" system"

end

aux_anual3 $=\operatorname{sum}(\operatorname{aux} 3[\mathrm{i}], \mathrm{i}=1,12)$

aux_anual4 $=\operatorname{sum}(\operatorname{aux} 4[\mathrm{i}], \mathrm{i}=1,12)$

$\mathrm{L}_{\text {_anual }}=\operatorname{sum}(\operatorname{Load}[\mathrm{i}], \mathrm{i}=1,12)$

F_anual3 = sum(f3[i] $* \operatorname{Load}[\mathrm{i}], \mathrm{i}=1,12) / \operatorname{sum}(\operatorname{Load}[\mathrm{i}], \mathrm{i}=1,12)$

F_anual4 $=\operatorname{sum}(\mathbf{f} 4[\mathrm{i}] * \operatorname{Load}[\mathrm{i}], \mathrm{i}=1,12) / \operatorname{sum}(\operatorname{Load}[\mathrm{i}], \mathrm{i}=1,12)$

F_anual4 $=0.5$

penalty $=100 *\left(F \_\right.$anual4 $-\mathrm{F} \_$anual 3$)$

\{cost_anual3 $=$ sum $(\operatorname{cost} 3[\mathrm{i}], \overline{\mathrm{i}}=1,12)$ "anual cost of auxiliary energy"

cost_anual $4=\operatorname{sum}(\cos t 4[i], i=1,12)$ "anual cost of auxiliary energy"

savings_anual $3=$ sum(fullcost $[\mathrm{i}], \mathrm{i}=1,12)$ - cost_anual 3 "anual solar savings"

savings_anual $4=\operatorname{sum}($ fullcost $[\mathrm{i}], \mathrm{i}=1,12)$ - cost_anual4 "anual solar savings" 
160

init_invest $3=\mathrm{C} \_\mathrm{A}^{*} \mathrm{~A} \_\mathrm{c} 3+\mathrm{C} \_\mathrm{E} 3$

init_invest $4=$ C_A A A_c4 + C_E4

N_payback3 = init_invest3 / savings_anual3

N_payback4 $=$ init_invest 4 / savings_anual4 


\section{APPENDIX C: FOUR-SEASON SYSTEM TRNSYS DECK}

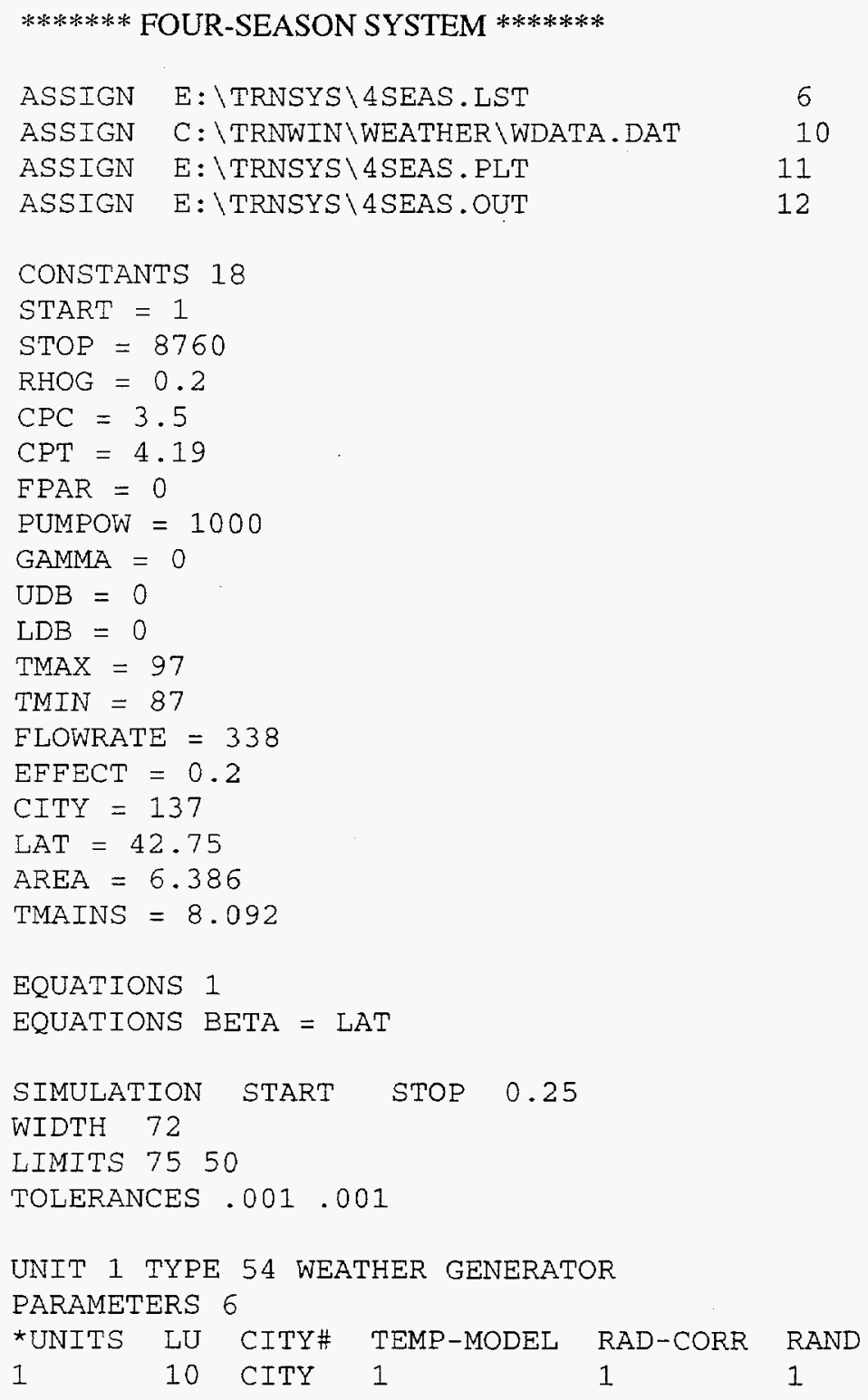


162

INPUTS 7

$\begin{array}{lllllll}* \text { I } & \text { IDN } & \text { TD1 } & \text { TD2 } & \text { RHOG } & \text { SLOPE } & \text { AZIMUTH } \\ 1,7 & 1,8 & 1.19 & 1,20 & 0,0 & 0,0 & 0,0 \\ 0.0 & 0.0 & 0.0 & 1.0 & \text { RHOG } & \text { BETA } & \text { GAMMA }\end{array}$

UNIT 3 TYPE 2 SOLAR PUMP CONTROLLER

PARAMETERS 4

*CYC/TSTEP UDB LDB HILIM-CUTOUT

$\begin{array}{llll}5 & 0 & 0 & 100\end{array}$

INPUTS 4

*THOT TCOLD HILIM-CUTOUT INPUT-CNTRL

$8,1 \quad 4,5 \quad 4,6 \quad 3,1$

20. 20. 100. 0.0

UNIT 4 TYPE 60 STRATIFIED FLUID STORAGE TANK

PARAMETERS 32

*INLET POSITION MODE, TANK VOLUME, TANK HEIGHT, PERIMETER, HEIGHT INLET 1

*HEIGHT OUTLET 1, HEIGHT INLET 2, HEIGHT OUTLET 2, CP, RHO, UTANK, $\mathrm{K}$, DELTA $K$,

*T-BOIL, AUX MODE, HT AUX1, HT STAT1, T SET1, DEL TDB1, QAUX1, HT AUX2, HT STAT2,

*T SET2, DEL TDB2, QAUX2, UA FLUE, T FLUE, CRIT FRACTION, GAS AUX, HX MODE, UMODE

$\begin{array}{llllllllllllll}1 & 0.3028 & 1.5 & -1 & 1.5 & 0.1 & 0.1 & 1.5 & 4.19 & 1000 . & 0 . & 2.304 & 0 .\end{array}$

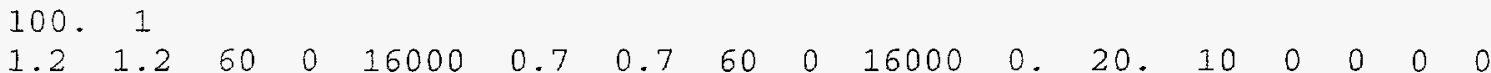

INPUTS 9

*MDOT1 IN, MDOT1 OUT, MDOT2 IN, MDOT2 OUT, T1 IN, T2 IN, T ENV, GAMMA1, GAMMA2

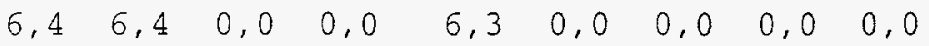

200. 200. -2.12 .1 20. TMAINS 20. 1.01 .0

DERIVATIVES 5

$20202020 \quad 20$

EQUATIONS 1

*FOUR SEASON SYSTEM

CNTRL $=[3,1]$

UNIT 5 TYPE 3 TANK LOOP PUMP

PARAMETERS 4

$\begin{array}{llll}\text { *MAX-FLOW } & \text { SPEC-HEAT } & \text { MAX-POWER } & \text { FRAC-2-THERM } \\ \text { FLOWRATE } & \text { CPT } & 1000 & \text { FPAR }\end{array}$

INPUTS 3

*T-IN MFLOW-IN CONTROL-FUNC

$4,5 \quad 4,2$

$\star 4,5 \quad 4,2$

CNTRL

20 . 200 .

CNTRLFUNCSC

UNIT 6 TYPE 5 HEAT EXCHANGER

PARAMETERS 4

${ }^{*}$ MODE $=$ CONST EFF, EFFECTIVNESS, CP HOT SIDE, CP COLD SIDE

4 EFFECT CPC CPT

INPUTS 4

*T HOT IN, MDOT HOT, T COLD IN, MDOT COLD

$8,1 \quad 8,2 \quad 5,1 \quad 5,2$ 


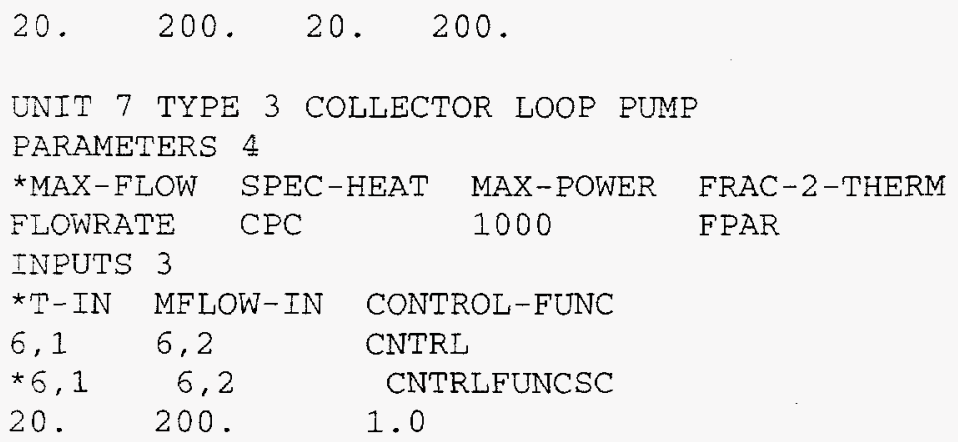


164

*TIME INTERVAL AT WHICH PRINTING WILL OCCUR, TIME AT WHICH PRINTING STARTS

*TIME AT WHICH PRINTING FINISHES, LOGICAL UNIT, UNITS

-1 START STOP 121

INPUTS 3

Q_SOLAR Q_LOAD Q_AUX

Q_SOLAR Q_LOAD Q_AUX

GJ GJ GJ

END 


\section{APPENDIX D: THREE-SEASON SYSTEM TRNSYS DECKS}

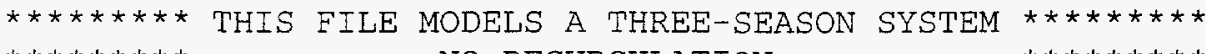

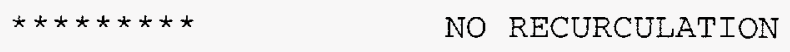

\begin{tabular}{|c|c|c|}
\hline ASSIGN & $E: \backslash T R N S Y S \backslash 3 S E A S . L S T$ & 6 \\
\hline ASSIGN & C $: \backslash T R N W I N \backslash W E A T H E R \backslash W D A T A . D A T$ & 10 \\
\hline SSIGN & $E: \backslash T R N S Y S \backslash 3 S E A S . P L T$ & \\
\hline ASSIGN & $E: \backslash T R N S Y S \backslash 3 S E A S . O U T$ & 12 \\
\hline
\end{tabular}

CONSTANTS 19

START $=1$

STOP $=8760$

$\mathrm{RHOG}=0.2$

$\mathrm{CPC}=4.19$

$\mathrm{CPT}=4.19$

$\mathrm{FPAR}=0$

PUMPOW $=1000$

GAMMA $=0$

$\mathrm{UDB}=0$

$\angle D B=0$

TMAX $=97$

TMIN $=87$

FLOWRATE $=338$

EFFECT $=1$

CITY $=137$

LAT $=42.93$

AREA $=6.948$

$\mathrm{BETA}=39.07$

TMAINS $=8.092$

SIMULATION START STOP 0.25

WIDTH 72

LIMITS $75 \quad 50$

TOLERANCES $.001 \quad .001$

UNIT 1 TYPE 54 WEATHER GENERATOR

PARAMETERS 6

$\begin{array}{llllll}\text { *UNITS } & \text { LU } & \text { CITY\# } & \text { TEMP-MODEL } & \text { RAD-CORR } & \text { RAND } \\ 1 & 10 & \text { CITY } & 1 & 1 & 1\end{array}$

UNIT 2 TYPE 16 RADIATION PROCESSOR

PARAMETERS 9

$\begin{array}{lllllllll}\text { *MODE } & \text { TRACK-MODE } & \text { SURF-MODE } & \text { DAY } & \text { LAT } & \text { SC } & \text { SHFT } & \text { SMOOTH } & \text { IE } \\ 7 & 1 & 1 & 1 & \text { LAT } & 4871 & 0 & 0 & -1\end{array}$

INPUTS 7 
166

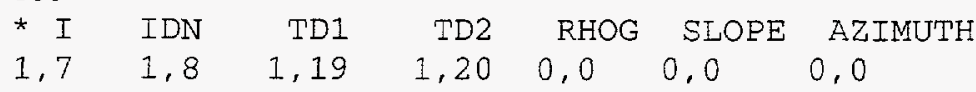

$\begin{array}{llllll}0.0 & 0.0 & 0.0 & 1.0 & \text { RHOG BETA GAMMA }\end{array}$

UNIT 3 TYPE 2 SOLAR PUMP CONTROLLER

PARAMETERS 4

*CYC/TSTEP UDB LDB HILIM-CUTOUT

$5 \quad 0 \quad 0 \quad 100$

INPUTS 4

*THOT TCOLD HILIM-CUTOUT INPUT-CNTRL

$8,1 \quad 4,5 \quad 4,6 \quad 3,1$

20. 20. 100. 0.0

UNIT 4 TYPE 60 STRATIFIED FLUID STORAGE TANK

PARAMETERS 32

* INLET POSITION MODE, TANK VOLUME, TANK HEIGHT, PERIMETER, HEIGHT INLET

1

*HEIGHT OUTLET 1, HEIGHT INLET 2, HEIGHT OUTLET 2, CP, RHO, UTANK, $K$,

DELTA $K$,

*T-BOIL, AUX MODE, HT AUX1, HT STAT1, T SET1, DEL TDB1, QAUX1, HT AUX2, HT STAT2,

*T SET2, DEL TDB2, QAUX2, UA FLUE, T FLUE, CRIT FRACTION, GAS AUX, HX MODE, UMODE

$\begin{array}{lllllllllllllll}1 & 0.3028 & 1.5 & -1 & 1.5 & 0.1 & 0.1 & 1.5 & 4.19 & 1000 . & 0 . & 2.304 & 0 .\end{array}$

100. 1

$\begin{array}{lllllllllllllllll}1.2 & 1.2 & 60 & 0 & 16000 & 0.7 & 0.7 & 60 & 0 & 16000 & 0 . & 20 . & 10 & 0 & 0 & 0 & 0\end{array}$

INPUTS 9

*MDOT1 IN, MDOT1 OUT, MDOT2 IN, MDOT2 OUT, T1 IN, T2 IN, T ENV, GAMMA1, GAMMA2

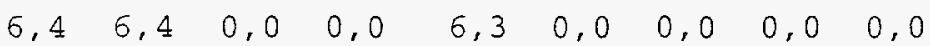

200. 200. - 2.12 .1 20. TMAINS 20. 1.01 .0

DERIVATIVES 5

$2020 \quad 2020 \quad 20$

UNIT 11 TYPE 14 THREE SEASON SYSTEM FLOWRATE FORCING FUNCTION

PARAMETERS 10

$\begin{array}{llllllllll}1 & 0 & 3624 & 0 & 3624 & 1 & 6552 & 1 & 6552 & 0\end{array}$

$\begin{array}{llllllllll}* 1 & 0 & 2880 & 0 & 2880 & 1 & 7296 & 1 & 7296 & 0\end{array}$

EQUATIONS 1

*THREE SEASON SYSTEM

CNTRL $=[11,1] *[3,1]$

UNIT 5 TYPE 3 TANK LOOP PUMP

PARAMETERS 4

*MAX-FLOW SPEC-HEAT MAX-POWER FRAC-2-THERM

FLOWRATE CPT 1000 FPAR

INPUTS 3

$\star_{T}$ T-IN MFLOW-IN CONTROL-FUNC

$4,5 \quad 4,2 \quad$ CNTRL

20. 200 . 1.0

UNIT 6 TYPE 5 HEAT EXCHANGER

PARAMETERS 4

*MODE = CONST EFF, EFFECTIVNESS, CP HOT SIDE, CP COLD SIDE

4 EFFECT CPC CPT 
INPUTS 4

* $T$ HOT IN, MDOT HOT, T COLD IN, MDOT COLD

$8,1 \quad 8,2 \quad 5,1 \quad 5,2$

20. 200. 20. 200 .

UNIT 7 TYPE 3 COLLECTOR LOOP PUMP

PARAMETERS 4

*MAX-FLOW SPEC-HEAT MAX-POWER FRAC-2-THERM

FLOWRATE CPC $1000 \quad$ FPAR

INPUTS 3

${ }^{*}$ T-IN MFLOW-IN CONTROL-FUNC

$6.1 \quad 6,2 \quad$ CNTRL

20. 200 . 1.0

UNIT 8 TYPE 1 SOLAR COLLECTOR

PARAMETERS 14

*MODE, SERIES, AREA, CP FLUID, EFFICIENCY MODE, G TEST, AO, A1

*A2, EPSILON HTX, CP TANK, OPTICAL MODE, 1ST ORDER INC ANG MOD, 2ND ORDER

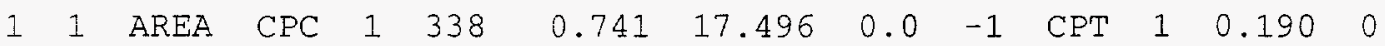

INPUTS 10

*TIN, MDOT IN, MDOT COLD SIDE, TAMB, ITILT, IHOR, IDIF, RHOG, INCANG, SLOPE

$\begin{array}{llllllllll}7,1 & 7,2 & 0,0 & 1,4 & 2,6 & 2,4 & 2,5 & 0,0 & 2,9 & 0,0\end{array}$

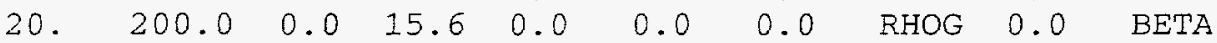

EQUATIONS 1

WATER_REQ $=[4,11]-[4,10]$

UNIT 10 TYPE 24 INTEGRATOR

PARAMETERS 1

*TIME INTERVAL OVER WHICH TO BE INTEGRATED

$-1$

INPUTS 3

* SOLAR RADIATION, USEFUL ENERGY TO TANK, QAUX FROM TANK

2,6 WATER_REQ 4,12

$0.0 \quad 0.0 \quad 0.0$

EQUATIONS 3

Q_SOLAR $=[10,1] / 1000000 *$ AREA

Q_LOAD $=[10,2] / 1000000$

Q_AUX $=[10,3] / 1000000$

UNIT 9 TYPE 65 ONLINE PRINTER

PARAMETERS 14

$\begin{array}{llllllllllllll}4 & 1 & -100 & 100 & -0.5 & 8 & 1 & 1 & 3 & 20 & 7 & 0 & 2 & 0\end{array}$

INPUTS 5

$1,4 \quad 8,1 \quad 4,6 \quad 4,5 \quad$ CNTRL

TAMB COLOUT TANKTOP TANKBOT CONTROL

LABELS 4

$\mathrm{C} \mathrm{kg/hr}$

Temp vs. Time

Flowrate into Tank vs. Time

UNIT 14 TYPE 25 YEARLY VALUE PRINTER 
168

PARAMETERS 5

*TIME INTERVAL AT WHICH PRINTING WILL OCCUR, TIME AT WHICH PRINTING STARTS

*TIME AT WHICH PRINTING FINISHES, LOGICAL UNIT, UNITS

- 1 START STOP 121

INPUTS 3

Q_SOLAR Q_LOAD Q_AUX

Q_SOLAR Q_LOAD Q_AUX

GJ GJ GJ

END 


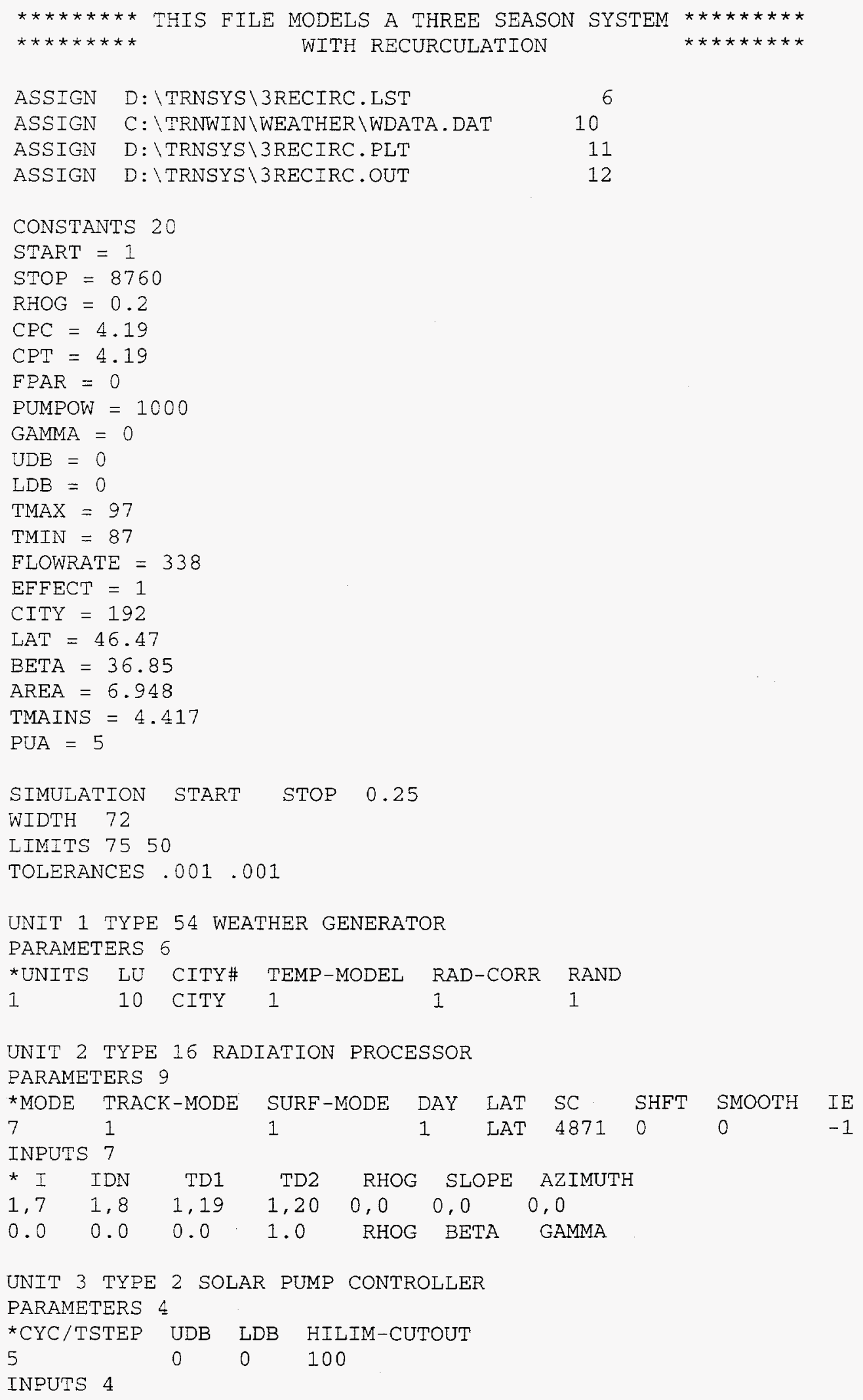


170

$\begin{array}{llll}{ }^{* T H O T} & \text { TCOLD } & \text { HILIM-CUTOUT } & \text { INPUT-CNTRL } \\ 8,1 & 4,5 & 4,6 & 3,1 \\ 20 . & 20 . & 100 & 0.0\end{array}$

UNIT 12 TYPE 2 FREEZE PROTECTION CONTROLLER

PARAMETERS 4

*CYC/TSTEP UDB LDB HILIM-CUTOUT

$\begin{array}{llll}5 & 0 & 0 & 100\end{array}$

INPUTS 4

*THOT TCOLD HILIM-CUTOUT INPUT-CNTRL

$1,4 \quad 0,0 \quad 4,6 \quad 12,1$

20. 5. 100 . 0.0

UNIT 4 TYPE 60 STRATIFIED FLUID STORAGE TANK

PARAMETERS 32

*INLET POSITION MODE, TANK VOLUME, TANK HEIGHT, PERIMETER, HEIGHT INLET 1

*HEIGHT OUTLET 1, HEIGHT INLET 2, HEIGHT OUTLET 2, CP, RHO, UTANK, K, DELTA $K$,

*T-BOIL, AUX MODE, HT AUX1, HT STAT1, T SET1, DEL TDB1, QAUX1, HT AUX2, HT STAT2,

*T SET2, DEL TDB2, QAUX2, UA FLUE, T FLUE, CRIT FRACTION, GAS AUX, HX MODE, UMODE

$\begin{array}{llllllllllllll}1 & 0.3028 & 1.5 & -1 & 1.5 & 0.1 & 0.1 & 1.5 & \text { CPT } & 1000 & 0 . & 2.304 & 0 . & 100 .\end{array}$

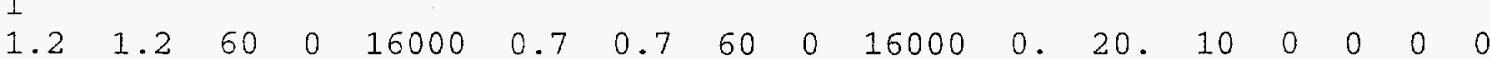

INPUTS 9

*MDOT1 IN, MDOT1 OUT, MDOT2 IN, MDOT2 OUT, T1 IN, T2 IN, T ENV, GAMMA1, GAMMA2

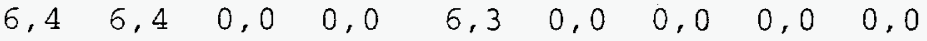

200. 200. -2. 12.1 20. TMAINS 20. 1.01 .0

DERIVATIVES 5

$20202020 \quad 20$

UNIT 11 TYPE 14 THREE SEASON SYSTEM FLOWRATE FORCING FUNCTION

PARAMETERS 10

$\begin{array}{lllllllllllll}1 & 0 & 2880 & 0 & 2880 & 1 & 7296 & 1 & 7296 & 0 & 8760 & 0\end{array}$

EQUATIONS 4

*THREE SEASON SYSTEM

CNTRLFUNCSC $=[11,1] *[3,1]$

CNTRLFUNCFP $=[11,1] *$ NOT $([12,1])$

CNTRL $=$ GT $(($ CNTRLFUNCSC+CNTRLFUNCFP $), 0)$

$\mathrm{VAR}=5$

UNIT 5 TYPE 3 TANK LOOP PUMP

PARAMETERS 4

*MAX-ELOW SPEC-HEAT MAX-POWER FRAC-2-THERM

FLOWRATE CPT 1000 FPAR

INPUTS 3

*T-IN MFLOW-IN CONTROL-FUNC

$4,5 \quad 4,2 \quad$ CNTRL

20. 200. 1.0

UNIT 6 TYPE 5 HEAT EXCHANGER

PARAMETERS 4 
$*_{\text {MODE }}=$ CONST EFF, EFFECTIVNESS, CP HOT SIDE, CP COLD SIDE 4 EFFECT CPC CPT

INPUTS 4

* T HOT IN, MDOT HOT, T COLD IN, MDOT COLD

$\begin{array}{llll}13,1 & 13,2 & 5,1 & 5,2\end{array}$

20. 200. 20. 200 .

UNIT 7 TYPE 3 COLLECTOR LOOP PUMP

PARAMETERS 4

$\begin{array}{llll}\text { *MAX-FLOW } & \text { SPEC-HEAT } & \text { MAX-POWER } & \text { FRAC-2-THERM } \\ \text { FLOWRATE } & \text { CPC } & 1000 & \text { FPAR }\end{array}$

INPUTS 3

${ }^{*}$ T-IN MFLOW-IN CONTROL-EUNC

$6,1 \quad 6,2 \quad$ CNTRL

20. 200 . 1.0

UNIT 12 TYPE 31 PIPING FROM HEAT EXCHANGER TO COLLECTOR

PARAMETERS 6

*IN DIAM, LENGTH, UA, DENS, CP, INITIAL TEMP

0.0120 PUA 1000 CPC 20

INPUTS 3

${ }^{*}$ TIN, MDOT IN, TENV

$7,1 \quad 7,2 \quad 0,0$

20. 200. 20 .

UNIT 8 TYPE 1 SOLAR COLLECTOR

PARAMETERS 14

*MODE, SERIES, AREA, CP FLUID, EFFICIENCY MODE, G TEST, AO, A1

*A2, EPSILON HTX, CP TANK, OPTICAL MODE, 1ST ORDER INC ANG MOD, 2ND ORDER

$\begin{array}{llllllllllllll}1 & 1 & A R E A & C P C & 1 & 338 & 0.741 & 17.496 & 0.0 & -1 & \mathrm{CPT} & 1 & 0.190 & 0\end{array}$

INPUTS 10

*TIN, MDOT IN, MDOT COLD SIDE, TAMB, ITILT, IHOR, IDIF, RHOG, INCANG, SLOPE

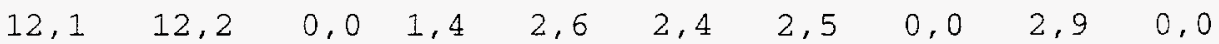

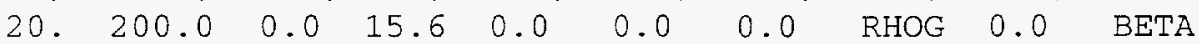

UNIT 13 TYPE 31 PIPING FROM COLLECTOR TO HEAT EXCHANGER

PARAMETERS 6

*IN DIAM, LENGTH, UA, DENS, CP, INITIAL TEMP

0.0120 PUA 1000 CPC 20

INPUTS 3

*TIN, MDOT IN, TENV

$8.1 \quad 8,2 \quad 0,0$

20. 200. 20 .

EQUATIONS 1

WATER_REQ $=[4,11]-[4,10]$

UNIT 10 TYPE 24 INTEGRATOR

PARAMETERS 1

*TIME INTERVAL OVER WHICH TO BE INTEGRATED

$-1$

INPUTS 3

*SOLAR RADIATION, USEFUL ENERGY TO TANK, QAUX FROM TANK 
172

2,6 WATER_REQ 4,12

$0.0 \quad 0.0 \quad 0.0$

EQUATIONS 3

Q_SOLAR $=[10,1] / 1000000 *$ AREA

Q_LOAD $=[10,2] / 1000000$

Q_AUX $=[10,3] / 1000000$

UNIT 9 TYPE 65 ONLINE PRINTER

PARAMETERS 14

$\begin{array}{llllllllllllll}5 & 1 & -100 & 100 & -0.5 & 8 & 1 & 1 & 3 & 20 & 7 & 0 & 2 & 0\end{array}$

INPUTS 6

1,4 VAR 8,1 4,6 4,5 CNTRL

TAMB 5 COLOUT TANKTOP TANKBOT CONTROL

LABELS 4

$\mathrm{C} \mathrm{kg/hr}$

Temp vs. Time

Flowrate into Tank vs. Time

UNIT 14 TYPE 25 YEARLY VALUE PRINTER

PARAMETERS 5

*TIME INTERVAL AT WHICH PRINTING WILL OCCUR, TIME AT WHICH PRINTING STARTS

*TIME AT WHICH PRINTING FINISHES, LOGICAL UNIT, UNITS

-1 START STOP 121

INPUTS 3

Q_SOLAR Q_LOAD Q_AUX

Q_SOLAR Q_LOAD Q_AUX

GJ GJ GJ

END 


\section{APPENDIX E: EUSESIA TRNSED DECK}

$* * * * * * *$ FOUR SEASON SYSTEM $* * * * * * *$

*TRNSED

ASSIGN C: $\backslash$ EUSESIA \SYSTEMS \SDHWITNK.LST

ASSIGN C: \EUSESIA \SYSTEMS SDHW1TNK.OUT

ASSIGN C:\EUSESIA \SYSTEMS\SDHW1TNK. PLT

ASSIGN $C: \backslash E U S E S I A \backslash S Y S T E M S \backslash H R D R A W . D A T$

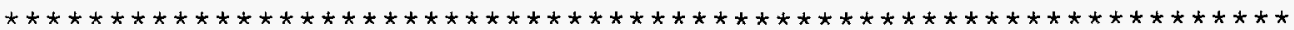

* This file predicts the required electric input to a solar *

* domestic hot water system

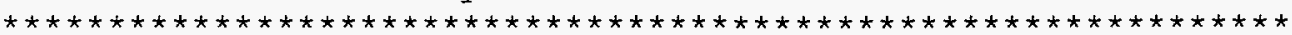

* 1 * Utility Location

ASSIGN C: \EUSESIA \sYstems \MLKWTR91.DAT 14

* $1<$ City in which utility is located in

|C: \EUSESIA \SYSTEMS \CITIES.DAT $|1| 2 \mid 0$

EQUATIONS 1

$\mathrm{LAT}=4.2950 \mathrm{E}+0001$

* $\mid<$ City in which utility is located in

|C: \EUSESIA \SYSTEMS \CITIES.DAT | $0|3| 0$

ASSIGN C:\EUSESIA \SYstems \MLKMAIN.DAT 16

* $\mid<$ City in which utility is located in

$\mid \mathrm{C}: \backslash$ EUSESTA $\backslash S Y S T E M S \backslash C I T I E S . D A T|0| 4 \mid 0$

* 1 *

\section{** * SYSTEM PARAMETERS ***}

EQUATIONS 6

TSET $=60$

$\mathrm{TENV}=18$

$\mathrm{TI}=6.9$

*

* Determine the required draw from the tank. The following equations

* account for the tempering valve. They result from simplified mass

* and energy balances where Cp is assumed constant.

$\operatorname{TDIEF}=\operatorname{MAX}(0.000001,([4,3]-[39,1]))$

TNKDRW $=\operatorname{MIN}(1,((\operatorname{TSET}-[39,1]) / \mathrm{TDIFF}))$

MLOAD $=[29,1] *$ TNKDRW

*

** * STANDARD ELECTRIC hOT WATER TANK

* Volume: 80 gallon tank $\rightarrow .3028 \mathrm{~m} 3$;

* Height: 4.89 ft $->1.4905 \mathrm{~m}$ 
174

* R-value: 16.7 (hr-ft2-F/Btu) -> ULOSS=1/R

* $\quad .0489194(\mathrm{hr}-\mathrm{m} 2-\mathrm{C} / \mathrm{kJ}) /(\mathrm{hr}-\mathrm{ft} 2-\mathrm{F} / \mathrm{Btu})$

* I* Tank Parameters

EQUATIONS 7

TNKSIZE $=8.0000 E+0001$

* Tank size

TSIZE $=.0037854 *$ TNKSIZE

Igal|gal10111011000.0010

HEIGHT1 $=4.8900 \mathrm{E}+0000$

* Tank height

HEIGHT $=.3048{ }^{*}$ HEIGHT 1

RVAI $=1.6700 \mathrm{E}+0001$

* I Insulation R-Value

F/Btul0111011000.0010

RVAL1 $=$ RVAL *.0489194

ULOSS $=1 /$ RVAL 1

* $\mid$ *

EQUATIONS 3

NODES $=3$

Tdond $=0.0$

$Q \max =4.5 * 3600$

* * Solar Collector Parameters

EQUATIONS 8

COL $=2.0000 \mathrm{E}+0000$

*I Number of collectors in array

11101111100010010

AREA1 $=6.0000 \mathrm{E}+0001$

* I Area of a single collector

$|\mathrm{ft}| \mathrm{ft} \mid 0111010030.0010$

|hr-ft2-F/Btulhr-ft2-

AREA $=C O L * A R E A 1 * .0929$

FRta $=7.0000 \mathrm{E}-0001$

* FRta of collector (Intercept efficiency)111011101001.0013

FRUL1 $=7.4900 \mathrm{E}-0001$

* FRUL of collector (- slope of eff. Curve)|Btu/hr-ft2-F|Btu/hr-ft2-

$F|011| 0110.00010$

FRUL $=20.4418 *$ FRUL1

SLOPE $=3.8000 E+0001$

* 1 Collector slope

|degrees|degrees 10111010090.010

GAMMAI $=0.0000 \mathrm{E}+0000$

* Collector azimuth angle

| degrees|degrees $|0| 1 \mid$ -

9010090.010

* $*$

* * Heat Exchanger Parameters

EQUATIONS 3

$E F F=-1.00000 E+0000$

* | Heat exchanger effectiveness $(-1 \Rightarrow$ no $h x)|||0| 1|-1| 01.000 \mid 3$

$\mathrm{CPHI}=5.7700 \mathrm{E}-0001$

* Specific heat of collector side fluid |Btu/lbm-R/Btu/lbm-

$R|0| 1|0| 10.000 \mid 0$

$\mathrm{CPHOT}=4.1868^{*} \mathrm{CPHI}$

* 1 *

* 1 * Pump Parameters

EQUATIONS 2 
PMPPOW $=5.0000 E+0001$

* 1 Pumping power

$|W| W|0| 1|0| 10000.010$

PPUMP $=$ PMPPOW $* 3.6$

* $1 *$

* 1 * Daily Water Draw

EQUATIONS 3

FACTOR $=3.7853$

MLTPLY $=6.9000 E+0001$

* I Average daily water draw (69 gal/day standard)

Igal/daylgal/day|011101100.010

SCALE $=$ FACTOR $*$ MLTPLY $/ 69$

* Standard draw based on approximately 69 gal/day. MLTPLy allows the

* user to scale the draw as seen fit. By setting the value to 69 the

* draw remains the same.

* $\mid$ *

** SIMULATION PARAMETERS ***

EQUATIONS 4

START $=1$

START $1=$ START -48

$S T O P=8760$

step $=.1$

EQUATIONS 4

$R H O G=2.0000 E-01$

STRTDAY $=\operatorname{INT}(\operatorname{START} 1 / 24)$

$\mathrm{SC}=4871$

$\mathrm{SHIFT}=0.0$

* Calculate the critical timestep for the system.

* Use STEP < t_critical as a safety factor

* Calculation done assuming an instantaneous draw will

* * be no more than $10 \mathrm{gal} / \mathrm{hr}$

*EQUATIONS 6

*MASSTANK $=$ TNKSIZE*FACTOR

* MCOLL $=325$

${ }^{*}$ MLOADMAX $=10 *$ FACTOR

*TCRIT $=($ MASSTANK/NODES $) /($ MCOLL+MLOADMAX)

* STEPI = TCRIT/2

${ }^{*} \operatorname{STEP}=\operatorname{MIN}(\operatorname{STEP} 1,1)$

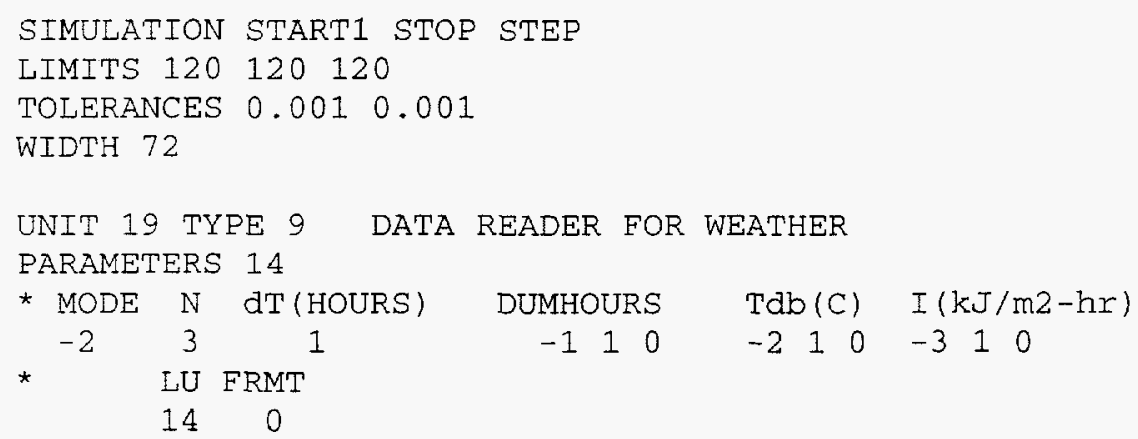


176

*OUTPUTS: $2, \mathrm{Tab} 3, I$

UNIT 29 TYPE 9 DATA READER FOR WATER DRAWS

*WATER DRAWS: (GAL/HR) - CONVERT TO KG/HR

* USE FACTOR 3.7853, FURTHER SCALING DONE WITH MLTPLY/69

FARAMETERS 8

* MODE N STEP DRAWS MULT ADD LU FRMT

$\begin{array}{llllllll}-2 & 1 & 1 & -1 & \text { SCALE } & 0 . & 15 & 0\end{array}$

*OUTPUTS : 1 , DRAW (KG / HR)

UNIT 5 TYPE 14 THREE SEASON SYSTEM FORCING FUNCTION

PARAMETERS 12

START1 028800288017296172960 STOP 0

UNIT 39 TYPE 9 DATA READER FOR MAINS WATER TEMPERATURE

* CHANGES MONTHLY BUT READ IN DAILY (24 HOURS) FROM F-CHART FILE

PARAMTERS 8

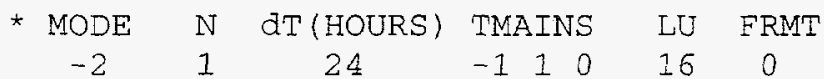

*OUTPUTS: 1, TMAINS

UNIT 16 TYPE 16 RADIATION PROCESSOR

PARAMETERS 8

* RADMODE TRACKMODE TILTMODE DAY LAT SC SHIFT SMOOTH

$\begin{array}{llllllll}3 & 1 & 1 & \text { STRTDAY } & \text { LAT } & \text { SC } & \text { SHIFT } & 2\end{array}$

INPUTS 6

* I (kJ/m2-hr) tal td2 RHOG BETAI GAMMAI INext(IF $\mathrm{SMOOTH}=1$ )
19,3
$19,19 \quad 19,20 \quad$ RHOG
$0.0 \quad 0.0$
RHOG
SLOPE
GAMMAI 19,23
0.0
SLOPE
GAMMAI 0.0

*OUTPUTS: 1, Io 2, THETAz 3, GAMMAs 4, I 5,Id 6,IT1 7,IbT1 8,IdT1 9,THETA1

* 10, BETA1 11, IT1

EQUATIONS 3

$\operatorname{RADT}=[16,6] *[5,1]$

$\mathrm{RAD}=[16,4] *[5,1]$

$\operatorname{RADD}=[16,5] *[5,1]$

UNIT 1 TYPE 1 COLLECTOR

PARAMETERS 14

* MODE $N$ AREA CP EFFMD $G$ ao a1 a2 EFF CPHX OPTMD bo b1 0.0

INPU'TS 10

* Ti mCOLL $(\mathrm{kg} / \mathrm{hr}$ ) mHX Tamb It I Id RHOG THETA BETA(SLOPE)

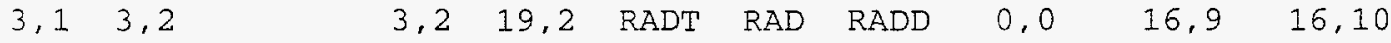

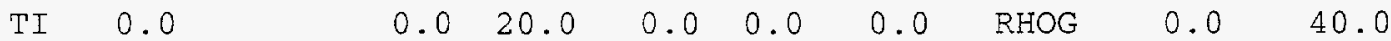

*OUPUTS: 1, To 2, mo 3, Qgain (KJ/HR) 4, TCO

EQUATIONS 2

DEADH $=0$

$\mathrm{DEADL}=0$

UNIT 2 TYPE 2 PUMP CONTROLLER 
PARAMETERS 4

* NSTK dThigh dTlow Tmax

$$
11 \text { DEADH DEADL } 100
$$

INPUTS 4

* Th T1 tin gammaI

$1,4 \quad 4,1 \quad 0,0 \quad 2,1$

15. TI 100 0.

*OUTPUTS: 1 , GAMMAO (CONTROL FUNCTION)

UNIT 3 TYPE 3 PUMP

PARAMETERS 4

* MMAX CP $P \max (\mathrm{KJ} / \mathrm{HR}) \quad$ fpar

325. 4.19 PPUMP 0.

INPUTS 3

* Ti mi GAMMA

$4,1 \quad 4,2 \quad 2,1$

TI $\quad 0.0 \quad 0.0$

*OUTPUTS: 1, To 2, mo 3, Ppump

EQUATIONS 1

HGT $=$-HEIGHT

UNIT 4 TYPE 4 SOLAR STORAGE TANK

PARAMETERS 20

*MODE VOL CPF RHO UT

2 TSIZE 4.191000 ULOSS HG

*TSET DTDB OAUX1 NODE2 NODET2

$\begin{array}{cccc}\text { TSET } & 0 & \text { QMAX } & 1\end{array}$

* UAFLUE TFLUE TBOIL

0.0 TENV 100

INPUTS 5

* TH MH TL ML TENV

$1,1 \quad 1,2 \quad 39,1$ MLOAD 0,0

$\begin{array}{lllll}0.0 & 0.0 & \text { TI } & 0.0 & \text { TENV }\end{array}$

DERIVATIVES NODES

TSET TSET TSET TSET TSET TSET TSET TSET TSET

*UNIT 4 OUTPUTS:

*oUTPUTS: 1, Trtn 2,m_rtnCoLL 3, Tload 4,m_load 5, Qenv, loss 6, Qs

* $\quad 7$, aEtank 8, Qaux1

UNIT 24 TYPE 24 INTEGRATOR

PARAMETERS 1

*DT RESET

1

INPUTS 2

$4,8 \quad 3,3$

$0.0 \quad 0.0$

EQUATIONS 2

* Electric input required (auxiliary heater + collector pump power) ELECDMND $=([24,1]+[24,2]) / 3600$

QAUX $=([24,1]) / 3600$ 
178

UNIT 25 TYPE 25 PRINTER

PARAMETERS 4

* DT TON TOFF LU

1 START STOP 10

INPU'TS 1

elecamna

elcamd

UNIT 26 TYPE 25 plotting PRINTER

PARAMETERS 4

* DT TON TOFF LU

1 START STOP 22

INPUTS 1

elecamnd

elcamd

* 1 * Display Options

EQUATIONS 2

IREF $=1 /($ STEP +.00001$)$

SWITCH $=1.0000 \mathrm{E}+0000$

* On-Iine graphic display (1=yes, $-1=$ no)

$1|10| 1|-2| 2 \mid 0$

UNIT 65 TYPE 65 ON-LINE PRINTER

PARAMETERS 14

$\begin{array}{lllclrrrr}\text { *NTOP } & \text { NBOT } & \text { YMIN1 } & \text { YMAX1 } & \text { YMIN2 } & \text { YMAX2 } & \text { IREF } & \text { IUP } & \text { UNITS } \\ 2 & 1 & 0 & 5 & 0 & 80 & \text { IREF } & 1 & 3\end{array}$

*NPIC GRID STOP SYMBOLS OUTPUT

$\begin{array}{lllll}1 & 7 & 0 & 2 & \text { SWITCH }\end{array}$

INPUTS 3

QAUX ELECDMND MLOAD

Qaux ElecDmnd Mtank

LABES 4

$\mathrm{kW} \mathrm{kg} / \mathrm{hr}$

Average System Demand

Tank Draw

END 


\section{REFERENCES}

Arny, M.D. and R.J. Harsevoort, "A Method for Comparing the Contribution of Supply Side and Demand Side Resources to Customer Reliability." Draft, 1994

Askeland, D.R., The Science and Engineering of Materials. $3^{\text {rd }}$ edition, Boston: PWS Publishing Company, 1994.

Barnaby, C.S., and B.A. Wilcox, "Freeze Protection for Flat Plate Collectors Using Heating." Solar Energy Journal 19.6 (1977) : 745-746.

Beer, F.P., and E.R. Johnston Jr., Mechanics of Materials. $2^{\text {nd }}$ edition, New York: McGraw Hill, Inc., 1992.

Bickle, L.W., "Passive Freeze Protection for Solar Collectors" Solar Energy Journal $17.6(1975)$ : 373-374.

Beckman, W.A., S.A. Klein, and J.A. Duffie, Solar Heating Design by the $f$-Chart Method. New York: John Wiley and Sons, Inc., 1977)

Bradley, J.M., "Development of a Freeze Tolerant SDHW System Using Cross Linked Polyethylene as a Material of Construction, " USDOE Contract EY76-C-02-2956 (1977)

Buckles, W.E., MS Thesis, Mechanical Engineering, University of WisconsinMadison (1983). "Short Term Monitoring and Performance Evaluation of Solar Domestic Hot Water Systems."

Commonwealth Electric Rate Card, 1997

Craig, S., and G.L. Harding, "Thermosiphon Heat Extraction and Automatic Freeze Protection in a Hot Water System Incorporating Evacuated Solar Collectors" Solar Energy Journal 38.4 (1987) : 297-301.

Cragan, K.E., MS Thesis, Mechanical Engineering, University of WisconsinMadison (1994). "Impact on a Utility of an Ensemble of Solar Domestic Hot Water Systems." 
Dayan, M., MS Thesis, Mechanical Engineering, University of Wisconsin-Madison (1997). High Performance in Low Flow Solar Domestic Hot Water Systems."

Duffie, J.A., and W.A. Beckman, Solar Engineering of Thermal Processes. $2^{\text {nd }}$ edition, New York: John Wiley and Sons, Inc. (1991)

Fanney, A.H., and B.P. Dougherty, "A Photovoltaic Solar Water Heating System," presented at ASME International Solar Energy Conference, San Antonio, TX, April, (1996)

Farrington, R., "Polybutylene Pipe Freeze/Thaw Reliability Testing." American Solar Energy Society Annual Conference Proceedings (1987)

Holman, J. P., Heat Transfer. $7^{\text {th }}$ edition, New York: McGraw Hill, Inc., 1990.

http://stats.bls.gov/news.release/cpi.nws.htm

Jahnig, D., MS Project, Mechanical Engineering, University of Wisconsin-Madison (1997). "Photovoltaic Water Pumping."

Klein, S.A., FEHT-Finite Element Heat Transfer Software, version 6.99, 1997

Klein, S.A., $f$-Chart software, version 5.88W, 1997

Klein, S.A. et al., TRNSYS 14.2 Reference Manual. Solar Energy Laboratory, University of Wisconsin-Madison, July, 1996

Klein, S.A. et al., TRNSED Version 2.0. Solar Energy Laboratory, University of Wisconsin-Madison, June, 1996

Klein, S.A. et al., TRNSHELL Version 2.0. Solar Energy Laboratory, University of Wisconsin-Madison, June, 1996

Lutgens, F.K. and E. J. Tarbuck, The Atmosphere

Meaken, D. A., Directory of SRCC Certified Solar Collector and Water Heating System Ratings. Washington, DC: SRCC, 1994

Madison Gas and Electric Rate Card, 1997

National Solar Radiation DataBase (1961-1990). Golden, National Renewable Energy Labs, 1992 
Peters, J.S., D. Robison and R. Winch, “Final Report: Wisconsin Domestic Water Heater Market Research,” (1997)

Smith, C.R. Secretary, Weather Atlas of The United States. Detroit: Gale Research Company: (1975)

Trzesniewski, J.A., MS Thesis, Mechanical Engineering, University of WisconsinMadison (1995). "Electric Utility Interest in Solar Energy Systems"

Williams, P.A., MS Thesis, Mechanical Engineering, University of WisconsinMadison (1996). "Development and Analysis Tool for Photovoltaic-Powered Solar Water Heating Systems." 